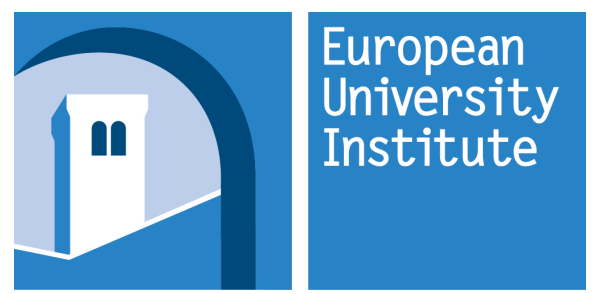

DEPARTMENT

OF LAW

\title{
Social legitimacy in the internal market - a dialogue of mutual responsiveness -
}

Jotte Mulder

Thesis submitted for assessment with a view to obtaining the degree of Doctor of Laws of the European University Institute

Florence, 09 May 2016 (defence date) 



\section{European University Institute \\ Department of Law}

Social legitimacy in the internal market -

a dialogue of mutual responsiveness

Jotte Mulder

Thesis submitted for assessment with a view to obtaining

the degree of Doctor of Laws of the European University Institute

\section{Examining Board}

Prof. Giorgio Monti, European University Institute (supervisor)

Prof. Loïc Azoulai, European University Institute/ Sciences Po

Prof. Anna Gerbrandy, Utrecht University

Prof. Christian Joerges, Hertie School of Governance/University of Bremen

(C) Jotte Mulder, 2016

No part of this thesis may be copied, reproduced or transmitted without prior permission of the author 



\section{Researcher declaration to accompany the submission of written work Department of Law - LL.M. and Ph.D. Programmes}

I Jotte Mulder certify that I am the author of the work 'Social legitimacy in the internal market - a dialogue of mutual responsiveness' I have presented for examination for the Ph.D. at the European University Institute. I also certify that this is solely my own original work, other than where I have clearly indicated, in this declaration and in the thesis, that it is the work of others.

I warrant that I have obtained all the permissions required for using any material from other copyrighted publications.

I certify that this work complies with the Code of Ethics in Academic Research issued by the European University Institute (IUE 332/2/10 (CA 297).

The copyright of this work rests with its author. Quotation from this thesis is permitted, provided that full acknowledgement is made. This work may not be reproduced without my prior written consent. This authorisation does not, to the best of my knowledge, infringe the rights of any third party.

I declare that this work consists of 135.701 words.

\section{Statement of inclusion of previous work:}

I confirm that chapters I and III draw upon an earlier article and a conference paper I published: J Mulder, 'A New Chapter in the European Court of Justice Gambling Saga: A Stacked Deck?' 38(2011) Legal Issues of Economic Integration, p. 243-262; J. Mulder, 'Finding the public interest and the case of the Friesian horse', 2013 ACLE Conference Paper http://acle.uva.nl/events/competition--regulationmeetings/conference-papers-9th-cr-meeting-2013.html (accessed 10-02-2016).

\section{Statement of language correction:}

This thesis has not been corrected for linguistic and stylistic errors.

Signature and date:

10-02-2016

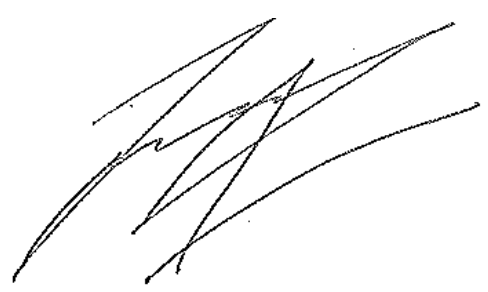





\section{ACKNOWLEDGEMENTS}

The clichés apply

The process of writing this $\mathrm{PhD}$ was, although incredibly frustrating at times, eventually a profoundly fulfilling experience. The $\mathrm{PhD}$ experience for me was, quintessentially, one of overcoming self-constructed obstacles. That is to say, in developing and applying a normative argument that is coherent and consistent, the obstacles one encounters are, quite literally, products of your own imagination. As a result, writing a $\mathrm{PhD}$ was very much a struggle with myself to remain disciplined, to remain encouraged, creative and, perhaps above all, to remain confident that somewhere within the daunting amount of literature on the topic I choose to engage with, I would be able to make a contribution with a claim to some level of originality. This final judgment is not in my hands but standing now at the end of this process, I feel a sense of autonomous and inherent 'victory', having gone through this whole exercise, and this is perhaps the true 'reward' of the effort.

The journey towards completion was not a linear process and, perhaps necessarily not so. I have strayed away many times from the work that is eventually presented here and I suspect that I have written and then discarded another half-PhD. In a more favourable reading: I have decided to park a lot of ideas for potential future research. I lost about six months of working and thinking on Michel Foucault and developing a "governmentality" approach to internal market law. Also, I still hope one day to reap the full benefits of attending a summer school on critical discourse analysis. Although one might see these intellectual outings as a loss since they have not been, with the exception of a footnote here and there, included in the thesis, I would highly recommend such outings because they sow benefits of a more hidden and subtle nature. They shape and 'embed' the academic mind-set, contributing to the development of a certain individualised 'voice' and will determine, I am sure, much of my future choices of academic work. Although not included in the thesis, all my intellectual straying was certainly not a "deadweight loss".

The principal person responsible for, eventually, nudging me to the path that has led to a manageable and measured project is my supervisor, Giorgio Monti. Supervision is a delicate process that ideally allows for some level of intellectual straying but should also put tangible 
limits to it. I clearly remember an eerie moment during my $\mathrm{PhD}$ where nearly all works I passed by in the library seemed somehow relevant to me. Luckily, the necessary limits arose fluently and quickly on the basis of Giorgio's natural aversion to the nebulous over-usage of concepts and his near clairvoyance to foresee the potential and limitations of a line of argumentation. These have been the crucial elements that allowed me to complete and now present this work and I owe much of what is good in this thesis to the dedication, professionalism, level of detail and effort that Giorgio has put in supervising my work.

There are many occasions where I have benefitted enormously from comments on my work both within and outside the European University Institute. Within the EUI, in particular comments and instructions from Loïc Azoulai and Claire Kilpatrick have made a lasting impact. Outside of the EUI, I have greatly benefitted from a research visit to the Copenhagen Business School, where I was able to tap from the deep theoretical insights of Poul Kjaer on 'governing and governance'. Christian Joerges has been an immense source of inspiration, both through his work, to which this thesis is profoundly endowed, and on the basis of his enduring positive encouragement for this project, throughout the process, from the very beginning.

The research could not have been undertaken without the financial support of the Dutch government (the grant authority Nuffic) or without the financial support of the EUI for mission funding. I have also benefitted from a grant of the Hijmansbeurs at the University of Amsterdam to develop my original research ideas, with the support of Rein Wesseling. I have found the EUI an immensely stimulating academic environment, with excellent seminars, dedicated to creating the conditions for researchers to commit fully to developing their ideas. Specifically, the excellent library services and, not to think lightly of, the outstanding lunch made available in the canteen, have made the whole experience quite agreeable.

However, the biggest surprise and most unexpected gift I shall cherish from all of this is not of an intellectual but more ubiquitous nature. That I have found my Noelle, my love (and my favourite proof reader) here in Florence has already made it all worthwhile. 


\begin{abstract}
Social legitimacy is conventionally conceived to encompass an empirical notion based on the idea that, lacking societal acceptance, a (political or legal) regime will eventually disintegrate. This concern is reflected in the original compromise of 'embedded liberalism', which stands at the basis of the internal market of the European Union. The primary law set up of the internal market, indeed, shares the idea that the benefits of a joint commitment to free trade can only be achieved in a sustainable way if combined with an acknowledgement of domestic societal objectives within the same frameworks. Nevertheless, social legitimacy will eventually depend on the institutional design and structural rationales that embed societal values within such regimes and vice versa. This perspective is further developed, normatively, on the basis of the work of Karl Polanyi and adopted to critically assess the structural rationales that are developed within internal market adjudication, which the thesis approaches as a separate field of social ordering within the European Union. Thus, social legitimacy is developed as a requirement that perceives the legitimacy of internal market law on the basis of the extent to which it can respond and integrate social practice and values.

On this point the thesis finds that the internal market lacks a sufficiently developed rationale or "common language" that is able to address the normative concerns of social legitimacy. Societal realities are often valued within a metric that risks doing violence to potentially genuine and worthwhile aspects of Member States' 'social spheres'. The thesis develops that the normative claims of social legitimacy are best addressed on the basis of $a$ rationale of mutual responsiveness, which is considered a necessary but underdeveloped element of the constitutional form and social purpose of the internal market that is implicit in the constitutional theory of transnational effects. From a perspective of mutual responsiveness, the social purpose of the internal market is not to condition choices that necessarily require the market to trump the social sphere - or the opposite- to allow the social to necessarily trump the market. Mutual responsiveness advances a more holistic approach that conceives the market and the social, literally, as 'communicating vessels'. The normative concerns of social legitimacy and the potential of mutual responsiveness to address these normative claims are the central and connecting elements throughout the thesis.
\end{abstract}




\section{The social legitimacy of EU internal market law}

- A dialogue of mutual responsiveness -

\section{TABLE OF CONTENTS}

Abbreviations $\quad$ ix

Introduction: objectives, approach and contribution $\quad x i$

Chapter I: Social legitimacy in EU internal market law: A research agenda

I. Introduction to the argument 2

II. The social problematique and the argument from transnational effects 9

A. The social problematique discussion 9

B. Transnational effects and the legitimacy of the social deficit: Joerges and Maduro 13

C. Somek's fundamental question

III. The emergence of 'the social' and a constitutional principle of responsiveness within the multilevel context of the $\mathrm{EU}$

A. The social sphere within the internal market $\quad 21$

B. The 'positive' social $\quad 23$

C. The internal market rules as a contingent form for the social sphere 27

D. The constitutional obligation of responsiveness 31

IV. The normative-instructive value of embeddedness 35

A. Introduction $\quad 35$

B. Notes on Polanyi $\quad 36$

C. The enduring relevance of Polanyi $\quad 47$

D. A rationale of responsiveness: moving beyond Polanyi? 54

E. Polanyi in Luxembourg?

V. Social legitimacy in the context of internal market adjudication: (e)valuation and the expressive function of internal market law as a dialogue of mutual responsiveness 63

VI. Outlook for the thesis: a research agenda $\quad 70$

Chapter II: Social legitimacy in EU free movement law

I. Introduction

II. Problematisation: Valuation, indeterminacy and incommensurability in free movement adjudication

A. The organizational principles of EU free movement law 
B. The expedient 'rights inflation' proportionality model in EU free $\begin{array}{ll}\text { movement adjudication } & 84\end{array}$

i. The basic structure $\quad 84$

ii. The unqualified market access test as a means to frame the free movement conflict 85

iii. The structure of proportionality 96

III. Responsiveness in the proportionality analysis of the Court in free movement 99

A. Introduction 99

B. Substantive efficiency model 100

C. The margin of discretion model 106

D. The procedural good governance model 109

E. Incoherence in the application of the different rationales $\quad 120$

IV. A dialogue of mutual responsiveness: the interplay of principles of substantive efficiency, margins of discretion and good governance in free movement adjudication

A. Between managerialism, margins of discretion and good governance:

A responsive model 123

B. Reframing exemplary free movement cases within the proposed rationale 127

i. Volkswagen: valuing the "social acquis" of a Member State within the internal market

ii. Omega: the importance of mutual responsiveness in the pursuit of legitimate objectives 130

iii. Viking: resolving the fundamental tension of the internal market on the basis of $\begin{array}{lr}\text { a dialogue of mutual responsiveness } & 132\end{array}$

V. Conclusion

Chapter III: Social legitimacy in EU competition law

\section{Introduction}

II. Problematisation: Valuation, indeterminacy and incommensurability in EU competition law

A. Organizational principles in EU competition law: the debate on valuation 145

i. Goals of competition law

ii. Non-competition interests within competition law assessments $\quad 148$

iii. The problem of indeterminacy and the expressive value of competition law 153

iv. Competition law as a platform for societal dialogue 162

B. Introduction to the case studies 163

i. The Friesian Horse: the legitimacy of private led public interest objectives 166

ii. The Energy Agreement for Sustainable Growth: the societal relevance of the process

$\begin{array}{ll}\text { or the rationality of its outcome? } & 168\end{array}$

iii. The Chicken of Tomorrow: the market rules when the state retracts? 172

III. Responsiveness in the case law of the Court of Justice 177

A. Responsiveness to social context in Albany, Poucet Pistre and Wouters 178

i. The Albany building block: valuation of different social spheres 178 
ii. Poucet and Pistre building block: a rationale for the alternative valuation of a noneconomic social sphere (part one)

iii. Wouters: a rationale for the alternative valuation of a noneconomic social sphere (part two)

B. The requirements of mutual responsiveness in Arduino, Cipolla and Mauri

IV. A dialogue of mutual responsiveness: the interplay of principles of substantive efficiency, margins of discretion and good governance in competition law

A. A framework of mutual responsiveness

B. A return to the case studies on the basis of mutual responsiveness

i. Mutual responsiveness in the Friesian Horse case

ii. Mutual responsiveness in the Energy Agreement for Sustainable growth

iii. Mutual responsiveness in the Chicken of Tomorrow case

\section{Chapter IV: Social legitimacy in EU state aid law}

\section{Introduction}

II. Problematisation: Valuation, indeterminacy and incommensurability in state aid law

A. Organizational principles in EU state aid law 214

i. Introduction $\quad 214$

ii. The proceduralisation of the state aid rules 216

iii. Modes of valuation in state aid: market versus regulation 223

B. The expedient nature of market derived standards within state aid law 225

i. Introduction 226

ii. The potential expedient scope of the market economy operator principle (part one): the absence of rationale of genuine regulation versus the clear rationale of a private investor/creditor 228

iii. The scope of the market economy operator principle (part two): control over economic assets or public infrastructure

C. The potential crowding out effects of the market operator principle

D. The conditional pursuit of services of general interest on the basis of adversarial relationships

III. Responsiveness in the models of adjudication of the Court in state aid law

A. Introduction

B. Mutual responsiveness: between regulation and the market

i. The quest for a more comprehensive rationale for public authority

ii. The individual aid measure in its wider context

iii. The connection to the wider regulatory context: a good governance model

C. Mutual responsiveness in the application of the Altmark framework

IV. A dialogue of mutual responsiveness: the interplay of principles of substantive efficiency, margins of discretion and good governance in State aid 
$\begin{array}{ll}\text { A. Introduction } & 267\end{array}$

B. The dialogue of mutual responsiveness in state aid 268

C. The required mutuality of the dialogue $\quad 272$

$\begin{array}{ll}\text { V. Conclusion } & 274\end{array}$

Chapter V: Conclusion - social legitimacy in the internal market on the basis of the dialogue of mutual responsiveness

I. The argument as a whole: normative claims and results

II. Social legitimacy in the internal market: free movement, competition and state aid

A. Social legitimacy in EU free movement law 285

B. Social legitimacy in EU competition law 289

C. Social legitimacy of EU state aid law 295

III. Some final remarks 299

$\begin{array}{ll}\text { Bibliography } & 303\end{array}$

$\begin{array}{ll}\text { Consulted cases, legislation, decisions } & 327\end{array}$ 


\section{ABBREVIATIONS}

AG

Art

$\mathrm{ACM}$

CJEU

$\mathrm{COM}$

Eds.

ECJ

ECR

EC

EU

FSU

GC

ITF

OJ

TFEU

TEU

TGT

VoC
Advocate General

Article

Authority for Consumer and Market

Court of Justice of the European Union

Communication

Editors

European Court of Justice

European Court Reports

European Community

European Union

Finnish Seamen's Union

General Court

International Transport Worker's Federation

Official Journal of the European Union

Treaty on the Functioning of the European Union

Treaty on European Union

The Great Transformation

Varieties of Capitalism 


\section{Introduction: objectives, approach and contribution}

This thesis develops a multidimensional critique on the legitimate 'social impact' of internal market law. As such, it is part of a wide academic stream, whose narratives target the potential structurally distortive effects of economic integration on the fundamental structures of domestic societies. Critiques within this narrative may consider that interests that are promoted on the basis of market integration displace what makes the traditional values of social life in Europe worthwhile. ${ }^{1}$ The law of the internal market within this narrative is considered to be negatively constitutive of socio-economic life within the Member States. Such critiques perceive a fundamental tension between market integration and 'social values' and may call for 'radical' reforms, such as the possibility to transfer powers back to the Member States, or argue for a more limited scope of the internal market freedoms and objectives. ${ }^{2}$ This fundamental tension concerns the perceived manifest irreconcilability between 'the market' and 'the social'. Indeed, it is this fundamental tension that will be more closely investigated in this thesis. It is also with respect to the conventional understanding of this fundamental tension that this thesis departs from the larger stream and aims to pursue its own path. Instead of perceiving the market and the social as necessarily requiring one to trump the other in situations of conflict, or to perceive the social merely as ancillary to economic objectives (flexicurity and so forth), this thesis advances a more reconciliatory approach that conceives the market and the social as 'communicating vessels'. To perceive the internal market as a means to start a transnational dialogue is a quintessential part of the EU constitutional theory of transnational effects or 'the argument from transnational effects'. ${ }^{3}$ Within the perspective of the argument from transnational effects, the internal market is infused with

G. Davies, "Internal market adjudication and the quality of life in Europe", (2014) EUI Working Paper 2014/07.

2 Editorial Comments in Common Market Law Review 52 (2015) at p. 881-888.

3 A. Somek, "The argument from transnational effects I: Representing outsiders through freedom of movement”, European Law Journal 16 (2010) at p. 320. 
a clear social purpose, namely, as a platform for inter and intra societal dialogue. This is, however, a fundamentally underdeveloped part of the theory and an important part of the objectives of this thesis is to bring the preconceived social purpose to its full fruition.

Crucially, the internal market lacks a shared language that will allow the fulfilment of this purpose. In this respect, Marco Dani has submitted that Europe needs a better infrastructure and rationale to accommodate social conflicts and that the suppression of social conflict on the basis of a "consensus culture" has hampered further integration. Moreover, the re-emergence of social conflict in recent times now poses fundamental "challenges to the current institutional setting" which is in need of a new conceptual language for social conflicts within the internal market. ${ }^{4}$ This thesis aims to develop a common language for internal market law on the basis of a dialogue of mutual responsiveness. Only on this basis can the social purpose of the internal market become a structural part of European legal space.

In developing a common language the thesis first builds a normative framework on the basis of the idea of social legitimacy, which finds its origin in the 'embedded liberalism' compromise that stands at the basis of the legal infrastructure of the internal market. This infrastructure responded to a social urgency and common understanding that pressure of markets on societal structures should be kept in check by allowing domestic concerns to restrict free trade objectives if deemed necessary. The intellectual father of the idea that markets can harm social structures by rearranging them within a selfregulating, market-enabling rationale is Karl Polanyi. The first chapter develops a normative framework that is inspired by his ideas. As such, the normative argument that is developed in the thesis is multidimensional as even though it contributes to an important and continuing constitutional narrative, it is nevertheless infused with ideas from another discipline. This is particularly aspired with respect to the question how the knowledge that economic action is and always has been deeply embedded in social relations should affect the interplay between supranational market integration and the remaining locality of the social within the legal framework of the internal market. Thus,

4 M. Dani, "Rehabilitating social conflicts in European Public Law", (2012)18 European Law Journal at p. 621 . 
social legitimacy is developed as a requirement that connects the legitimacy of internal market law to the extent that it can respond and integrate social practices and values.

These wider objectives of the thesis place it within a tradition of legal realism or law in context approaches. This tradition challenges the claim that legal thought is separate and autonomous from moral and political discourse and adopts materials from other social sciences, or from any other discipline, when it aids to further illuminate the normative operation of laws in their wider societal context. Both legal realists and law in context orientations provide neither a coherent intellectual movement nor a consistent autonomous jurisprudence. Rather, they can both be labelled as critiques on existing orthodox doctrine or simply 'a critical intellectual mood'. Indeed, many of the realists in the 1930s and 1940s in the Unites States challenged the way that judges actually decided in cases. One part of this challenge focused on formalism that was based on the idea that judicial rulings are simply a matter of applying legal principles to particular cases. Legal realists opposed this idea and argued that most cases involved conflicts between opposing principles and that there are always gaps and ambiguities in any field of law that make it impossible to formally apply law on the basis of just, first principles. In particular, they opposed the thought "that embraced the idea that a self-executing, decentralized, competitive market economy would permit legal institutions to function as neutral, apolitical, and impartial arbiters over the just distribution of wealth and justice". ${ }^{5}$ This orthodox idea build on the presumption that unequal results were 'just' because they merely reflected the unequal abilities that individuals brought to the market and attempts to interfere with these results would undermine the legitimacy of legal institutions. ${ }^{6}$ Thus, although there was a commitment to neutrality, according to these legal realists this commitment was based on a false premise. As such, they questioned the axioms that underlie the rules that govern adjudicative decision-making processes.

Contemporary legal commentators who claim to follow through in the tradition of the American legal realists define their critique as being opposed to the straightforward and unchecked application of microeconomic analysis of law and policy-making. ${ }^{7}$ Legal

5 M.J. Horwitz, The Transformation of American Law, 1870-1960: The Crisis of Legal Orthodoxy (Oxford University Press 1992). p. 193.

6 Ibid.

7 V. Nourse, and G. Shaffer, "Varieties of New Legal Realism: Can a New World Order Prompt a New 
realism rejects formalism and finds that rationalism is not sufficient to explain the law's reach and aspirations. ${ }^{8}$ For contemporary legal realists, the target in particular is the use of these formalised models that reduce and subject social goals to principles of efficiency and wealth maximization, which are based on simplified assumptions rather than real-life facts and institutional processes. ${ }^{9}$ The focus of new legal realists is to identify instances when formalism becomes automatic and blind to the assumptions and consequent statusquo biases that result from it. ${ }^{10}$ As such, new legal realists call for a sounder analysis of how an overly formal approach in law is liable to install a bias in favour of a certain societal outcome. In this vein, the objectives of this intellectual movement of legal commentators are similar to those advanced on the basis of this thesis. The connection exists in the critical analysis of the existing formal legal premises within the internal market that structure the interaction between market integration and restrictive social objectives within the Member States. More specifically, my approach relates to critical legal realism since it adopts a similar outlook, which I will briefly highlight below.

I approach internal market adjudication as a separate field of social ordering within the European Union. Court rulings determine how the relationship between the social and economic sphere is to be governed and these findings may enter in some degree into the future relationship between these two spheres in the internal market. ${ }^{11}$ As such, this provides a negative form for the emanation of the social sphere within the rules of the internal market and this can be approached as a separate field of study. The thesis will focus exclusively on the adjudicative rationales that have been developed to govern the interplay between the objectives of the internal market and restrictive social interests within the three pillars of internal market law: free movement, competition and state aid. Occasional reference will of course be made to relevant policy and legislative contexts, which may already predetermine and influence the extent to which adjudication can have an impact on Member State's social spheres. Within the adjudicative context, the normative concerns of social legitimacy boil down to the issues of valuation,

Legal Theory?" Cornell Law Review 95 (2009) , p. 65.

8 Ibid., p. 95.

9 Ibid., p. 65.

10 Ibid., p. 125.

11 L. Fuller and K. Winston, "The Forms and Limits of Adjudication" (1978) 92 Harvard Law Review at p. 353. 
indeterminacy and incommensurability. The evaluative standards applied by the Court of Justice may value a certain context on the basis of a rationale that reduces or ignores some important parts of the social interests that are at stake within an internal market conflict. As such, its valuation may be indeterminate with respect to the potential conflict between genuine normative orders and therefore subsequently evaluate irreconcilable objectives as being commensurable within a single metric, despite the fact that they are in fact incommensurable. This in turn forecloses the potential expressive value of internal market law, which is, arguably, precisely to articulate situations of irreconcilable social conflict, such as, for example, between solidarity and the market. Consequently, the following main research questions underlie and structure the thesis: (i) what are the adjudicative rationales that govern conflicts between interests of a social nature and market integration objectives?; (ii) how can these adjudicative rationales be critiqued within a normative perspective of social legitimacy?; and (iii) if found lacking what is a better alternative based on social legitimacy ${ }^{12}$

The approach of this thesis can be best described as the construction and application of a normative legal argument. The concept of social legitimacy is constructed in the first chapter and is injected with the normative preconceptions about how the relationship between supranational law and 'embedded' social choices within the Member States should take place. As such, social diversity is valued over administrability or legal certainty and the explicit articulation of genuine normative conflicts is valued over an approach that suggests that "everything can be reconciled", which is dishonest and may exclude social interests: we have to face the truth that there are genuine normative conflicts in the internal market and that choices have to be made. Although these are normative preconceptions, the thesis also argues that such conceptions are justified on the basis of the (evolution) of the legal infrastructure within the internal market, which points towards a higher valuation of institutionalising diversity as an autonomous EU value. Again, it has to be emphasized that this should be considered as

12 This approach and these research questions can of course also be applied to an area of social ordering such as internal market legislation and some would argue that this is the field of internal market law that has a more profound impact on the 'social sphere' within Member States. Including the internal market legislation dimension would involve another kind of study, perhaps even a whole other $\mathrm{PhD}$. Therefore, for the simple reasons of space and time I have chosen to focus on the adjudicative sphere. 
one of the fundamental "challenges to the current institutional setting", which is in need of a new conceptual language to accommodate social diversity within the internal market. ${ }^{13}$

On the basis of this normative framework the thesis approaches the areas of free movement, competition and state aid respectively. Each chapter follows the same structured argument and sets out: (i) where and how the normative concerns of social legitimacy arise; (ii) what the starting points are within existing adjudicative approaches for an alternative that is in accordance with social legitimacy; and (iii) what a coherent rationale on the basis of a dialogue of mutual responsiveness would look like. Each of the substantive chapters is characterised by a mixture of rigid black letter analysis of the case law and a discussion and reconstruction of that case law within the normative framework of social legitimacy. As such, the intention within each chapter is to combine theoretical reflections with a sound analysis of case law. The 'dialogue of mutual responsiveness' is based on the idea that internal market law is a means to start a conversation with Member States on the normative choices of restrictive laws and regulatory schemes. This dialogue requires on one side responsiveness within the application of internal market law to social context in Member States. Concomitantly, it also seeks to incite a clear understanding and articulation of restrictive objectives within the Member States. The normative concerns of social legitimacy and the potential of mutual responsiveness to address these normative claims are the central and connecting elements throughout the thesis. The substantive chapters shall unveil that an overarching dialogue of mutual responsiveness is possible on the basis of a shared language of substantive efficiency, margins of discretion and good governance.

The contribution of the thesis to the literature can be discussed with respect to its separate parts and as a whole. Regarding its separate parts, Chapter I develops a normative outlook based on the work of Karl Polanyi and contributes to earlier debates, which have attempted to develop a 'Polanyian' approach to EU internal market integration. ${ }^{14}$ I find in these contributions that the case law of the Court of Justice is too

13 Again Dani, see above (no 4).

14 A very early version of this Chapter has partly been published in J. Mulder, 'Re-embedding EU Governance Fields: A Research Agenda', in C. Joerges and C. Glinski (eds.), The European Crisis and the Transformation of Transnational Governance. Authoritarian Managerialism versus Democratic 
selectively analysed and commented on without a sufficient eye for detail. Often, these accounts seem to underestimate the quite subtle balancing work and adjudicative techniques offered by the Court of Justice, which provide for a slightly more positive outlook. Furthermore, this debate is connected to a development of the constitutional narrative of the argument of transnational effects. Specifically, the chapter sets out the importance of the fundamental question that was posed by Alexander Somek with respect to the theory by asking : "what might be done to prevent the argument from transnational effects from slipping into a freewheeling rampage of economic due process"? ${ }^{15}$ One of the contributions of the thesis is to provide an answer to this question on the basis of mutual responsiveness. Moreover, the introduction of the normative framework based on social legitimacy introduces a novel method to critically assess case law along the lines of the interrelated terms of valuation, indeterminacy and incommensurability, as introduced above.

The chapters regarding the internal market all separately engage and contribute to specific and insulated debates on the basis of a novel reading and reconstruction of case law within a model of social legitimacy. Each of the chapters clarifies the nature of the conflict between the 'market and the social', which manifests differently in each area of internal market law. Specifically, Chapter II on free movement, contributes to the widely held debate on the legitimacy of the social impact and reach of free movement law by developing a prescriptive model of adjudication, allowing the Court to speak to a range of social interests and actors. Claims to originality have to face the daunting amount of literature in this area of internal market law and certainly, many of the observations made

Governance, (Oxford: Hart Publishing 2014), at 181 and further and J. Mulder, 'Finding the public interest and the case of the Friesian horse', 2013 ACLE Conference Paper http://acle.uva.nl/events/competition--regulation-meetings/conference-papers-9th-cr-meeting-2013.html (accessed 10-12-2015).

15 Somek, above (no 3) at 332. "Economic due process" originates from the Unites States as the idea that substantive due process protects some rights from deprivation. In simple terms this means that government may not hamper the exercise of certain 'rights', even where due processes have been adopted. In the famous Supreme Court decision Lochner v. New York, New York State law that regulated the hours and working conditions of bakery employees was held to intrude too far into the "fundamental right for an employee and an employer to freely contract". This "fundamental right" to contract freely could not be limited, even by fair legislative processes. And came to be known as having established "economic" substantive due process. It was later overturned in the context of the aftermath of the Great Depression and the New Deal rationale which may have inspired the Supreme Court in its decision of West Coast Hotel, which overturned the Lochner jurisprudence. See further M.J. Lindsay, 'In Search of Laissez-Faire Constitutionalism', Harvard Law Review 3(2010) at 55. 
with respect to free movement case law have been made before. The fact that an unqualified market access test is potentially problematic is obviously not new. ${ }^{16}$ Similarly, the observation of the emergence of a procedural proportionality test in certain lines of case law and its potential importance for deciding salient issues within the internal market has been made before. ${ }^{17}$ However, it is submitted that the identification of 'ideal type' standards of evaluation that the Court adopts in its proportionality analysis, combined with a wider contextualisation of these adjudicative means within a dialogue of mutual responsiveness, and the 'inherently irreconcilability test' as a means to adopt evaluative standards that are congruent with underlying social context is a novel view and one which is able to substantially contribute to the state of the art.

Chapter III on competition adds to the long standing and on-going debate regarding how, and to what extent, so-called non-competition or non-efficiency interests have a role to play within the legal framework of the competition rules and the literature on the wider constitutional function of EU competition law. ${ }^{18}$ The chapter identifies a policy-induced trend in competition law, which requires social actors to implement a narrow efficiency based framework in their behaviour within the market, especially when they pursue wider social objectives. This allows for a largely novel critique on the social impact of competition law, which should resonate within the adjudicative rationales of the courts. ${ }^{19}$ The subsequent discussion of the case law provides for some novel

16 E.g. J. Snell, "The Notion of Market Access : A Concept or a Slogan?," Common Market Law Review 47, no. 2 (2010).

17 E.g. D. Damjanovic, "The EU Market Rules as Social Market Rules: Why the EU Can Be a Social Market Economy," Common Market Law Review 50, no. 6 (2013): 1685-1717; F. de Witte, "Sex, Drugs \& EU Law: The Recognition of Moral and Ethical Diversity in EU Law," Common Market Law Review 50, no. 6 (2013): 1545-78. G. Mathisen, "Consistency and Coherence as Conditions for Justification of Member State Measures Restricting Free Movement," Common Market Law Review 47, no. 4 (2010): 1021-48.

18 This Chapter has partly been published as a conference paper J. Mulder, 'Finding the public interest and the case of the Friesian horse', 2013 ACLE Conference Paper http://acle.uva.nl/events/competition-regulation-meetings/conference-papers-9th-cr-meeting-2013.html (accessed 10-12-2015) and two Dutch Journal articles: J Mulder, 'Een duurzame maatschappij, wat mag dat kosten?', NJB 2015/1400 19121920 and J. Mulder, 'Op het snijvlak van onafhankelijkheid en openheid :wat is de rol van de ACM in een duurzamemaatschappij?', SEW 2014, p. 565-578.

19 In close proximity to arguments presented first by H. Schepel, "Delegation of regulatory powers to private parties under EC competition law: towards a procedural public interest test", Common Market Law Review 39 (2002) p. 31-51. For a development of that view see W. Sauter and H. Schepel, 'State and market in European Union law: the public and private spheres of the internal market before the EU Courts' (Cambridge University Press 2009), 114. 
understandings and a distinct reading of seemingly unconnected lines of case law that can be connected on the basis of the normative perspective of social legitimacy and the dialogue of mutual responsiveness. The chapter finds that the dichotomy between market and nonmarket, or economic and noneconomic, is there to allow or even force a deliberative space for broader than monetary or efficiency based considerations of what matters in social relations. ${ }^{20}$ Important considerations that range from sustainability, the integrity of certain professions or the ethical treatment of animals, harbour important social values that do not necessarily speak market talk. However, such market talk is provided with a source of legitimacy within the EU competition rules and can be applied to initiate a social dialogue on the validity and systemization of regulatory choices within the Member States. Competition law should seek to incorporate the means by which to value different social contexts differently, in accordance with the underlying normative commitments of those contexts. Such responsiveness ultimately depends on institutional design within Member States.

Chapter IV, the chapter on state aid, engages with the potential impact of the EU state aid rules on the pursuit of social objectives by Member States. It is fair to say that of all areas of internal market law, state aid rules are the least theorised. Nevertheless, over recent years some important contributions have been made to the discussion of the EU state aid rules concerning their wider function and constitutional status within the internal market ${ }^{21}$ in a field of internal market law that is otherwise primarily dominated by insulated and practitioners led specialised debates. The salience of this chapter, in light of the existing contributions, is claimed to be particularly pertinent in two ways. Firstly, in the discussion of the structural social legitimacy concerns with regard to the potentially expedient nature of market based evaluations in state aid cases. Secondly, with the

20 J. Mulder, 'Finding the public interest and the case of the Friesian horse', 2013 ACLE Conference Paper http://acle.uva.nl/events/competition--regulation-meetings/conference-papers-9th-cr-meeting2013.html (accessed 10-12-2015). Chapter III was previously published in part in this conference paper.

21 F. De Cecco, State Aid and the European Economic Constitution (Hart Publishing 2013) and J.J.P. Lopez, The Concept of State Aid under EU Law - From internal market to competition and beyond (Oxford University Press 2015). See also M. Ross, 'State Aids: Maturing into a Constitutional Problem' (1995) Yearbook of European law 79; M. Ross, 'State Aid and National Courts: Definitions and Other Problems - a Case of Premature Emancipation?' (200) Common Market Law Review 401; M. Ross, 'Decentralization, Effectiveness, and Modernization: Contradiction in terms?' (2004) in A. Biondi, P. Eeckhout and J. Flynn (eds), The Law of State Aid in the European Union (Oxford University Press, 2004). 
introduction of the idea of mutual responsiveness to state aid law. This allows a connection between state aid law and the wider debate on the social legitimacy of the internal market.

Chapter V concludes that as a whole the thesis contributes to the debate and the legitimate role and social purpose of the internal market within the European Union. It should be noted that the literature that aims to contribute to this debate on the internal market tends, with notable exceptions ${ }^{22}$ to focus primarily, if not exclusively, on the impact of free movement case law. In addition, competition law and state aid are mostly subject to specialised debates, related to the limited insulated approaches within those areas of law. The latter fact must be related to ever-increasing specialisation within each area of internal market law, in particular the fact that competition and state aid rules are subject to a high degree of practitioners led debates, whereas free movement tends to be mostly an academic affair. Free movement is therefore relatively more often the subject to wider academic reflections, whereas competition and state aid are more inwardly focused. Nevertheless, a critique on the legitimate 'social impact' of internal market law, and the potential structurally distortive effects of economic integration on the fundamental structures of domestic societies, has to take an overall approach. The benefit of such an overarching approach has been demonstrated. The thesis extrapolates and reconstructs interlinkages between the three fields of the internal market on the basis of a shared language that takes place in the context of a dialogue of mutual responsiveness, which allows the social purpose of the internal market to become a structural part of the European legal space.

22 E.g. J. Baquero Cruz, Between competition and free movement: the economic constitutional law of the European Community (Hart Publishing 2002), 123; L. Ankersmit, 'Globalization and the Internal Market: Process-based Measures Within the EU Legal Order' (2015, PhD thesis, Vrije Universiteit Amsterdam); De Cecco above (no. 21); W. Sauter and H. Schepel, above (no. 19). 


\section{CHAPTER I}

\section{Social legitimacy in the internal market:}

\section{A research agenda}

I. Introduction to the argument 2

II. The social problematique and the argument from transnational effects 9

A. The social problematique discussion 9

B. Transnational effects and the legitimacy of the social deficit: Joerges and Maduro 13

C. Somek's fundamental question 18

III. The emergence of 'the social' and a constitutional principle of responsiveness within the multilevel context of the EU

A. The social sphere within the internal market $\quad 21$

B. The 'positive' social 23

C. The internal market rules as a contingent form for the social sphere 27

D. The constitutional obligation of responsiveness 31

IV. The normative-instructive value of embeddedness 35

A. Introduction $\quad 35$

B. Notes on Polanyi 36

C. The enduring relevance of Polanyi 47

D. A rationale of responsiveness: moving beyond Polanyi?

E. Polanyi in Luxembourg?

V. Social legitimacy in the context of internal market adjudication: (e)valuation and the expressive function of internal market law as a dialogue of mutual responsiveness $\quad 63$

$\begin{array}{ll}\text { VI. Outlook for the thesis: a research agenda } & 70\end{array}$ 


\section{Introduction to the argument}

Conventionally, the legitimacy of governance in the European Union is discussed on the basis of three core concepts: 'input legitimacy, 'throughput legitimacy' and 'output legitimacy'. ${ }^{1}$ The conventional meaning of these concepts is to see 'input' as the potential openness of the decision-making process for citizens, 'throughput' as the quality of the processes that subsequently process the input and 'output' as the quality of the result of the decision making process. In addition to this set of normative concepts, the concept of social legitimacy is normally conceived to encompass an empirical notion that measures, with tools provided by social science, the societal attitudes and acceptance towards, for example, a political or legal regime. ${ }^{2}$ The idea behind the concept is that lacking empirically measurable societal acceptance, a political regime will eventually disintegrate and a law shall, generally, not be respected since it is too unconnected from prevailing social norms. I will not adopt this empirical outlook on social legitimacy in this thesis. What is hardly ever discussed is that social legitimacy also carries a normative commitment, specifically, and perhaps exclusively, in the context of multilateral trading regimes. That is to say, if one accepts that these regimes need a level of social legitimacy to be sustained in the long run, one also has to accept that such legitimacy then depends on the structural institutional design and rationales that embed the normative orientations of societies within those regimes and vice versa. ${ }^{3}$ This aspect of social legitimacy embodies a commitment that can be translated into normative claims on how transnational regimes respond to conflicts between interests of a social nature within states and supranational trade objectives. It is possible to approach such responses from multilateral trade regimes

V. Schmidt, 'Democracy and Legitimacy in the European Union Revisited: Input, Output and "Throughput" (2013) 61 Political Studies at p. 2; F.W. Scharpf, 'Legitimacy in the Multilevel European Polity' (2009) 1 European Political Science Review at p. 173.

2 For example, J. H. H. Weiler (2012) In the Face of Crisis: Input Legitimacy, Output Legitimacy and the Political Messianism of European Integration, Journal of European Integration, 34:7, 826.

3 A. Rawi, and J. G. Ruggie. "The Principles of Embedded Liberalism: Social Legitimacy and Global Capitalism." in New Perspectives on Regulation D. Moss and J. Cisternino (eds.), (Cambridge 2009) pages $151-162$. 
in normative terms, based on the notion of social legitimacy. It is this aspect of social legitimacy that shall be further developed in this thesis.

As such, social legitimacy has a distinct meaning and function within the multilevel context of the EU and specifically with regard to the areas of law that are concerned with the internal market project. To further contextualise this specificity we have to take a step back and look at the institutional structures that were developed for international trade regimes in the post-1945 world economy, which have been described as embodying a particular social bargain. ${ }^{4}$ This social bargain stands behind the normative grounding of social legitimacy. Policymakers were looking to reinvigorate the world economy on the basis of open markets but within an institutional context that would mitigate their recognised adverse social consequences. ${ }^{5}$ It was a shared concern that the absence of such a compromise had led to the collapse of international cooperation in trade and macroeconomic policy during the 1920s and 1930s. ${ }^{6}$ One of the proponents of this latter idea was Karl Polanyi. In his 1944 book, The Great Transformation he introduced the idea of “embedded" versus "disembedded" socio-economic orders. ${ }^{7}$ Polanyi's historical inquiry led him to conclude that economic orders tend to be characterised by the values of societies in which they are situated. However, the middle of the nineteenth century had seen the rise of the idea of economy separate from society in the form of a collection of self-regulating and autonomous markets, which required social relation to be transformed within its own logic:

"the control of the economic system by the market is of overwhelming consequence to the whole organization of society: it means no less than the running of society as

4 J.G. Ruggie, "International Regimes, Transactions and Change: Embedded Liberalism in the Postwar Economic Order, International Organization", 36(2) International Regimes (1982), 392: “[To] say anything sensible about the content of international economic orders and about the regimes that serve them, it is necessary to look at how power and legitimate social purpose become fused to project political authority into the international -system. Applied to the post - World War II context, this argument leads me to characterize the international economic order by the term 'embedded liberalism'."

5 Ibid., p. 388. Also R. Nurkse, League of Nations Report: International Currency Experience: Lessons of the Inter-War Period (League of Nations, Economic, Financial and Transit Department, 1944)

6 Ibid., p. 392; also S. Marglin and J. Schor, The Golden Age of Capitalism : Reinterpreting the Postwar Experience (Oxford University Press 1990).

7 K Polanyi, The Great Transformation: The Political and Economic Origins of our Time, (Boston, The Beacon Press, [1944] second edition reprinted in 2001). 
an adjunct to the market. Instead of economy being embedded in social relations, social relations are embedded in the economic system".

In this market run dystopia, markets had to be shielded against political intervention so as not to disturb the allocative flow of supply and demand, which was best safeguarded by separating politics and the economy. Dis-embedding the economy implied a process of commodifying the "very substance" of society, which was determined through market exchange rather than through political deliberation. ${ }^{9}$ There was, in other words, no social legitimacy in its empirical understanding. This turned out to be politically unsustainable and Polanyi considered it to be one of the important contributing factors for the rise of fascist like movements who resolved the problem by taking over control of markets completely.

Against this background it seems that the post-1945 U.S. and European policymakers agreed with the basic insights articulated by Polanyi. ${ }^{10}$ On the basis of John Maynard Keynes' ideas, rules were shaped on the basis of which the international economy was to be reconstructed. Similar to Polanyi's concerns, Keynes considered that the role of the international monetary order had put politically unsustainable pressures on societies to adjust policy and accommodate the needs of financial markets. A driving notion behind this was, indeed, the idea that markets, which are not considered legitimate within societies, are not sustainable. Therefore, it was considered a necessity to reconcile open and free markets with the prevailing values of the social-economic systems that they affected: a reconciliation of markets and politics. This has been famously coined by John G. Ruggie, relying on insights from Polanyi, as the reconciliation on the basis of the compromise of 'embedded liberalism':

Ibid., p. 57.

G. Dale, Karl Polanyi: The Limits of the Market (Cambridge Polity Press, 2010); F. Block, "Karl Polanyi and the Writing of The Great Transformation," Theory and Society Theory and Society: Renewal and Critique in Social Theory 32, no. 3 (2003), p. 275-306.

10 J. Ruggie, 'Taking Embedded Liberalism Global: The Corporate Connection', Institute for International Law and Justice Working Paper 2003/2, New York University School of Law and J. Ruggie, "Multilateralism: The Anatomy of an Institution," International Organization 46, no. 3 (1992), p. 56198. 
"Unlike the economic nationalism of the thirties, it would be multilateral in character; unlike the liberalism of the gold standard and free trade, its multilateralism would be predicated upon domestic interventionism". ${ }^{11}$

The idea behind this 'social bargain' was that through domestic interventionism the socially disruptive effects of markets would be mitigated without, however, eliminating the economic gains that could be derived from open and transnational markets. Therefore, the idea of social legitimacy requires trade regimes to be responsive to a variety of social contexts. In Europe this concretised in the development of the European welfare state models and the laws of the EU internal market share an explicit concern for embedding markets in social foundations of the Member States. ${ }^{12}$ Despite the norm based 'Hayekian' revolution in public policy of the 1970s and 1980s, the idea of a European welfare state remains alive today as well as the fact that the European Treaties still reflect to a large extent the institutional set-up and rules that are reflective of the original embedded liberalism compromise. ${ }^{13}$ The internal market laws determine that, although there is a commitment to intra-European free trade, Member States retain control over domestic public interests that are able to override trade interests. Moreover, the Court of Justice of the European Union (Court of Justice) has repeatedly called for a balancing of both the economic and social objectives of the Union. In addition, the EU has a limited competence to produce rules with a 'social' dimension.

Nevertheless, EU law finds itself in what can be described as a crisis of social legitimacy. Many factors contribute to this crisis, not least the fact that the EU induced austerity programmes have enforced the view that the EU is one of the main if not 'the' key driver in the dismantling of social protection within the

11 Ruggie, above (no. 4), p. 393.

12 Ibid.

13 Confirmed by the historical reconstruction of Giubboni who coined this as a "historical compromise": S. Giubboni, Social Rights and Market Freedoms in the European Constitution. A Labour Law Perspective, (Cambridge: Cambridge University Press, 2006), at 7; more recently see R. Dukes, The Labour Constitution. The Enduring Idea of labour Law, (Oxford: Oxford University Press, 2014), at $130 \mathrm{ff}$. 
Member States and only pushes for a very limited understanding of the balance between social and market objectives. The 'social' is perceived as a 'restriction' of the economic objectives of the Union or as merely ancillary to them. This ambiguous relationship is reflected in a passage of the Court of Justice where it held in one of its most contentious decisions in recent history: ${ }^{14}$

"Since the Community has [...] not only an economic but also a social purpose, the rights under the provisions of the Treaty on the free movement of goods, persons, services and capital must be balanced against the objectives pursued by social policy $[\ldots] " .{ }^{15}$ (emphases added)

The statement of the Court of Justice is ambiguous because in this case 'the balance' was found by subordinating the right to strike to market freedoms. The social purpose of the EU remains aloof and the commitment of Member States to ever further integration cannot be taken for granted any longer. ${ }^{16}$ Diverging interests of an increasingly heterogeneous Union increase the importance of some clear notion, a sense of purpose, that can be attached and serve as a focal point for challenges that lie ahead. The firm believe behind the studies in the next chapters of this thesis is that a social purpose has to become an explicit part of the structure of EU law or the 'European legal space'. This thesis identifies one of the roots of the crisis in the fact that the social purpose of the EU has never been fully established and has never become a concrete and structural part of that legal space. How to conceptualise that social purpose? Although the social purpose of the EU has never been clearly articulated it will be argued further below that such purpose can be derived from the conceptualisation of the EU internal market in terms of the original embedded liberalism compromise. In short, on this basis, the social

14 Although not related to the Lisbon Treaty and stated in one of the most socially controversial cases of the Court.

15 Case C-438/05, International Transport Workers' Federation and Finnish Seamen's Union v Viking Line ABP and OÜ Viking Line Eesti, [2007] ECR p. I-10779 at paras. 78-79. This statement of the Court is similar to the one formulated in 1976 in the case Defrenne where the Court held that "the social objectives of the community, which is not merely an economic union, but is at the same time intended, by common action, to ensure social progress and seek the constant improvement of the living and working conditions of their peoples Case 43/75 Defrenne [1976] ECR 00455, para. 10: "the social objectives of the Community, which is not merely an economic union".

16 See for a shared outlook also the Editorial Comments of Common Market Law Review 52: 881-888, 2015. 
purpose of the internal market is to provide for an infrastructure for the conflict of norms within the Union that arise through the interaction between principles of economic integration and the pursuit of social interests on a Member State level. ${ }^{17}$ Clearly, an understanding of the internal market as a platform for social conflict is in need of reinvigoration. As such, Dani has argued that the effect of internal market law is rather one of "marginalising social conflicts". ${ }^{18}$ Dani submits that a development of a language for social conflicts within internal market law will be a main factor contributing to its stability and legitimacy. Section two below discusses that this conceived social purpose is implicit in the constitutional form that is advanced on the basis of the argument from transnational effects.

The thesis joins streams with forms of critique that aim to show that EU law is capable to distort social relations since objectives of pure economic integration carry the inherent risk to disregard the fundamental structures of domestic societies. ${ }^{19}$ However, it is one thing to simply call for a substantial transformation of the European integration project, arguing that its laws and adjudication should be sensitive to social interests and local contexts; it is quite another thing to conceive of a rationale that accomplishes this, without completely forgoing the objectives of integration, free trade and legal certainty. ${ }^{20} \mathrm{My}$ argument in this thesis is that it is exactly in developing a 'rationale of mutual responsiveness' that the EU internal market finds its existential reason and social purpose; a reconciliation of local domestic social values with and within supranational market objectives. Clearly, such a rationale of responsiveness will look different within the different governance fora of the European Union. As was highlighted in the general

17 KH Ladeur, “Conflicts Law as Europe's Constitutional Form” ... and the Conflict of Social Norms as Its Infrastructure' [2014] in (C. Joerges and C. Glinski eds.), European crisis and the transformation of transnational governance : authoritarian managerialism versus democratic governance, at $\mathrm{p} 383$.

18 M Dani, 'Rehabilitating social conflicts in European Public Law', (2012) 18 European Law Journal at p. 621

19 See e.g. Menéndez, "Which citizenship? Whose Europe? - The many paradoxes of European citizenship", (2014) German Law Journal, 907-933; G. Davies, "Internal market adjudication and the quality of life in Europe”, (2014) EUI Working Paper 2014/07.

20 Loïc Azoulai, "The Court of Justice and the Social Market Economy: The Emergence of an Ideal and the Conditions for Its Realization" (2008) 45 Common Market Law Review 1335; Loïc Azoulai, "The European Court of Justice and the Duty to Respect Sensitive National Interests" [2013] in Judicial activism at the European Court of Justice, at p. 167. 
introduction, this thesis is specifically concerned with the development of a rationale of responsiveness for adjudicative contexts. The aim of this thesis then is to provide for means to make the social part of that legal space, concretely, within the adjudicative model and rationales of the Court of Justice in the application of internal market law, based on an idea of social legitimacy.

It shall be further discussed below in this chapter that the idea of embeddedness as developed in the work of Karl Polanyi, provides normative instructions for adjudicative rationales to distinguish 'the social' from 'the economic', in terms of potentially irreconcilable organisational principles. Thinking about internal market conflicts in this way and adopting evaluative principles that are congruent with potentially incommensurate objectives will allow the Court to develop a rationale of mutual responsiveness. It shall be investigated in the next chapters to what extent the Court of Justice has developed adjudicative rationales that respond to social context and whether that provides a basis for a coherent articulation of a social purpose within European legal space.

This chapter shall further outline how the concept of social legitimacy shall be developed and applied throughout the next chapters of the thesis. Simply said, in this chapter I develop the normative understanding of social legitimacy and argue that the social purpose of the internal market is inherently linked to it. The next chapters will then apply that normative understanding to the main areas of internal market law, i.e. the free movement, competition and state aid laws. First, below, section II shall contextualise social legitimacy within EU internal market law by discussing it in the context of the general social problematique narrative that is prevalent as part of a critique on the effects of economic integration on fundamental social structures within the Member States. The argument of social legitimacy shall then be contextualised within EU constitutional theory, more specifically the argument from transnational effects. Section III discusses the meaning of the social within the internal market and how it is, potentially, opposed to economic objectives and why that matters for the idea of 'responsiveness' as a compulsory and constitutional feature of the internal market project that is built on the premise of embedded liberalism. Section IV further introduces the ideas of Karl Polanyi 
specifically with the intention to highlight how these ideas instruct and provide an underlying normative commitment to a further development of a rationale of mutual responsiveness. Section V discusses the implications of social legitimacy in adjudicative contexts. This section discusses some of the adjudicative rationales that are available to the Court and introduces how social legitimacy provides normative instructions as to which rationale should be applied in certain social contexts. Section VI concludes briefly with a research agenda that transposes this view of social legitimacy to the EU internal market project and provides an outlook for the subsequent chapters.

\section{The social problematique and the argument from transnational effects}

\section{A. The social problematique discussion}

The EU internal market project has provided fertile ground for what can be seen as 'social critiques' that, roughly, argue that most outcomes in cases before the Court of Justice are attributable to a 'pro trade bias' that is not only anchored in the ontology of the whole of Union law but also ranks highest on the institutional agendas of the Court of Justice and the European Commission. ${ }^{21}$ Although it is clear that Member States have committed themselves to market integration and in that sense, the basic requirements of the internal market are obvious, such as the

\footnotetext{
Amongst an ever increasing and daunting amount of literature the selected publications here are just a small sample: B. Van Apeldoorn, J. Drahokoupil, and L. Horn, Contradictions and limits of neoliberal European governance: from Lisbon to Lisbon (Palgrave Macmillan 2008); C. Joerges, 'A Critique of the Disregard for History in European Constitutional Theory: Are Those that Forget the Past Doomed to Repeat its Mistakes?', Florence, EUI Working Paper LAW No. 2005/14; C. Joerges and F. Rödl, 'Informal Politics, Formalised Law and the "Social Deficit" of European Integration: Reflections after the Judgments of the ECJ in Viking and Laval' (2009) 15 European Law Journal, pp. 1-19; F. Scharpf, "The asymmetry of European integration, or why the EU cannot be a "social market economy" (2009) 8, Socio-Economic Review, pp. 211-250 ; F. Scharpf, 'The European Social Model: Coping with Challenges of Diversity', 40 JCMS 4 (2002),p. 645-670J; Höpner and Schäfer, 'Embeddedness and Regional Integration: Waiting for Polanyi in a Hayekian Setting' (2012) 66 International Organization 429; S. Deakin, 'The Lisbon Treaty, the Viking and Laval Judgments and the Financial Crisis: In Search of New Foundations for Europe's Social Market Economy', in N. Bruun et al., The Lisbon Treaty and Social Europe (Hart, Oxford 2012), p. 19.
} 
textbook examples of the prohibition of quota's, custom duties and protectionist arrangements, a lot of questions remain, mostly resulting from the significant expansion in scope of all the free movement provisions over the last two decades. ${ }^{22}$ Specifically, this has led to a number of controversial judgments of the Court on the balance between market objectives and social interests. Despite the increased attention for the 'social' in the Lisbon Treaty, on the basis of a commitment to a 'competitive social market economy', the recognition of 'social rights' in the Charter and new 'soft law' mechanisms for the coordination of social and labour market policies, controversial case law from the Court has resulted in a culmination of social critiques that consider fundamental social objectives such as the right to strike and collective negotiating/agreements to be subordinate to economic rights of free movement. ${ }^{23}$

The social critique mostly targets obvious biases, or asymmetries, in the way that, for example, EU free movement law operates. ${ }^{24}$ The argument runs roughly as follows. As a result of the trade bias there is a structural preference in favour of deregulation that is targeted against forms of social regulation and interest at the

22 See for a generally good collected overview of issues in E. Spaventa, 'From Gebhard to Carpenter: Towards a (non-)economic European constitution' (2004) 41 Common Market Law Review, p. 743-773; also in F. De Cecco, Chapter 2 'The Constitutional Framework', in State Aid and the European Economic Constitution (Oxford: Hart. Publishing, 2013).

23 Again just a selection; “C. Barnard, 'Viking and Laval: An Introduction' (2007-2008) 10 Cambridge Yearbook of European Legal Studies 464; A Dashwood, 'Viking and Laval: Issues of horizontal Direct Effect' (2007-2008) 10 Cambridge Yearbook of European Legal Studies 525; A Davies, 'One Step Forward, Two Steps Back? Laval and Viking at the ECJ' (2008) 37 International Law Journal 126; S. Deakin, 'Regulatory competition after Laval' (2007-2008) 10 Cambridge Yearbook of European Legal Studies 581; C Kilpatrick, 'Laval's Regulatory Conundrum: Collective Standard-Setting and the Court's New Approach to Postal Workers' (2009) 34 European Law Review 844; C Joerges and F Rödl, 'Informal Politics, Formalised Law and the Social Deficit of European Integration: Reflections after the Judgments of the ECJ in Viking and Laval' (2009) 15 European Law Journal 1; J. Malmberg and T. Sigeman, 'Industrial Action and EU Economic Freedoms: The Autonomous Collective Bargaining Model Curtailed by the European Court of Justice' (2008) 45 Common Market Law Review 1115; T Novitz, 'A Human Rights Analysis of the Viking and Laval Judgments' (2007-2008) 10 Cambridge Yearbook of European Legal Studies 541; S Sciarra, 'Viking and Laval: Collective Labour Rights and Market Freedoms in the Enlarged EU' (2007-2008) 10 Cambridge Yearbook of European Legal Studies 563; P Syrpis and T Novitz, 'Economic and Social Rights in Conflict: Political and Judicial Approaches to their Reconciliation' (2008) 33 European Law Review 411".

24 Most prominently argued by F. Scharpf see above (no. 21). However, in contrast see Caporaso and A. Tarrow, 'Polanyi in Brussels: Supranational Institutions and the Transnational Embedding of Markets', (2009) 63 International Organization, p. 593-620; K. Lenaerts and T. Heremans, 'Contours of a European Social Union in the Case-Law of the European Court of Justice' (2006) 2 European Constitutional Law Review, p. 101-115. 
Member State level. Moreover, privatisation of public sectors is pushed through internal market legislation and the application of the competition rules, targeting sectors that where previously in public hands. ${ }^{25}$ Unsurprisingly, according to these critiques, the internal market set-up has not resulted in a strong publicly supported European Union but rather, to a situation where it seems that scepticism directed towards the EU is distributed unevenly among social groups, between those who have the capability to benefit from the supremacy of the free trade objectives and those who do not. ${ }^{26}$ Negative public sentiment is fed through the impact of case law of the Court that often appears to set aside social objectives whose impetus originates from a long-standing Member State context. ${ }^{27}$ Such 'judicial activism' of the Court of Justice does not pass by unnoticed and it has become commonplace in political circles and mainstream media to question the agenda of the Court of Justice. Former German President and former President of the German Constitutional Court, Roman Herzog wrote in 2008 that "the ECJ deliberately and systematically ignores fundamental principles of the Western interpretation of law", so that "its decisions are based on sloppy argumentation, it ignores the will of the legislator, or even turns it into its opposite". ${ }^{28}$

The EU induced austerity programmes have enforced the view the EU is the "key driver in the dismantling of social rights within the Member States". ${ }^{29}$ This, coupled with the fact that these instances receive high levels of public attention have been an additional cause for Euro scepticism and, what can be coined as, and

25 Höpner and Schäfer, above (no 21), p. 11.

26 L. Mc Laren, 'Explaining Mass-Level Euroskepticism: Identity, Interests, and Institutional Distrust' Acta Politica 42(2007) p. 233-51; H. Kriesi, West European Politics in the Age of Globalization (Cambridge 2009).

27 Frequently referred to examples in CJEU case-law are cases such as the Centros, Überseering and Inspire Art that allow companies to circumvent, for example, national codetermination procedures in Germany by establishing themselves in the UK (C-212/97, Centros; C-208/00, Überseering; C-167/01, Inspire Art) or the Viking, Laval and Rüffert cases( C-438/05, Viking; C-341/05, Laval, C-346/06, Ruffert) that, frame the right to strike as a narrow exception to the free trade rules, or the Cadburry Schweppes and Marks \& Spencer cases (C-196/04, Cadbury Schweppes, C-446/03, Marks \& Spencer) that, similarly, allow tax-avoidance practices by companies. Further on this in Chapter II.

28 Frankfurter Allgemeine Zeitung (8 Sept. 2008). See also Editorial comments, "The Court in the limelight - again", Common market Law Review 45(2008), 1571-1579.

29 D. Ashiagbor, 'Unravelling the Embedded Liberal Bargain: Labour and Social Welfare Law in the Context of EU Market Integration', 19 European Law Journal 3(2013), p. 324 
has been mentioned shortly above as a crisis of social legitimacy. ${ }^{30}$ These critiques often consider that the EU internal market instils regulatory competition between Member States with the effect that the overall standard of protection of social concerns will spiral downwards. ${ }^{31}$ Moreover, social critiques recognise that this problématique is strengthened by the approaches of Member States to social, cultural and ecological objectives that are characterised by diversity ${ }^{32}$ Some, most prominently Fritz Scharpf, argue that due to a structural institutional incapacity, the EU will forever be inhibited to deal with social issues. ${ }^{33}$ Therefore, the view of most social critique commentators is that there will be a continuing institutional asymmetry between the Union's trade and social objectives, which has been coined as the "social deficit". ${ }^{34}$ Within this narrative a solution to the social deficit is sometimes conceived in the form of a reconceptualization between EU economic and social policy, which must be done by increasing the EU's legislative competence in the social field in order to remedy the asymmetry. ${ }^{35}$ As Höpner and Schäfer have noted, this continued asymmetry means in practice that proponents of the social have to direct their demands mainly to the national level, while

30 See Davies, above (no. 19).

31 E.g. in general on the federalist competition structure in the EU see L. Hooghe and G. Marks, 'The Making of a Polity: The Struggle over European Integration', in H. Kitschelt, et al (eds), Continuity and Change in Contemporary Capitalism, (Cambridge University Press 1999), p. 70-97.

32 P. Beramendi, 'Inequality and the Territorial Fragmentation of Solidarity', International Organization 4(2007) p. 783-820. As Beramendi demonstrates, the more divers the EU Member States are in terms of wealth, inequality and the organisation of public tasks, the less likely it is that social policies emerge at the European level, despite the fact that EU primary law sources increasingly refer to social progress

33 Scharpf see above (no. 21).

34 See for coining of the term Joerges and Rödl, above (no. 23): 1-19. Similar legitimacy issues are explored in G. de Burca, "The Quest for Legitimacy in the European Union", Modern Law Review 59 (1994) 349; J. Weiler, "Fin-De-Siècle: Do the New Clothes Have an Emperor?", in The constitution of Europe: 'Do the new clothes have an emperor? And other essays on European integration, (Cambridge University Press, 1999) 238; C. Joerges, What is Left of the European Economic Constitution? (European University Institute, Working Paper Law No. 2004/13, 2004). On the general democratic deficit of the Union, see S. Hix and A. Follesdal, "Why There Is a Democratic Deficit in the EU: A Response to Majone and Moravscik", Common Market Studies, 44(2006) 533.

35 D. Schiek, "The EU Constitution of Social Governance in an Economic Crisis in Defence of a Transnational Dimension to Social Europe', Maastricht Journal of Comparative and European Law 2 (2013) p. 185-208 
proponents of liberalisation and free trade benefit from the supremacy of free market objectives. ${ }^{36}$

B. Transnational effects and the legitimacy of the social deficit: Joerges and Maduro

As conceived by Christian Joerges, it is important to note that, in principle, this divide between Member State social policy and the supranational 'economic constitution' has always been intentional and very much a part of the constitutional model of the Union: ${ }^{37}$ :

"This was its constitutional-supranational raison d'être. Social policy was treated as a categorically distinct subject. It belonged to the domain of political legislation, and, as such, had to remain national. The social embeddedness of the market could, and, indeed, should, be accomplished by the Member States in various ways [...]". ${ }^{38}$

The Union's economic objectives were therefore to be seen as transnational and apolitical whereas the social remained national and political. This dichotomy led Joerges to conceptualise the EU internal market in terms of 'deliberative supranationalism'.$^{39}$ The argument of deliberative supranationalism is, roughly, that the 'post-national' legitimacy of governance within constitutional states is flawed to the extent that it is unable to include 'foreign' identities and their interests within national decision-making processes. Therefore, the legitimacy of supranational institutions can be derived from this compensatory function:

"We must conceptualise supranational constitutionalism as an alternative to the model of the constitutional nation-state which respects that state's constitutional legitimacy, but, at the same time, clarifies and sanctions the commitments arising from its interdependence with equally democratically legitimised states and with the

36 Höpner and Schäfer, see above (no. 21). The conceptualisation of the supremacy of free trade objectives and the struggle for social objectives originates from the original legal infrastructure of the EU that is designed to promote competitive federalism as identified by G. Marks, L. Hooghe and K. Blank, "European Integration since the 1980s: State-Centric versus Multi-Level Governance", (1996) 34 Journal of Common Market Studies, pp. 343-78.

37 Ruggie, see above (no. 4), p. 393.

38 Joerges and Rödl see above (no. 21).

39 C. Joerges and J. Neyer, "From Intergovernmental Bargaining to Deliberative Political Processes", 3(1997) European Law Journal, p. 273. 
supranational prerogatives that an institutionalisation of this interdependence requires". ${ }^{40}$

Joerges' argument developed in what is now mostly, and arguably more aptly, coined as the "argument from containment" or the "argument from transnational effects ${ }^{41}$ and instructs to qualify the process of integration as an exercise whereby traditional, out-dated, unrepresentative manifestations of national defected forms of decision making are removed on the basis of the idea that these are hostile towards transnational interests and inappropriate within an integrating European market, at least the one to which Member States have committed themselves in the Treaties. ${ }^{42}$ For example in the case Corbeau the Court reviewed the Belgian postal monopoly created by laws in the 1950 s and 1970 s. ${ }^{43}$ Demand for the courier service offered by Corbeau did not exist to the same extent then and the monopoly was considered to exclusively serve a privileged and entrenched group of interests. However, in 1993 societal developments had outgrown the basis for the law at that time and needed to be reconsidered, modernised. Similarly, in the case Albany, certain individuals were concerned that they would be forced to join compulsory industrial pension schemes, despite the fact that the free market offered better deals. ${ }^{44}$

The dynamic that internal market law creates on this basis can be compared with the effects of technological innovation on regulated embedded market structures. For example the dynamic that the Uber app brings to regulated taxi sectors within countries across the globe. Uber develops, markets and operates a mobile app, which allows consumers with smartphones to book a trip which is then

40 C. Joerges, “Deliberative Political Processes" Revisited: What Have we Learnt About the Legitimacy of Supranational Decision-Making ?', (2006) 44 Journal of Common Market Studies 779, at 790

41 To be traced back to Joerges and Neyer above (no. 39), 273-299. Also C. Joerges, "European law as conflict of laws", in Joerges and Neyer (eds.), "Deliberative supranationalism revisited", 20 EUI Working Paper (2006). Most recently C. Joerges, 'Unity in Diversity as Europe's Vocation and Conflicts Law as Europe's Constitutional Form', in R. Nickel and A. Greppi (eds.), The Changing Role of Law in the Age of Supra- and Transnational Governance, (Baden-Baden: Nomos, 2014), 125-176. See also Somek, "The argument from transnational effects I: Representing outsiders through freedom of movement", 16 European Law Journal (2010), 320 and M.P. Maduro, We the Court, (Oxford: Hart Publishing 1998), who then proceeded to popularize the argument.

42 Schiek, see above (no. 35).

43 Case C-320/91 Corbeau [1993] ECR I-2533.

44 Case C-67/96 Albany [1999] ECR I-05751. 
automatically routed to 'Uber drivers' who use their own cars for the service. Bills are automatically paid online and Uber is considered in many countries as a major threat to the vested taxi industries who found themselves suddenly confronted with an army of competitors, who, unlike in many regulated taxi industries are not required to finance their license with significant funds. In effect Uber challenged many regulatory regimes and the responses of these regimes revealed to some extent their 'producerist' or 'consumerist' orientations. With producerist I refer to an orientation of the state on the supply side of a market. Producers are accorded a central function in society that goes further than merely an economic function but is able to provide a certain social identity to people. The protection of guilds (lawyers, waiters in France, pharmacists), certain ways of making products (pasta, wine, reinheitsgebot) or even the size of stores and their opening times thereby fulfil a social function that resonates with a certain culture, history and identity. ${ }^{45}$ Obviously such functions are subject to social change. A (economic) consumerist orientation is, by contrast, focussed on rights and interests on the demand side of the market-in particular, primarily as an interest in competitive prices and choice. Europe is traditionally perceived as oriented more towards the supply side (in particular the Netherlands, Germany and France) whereas the US harbours the fundamental consumerist interest. Perceived in this way the 'Uber app', which gained ground and regulatory recognition in the US, can be framed as an attack on European 'producerist' orientations.

The dynamic is comparable with situations where, e.g., service providers from a 'consumerist' oriented Member State are restricted in their trade due to a 'producerist' regulatory framework and the 'producerist' oriented legal system cannot provide good arguments for its existence (such as an important societal function of national identity) it is liable to be qualified as a restriction of free movement that cannot be justified and it can be overridden by the consumerist interest coming from another Member State. Although this is of course a slightly

45 See for example J. Whitmanm "Consumerism versus Producerism: A study in Comparative Law" (2007) Yale Law Journal p. 340. 
different situation, the inherent regulatory dynamic that Uber brings to the countries where it is launched seems to be essentially the same. That is to say that the existing regulatory protections of the taxi industry are being critically assessed with respect to the function that they actually provide and the suitability of the regulatory framework and restrictions they bring on competition. Unlike as is the case in Britain, in the Netherlands an argument can be advanced that the social function of taxis is negligible if not negative. ${ }^{46}$ The taxi industry in Amsterdam has been dominated by one operator that has used is dominance to bully away any attempts to open the market or increase the quality of service. None of the regulatory changes in the framework have really worked out due to, arguably, the dominant economic presence of the vested player. In this situation it therefore seems that the 'producerist' focus on the industry has been mainly to do with interest capture and attempts to remedy a bad situation. No social function is being served. In such a situation of bad regulation it can be argued that the consumerist break through strategy of allowing Uber to rationalise the industry is not such a bad idea. In this way a concentration of economic power and interest capture of a regulatory framework can be circumvented. ${ }^{47}$

Maduro popularised this impact of the argument of transnational effects with respect to the fundamental internal market freedoms and applied this idea to demonstrate, in a structural manner, why and how the argument from transnational effects can be read into the application of the internal market rules and require states to internalise their choices that affect outsiders. ${ }^{48}$ Maduro notes for example, with regard to free movement case law, that even where the Court has adopted a wide interpretation of the scope of free movement provisions, it has done so in the belief for a need to place constitutional limits on State interventions in the market, not for the purpose of the market but for considerations related to the

46 In some places you have to be careful not to be bullied away by groups of taxi drivers if you question their practices, if not even getting beat to death as happened in 2009 to someone in Amsterdam complaining about the fare.

47 However, initial regulatory responses in the Netherlands did not point in that direction.

48 M. Maduro, 'Reforming the Market or the State? Article 30 and the European Constitution: Economic Freedom and Political Rights', (1997) 3 European Law Journal p. 55-82. 
accommodation of interests that are not part of national democratic governance structures. ${ }^{49}$ In other words, the ambitions of the EU free movement rules are not 'market' oriented but aim to achieve integration amongst otherwise defunct national democracies. This is a view that Maduro later, quite literally, tried to consistently include in his personal construction of a European legal space in many of his AG opinions that cover a significant amount of seminal case law of the Court of Justice.$^{50}$ The larger point here is that internal market law potentially allows reconsideration and emancipation from out-dated, unrepresentative forms of institutions and schemes. Modern perspectives on life (no 'job for life', mobility and flexibility) have influenced people's identity, “depending on their geographical proximity, collective history and experiences, common values and ambitions" ${ }^{\text {51 }}$.

Within this view the EU internal market is or should be a subtle and constructive means towards a new transnational more responsive democratic nation state, one that is sensitive towards the interests of entities that fall outside of its direct political reach and procedures. The traditional internal market obligations for Member States fit within this perspective: they cannot implement their interests or laws without restraint, but are "obliged to respect the European freedoms; they are not allowed to discriminate and can pursue only legitimate regulatory policies; they must, in relation to the objectives that they wish to pursue through regulation, harmonise with each other, and they must reform their national systems in the most community-friendly way possible". ${ }^{52}$ In other words, the value of internal market integration is exactly to constrain national self-expression, "so as to mitigate what are regarded as its potential excesses: the exclusion of certain interests from the political process, and its capacity for sovereign violence in limiting permissible

49 Maduro, see above (no. 41) p. 150.

50 For example his AG Opinion in the Cipolla case C-94/04, para. 56: "Member States are required to take into account the effects that measures they adopt to regulate their national markets will have as regards the exercise by providers established in other Member States of their right to freedom to provide services. In that context, it is not only discrimination on grounds of nationality that is prohibited but also discrimination imposing, in respect of the exercise of a transnational activity, additional costs or hindering access to the national market for service providers established in other Member States".

51 E. Horvath, Mandating Identity: Citizenship, Kinship Laws and Plural Nationality in the European Union (Kluwer Law International 2007) at p. 126.

52 Joerges and Rödl (2009) see above (no. 21) p. 1-19. 
behaviour" ${ }^{53}$. Hence, the argument from containment conceptualises the intentions of the EU internal market not necessarily as 'pro trade' but as a means to engage in a dialogue with Member States on how their national systems can and need to be adjusted in order to accommodate the out of nation state interests that are to be made part of national processes of governing or governance structures. As such, this view is informed by the most obvious empirical facts that characterise the European Union today: the diversity of socio-economic constellations of the Member States and the increasing asymmetry of interests amongst Member States. ${ }^{54}$ Such diversity results in a need for communication and internalisation of their extraterritorial effects.

\section{Somek's fundamental question}

In an ideal form the argument from transnational effects conceptualizes a type of European law that responds to differences in the laws of the EU Member States by resorting to principles that should respect and accommodate diversity. That is why, in the context of the social deficit issue, which leads to diversity in the way that social objectives are pursued amongst all individual Member States, the argument from transnational effects posits a supranational legal structure that is compatible with the social deficit. Not only that, it also provides for a theory of legitimacy for the social deficit, or in other words, a theory for the social legitimacy of the European internal market project. This would imply that the rules and principles that are applied through the argument of transnational effects are responsive to social context in the sense that social objectives can be legitimately challenged on the basis of the absence of representation of potential transnational effects they may have. However, as argued by Somek, on this point the argument

3 F. de Witte, 'Sex, drugs \& EU law: The recognition of moral and ethical diversity in EU law' (2013) 50 Common Market Law Review, Issue 6, p. 1551.

54 P. Beramendi, 'Inequality and the Territorial Fragmentation of Solidarity' (2007) 61 International Organization at p. 783. 
from transnational effects is often far from the actual reality of the EU internal market project:

"In fact, this is clearly revealed in how its focus on transnational effects is mediated by the equal distrust of national regimes burdening, in one way or another, international economic mobility. Anchoring the mitigation of transnational effects in the facilitation of market access modifies the focus of the argument. It is thereby made subservient to an altogether different aim, namely, economic due process" ${ }^{55}$

The identification of the potential out of state interest that finds insufficient access within another Member State is identified, solely, on the basis of market access. Somek's point here is that despite the clear merit in the legitimising idea of EU internal market law as removing traditional, out-dated, unrepresentative manifestations of national defected forms of decision making, the grammar and language of this debate may contain inherent limits. This has led him, in his seminal discussions on the wider importance of the argument of transnational effects for European integration to pose a fundamental question: "what might be done to prevent the argument from transnational effects from slipping into a freewheeling rampage of economic due process" ${ }^{\prime 56}$ ?.

Despite some interesting and promising attempts, this question has never been addressed in a structural way, across all fundamental areas of the internal market. The risk of "slipping into a freewheeling rampage of economic due process" manifests differently within each area of internal market law and the following chapters will dissect how this risk materialises specifically. The argument from transnational effects is therefore better perceived as providing a normative perspective that sets out how the EU internal market laws should be applied, in order to be socially legitimate. The argument harbours an unfulfilled implicit understanding of the social purpose of the internal market. Roughly, that social purpose is the respect and accommodation of social diversity amongst Member States, whilst promoting the objectives of the internal market by scrutinizing the internalization of the transnational effects of Member State social measures.

Somek, see above (no. 41) at p. 320

6 Ibid., p. 332. 
However, and importantly, Somek has demonstrated that the argument from transnational effect is incomplete as it has not provided us with the actual principles nor with the conceptual apparatus that we might resort to in order to govern the social diversity of the internal market. There is therefore a need to move beyond the argument from transnational effects for it to have real normative value.

This thesis can be positioned, partly, as furthering the argument from transnational effects through a perspective that goes beyond emphasizing either (i) the importance for EU law to respect the structures that are expressive of Member State choices, which embed the pursuit or protection of certain interests or (ii) the requirements for Member States to open up these embedded structures in order to develop towards a post-national constellation that remedies potential democratic deficits or out-dated unrepresentative or discriminatory structures. What is required and pursued, instead, is a more holistic approach to the issue, recognising the interdependence of both central facets for the structure and development of the internal market in a mutually responsive manner. This is the idea of mutual responsiveness, as a means for the EU internal market project to achieve the social legitimacy that it is envisaged to have within the argument from transnational effects. Without this responsiveness the social purpose of the EU remains aloof. ${ }^{57}$

For this purpose section III discusses what the 'social' means within the multilevel context of the EU. It is only if we have a clear picture of this that we can say something about how the social should be dealt with. Section III furthermore develops the argument that the evolved supranational internal objectives of the EU require social legitimacy through the adoption of responsiveness towards a diversity of national social interests and structures in the way the EU operates. In a sense, the argument from transnational effects, as a theory of social legitimacy for the EU internal market project, is validated on this basis. Section IV discusses how the ideas of embeddedness and the double-movement as conceived by Karl Polanyi

See for a related discussion D. Schiek, 'The EU's Socio-economic Model(s) and the Crisi(e)s - any perspectives?', in D. Schiek (ed.), The EU Economic and Social Model in the Global Crisis, (Ashgate, Farnham 2013). 
are able to inform and enrich the principles and the conceptual apparatus to govern social diversity within the internal market.

\section{The emergence of 'the social' and a constitutional principle of responsiveness within the multilevel context of the $\mathrm{EU}$}

\section{A. The social sphere within the internal market}

Some words on the meaning and use of the concept 'social' in the thesis are required. It has already been used in various ways in the foregoing and it is important not to assume its meaning, for example, in terms of the social as opposed to the economic. The social is a fuzzy concept and has different meanings depending on different contexts and can, for example, be both of an economic and non-economic nature. Moreover, it has different dimensions and may, for example, relate to questions of horizontal redistribution as an expressive relationship of solidarity between citizens, concern the design of institutional structures within a nation or the regulation of industrial relations. These different meanings and contexts of the social can be gathered under the heading of the social in terms of a nation state's "social acquis". ${ }^{8}$ It is this meaning of the social that I adopt in the thesis and it should be understood as the sphere that determines the underlying normative infrastructure of the economy within Member States.$^{59}$ Importantly, these normative underpinnings may be different from one Member State to the next and the underlying rationales have an important impact on the qualification of these social spheres. This is insightfully described by Aleksander Ebner with respect to the design of labour markets:

"This specification is well illustrated by the case of labour markets. Rules that simply fulfil a market enhancing function, for instance, by reducing transaction costs and information asymmetries in wage setting, do not qualify as embedding rules. They support a rationale of commodification that follows the allocative logic of market supply and demand. However, a set of rules that delegates some components of wage-

58 As submitted by C. Joerges, 'Market Integration and Europeanisation of Private Law', Jean Monnet Project Conference Paper (May 2015), on file with author.

59 Ibid. 
setting and the related features of industrial relations to an institutional domain beyond this commodity logic qualifies as a factor in the embedding of markets. These sets of rules, which may refer to the inclusion of welfare arrangements in wage-setting or to the participation of the workforce in management decision [...] may promote a decommodification of labour, as they shield its reproductive conditions from market conditions". ${ }^{60}$

The underlying normative infrastructure or social sphere of both types of labour market rules are fundamentally different. One may be qualified economic since the underlying rationale follows the allocative logic of the market whilst the other is non-economic and involves a structure of negotiated deliberative coordination. The understanding of the social in these terms is inspired by Polanyi and shall be further contextualised below in section (C) and in section IV.

There are various ways to look upon the way that the internal market inhibits and conditions the emergence of this social sphere within its legal framework. Within the multilevel context of the EU, the social sphere is influenced in at least two ways that are relevant to distinguish from each other for the purpose of the social legitimacy issue that was raised in the previous sections. On one level the EU produces legislation that influences the social sphere. This can be said to be the 'positive' form of influence on the social sphere. On another level the social sphere is contingent on the fulfilment of requirements that flow from the internal market rules. This can be said to be the 'negative' form of influence on the social sphere. ${ }^{61}$ Both forms are of importance for the 'social purpose' of the EU and can be approached on the basis of questions related to their social legitimacy. However, both are also governed by different dynamics, institutional contexts and from the perspective of legitimacy, touch on separate potential issues. For example, the positive influence on the social sphere can be more easily discussed in terms of its potential openness of the decision-making process for citizens and interests, the

60 A. Ebner, 'Transnational Markets and the Polanyi Problem' in Christian Joerges and Josef Falke (eds), Globalisation and the Potential of Law in Transnational Markets (Hart Publishing 2011) at p. 28..

${ }^{61}$ Compare with Scharpf's distinction of positive and negative integration 'Negative and Positive Integration in the Political Economy of European Welfare States' in G. Marks, F.W Scharpf, P. Schmitter and W. Streeck (eds) Governance in the European Union (London Sage publication 1996) at p. 15. 
quality of the processes that subsequently process that input and the quality of the result of the decision making process. ${ }^{62}$ The negative provides a conditional form for the social sphere that is deemed contingent on the fulfilment of specific EU internal market requirements. Here adjudication of the Court, in determining the conditions under which certain policy within Member States is restrictive, becomes a form of social ordering. ${ }^{63}$ It determines how the relationship between the social and economic sphere is to be governed and the adjudicative determinations of the Court regarding this relationship will normally enter in some degree into the future relationship between these two spheres in the internal market. As such, this negative form of influence on the social sphere can be approached as a separate field of study. This form of the social, which is the main focus of the thesis, shall be further discussed below under (C).

The positive form exists on the level of EU policy and within specific EU institutional and legal contexts. Its sources are found in the legal provisions that govern the competence of different institutions to enact legislation for the functioning of the internal market. ${ }^{64}$ Regulations, Directives and non-legislative acts including new forms of governance fall under this heading of the positive social sphere. I shall briefly discuss this form, which I consider to be for a large degree a commodified version of the social sphere, below.

\section{B. The 'positive' social}

In 1957 the principle of equal pay for men and women was part of the Treaty of Rome. Although undeniably of social content, this did, however, not influence, concretely the social sphere within Member States, nor did the Social Charter of 1986, which was at that time, only declaratory. ${ }^{65}$ The first more concrete positive

62 V.A. Schmidt, see above (no. 1) at p. 2.

${ }^{63}$ L. L Fuller and K.I Winston, 'The Forms and Limits of Adjudication' (1978) 92 Harvard Law Review 353.

${ }^{64}$ Articles 114, 115 and 352 of the Treaty on the Functioning of the European Union.

${ }_{65}$ M. Savevska, "Polanyian Reading of the Socio-Economic Transformations of the European Union", Journal of Contemporary European Studies, 22(2014) p. 395-410. 
influence concerned the Social Protocol of the Maastricht Treaty, which added social provisions on workers' safety and health and introduced obligations for the Commission to consult management and labour when proposing legislation. ${ }^{66}$ It also established the Social Dialogue. ${ }^{67}$ The so-called European Employment Strategy was introduced with the Amsterdam Treaty in 1997, which also established the Employment and Social Policy Titles. ${ }^{68}$ The Treaty of Nice (2001) also established some joint rights for the Community to take action in tackling social exclusion. ${ }^{69}$ More generally, one can see a trend from the 1990s onwards of an increase of 'minimal standards' introduced at the EU level. ${ }^{70}$ Moreover and in particular, the environmental policy output over the years has been impressive, ${ }^{71}$ with Directives on a variety of topics. ${ }^{72}$. Importantly, the 'Lisbon Strategy' in 2000 introduced and set out the Open Method of Coordination (OMC) in social policy. Environmental policy was added to the OMC one year after. The OMC introduced 'close coordination' between the member states in areas that fall outside the exclusive competence of the EU. ${ }^{73}$ The OMC is also used for the implementation of

66 See further J. Goetschy, 'Taking stock of social Europe: is there such a thing as a Community Social Model?', in M. Jespen, and A. S. Pascual, (eds.), Unwrapping the European Social Model (Bristol 2006), p. 66.

67 See further C. De Gryse, 'Historical and Institutional Background to the Cross-industry Social Dialogue', in A.D. Dufresne, and P. Pochet (eds.), The European Sectoral Social Dialogue (Brussels: P.I.E. 2006), p. 31.

68 J. Goetschy, 'The Lisbon Strategy and Social Europe: Two Closely Linked Destinies' in M.D. Rodrigues (ed.) Europe, Globalization and the Lisbon Agenda, (Cheltenham: Edward Elgar 2009) 7490.

69 P. Watson, EU Social and Employment Law (Oxford: Oxford University Press 2009).

70 See further the overview in Savevska above (no. 65): minimum rules concerning gender equality, parttime regulation, fixed-term work, parental leave, consultation of labour, work council, health and safety at work and transfer of social benefits.

${ }^{71}$ See further J. McCormick, Environmental Policy in the European Union (Palgrave 2001); S. Oberthür and others (eds), 'The New Climate Policies of the European Union: Internal Legislation and Climate Diplomacy' (2010).

72 See also the European Commission, Climate Action policy brief http://ec.europa.eu/clima/policies/brief/eu/index_en.htm (accessed 10-12-2015) and M. Pallemaerts, The New Climate Policies of the European Union : Internal Legislation and Climate Diplomacy (Vubpress 2010): E.g. Renewable Energy Directive, the Emissions Trading Scheme (ETS), the Carbon Capture and Storage Directive, the Effort-Sharing Directive, Energy Efficiency Directives, the Ozone Protection Regulation, F-gases Regulation.

73 L. Tholoniat, 'The Career of the Open Method of Coordination : Lessons from a "Soft" EU Instrument' (2010) 33 West European Politics p. 93-117; C.F. Sabel and J. Zeitlin, Experimentalist Governance in the European Union towards a New Architecture (Oxford University Press 2010). 
the new 2020 Strategy, which "consists of quantitative targets aimed at securing smart, sustainable and inclusive growth" ${ }^{, 74}$.

These examples of a positive, constitutive impact on the social sphere have to be contextualised within the specific function and context that they emerge on an EU level. Simply said, it is often social content that can be seen as something ancillary to wider economic objectives. ${ }^{75}$ An example is the definition of social inclusion as an employment objective such as employability, empowerment and the enablement of the individual. ${ }^{76}$ The Lisbon Agenda that was continued in the new Europe 2020 Agenda equates social cohesion (normally defined as the bond that brings people together in a given society) with activation, lifelong learning and flexicurity. Social cohesion is therefore sought not through protecting labour from market forces but to include labour in the market as much as possible. ${ }^{77}$ Discourses are created that equate social cohesion with peoples potential to participate in the labour market. Importantly, the discourse that is established in the pursuit of social cohesion and inclusion does not consider that there may exist a tension between transforming the Union into "the most competitive and dynamic knowledge-based economy" and the development of social cohesion and inclusion policy. ${ }^{78}$ Social policy is supposed to assist people into becoming successful market participants. ${ }^{79}$ In this way the social objective of inclusion is 'regulated' in order to channel this interest through an institutional mechanism that makes it controllable with the ultimate objective to allow sectors of an economy to perform better. As an example, environmental regulation in the EU is shaped in the form of tradable rights to pollute, subjected to self-regulating market mechanisms.

74 European Commission. 2010. EUROPE 2020: A Strategy for Smart, Sustainable and Inclusive Growth. COM(2010) 2020. March 3. Brussels: European Commission.

75 See further also the brilliant analysis of A. Somek, Engineering Equality : An Essay on European AntiDiscrimination Law (Oxford University Press 2011).

76 E.g. B. van Apeldoorn, 'The Contradictions of 'Embedded Neoliberalism' and Europe's Multi-level Legitimacy Crisis: The European Project and its Limits', in B. van Apeldoorn, J. Drahokoupil and L. Horn (eds.) see above (no. 21), p. 21-43.

77 Ibid.

78 Ibid.

79 See Ashiagbor above (no. 29). 
This trend on the EU level followed a wave of reforms during the 1980's in many OECD countries that were inspired by market informed measures, that led to liberalization of labour markets, capital markets, deregulation of industry and the privatization of state enterprises ${ }^{80}$ Importantly, during this time, many public sector departments were restructured and downsized through outsourcing and the instalment of so called 'new public management' tools. ${ }^{81}$ This basically installed a new rationality with respect to public management, introducing a move towards entrepreneurial systems of public management that were largely market informed. Although, over the course of the 1990s' this trend became less radical through counter-reforms, today, a lot of public policy is still informed by and measured in terms of success through a market based metric. ${ }^{82}$

Within the context of EU internal market legislation, the social sphere is mostly engineered instrumentally for the purpose of, essentially, economic objectives. ${ }^{83}$ This is social policy that is created mainly with the purpose of making markets work better by channelling social concerns within a model that renders the social more manageable. ${ }^{84}$ Hence, this emanation of the social is generally considered as irreconcilable with the EU's economic objectives. ${ }^{85}$ That is to say, if the social is engineered to function as a measure of increased productivity it qualifies as a beneficial constraint on the market because it actually lets the market function better than it would function without the constraint. ${ }^{86}$

80 F. Toth, 'Healthcare Policies over the Last 20 Years: Reforms and Counter-Reforms' (2010) 95 Health policy p. 82; T. Judt, Postwar: A History of Europe since 1945 (Penguin Group (USA) Incorporated 2006) p. 556. See further also J. Mulder, 'Finding the public interest and the case of the Friesian horse', 2013 ACLE Conference Paper http://acle.uva.nl/events/competition--regulation-meetings/conferencepapers-9th-cr-meeting-2013.html (accessed 10-12-2015).

81 JE Lane, New Public Management (Routledge 2002), p. 147.

82 E.g. OECD (2010), Public Administration after "New Public Management": Value for Money in Government, Vol. 1, OECD Publishing, Paris.

83 Ibid.

84 See more generally N. S Rose, Governing the Present: Administering Economic, Social and Personal Life (Polity 2008).

85 See also C. Kaupa 'Maybe not activist enough? On the Court's alleged neoliberal bias in its recent labor cases', in B. de Witte, E. Muir and M. Dawson, Judicial Activism at the European Court of Justice: Causes, Responses and Solutions (Edward Elgar Publishing 2013), p. 56-75.

86 On the concept of beneficial constraints see originally W. Streeck, 'Beneficial Constraints: On the Economic Limits of Rational Voluntarism', in Hollingsworth, J. Rogers and Boyer, Robert (eds), Contemporary Capitalism: The Embeddedness of Institutions, (Cambridge: Cambridge University 
C. The internal market rules as a contingent form for the social sphere

The legislative powers conferred on the Union to harmonize laws for the purpose and benefit of the functioning of the Internal Market have been largely employed to pursue the commodified social as discussed above. There may be legitimate reasons for this since the Union legislature will seek recourse to it in at the moment that there are differences between national rules, "which are such as to obstruct the fundamental freedoms and thus have a direct effect on the functioning of the internal market" ${ }^{\prime 87}$. This influence from the internal market rules on the social sphere shall, however, not be addressed in this thesis. Normative concerns over the functioning of the positive impact on the social sphere from an EU level can exist on the basis of the fact that they are largely established on the basis of a covert technocratic process that depoliticizes the formulation and pursuit of social objectives and disregard the normative infrastructure of the economies within the Member States. This leads to concerns about its democratic legitimacy and can be seen as an encroachment on the constitutional space for Member States to develop social policy. Although, this commodified social content can in many ways be critiqued as being unresponsive to the idea of social plurality and diversity, it falls outside of the scope of this thesis because, as was explained above, this type of positive influence on the social sphere is governed by its own specific dynamic and actors that can be considered separate from the contingent influence on the social sphere, which is primarily governed by an adjudicative context.

As such, the positive influence on the social sphere should be differentiated from the more covert and contingent emanation of the social within EU internal market law. The latter refers to situations where the internal market rules are

Press 1997), p. 197-218. Further discussion in T. Dobbins, 'The Case for "beneficial Constraints": Why Permissive Voluntarism Impedes Workplace Cooperation in Ireland', Economic and Industrial Democracy 35(2010) p. 497; W. Streeck, 'Educating Capitalists: A Rejoinder to Wright and Tsakalotos', Socio-Economic Review 2(2010) p. 425; E. Tsakalotos, 'Market Constraints, Economic Performance and Political Power: Modernizers versus Leftists', Socio-Economic Review 2(2004) p. 415..

87 Case C-58/08 Vodafone and Others [2010] ECR I-4999, para. 32 
functioning in their evaluative role and govern Member State social rules and structures by virtue of the fact that these social contexts can be considered as restrictive of the free circulation of economic factors and, from that point onwards, can only be considered to be in accordance with EU internal market law if they can be considered as 'legitimate' and 'proportionate' or, in the case of the competition rules, if they fulfil a set of efficiency criteria. These rules can be said to be constitutive of social policy. If the test is passed then the social policy, although restrictive, can be considered to exist in accordance with European internal market law. The importance of this emanation of the social within the legal frameworks of the EU internal market should not be understated. The increase of the scope of application of the EU free movement rules has led to a situation where, theoretically, all social policy measures that are capable of restricting access to a market of an economic operator, that are restrictive of competition or provide a selective economic advantage are captured and in that sense the EU legal frameworks can to a large extent be seen as a constitutive framework of social realities that originate from a Member State level, targeting a wide variety of member states' political regulations as obstacles to European law and not only political regulations but also the actions of private bodies such as firms or trade unions. ${ }^{88}$ Moreover, the decentralised enforcement of the EU competition rules, which require self-assessments from undertakings have the potential to significantly influence the social content of 'private sphere' initiatives with social dimensions.

However, some would argue that any effects of EU internal market law on the social diversity of Member States is minimal in view of the fact that Member States' political authority in the determination of their 'social identities' has been significantly impeded by the 'globalization of economic processes' ${ }^{99}$ Due to a threat of exit, the disciplining forces of markets, supranational monetary policy and

88 Case C-438/05, International Transport Workers' Federation and Finnish Seamen's Union v Viking Line ABP and OÜ Viking Line Eesti, [2007] ECR p. I-10779. See on horizontal effect H. Schepel, 'Constitutionalising the Market, Marketising the Constitution, and to Tell the Difference: On the Horizontal Application of the Free Movement Provisions in EU Law', European Law Journal 18(2012), p. 177-200.

89 A. Glyn, Capitalism Unleashed: Finance, Globalization and Welfare (Oxford: OUP, 2007); see also F. de Witte, Justice in the EU: The Emergence of Transnational Solidarity (Oxford: OUP, 2015), p. 37. 
fiscal oversight Member States no longer have the power to implement whatever 'social identity' they may desire. In the words of Streeck, "the market have begun to dictate in unprecedented ways what presumably sovereign and democratic states may still do for their citizens and what they must refuse them". ${ }^{90}$ Regardless of the dispersive effects that the global markets dynamics, undeniably, brings on Member States' regulatory options, there is a bulk of literature based on the varieties of capitalism, which has established that, despite globalising effects, the informal rules or common knowledge that is acquired by actors on the basis of the history and culture of nations leads to a variety of capitalist organisation. ${ }^{91}$ This literature suggests that the development of a particular type of institution will develop complementary, cohesive, institutions in other spheres of its socio-economic constellation. ${ }^{92}$ Therefore, one can see in countries that have adopted stock market liberalization a tendency to have less labour protection.

The overall idea behind the varieties of capitalism school of though is that the operation of capitalist market economies is not uniform. On the basis of the question how "firms resolve the coordination problems they face" in different countries, Hall and Soskice found a distinction between the (Anglo-Saxon) liberal market economies and the northern European coordinated market economies. ${ }^{93}$ Those two types could be distinguished on how firms coordinate with each other and other actors, such as trade unions. In liberal market economies firms will primarily coordinate on the basis of market mechanisms. In coordinated market

90 W. Streeck, 'The Crises of Democratic Capitalism', New Left Review 71(2011), p .26.

91 Also, F.W. Scharpf, 'After the Crash: A Perspective on Multilevel European Democracy', European Law Journal 21(2015), p. 384-405.

92 See e.g. D. Rodrik, The Globalization Paradox, (London-New York: W.W. Norton, 2011), 74: "The considerable manoeuvring room afforded by [...] trading rules allowed advanced nations to build customized versions of capitalism around distinct approaches to corporate governance, labor markets, taks regimes, business - government relations, and welfare state arrangements. What emerged in a phrase coined by the political scientists Peter Hall and David Soskice, were 'varieties of capitalism'. The United States, Britain, France, Germany, or Sweden were each market - based economies, but the institutions that underpinned their markets differed substantially and bore unmistakably national characteristics".

93 P. A. Hall and D. W. Soskice, Varieties of Capitalism : The Institutional Foundations of Comparative Advantage (Oxford University Press 2001); also specifically P.A. Hall, 'Varieties of Capitalism and the Euro Crisis', West European Politics 37(2014), p. 1223-1243. 
economies firms will rely more heavily on non-market forms of interaction in the coordination of their relationships with other actors. Therefore, firms of liberal market economies and coordinated market economies tend to respond differently to a similar economic shock and its institutions have been characterised as 'socializing agencies' that go through a continuous processes of adaptation. ${ }^{94}$ Some normative implications have been drawn from this literature. Firstly, that a transformation of one variety into another is hard to achieve and, secondly, the selective insertion of elements of one variety into the fabric of the other can have disintegrative effects. ${ }^{95}$

This builds on the idea that the diversity of preferences and orientations in the EU is the product of specific historical experiences, political contestation, societal learning and continuous political decision-making. ${ }^{96}$ As such, despite globalizing trends Member States vary deeply in terms of institutional preferences and structural policy differences. ${ }^{97}$ In similar terms the economic historian Werner Abelshauser, has underlined the resistance of the varieties of capitalism against economic integration and argued that this resistance is an asset. Diversity is economically beneficial, rather than detrimental. ${ }^{98}$

The central issue pursued from the perspective of social legitimacy is how to adjudicate the potential incommensurability between normative objectives of the internal market regime and social objectives that formulated on a Member State level. This occurs, for example, when objectives pursued by Member States cannot be aligned along the metric that is pursued within internal market rules without

94 Ibid., p.5.

95 See for example A. Hassel, 'Adjustments in the Eurozone: Varieties of Capitalism and the Crisis in Southern Europe', LEQS Paper No. 76/2014; A. Hassel, ‘The German Model in Transition', in B. Unger (ed.), The German Model, (Düsseldorf: Hans-Böckler-Stiftung 2015), p. 105-134.

96 As submitted by C. Joerges, 'Market Integration and Europeanisation of Private Law', Jean Monnet Project Conference Paper (May 2015), on file with author.

97 These can for example been classified in benefit structures, methods of financing, service intensity, family policy, employment regulation, logic of governance and the regulation of industrial relations in A. Hemerijck, 'The Self-Transformation of the European Social Model(s)', in G. Esping Andersen (ed.), Why we need a Welfare State (Oxford: OUP, 2002) 178. See also P. Beramendi, 'Inequality and the Territorial Fragmentation of Solidarity', International Organization $(2007,4)$ p. $783-820$.

98 See W. Abelshauser, 'Ricardo neu gedacht: Komparative institutionelle Vorteile von Wirtschaftskulturen', in W. Abelshauser, et al. (eds.), Kulturen der Weltwirtschaft", Geschichte und Gesellschaft, (Sonderheft 2012), p. 24; W. Abelshauser, (2014), Europa in Vielfalt einigen. Eine Denkschrift. On this topic also G. Majone, The Deeper Euro-Crisis or: The Collapse of the EU Political Culture of Total Optimism, EUI Working Paper LAW 2015/10. 
doing violence to the potentially genuine and worthwhile aspects of those objectives. It will be discussed below in section five that the social purpose of EU law in the internal market in adjudicative terms is to express instances of such irreconcilability before adopting evaluative principles that are congruent to the conflict that is being adjudicated. Social legitimacy, in turn, depends on the extent that the Court is able to accommodate and identify genuine social objectives within its evaluative rationales.

D. The constitutional obligation of responsiveness

In terms of primary law, the EU internal market has evolved to become, constitutionally, more tuned towards accommodating interests that are of a broader concern than merely the creation of an area in which the components of trade move freely between the Member States. ${ }^{99}$ As such, the centrality of the integrating market as a focal point for EU policy objectives has transformed. Whereas the "internal market" of Lisbon requires the abolition of the same barriers to trade, it appears that the connection to broader social values has evolved.

It has been argued that, specifically after the entry into force of Lisbon, the new constitutional balance towards broader social objectives should resonate in the adjudicative techniques employed by the Court. AG Cruz Villalón suggested in Santos Palhota: ${ }^{100}$

"As a result of the entry into force of the Treaty of Lisbon, when working conditions constitute an overriding reason relating to the public interest justifying a derogation from the freedom to provide services, they must no longer be interpreted strictly. In so far as the protection of workers is a matter which warrants protection under the Treaties themselves, it is not a

99 See also the historical account P. Craig, The Lisbon Treaty : Law, Politics, and Treaty Reform (Oxford University Press 2013). Although, the Maastricht Treaty (1992) already included, in one way or another, a majority of the social objectives that are include in the Lisbon Treaty (2007), a difference is that in the Maastricht Treaty these objectives were to be achieved mainly through the creation of an area without internal frontiers and through the establishment of economic and monetary union. In other words: through the creation of an internal market. As such, achieving certain market objectives was understood to bring forth other (social) benefits also. The idea of market progress was that it necessarily included a social purpose, a fulfilment inherent to achieving market objectives.

100 Case C-515/08 Santos Palhota [2010] ECR I-000 
simple derogation from a freedom, still less an unwritten exception inferred from case-law. To the extent that the new primary law framework provides for a mandatory high level of social protection, it authorises the Member States, for the purpose of safeguarding a certain level of social protection, to restrict a freedom, and to do so without European Union law's regarding it as something exceptional and, therefore, as warranting a strict interpretation".

Although the main objective spelled out in the Lisbon Treaty remains the establishment of the internal market, ${ }^{101}$ this is combined with, compared to previous Treaties, increased emphasis on sustainable development of a Europe based on balanced economic growth and price stability, policies based on a spirit of solidarity, a competitive social market economy aimed at full employment and social progress, the pursuit of social cohesion and a high level of protection and improvement of the quality of the environment. ${ }^{102}$ Moreover, from the Treaty of Amsterdam the coherence of EU policies is considered more important through the creation of cross-sectional clauses. ${ }^{103}$ The Lisbon Treaty includes a requirement of consistency among Union policies (Article 7 TFEU), a duty to eliminate inequalities and promote equalities between men and women in all activities (8 TFEU), a duty to take into account employment, social protection, education,

101 Article 3(2) TEU.

${ }^{102}$ Compared with the objectives in previous Treaties one could argue that an important addition concerns the aim to work for a 'highly competitive social market economy' especially when compared with the objective of the 'open market economy'. The term 'social market economy' upon inclusion in the Constitutional Treaty was meant to summarize the EU's commitment to 'greater coherence between economic and social policies' (Working Group XI on Social Europe - CONV 516/1/03/ REV 1). Paul Craig argues that the reference to social market economy is specified by the phrase 'highly competitive' and hence 'a signal of compromise in the corridors of power'. He also notes, however, that this does not undermine the significance of use of the term 'social market economy'. In a similar vein, J.C. Piris, 'The Lisbon Treaty: A Legal and Political Analysis', (Cambridge University Press 2010), relates this idea of the social in the economy to the system that was developed in Germany in the post-war Federal Republic also described as ordoliberalism. It aims for a balance between the market and social policy and Piris submits that it is comparable to the 'European Social Model' in that it enables the free play of forces on the market with the State creating the framework for competition to work and combining that with a complete system of social protection.

103 M. Dawson and B. de Witte, 'The EU Legal Framework of Social Inclusion and Social Protection: Between the Lisbon Strategy and the Lisbon Treaty', in B. Cantillon et al. (eds.), Social Inclusion and Social Protection in the EU: Interactions between Law and Policy (Intersentia, Cambridge 2012), p. 41; M. Ferrera, 'Modest Beginnings, Timid Progresses: What Next for Social Europe?', in B. Cantillon et al. (eds.), Social Inclusion and Social Protection in the EU: Interactions between Law and Policy (Intersentia, Cambridge 2012), p. 17-39. 
health, combating discrimination in the definition and implementation of its policies (9/10 TFEU), integration of environmental protection requirements and consumer protection requirements in defining and implementing Union activities (11/12 TFEU). Article 3(3) TEU's embrace of the 'social market economy' and the binding effect that is attributed to the Charter of Fundamental Rights could also be employed to argue that the constitutional character of the internal market has been altered by the Lisbon Treaty. ${ }^{104}$ Relevant in this respect is also that pre-Lisbon Article 3(1)(g) TEC provided that the activities of the EC shall include 'a system ensuring that competition in the internal market is not distorted.' The Lisbon Treaty removed the reference to undistorted competition from the Treaty and placed it instead in a Protocol attached to both the EU Treaty and the TFEU, which states that the internal market referred to in Article $2 \mathrm{EU}$ 'includes a system ensuring that competition is not distorted'. A Protocol is legally binding. However, the argument can be made that obscuring the reference to undistorted competition could adjust the constitutional balance in favour of socially-motivated adjudication and regulation at the expense of market competition, and that this should be taken into account in the interpretation and application of the internal market provisions. ${ }^{105}$ How to achieve this leads to an open question that is explicitly raised and left open in many contributions that critically analyse the future of the EU internal market project. Hervey, for example, suggests that

"EU law is no more (if it ever has been) simply, or even essentially or fundamentally about markets, leaving 'the social' to the Member States and national law. The roles of EU internal market and competition law are no longer (if they ever were) simply a means to achieve movement between markets, opening markets, and preventing nationality-based discrimination. Rather, EU free movement and competition law should become (or have become) a locus within which we collectively determine the balance of values, between (economic) freedom and (social) security; between competition and solidarity". ${ }^{106}$

104 See D. Schiek, Economic and Social Integration: the Challenge for EU Constitutional Law (Edward Elgar, Cheltenham 2012), p. 102-106.

105 For example also Schiek above (no. 35), at 185.

106 T. Hervey 'If only it were so simple: Public Health Services and EU Law', in M. Cremona (ed.), Market Integration and Public Services in the European Union (Oxford University Press 2011), p. 247. 
Hervey sees the insertion of social objectives within the primary law framework as a reason to (collectively) (re)determine a balance of values, such a between competition and solidarity. I will argue further below in section V that this balance of values is to be achieved through responsiveness. The developments in primary law have led to a constitutional obligation for the evaluative and constitutive frameworks of the EU internal market to become specifically responsive to social diversity and plurality. This becomes clearer when these developments are contextualised within Articles 3 and 4(2) of the Treaty on the European Union (TEU). As discussed, Article 3 TEU sets out a dual commitment to both promote the objectives of the internal market and the objectives of sustainability, social inclusion/cohesion and a social market economy. The objectives of the internal market are supranational and require responsiveness from Member States, whilst objectives normally associated with sustainability, social inclusion/cohesion and a social market economy predominantly find their origin within Member State national identities and structures and are therefore by nature diverse. It is the latter that Article 4(2) TEU is then particularly concerned with, by carving out the general commitment of the Union to 'respect' national identities of Member States that are inherent in their national, regional and local, fundamental political and constitutional structures. ${ }^{107}$ In the 2010 Monti Report, addressing "tensions between market integration and social objectives", it was stated that:

"These are even more vividly exposed, now that the Lisbon Treaty has introduced, even formally, the objective of achieving a 'highly competitive social market economy'. If the market and the social components do not find an appropriate reconciliation, something has to give in. Following the crisis, with the declining appetite for the market and the increasing concern about inequalities, it is by no means clear that it would be the market, i.e. the single market, to prevail" ${ }^{108}$.

${ }^{107}$ E.g. L.F.M Besselink, 'National and Constitutional Identity before and after Lisbon' (2010) 6Utrecht Law Review p. 36; T Konstadinides, 'Constitutional Identity as a Shield and as a Sword: The European Legal Order within the Framework of National Constitutional Settlement' (2011) 13 Cambridge yearbook of European legal studies p. 195; A von Bogdandy and S Schill, 'Overcoming Absolute Primacy : Respect for National Identity under the Lisbon Treaty' (2011) Common Market Law Review p. 48.

${ }^{108}$ M. Monti, 'A new strategy for the single market: at the service of Europe's Economy and Society, (2010) p. 26 available at http://ec.europa.eu/internal_market/strategy/docs/monti_report_final_10_05_2010_en.pdf (accessed 1001-2016). 
I propose that in the context of the internal market the normative claims of social legitimacy are best addressed with the idea of mutual responsiveness. From a perspective of mutual responsiveness, the social purpose of the internal market is not to condition choices that necessarily require the market to trump the social sphere - or the opposite- to allow the social to trump the market. Mutual responsiveness advances a more holistic approach that conceives the market and the social, literally, as 'communicating vessels'. Hence, this 'dialogue of mutual responsiveness' is based on the idea that internal market law is a means to start a conversation with Member States on the normative choices of restrictive laws and regulatory schemes. Within the multilevel context of the EU and specifically a context within which there exists a constitutional obligation to respect diversity and a plurality of social objectives it is imperative for legal review to become responsive to context. However, there first has to be an understanding about what there may exist to respond to.

The normative argument requires a better understanding of the 'social' in the context of the transnational and an understanding of what 'responsiveness to social context' means and implies. That is to say, how should we think about the social and market integration for governance purposes in a multilayer context such as we have in the EU? The previous sections have discussed, inter alia, that the social emanates in different ways within the internal market framework and that there should be 'a responsiveness' from the supranational towards the national social context for the purpose of its social legitimacy. The rationale of responsiveness further unfolds on the basis of social theory insights based on the idea of embeddedness in the work of Karl Polanyi, which provides for a normative grounding of the argument that is developed in this thesis.

\section{The normative-instructive value of embeddedness}
A. Introduction 
Karl Polanyi provides an appealing perspective that has increasingly been used and heralded as a moral framework for arguments of contemporary market critics. ${ }^{109}$ The following section (B) is aimed at familiarising the reader with the narrative and conceptual apparatus that Polanyi introduced with his much acclaimed work 'The Great Transformation: the political and economic origins of our time' (TGT). ${ }^{110}$ Section (C) below shall explore the normative value of Polanyian insights for the idea of social legitimacy as it was introduced above. Section (D) develops the idea of a rationale of responsiveness based on the work of Polanyi and section (E) shall highlight how that differs and moves beyond existing Polanyian accounts of the role of the Court of Justice vis-à-vis market integration in the European Union.

\section{B. Notes on Polanyi}

\section{i. Summary of the argument}

TGT was written in the early 1940s and first published in 1944. In it Polanyi provides a theory for the origin of the political turbulence and economic collapse of 19th century civilisation. These events puzzled Polanyi. A long period in Europe of peace and prosperity was quite suddenly exchanged for huge economic, political and human disasters. His distinctive vision on these events qualifies 'world war Great Depression - world war' not as disconnected events but as symptoms of one deep societal problem. ${ }^{111}$ Polanyi argues that the main cause for the disaster is the utopian endeavour of market liberalism to set up a self-regulating market system.

${ }^{109}$ Christian Joerges was one of the first to give Polanyi a serious and multifaceted consideration in a (transnational) law context. See C Joerges and J Falke (eds), Karl Polanyi: Globalisation and the Potential of Law in Transnational Markets (Oxford- Portland OR, Hart Publishing, 2011). See also J Caporaso and A Tarrow, 'Polanyi in Brussels: Supranational Institutions and the Transnational Embedding of Markets’ (2009) 63 International Organization 593-620; M Höpner and A Schäfer, 'Polanyi in Brussels? Embeddedness and the three dimensions of European economic integration' (MPIfG Discussion Paper 2010).

110 K Polanyi, The Great Transformation: The Political and Economic Origins of our Time, 2nd edn (Boston MA, The Beacon Press, [1944] 2001).

111 See Dale above (no. 9), p. 2. 
His core argument is that market liberalism requires everything to be tradable, including important ecological and societal phenomena such as labor, land and money. To place these within the impersonal mechanisms of a self-regulating market is the main, and at the same time self-destructive, flaw of market liberalism. The self-regulating market requires a separation of politics and the economy and this plants a seed for political and economic unsustainability. The commodity fiction of societal and ecological interests led to a degree of social dislocation that no society can sustain. Eventually, a countermovement against liberalization will seek to de-commodify the commodity fiction. This process undermines the efficiency of the market and thus provides a major cause for further economic crisis, thereby opening up the political stage to fascist like movements. The following sections dissect his argument.

\section{ii. The institutional design of the 100 years 'peace interest'}

Polanyi's analysis starts with an investigation into the institutional design that was in place during the hundred year's peace: 1815-1914. Polanyi discusses the reasons for the sudden, strong and shared peace interest amongst the main powers in the beginning of the $19^{\text {th }}$ century. Its main cause, Polanyi argues, is the English Industrial Revolution that propounds peaceful business as a global interest. ${ }^{112}$ The peace interest is enforced through a new sort of social instrumentality: haute finance. This, Polanyi considers, is the main link between the political and the economic organization of the world at that time: ${ }^{113}$

\footnotetext{
"Independent of the central banks [...] it was closely connected with them. There was intimate contact between finance and diplomacy; neither would consider any long-range plan, whether peaceful or warlike, without making sure of the other's goodwill. Yet the secret of the successful maintenance of general peace lay undoubtedly in the position, organization and techniques of international finance".
}

112 TGT, p.7

${ }^{113} \mathrm{Ibid}$, p. 10 
Polanyi illustrates how trade becomes linked with a peace interest. Financiers direct their attention to a spread of constitutional government and free markets, recognising that their long-term interests can be achieved better through these means. The influence of international finance on external value of currency makes debtor governments sensible for the appreciation of their policies. Trade and prosperity is made dependent on an international monetary system that would be threatened by general war and therefore instils a peace interest. ${ }^{114}$ International finance provided the means to replace mutual hostility with a mutual interest. It provided a mechanism for the balance of power system between the Great Powers. This mechanism was completed with the use of the international gold standard, the idea of a self-regulating market and the liberal state.

The balance of power system starts to disappear in the beginning of the $20^{\text {th }}$ century. It suddenly dissolves and is replaced by two hostile power groups (Germany, Austria-Hungary and Italy vs. Great Britain, France and Russia). Polanyi argues that it was essentially a disruption of the self-regulating market that also disrupted the political and economical stability at that time. ${ }^{115}$ The selfregulating market utopia provided for the 'fount and matrix' of the whole system and a systemic error in this idea provided for the whole system to collapse. To substantiate his argument Polanyi first turns to the roots and intellectual origins of the idea of a self-regulating market.

\section{iii. The birth of a market-run society}

Simultaneously with the English Industrial Revolution, market idealism becomes an organizing principle of world economy. ${ }^{116}$ Polanyi's analysis of this event, in short, is that altered cost structures of producers, affected by the availability of new technologies started to dictate market expansion and managed to

\footnotetext{
114 Ibid, p. 16.

115 Ibid p. 3.

116 Ibid, p. 35.
} 
bring elite opinion behind the political economist's case for a free market regime. This new order was then actively made by state policy. ${ }^{117}$

The introduction of large industrial machines in society influenced and directed society and the intellectual movements behind market liberalism. Production by specialized, elaborate, expensive tools and plants require large upfront investments. Producers can make these investments as long as the purchase of machinery will not involve them in a loss. In order to mitigate risks it is necessary that the producer is ensured a steady production after purchasing the necessary labour and raw material. Since big machines are expensive, they do not pay unless large amounts of goods are produced. They can be worked without a loss only if the goods can be sold and production is not disrupted by lack of inputs for the machines. Therefore, all inputs must be available on sale in ready available quantities to anybody who is prepared to pay. In agricultural society as it existed up to that point in time, such conditions had to be created. This, Polanyi argues, implies a fundamental change in the motive of action on the part of members of a society. Now transactions must be turned into money transactions, incomes must derive from sale and market derived prices must rule the system. Market prices alone provide the order in the production and distribution of goods. Importantly, human beings must start acting as profit maximisers because the supply of goods and services must equal the demand at a certain price and money must be present as a source of constant buying power. The concepts of individual profit, gain and accumulation must become inherent to human fulfilment and the market mechanisms must be allowed to function without outside governmental interference in order not to disrupt the expectations of buyers and sellers: ${ }^{118}$ "A self-regulating market demands nothing less than the institutional separation of society into an economic and a political sphere”.

According to Polanyi, the main threat to society then becomes the fundamental difference between selling and buying activities of the producer. What

117 Ibid, chapter three.

118 Ibid, p. 74. 
the producer sells is generally harmless to society but what he buys is raw material and labor. In Polanyian terms, he buys nature and man: ${ }^{119}$ "Machine production in a commercial society involves in effect no less a transformation than that of the natural and human substance of society into commodities."

The intellectual thought of that time that arises, together with the large machines and factories, is committed to provide a theoretical basis for "the expectation that human beings behave in such a way as to achieve maximum money gains" ${ }^{120}$ Polanyi considers the political economists Adam Smith, David Ricardo and Thomas Malthus as the main contributors. Adam Smith qualifies the market as the centre of economic life and driver for competition and introduces the myth of a man with the innate propensity to barter, truck and exchange. He thereby provides the conceptualisation of society as atomistic and driven by a self-interested 'Economic Man'. This conceptualisation of society and human purpose provides intellectual input for Ricardo and Malthus who use this for a claim that the laws of the market must also set limits on human possibilities and legitimate forms of human suffrage. ${ }^{121}$ Laws that interfere with the functioning of the market, such as poor laws, are considered counterproductive. Ricardo and Malthus thus introduce the iron law of wages and position orthodox economics on 'naturalistic foundations', invoking biology in support of the necessity to keep wages low: "the laws of a competitive society were put under the sanction of the jungle's rather than of human decision". ${ }^{122}$ Polanyi illustrates the delusion of this idea by discussing two assumptions that underlie the theory of market idealism at that time.

The first assumption concerns the notion of spontaneous and natural progress of economic systems into free markets. The consequence of this idea is that the role of government in economic life is marginalised (markets should be free to develop naturally) and requires the commodification of important societal and human

9 Ibid, p. 44.

${ }^{120}$ Ibid, p. 123.

${ }^{121}$ Here an example of the natural development of populations of wolves and goats on an island that at some point reaches a sustainable equilibrium is considered supporting the position of the proponents of full market idealism.

122 TGT, p. 128. 
conditions. Contrary to this assumption, Polanyi argues that a market-based society concerns a free choice and a conscious design of institutional mechanisms. There is therefore nothing free about the concept of laissez-faire.${ }^{123}$ Free markets do not come into being just by letting things run their natural course. Instead, industries require protective tariffs, export bounties and indirect wage subsidies from the government to succeed. As such, laissez-faire can only function within a surrounding infrastructure enforced by the state. Polanyi illustrates this by discussing how state restrictions were even regularly demanded by economic liberals in important fields of industrial organization, where the freedom of workers to withhold their labour either individually or collectively had, according to economic liberals themselves, to be regulated and restricted through trade union laws. ${ }^{124}$ Governments are therefore in the first place necessary for trade to take place at all. The crucial question from Polanyi's perspective is whether governments serve only the market and run society as an adjunct to market interests by providing market-biased regulation or whether they run the market from nonmarket considerations.

Polanyi proceeds his argument by describing economic systems prior to the rise of market idealism. He discusses how these were organised on totally different fundaments. Principles of reciprocity, redistribution and householding or a combination of the three were the main organising principles of society prior to our 'modern times'. ${ }^{125}$ In these 'early societies', the production of goods is disciplined through a variety of motives and general principles of behaviour amongst which gain is not leading. Reciprocity in social behaviour dominates: ${ }^{126}$ "In such a community the idea of profit is barred; haggling and haggling is decried; giving freely is acclaimed as a virtue; the supposed propensity to barter, truck and exchange does not appear. The economic system is, in effect, a mere functioning of social organization.” Polanyi argues that it is a strange particularity of his (and our)

Ibid, p. 145.

Ibid, p. 155

${ }^{225}$ Ibid, p. 57.

${ }^{126}$ Ibid, p. 53. 
time that we consider social conduct in these early societies, where non-economic motivation for every act performed is the standard and not the exception, to be so alien to our modern times. ${ }^{127} \mathrm{He}$ goes on to demonstrate how modern market society as we know it, and the 'Economic Man' that trucks and barters, is historically far more alien to human behaviour than a society based on mechanisms of reciprocity, redistribution or householding. ${ }^{128}$ Hence, the extent to which markets have control over society is not determined by a natural propensity of 'Economic Man' to truck and barter. Rather, it concerns a clear choice of design and institutional infrastructure: ${ }^{129}$ "Instead of economy being embedded in social relations, social relations are embedded in the economic system. [...] For once the economic system is organized in separate institutions, based on specific motives and conferring a special status, society must be shaped in such a manner as to allow that system to function according to its own laws."

The second assumption of free market theory concerns the legitimisation of so called 'long-run considerations'. The time rate of change compared with the time rate of adjustment decides what is to be regarded as the final net effect of market mechanisms. In other words, potential short-term harm and suffering will be remedied by longer-term wealth and progress. Polanyi illustrates this as follows: ${ }^{130}$

"The usual 'long-run' considerations of economic theory are inadmissible; they would prejudge the issue by assuming that the event took place under a market system. [...] long-run considerations are meaningless. If the immediate effect of a change is deleterious then until proof to the contrary, the final effect is deleterious. If conversion of arable land to pasture involves the destruction of a definite number of houses, the scrapping of a definite amount of employment and the diminution of the supplies of locally available food provision, then these effects must be regarded as final until evidence to the contrary is produced".

Polanyi does not exclude the possible positive effects of increased exports, employment and incomes. Instead, he highlights that the time rate of change compared with the time rate of adjustment will decide what is to be regarded as the

Ibid, p. 47.

Ibid, , chapter four.

${ }^{129} \mathrm{Ibid}, \mathrm{p} .60$.

${ }^{130}$ Ibid, p. 40. 
net-effect and that this is only relevant in the institutional setting of a market based economy and its accompanying market logic. The artificial determination of the long-term economic net-effect as positive disqualifies the human suffering in between. Short-term human suffering becomes a means to achieve a better end, i.e. a positive net-effect from the perspective of market interests. This is what Polanyi considers a major catastrophe. ${ }^{131}$ One that legitimised all the human suffering brought in the fringe of the English Industrial Revolution: ${ }^{132}$ "the new creed was utterly materialistic and believed that all human problems could be resolved given an unlimited amount of material commodities."

It is important to note here that Polanyi argues not against markets. He states explicitly "no society can exist without a system of some kind which ensures order in the production and distribution of goods" ${ }^{133} \mathrm{He}$ considers markets excellent means to divide scarce resources in society and acknowledges that its mechanisms provide revolutionary means to achieve increase in material wealth, but, so Polanyi argues, markets should always be merely a function of the social order. The potential for this function disappears because of the inherent system of fictitious commodification that is part of this market ideology.

\section{iv. Fictitious commodification}

It is the need for commodification resultant from the self-regulatory mechanisms of the market that causes social dislocation and disaster. Polanyi identifies great danger in subordinating society itself to the laws of the market. The concept of self-regulation and the consequential idea that all production is for sale on the market and all income derives from such sales has important implications. As described, this means that essential inputs for production need to be qualified as commodities in order to fit the self-regulatory mechanism. The process of commodification of things that are in reality not produced for sale is the fundamental error of the market mechanism. Polanyi submits that these fictitious

\footnotetext{
131 Ibid, p. 43.

132 Ibid, p. 42.

133 Ibid, p. 74.
} 
commodities can be grouped together as labor, land and money. ${ }^{134}$ These elements are simultaneously both a vital part of the economic system and not commodities because they are not produced for sale: 135 "Labor is only another name for a human activity which goes with life itself [...] that activity [cannot] be detached from the rest of life, be stored or mobilized; land is only another name for nature, which is not produced by man; actual money, finally, is merely a token of purchasing power which, as a rule, is not produced at all, but comes into being through the mechanism of banking or state finance."

Although these commodities are fictitious, they are also a fundamental part of any market run-society. This, Polanyi argues, has the capacity to demolish society. As described above, the long-term investments required by the introduction of large-scale machinery brought with it a need to reduce investment risks through the certainty of continuance of production. Polanyi's argument shows that it is this introduction of the factory system into commercial society that necessitated that all elements of industry are for sale: 136 "human society had become an accessory of the economic system”. But this, Polanyi argues, could not last for long.

\section{v. Societal resistance and the double-movement}

Here Polanyi introduces his next key thesis: the double-movement. The idea of the self-regulated market appears as a very strong force. There is however a big flaw: it is simply unsustainable. The spreading of market idealism is accompanied almost instantaneously with measures and policies designed to check the impact of the market on the fictitious commodities of labor, land and money ${ }^{137}$ Human beings will not accept that their livelihoods depend on the needs and changing tides of supply and demand. Polanyi submits that consequent counter- movements occur spontaneously and pragmatically across societies whenever human or natural resources disproportionally fall in the grip of self-regulatory models and are

Ibid, p. 71.

Ibid, p. 76.

6 Ibid, p. 79.

137 Ibid, p. 79. 
diminished to input commodities within a market mechanism. Spontaneous interventions from society in the form of legislation, administration and associative self-organization will be initiated in order to regain control over these things that Polanyi considers as 'fictitious commodities'. ${ }^{138}$

Polanyi records a high degree of diversity on the issues on which counteraction spontaneously arises, the common denominator being that they al deal with the safeguarding of some public interest against dangers in the market method of dealing with them. ${ }^{139}$ Contrary to the artificial construction of free markets, subsequent restrictions on the mechanisms of the market do raise spontaneously out of society: ${ }^{140}$ "Laissez-faire was planned; planning was not." Polanyi substantiates his point by showing how similar developments occurred in different countries in Europe. Both Victorian England, the Prussia of Bismarck, the France of the Third Republic and the empire of the Hapsburgs experience a period of free trade and laissez-faire followed by a period of anti-liberal legislation with regard to a variety of issues such as public health, factory conditions, municipal trading, social insurance, public utilities, trade associations etc. Polanyi sets out a clarifying timeline by which these 'double-movements' occurred. ${ }^{141}$ Polanyi considers this universal "collectivist" yet fragmented reaction against the expansion of market economy as conclusive proof of "the peril to society inherent in the utopian principle of a self-regulating market" ${ }^{142}$

Polanyi argues that social change such as the protectionist movements generally results from external changes to the societal structure as a whole. Whenever a new societal structure comes into existence, this necessarily impacts

138 Ibid, p. 136.

139 Ibid, 152. Polanyi provides the following examples: analysts of food and drink to be paid out of local rates; the inspection of gas works; making it penal to employ boys under twelve not attending schools and unable to read or write; enforced vaccinations; local boards authorized to fix rates of hire for means of conveyance; inspectors for the wholesomeness of food; laws preventing the deaths of children that were set to sweep too narrow slots; a contagious disease act; a public libraries act; and more examples of varying kinds.

${ }^{140}$ Ibid, 147.

141 Ibid, 153.

142 The other is that Polanyi rejects the idea of exclusive economic interests as drivers for social change. He argues that social change is generally driven by questions of social recognition. 
the interests of those groups most affected by the change. This is demonstrated by the various similar but diverging reactions of groups of people in different countries that experienced intense periods of laissez-faire politics, which impacted their position in society and consequently triggered a protectionist reaction. According to Polanyi, this protective movement should not be qualified as class interest but as spontaneous social interests and action imperilled by market mechanisms. ${ }^{143}$ This can produce situations of societal instability and collapse. This is what Polanyi considers as the problem of the separation of politics and economics in an age of democratization. Democracy and capitalism become irreconcilable enemies and society 'is inevitably doomed to collapse, or to revolution' ${ }^{144}$.

The capture of political power by the working classes provided effective means for protective movements to disrupt economic self-regulation: “Governments' commitment to fixed exchange rates at the price of falling wages, rising unemployment, and human misery radicalized the left in Europe". ${ }^{145}$ Eventually, Polanyi concludes, that the tension between capitalism and democracy became a disintegrating force: ${ }^{146}$ "Labor entrenched itself in parliament where its numbers gave it weight, capitalists built industry into a fortress from which to lord the land. [...] The captains of industry were subverting the population from allegiance to their own freely elected rulers, while democratic bodies carried on warfare against the industrial system on which everybody's livelihood depended."

Consequently, economic adjustments became impossible. The division of economy from society and the absence of change at a socially acceptable tempo caused a 'disembedding'. Social strains in society "would transcend the economic zone and the balance would have to be restored by political means" ${ }^{147}$. This necessitated a reuniting of economics and politics in a progressive and effective form. Short of that, workers were bound to deploy their electoral power to protective ends and capitalists to use their wealth and influence to weaken political

\footnotetext{
143 This a point where Polanyi clearly distinguishes himself from the social theory of Marx.

144 TGT, p. 207

145 See Höpner, Schäfer 2010 above (no. 21), at 5.

146 TGT, p. 235-236

147 Ibid., p. 235.
} 
democracy. ${ }^{148}$ This was, however, an irreconcilable conflict and the time was ripe for the "fascist solution". ${ }^{149}$

Thus goes the analysis of Polanyi as regards the origins of the collapse of $19^{\text {th }}$ century civilisation. In the last part of the book Polanyi turns his outlook shortly to the future. He expected that markets would not be self-regulating and that political choice would fix prices for land, labor, and money. ${ }^{150}$ Importantly, abandoning the gold standard would free governments from the chains of the international monetary system and facilitate international cooperation: "economic collaboration of governments and the liberty to organize national life at will" ${ }^{151}$. As was discussed before, these insights foreshadowed the idea and institutional construction of embedded liberalism in Europe. ${ }^{152}$

C. The enduring relevance of Polanyi

\section{i. Introduction}

It is not a surprise that there has been a revival of interest in Polanyi's work in recent years, across disciplines. ${ }^{153}$ Part of this popularity can be explained on the basis of his 'cite-ability' and eerie relevance for current and pressing themes, reflected, for example, in a passage such as the following where Polanyi discusses how the stabilization of currencies became the focal point of political thought in the 1920s:

${ }^{148}$ Ibid., p. 244.

149 Ibid., p. 244.

${ }^{150}$ Ibid., p. 250.

${ }^{151}$ Ibid., p. 254.

${ }^{152}$ See Ruggie above (no. 4).

${ }^{153}$ See for a recent explanation of this resurfacing F. Block and M. Somers, The Power of Market Fundamentalism: Karl Polanyi's Critique, (Harvard University Press, 2014). Examples related to the field of law include: Special Issue: New Directions in Polanyian scholarship (2014) 43 Economy and Society; D. Ashiagabor, P. Kotiswaran, and A. Perry-Kessaris (eds.), Special Issue: Towards an Economic Sociology of Law (2013) 40 Journal of Law and Society; and (2014) 65 Northern Ireland Legal Q. Also, G. Krippner et al., 'Polanyi symposium: a conversation on embeddedness' (2004) 2 Socio-Economic Rev. 109; J. Mulder, 'Re-embedding EU Governance Fields: A Research Agenda', in C. Joerges and C. Glinski (eds.), The European Crisis and the Transformation of Transnational Governance. Authoritarian Managerialism versus Democratic Governance, (Oxford: Hart Publishing 2014), at 181 . 
"the repayments of foreign loans and the return to stable currencies were [time and again] recognized as the touchstone of rationality in politics; and no private suffering, no restriction of sovereignty, is deemed too great a sacrifice for the recovery of monetary integrity. The repayment of foreign loans and the return to stable currencies were recognized as the touchstone of rationality in politics; and no private suffering, no restriction of sovereignty, was deemed too great a sacrifice for the recovery of monetary integrity". ${ }^{154}$

Today's market critics understandably derive a direct and profound normative and historically validated commitment from the work of Polanyi in critiquing contemporary atomistic austerity politics. ${ }^{155}$ Other than drawing on similarities such as these, commentators have also picked up on Polanyi's core concepts of the double-movement, fictitious commodification and embeddedness and started working with those concepts in terms of a Polanyian inspired research agenda. ${ }^{156} \mathrm{In}$ particular Polanyi's conceptual apparatus has been used to qualify the process of European integration in terms of a double movement, where 'disembedding' marketization efforts are counteracted by 'embedding' re-regulation. Moreover, the separation of the political from the economic sphere resounds strongly with the advance of technocratic forms of decision making within the Union. ${ }^{157}$ However, a strong critique on the work of Polanyi is that his central concepts lack theoretical specificity. ${ }^{158}$ In TGT they are defined sufficiently wide that the willing reader can interpret them in a way that captures most if not all social processes that involve a form of resistance or result in social policy of some kind as a response to 'the

${ }^{154}$ TGT, p. 148

155 E.g. D.M. Woodruff, 'Governing by Panic: The Politics of the Eurozone Crisis', LEQS Paper No. 81/2014, October 2014.

${ }^{156}$ E.g. M. Saveska, 'Polanyian Reading of the Socio-Economic Transformations of the European Union' 22(2014) Journal of Contemporary European Studies, p. 395-410 ; P. Copeland, "International Political Economy and European Integration- Applying Karl Polanyi's The Great Transformation." IPEG Papers on Global Political Economy 40 (2009)- 1-26; N. Lindstrom, 'Service Liberalization in the Enlarged EU: A Race to the Bottom or the Emergence of Transnational Political Conflict?' Journal of Common Market Studies 49(2010) p. 1307-27; Caporaso and Tarrow above (no. 24); Höpner and Schafer above (no. 21); Ashiagbor above (no. 29).

157 See also Saveska above (no 156).

${ }^{158}$ C. Holmes, 'Problems and Opportunities in Polanyian Analysis Today', Economy and Society Economy 41 (2012), p. 468. 
market' ${ }^{159}$ On this basis one legal commentator went as far as to say that 'we are all Polanyians now'. ${ }^{160}$ In adopting an explicit Polanyian vocabulary one should therefore carefully consider how that usage can be authentically traced back to Polanyi and from which point the conceptual apparatus needs to be extended to a post-Polanyian understanding in order to sufficiently capture the actual processes that are being described in order not to render Polanyi's valuable historical insights meaningless.

To begin, in any attempt to reinvigorate a Polanyian critique, it is imperative to overcome the obvious fact that Polanyi's main work was written in the early 1940 s and that today the orthodox market liberalism and social naturalism that formed the object of his critical, historical, investigations is without any (serious) intellectual support. More particularly, why and how should legal scholars, interested in legal issues in the EU internal market be interested in the historical analysis of Karl Polanyi, who was by training an economic anthropologist? This section explores this question, specifically with respect to the social problematique as it was previously introduced and contextualised within the argument from transnational effects.

Primarily, Polanyi's study brings to the concept of social legitimacy as applied in this study a normative commitment based on his historical analysis of the effects of a structural disregard of domestic social spheres in the organisation of state-market-society relationships. Polanyi can be read as providing a historical narrative that provides a normative commitment to the conceptualisation of social legitimacy as pursued in this thesis and for the idea that responsiveness in the governance mechanisms of the internal market is crucial for the social acceptance and hence political sustainability of internal market project. This becomes more apparent in discussing the core concepts Polanyi adopts in TGT.

159 E.g. R. Munck, 'Globalization and Contestation : A Polanyian Problematic' Globalizations 3(2006), p. 175-186.

${ }^{160} \mathrm{H}$. Schepel 'Rules of recognition: A constructivist approach to transnational private regulation' in P. F. Kjaer, P. Jurčys, R. Yatsunami (eds), Regulatory Hybridization in the Transnational Sphere (Martinus Nijhoff Publishers 2013), p. 193.. See also J. Beckert, 'The Great Transformation of Embeddedness: Karl Polanyi and the New Economic Sociology' in C. Hann K. Hart (eds.) Market and Society: The Great Transformation Today, (New York: Cambridge University Press 2009), p. 38-55. 


\section{ii. Embeddedness and the double-movement}

Although the term embeddedness is only occasionally used in the work of Polanyi, his work is clear on the dangers and in particular the social instability that results from attempts to 'disembed' the market from its fundamental socio-political settings and supports and "to treat it as if it has no dependence on a wider social context". ${ }^{161}$ Embeddedness has become a if not the core concept of the new economic sociology'. However, Polanyi himself makes no effort to clarify, conceptually, how embeddedness is to be made tangible. ${ }^{162}$ It is unclear if embeddedness is concerned with, for example, 'political institutions, legal controls, state policy or social conditions' ${ }^{163}$ Unsurprisingly, therefore, there is debate with respect to the exact meaning of embeddedness in Polanyian terms and it has been roughly described in two ways. Political economist Fred Block argues that markets are, necessarily, always embedded and that there can be no such thing as a pure and disembedded market economy: "Economic processes cannot but result from a mix of cultural, political and economic forces". ${ }^{164}$ Block submits that Polanyi was mainly concerned with identifying this 'always embedded economy'. The 'always embedded economy' thesis recognises that markets are always and necessarily somehow related to other social and cultural elements of societies and therefore never fully autonomous from the start. This interpretation of the concept mainly allows for descriptive research with respect to why economic infrastructures and institutions function and look the way that they do. ${ }^{165}$

Another, reading of Polanyi's concept of embeddedness acknowledges that Polanyi identified the need to position markets in an institutional order that is

161 R. Cotterrell, 'Rethinking 'Embeddedness': Law, Economy, Community' (2013) 40 Journal of Law and Society 49-67 at p. 53. Compare with Granovetter, who uses the concept of embeddedness in a similar way in his famous M. Granovetter, 'Economic Action and Social Structure: the Problem of Embeddedness', American Journal of Sociology, 91(1985), p. 481-93.

162 See Beckert above (no. 160), at 38-55.

163 Ibid.

${ }^{164}$ F. Block, 'Karl Polanyi and the Writing of the Great Transformation' Theory and society 32(2003), p. 275.

165 See Dale above (no. 9). 
'always embedded' but distinguishes this from what Polanyi considered to be the actual process of (dis)embedding markets. ${ }^{166}$ It is this process that is interesting for the development of a normative perspective on governance in the EU internal market. One lesson that can be taken from Polanyi's historical analysis is the 'trend' by which communities respond to atomised and under-socialised attempts to organise state-market-society relations on the basis of the self-regulating market rationale. The societal fragmentation and response occurs when such processes of societal change do not allow for pre-existing societal structures and choices to be recognised within those governance mechanisms. Hence, successful and enduring governance schemes will take account of the communities they regulate. This reading emphasises the importance of a micro-community based analysis of the actual content and object of socio-economic governance mechanisms.

There exists an analogy on this point with the debate on the interaction between social norms and the law, which is governed by roughly two ideas. One concerns the idea that 'custom' or norm based rules lack the flexibility and rational control that is considered desirable for some higher order reason. Law then could become the means to reform such 'old-fashioned' social norms. ${ }^{167}$ Some social norms may not be desirable from a particular higher rational perspective, and law can then improve the situation by regulating the concerned behaviour in congruence with the desired rationally and correcting undesirable phenomena, such as protectionist state aid schemes. ${ }^{168}$ This is reflected in the core nucleus of EU law where there are some interests (however social they may be) that are simply not part of the accepted EU internal market values scheme and will therefore always have to give way to the objectives of market integration and competition.

These include tariff/custom duties, national discrimination, the discriminatory subsidisation of national champions and price cartels. It appears that these bans are,

166 See Ebner above (no. 60) at p. 28..

167 As can be derived from H. L. A. Hart, The Concept of Law (Oxford: Clarendon Press 1961). Also R. Posner (1997), 'Social Norms and the Law: An Economic Approach', The American Economic Review 87(1997), p. 365-369.

168 E.g. R. Posner, Economic Analysis of Law (Boston: Little, Brown, 1972) argues in favour of the higher economic rationale. 
today, congruent with prevailing norms within Member States and EU law has been effective in implementing the idea that blatant protectionism amongst the Member States of the Union is a bad idea. However, outside of the core nucleus of mutually shared values, the balance between market integration and social interests that are restrictive of free movement and competition interests becomes more complex and in need of a more subtle rationale. This is the idea that legal and social norms do their job in the 'best' way when they are somehow aligned. ${ }^{169}$ Law and social norms should in a way complement each other. This position harbours more challenges, in finding the right interplay between social norms and enforcing a specific rationality through law. What underlies it is the idea that law should not be alien to society but instead that there should be some form a mutual communication between law and society. ${ }^{170}$ If law is completely alien it will risks loosing its legitimacy and become irrelevant. As such, the supranational EU law rules have to some extent align with social contexts within Member States and built in mechanisms of responsiveness in order to retain its legitimacy. Simply said, outside of the core nucleus the internal market allows for social diversity in and between the Member States.

Within the legal framework of the internal market this provides input for an evaluative rationale that needs to respond to diversity in approaches towards social objectives and interests. This is a reading of embeddedness that recognises the diversity and plurality of the central facets of organisational principles that determine the normative infrastructure of an economy. For example, relations of community can be based:

“(i) on a convergence of the participants' projects (instrumental community) which may be economic in nature; or (ii) on shared customs, traditions, physical environment or linguistic or historical heritage (traditional community) or (iii) on shared fundamental convictions (community of belief or values), or (iv) on essentially

169 E.g. R. D. Cooter, "Three Effects of Social Norms on Law: Expression, Deterrence, and Internalization," Oregon Law Review 79(2000) p. 1-22.; J. R. Hay, A. Shleifer, and R. W. Vishny, 'Toward a Theory of Legal Reform', European Economic Review, 40(1996) p. 559-567; J.R. Hay, and A. Shleifer, Private Enforcement of Public Laws: A Theory of Legal Reform," American Economic Review, 88(1998) p. 398-403.

170 E.g. D. Acemogluy and M. O. Jackson, 'Social Norms and the Enforcement of Laws', NBER Working Paper No. 20369 (Agust 2004), http://nber.org/papers/w20369. 
emotional attractions or rejections, likes or dislikes, loves or hatreds towards others (affective community)" ${ }^{171}$

The point here is the connection between embeddedness and context specificity in economic regulation. Some of these communal contexts lend themselves easily to economic regulation. The instrumental community fits within a form of regulation based on an evaluative principle of efficiency. Problems may arise, however, when such economic substantive efficiency oriented governance mechanisms would be installed to regulate traditional communities, communities based on belief or values and so forth. To do so would be to dis-embed the social context within a regulatory framework that is under-socialised. Regulation of the organisational principles that govern these social contexts would need to be responsive in order to be recognised and accepted within the social networks that they aim to regulate. In this specific sense, there are requirements of institutional design and rationality that can be read into the normative concerns that Polanyi's notion of embeddedness and processes of dis-embedding provides.

Polanyi's more general point with respect to his coining of the doublemovement is that accepting dominating principles of gain and profit as the sole organizing principles in society contributes to the rise of unstable societies. This instability arises through the domination of one organizing principle over, and to the exclusion of other, socially 'embedded' organizing principles. Again the point of Polanyi with a time-less relevance is that the structural disregard of important elements of the social sphere will at some undefined point in time, trigger opposition and contestation within society. A countermovement against the submersion within a dominant rationale will seek to protect that which is not recognised in the dominating principle. If such opposition and contestation is not adequately channelled, then society may begin to fracture, lose cohesion and can ultimately collapse. This is the oversimplified, basic point of Polanyi but it is easy to point towards general trends in society that would validate the intuitive appeal of

${ }^{171}$ See Cotterrell above (no. 159) at p. 55. 
his framework. ${ }^{172}$ Therefore, the specific relevance of the Polanyian 'double movement' for the principle of responsiveness in the EU internal market is (i) the importance of the identification and recognition of different organizing principles in society, whose treatment are directly related to the political sustainability and diversity of the European internal market project, and (ii) the need to develop a reciprocal dynamic between these different organising principles for any politically sustainable project, which relates directly to the need of an adjudicative rationale for situations where such organising principles might clash. ${ }^{173}$

\section{A rationale of responsiveness: moving beyond Polanyi?}

The relevance of Polanyi's work for responsiveness in the EU internal market towards social diversity is not based on his analysis of naturalistic orthodox market fundamentalism but based on a concern with more general applicability for the effects of EU internal market law on the social sphere within the Member States. The historical analysis of Polanyi shows recurring trends within societies that respond to under-socialised attempts to reframe market-state-society relationships. Polanyi therefore provides a historically grounded commitment to the idea of social legitimacy in terms of its normative claims on how transnational regimes should respond to conflicts between interests of a social nature and trade objectives. This concerns the idea that strong organizing principles that adopt a dominant and strict rationality carry the inherent risk of disregarding conflicting principles in society that do not fit within that rationale. Therefore, thinking in terms of embeddedness allows a conceptualisation of the meaning of the social and diversity as they emerge

${ }^{172}$ A case in point would be the latest Greek election that responded directly to such an under socialised and atomised system of decision making that has the potential of destabilising the entire Eurozone.

173 There is an interesting analogy here with the issue of functional rationalities and the complexities this brings for international law, which might be further explored, see G Teubner and A Fischer-Lescano, 'Regime-collisions: The Vain Search for Legal Unity in the Fragmentation of Global Law' Michigan Journal of International Law 25(2004) p 999-1046, A.L. Paulus in response to that article 'Commentary to Andreas Fischer-Lescano and Gunther Teubner: The Legitimacy of International Law and the Role of the State' Michigan Journal of International Law 25(2003) p. 1047-58, and again, G Teubner and A Fischer-Lescano, 'Reply to Andreas L. Paulus Consensus as Fiction of Global Law' Michigan Journal of International Law 25(2003), p. 1059. More recently see G. Teubner, Transnational Economic Constitutionalism in the Varieties of Capitalism (Ms. Frankfurt 2015). 
within legal frameworks that translate their social meaning for regulatory purposes. The assumption is that dominating principles will tease out conflict and contestation and if structurally ignored will also challenge the social and political sustainability of the whole project. Polanyi therefore provides a social urgency to develop a legal rationale that does not suppress but allows a diversity of embedding organizational principles to exist and communicate constructively within overarching legislative frameworks. ${ }^{174}$ In this context, social legitimacy would be foregone when EU internal market governance would apply an atomized, undersocialized conception of rational Member State action and ignores embedding social fabric that seeks to structure economic activities within the direction and values of a community.

As was touched on before, an issue that is often overlooked in the debates of the EU 'social deficit' is that it is important to be clear about the meaning of the social and how it specifically conflicts with the economic. It is important in order to distill the type of conflicts that may arise between clashes of different normative orders and the consequent need to have adjudicative and governance rationales that are able to deal with these different types of conflicts. Embeddedness thinking is instructive in this regard because it clarifies the nature of the social for regulatory purposes. That is to say, to see the social in terms of communal networks that may be dominated by economic objectives but will also consist on the basis of other normative principles. Regulating them will have to take into account the mixes of different types of normative infrastructures of economies that they may exhibit and thereby the internal market can be positioned within such 'legitimate social purposes $^{175}$. This exercise of clarification, in itself alone, would benefit the functioning of the EU legal system. ${ }^{176}$ Thus, the absence or presence of true or false conflicts in norms has consequences with respect to the means through which such conflicts should be resolved. For example, if a social objective can be translated

\footnotetext{
${ }^{174}$ As in E. Sternberg, 'Justifying Public Intervention without Market Externalities: Karl Polanyi's Theory of Planning in Capitalism', Public Administration Review, 53(1993), p. 100-109.

175 Caporoso and Tarrow above (no. 24).

${ }^{176}$ W.N. Hohfeld, 'Some Fundamental Legal Conceptions as Applied in Judicial Reasoning' (1913) 23 The Yale Law Journal at p. 16..
} 
into a market objective without losing anything of the social objective that is being pursued, there is no apparent norm conflict and, as shall be discussed further below, this should direct the adjudicative rationale that is required to resolve a conflict.

The Polanyian insights based on the societal phenomenon of the doublemovement provide for direction and a normative commitment to essentially 'manage' the double-movement. That is to say, to develop governance rationales that do not suppress but allow a diversity of embedding organizational principles to exist and to develop a reciprocal dynamic between these different organising principles for a politically sustainable project. Dominating principles will tease out conflict and contestation and one way to 'discover' the nature of the social as economic or noneconomic is through a residual approach. To define it through a process of opposition that allows elemental social fabric to be distinguished from market objectives. Indeed, this approach accepts the primacy of the market but then creates a space for everything 'noneconomic' to be identified as a residual, conflicting and potentially legitimate objective. ${ }^{177}$ This implies that the social is to be found in features of values that get lost, are not addressed or are negatively impacted within market based governance styles.

On the basis of the foregoing, a rationale of responsiveness, instructed by embeddedness has a procedural dimension that allows an evaluation of the social in its specific context. It has a substantive basis that recognises the limits of evaluative discourses and rationales that are unable to sufficiently weigh the objectives at stake. It may for example be the way that certain objectives are pursued, and not so much their outcomes, that makes them socially relevant. Some objectives share a social and political pact that underlies the objectives that are pursued. ${ }^{178}$

The distinction of Polanyi between embedded and disembedded markets allows reconciliation in the sense that markets as such are not rejected, but only the

This is partly an operationalization of the perspective that Colin Crouch develops around the idea of assertive social democracy that accepts the value and priority of markets in the economy, but is aware of their limitations and deficiencies as inappropriate in some areas of life, see C. Crouch, Making Capitalism Fit for Society (Cambridge-Malden MA, Polity Press, 2013) 37.

${ }^{178}$ See similarly, R. Bellamy, 'The liberty of the moderns: Market freedom and democracy within the EU' (2012) 1 Global Constitutionalism, pp. 141-172, at p.168. 
'dangerous, disembedded market' ${ }^{179}$ It is in this sense a reconciliatory rationale that Polanyi advanced. Nevertheless, this raises the question: is all dis-embedding necessarily harmful? Local values may be reflective of forms of discrimination and a communitarian bias may be used to legitimise practices that are perhaps focussed on entrenching privilege and exclusion. What commodification attacks is therefore not always worth defending and a process of marketisation may very well foster emancipation by weakening traditional entrenched forms of privilege. ${ }^{180}$ It is clear that Polanyi never set out to provide an idealized account of traditional society or favour domination of any sort. One of the main reasons for Polanyi's thesis advocating a resolution through which markets on the basis of democratic means could be positioned within communities to avoid the rise of an authoritarian, fascist alternative. In this way Polanyi made clear that not all regimes of protection were morally equivalent or worthy of protection. The point is that this was never concretized by Polanyi as part of his critical theory. That is to say, there is no concept that allows the distinction between good embedded markets or bad embedded markets (endorsing e.g. slavery and racial discrimination).

It is, in fact, on this point that a Polanyian inspired critique stands to gain significantly from the theoretical foundations of the argument from transnational effects, which brings the mutual into the dialogue of responsiveness. As was discussed above, the traditional internal market obligations for Member States can be perceived as not being able to pursue their interests or laws without restraint. Instead they are "obliged to respect the European freedoms; they are not allowed to discriminate and can pursue only legitimate regulatory policies; they must, in relation to the objectives that they wish to pursue through regulation, harmonise with each other, and they must reform their national systems in the most community-friendly way possible" ${ }^{181}$ In other words, the value of internal market integration is exactly to constrain national self-expression, "so as to mitigate what

\footnotetext{
179 N. Fraser, 'Can Society Be Commodities All the Way down? Post-Polanyian Reflections on Capitalist Crisis’ (2014) 43 Economy and Society 541.

180 Ibid.

181 See Joerges and Rödl (2009) above (no. 23).
} 
are regarded as its potential excesses: the exclusion of certain interests from the political process, and its capacity for sovereign violence in limiting permissible behaviour" ${ }^{182}$. In this way the thesis aims to move beyond the communitarian bias through an emphasis on the mutuality that responsiveness requires within internal market governance mechanisms.

\section{E. Polanyi in Luxembourg?}

Quite a number of Polanyian accounts have been given about the enactment of internal market legislation and, in particular most recently, the European response to the debt crisis. ${ }^{183}$ Interesting as such account may be ${ }^{184}$ this section focuses on Polanyian accounts and critiques on the case law of the Court of Justice.

The first serious attempt to connect the work of Polanyi to the dynamics of the internal market and specifically the case law of the Court of Justice was undertaken by Caporoso and Tarrow in 2009. ${ }^{185}$ Caporoso and Tarrow take a Polanyian inspired outlook by arguing that the Court of Justice has in its labour law case law started to develop what they describe as the structure for a supranational embedded liberal compromise. In its case law the Court of Justice has created a new social dimension where it recognises workers are 'human beings, with families, local commitments, and rights ${ }^{186}$. The authors distinguish different phases in the case law of the Court of Justice in the application of free movement law for workers. Starting from a perspective of market failure the Court of Justice first concern was to remove obstacles to the free movement of labour. ${ }^{187}$ In a second stage the authors argue that the Court developed a supranational embedded liberal compromise by recognising that workers were not just commodities and 'the social

${ }^{182}$ See de Witte above (no. 53) at p. 1551.

83 SeeWoodruff above (no. 155).

${ }^{184}$ See in particular Saveska above (no 156).

185 See Caporaso and Tarrow above (no. 24).

186 Ibid., p. 600.

187 See similar account for the free movement of healthcare services by M. Krajewski, 'Commodifying and Embedding Services of General Interest in Transnational Contexts: The example of healthcare liberalisation in the EU and the WTO', in Christian Joerges and Josef Falke (eds), Karl Polanyi, Globalisation and the Potential of Law in Transnational Markets (Hart 2011). 
standing of workers and people in general was taken into account' for the determination of their 'rights' based on the free movement of workers provisions in the Treaty. ${ }^{188}$ Therefore, the authors argue that social content has been infused into the application of the free movement rules. This they argue is evidence for the idea that the Court is inspired by Polanyi and pursues an ideal of the supranational embedded liberal compromise.

This attempt of a Polanyian reconstruction of a single line of cases of the Court is unconvincing and demonstrates a confused understanding of the meaning of embeddedness. That is in itself not surprising, since as was discussed above, the concept is never concretely grounded in the work of Polanyi. However, it is quite certain that Polanyi would not approve of Caporoso and Tarrow's use of his ideas. Their understanding of the embeddedness concept as the infusion of social rights based content within the supranational trade regime is closer to the interpretation that Granovetter has given to the embeddedness concept, which is according to Granovetter himself not inspired by Polanyi in any way. ${ }^{189}$ Granovetter argued that the perception of economic action within neoclassical economic accounts separated economics from society and culture in a 'undersocialized account' and atomised human behavior. In a similar way, he argued that sociologists employed an 'oversocialized' view of economic actors, refusing to see the ways that rational choice could influence the ways they acted in traditional, 'embedded' social roles: ${ }^{190}$

"Actors do not behave or decide as atoms outside a social context, nor do they adhere slavishly to a script written for them by the particular intersection of social categories that they happen to occupy. Their attempts at purposive action are instead embedded in concrete, ongoing systems of social relations".

It seems to be this understanding of embeddedness that underlies Caporoso and Tarrow's attempt to reconstruct the free movement of workers case law of the Court into a structure for a supranational embedded liberal compromise. That is to

\footnotetext{
188 Referring to the Carpenter Case C-60/00 [2002] ECR I-06279.

189 See M. Granovetter, 'Economic Action and Social Structure: the Problem of Embeddedness', American Journal of Sociology, 91 (1985), 481-93; also G. Krippner et al., 'Polanyi symposium: a conversation on embeddedness' (2004) 2 Socio-Economic Rev. p. 109.

190 Ibid., p. 487.
} 
say a free trade regime that is, on a supranational level infused with social content. Therefore, the trade regime is not overly commodified nor socialised. I partly agree with Scharpf who forcefully responded to this idea in his famous piece on the asymmetry of European integration. ${ }^{191} \mathrm{He}$ argued that it is true that, as Caporoso and Tarrow argue, the rights-based case law of the Court of Justice has evolved in a way that it is no longer primarily based on economic interests but also serves noneconomic interests. This development is, he argues, in no way evidence for the 'social embeddedness' of the European economy. ${ }^{192}$ Instead, the case law of the Court is primarily concerned with "individual rights of exit from, and entry into, democratically shaped and collectively financed systems of national solidarity". ${ }^{193}$ In this way the case law is more likely to undermine the reciprocity that is needed for rights and obligations to have a social foundation in the first place. ${ }^{194}$

Martin Höpner and Armin Schäfer joined and extended this critique by discussing lines of case law from the Court of Justice that demonstrate a tendency to undermine national social foundations within Member States. ${ }^{195}$ They recognise and acknowledge that the Court of Justice has established some significant antidiscrimination jurisprudence with an effect within all member states. However, they see this case law as reflecting 'social' content in the wider sense, but not as an element of a Polanyian inspired agenda: "it aims to create free access to the market, unhampered by discrimination, in other words: free but fair markets" ${ }^{196}$. Instead the picture they paint is very similar to that of Scharpf. The argument is that the direct effect of market freedoms ${ }^{197}$ has provided market agents with individual rights,

191 See Scharpf above (no. 21) at p. 211.

192 Ibid., p 226.

193 As argued by A. Somek, 'Individualism: An Essay on the Authority of the European Union', (Oxford: Oxford University Press 2008).

194 As argued by A. Menendez, 'European Citizenship after Martinez Sala and Baumbast: Has European Law Become More Human but Less Social? RECON Online Working Paper 2009/05 (Oslo: University of Oslo, ARENA - Centre for European Studies 2009).

195 See Höpner and Schäfer above (no. 21)

196 Ibid., p. 446.

197 As established in Case 26/62, N.V. Algemeine Transport-en Expeditie Onderneming van Gend \& Loos v. Netherlands Inland Revenue Administration, [1963] ECR 1. 
which they have enforced, making use of the supremacy of those laws ${ }^{198}$, mainly to undermine regulatory systems within Member States. ${ }^{199}$

"Armed with direct effect and supremacy, European competition law became a live weapon in the hands of supranational actors, because, from that point on, it could potentially be used to liberalize economic sectors for which it had initially not been made, namely third sector areas providing public goods and services, such as telecommunications, energy, and transportation".

Moreover, they argue, the replacement of the principle of nondiscrimination ${ }^{200}$ by the principle of nonrestriction ${ }^{201}$ in the case law of the Court has accelerated and enforced a dynamic that structurally allows supranational market actors to successfully question regulatory choices within Member States. ${ }^{202}$ In the words of Scharpf ${ }^{203}$

"the only thing that stands between the Scandinavian welfare state and the market is not a vote in the Council of Ministers or in the European Parliament, but merely the initiation of [ . . ] legal action by potential private competitors before a national court that is then referred to the European Court of Justice for a preliminary hearing".

It is this constitutional set-up that stands at the basis of the integration through law movement. ${ }^{204}$ Höpner and Schäfer provide ample examples to justify their claim. The liberalization of corporate law by overturning the "company seat theory" or "real seat doctrine" in Centros, Überseering, and Inspire Art judgments of the Court of Justice on the basis of the free movement of establishment provisions. ${ }^{205}$ This has led to a transformation of German co-determination rules, which are now easily avoided. Secondly, they refer to the Laval and Viking judgments, where the Court effectively decided to limited the host countries' room

198 As established in Case 6/64, Costa v. ENEL, [1964] ECR 586.

199 See Höpner and Schäfer above (no. 21), at 441.

200 As established in Case 8/74 Procureur du Roi v Benôt and Gustave Dassonville [1974] ECR 837.

201 As established in Case 120/78 Rewe-Zentral AG v Bundesmonopolverwaltung für Branntwein (Cassis de Dijon) [1979] ECR 650

${ }^{202}$ See also J.H.H. Weiler, “The Transformation of Europe”, Yale Law Journal 100(1991) at p.2403

${ }^{203}$ F.W. Scharpf, 'The European Social Model: Coping with the challenges of diversity', JCMS 40 (2002), at p. 657.

204 See also J.H.H. Welier, 'Van Gend en Loos: The Individual as Subject and Object and the Dilemma of European Legitimacy', International Journal of Constitutional Law 12(2014) p. 94-103.

205 See cases C-212/97, Centros; C-208/00, Überseering; C-167/01, Inspire Art 
to manoeuvre in preventing races to the bottom in the field of labor standards (Laval) and created a horizontal effect by deciding that the European market freedoms only oblige member states, but also private bodies to refrain from actions that might restrict market freedoms (Viking). ${ }^{206}$ Thirdly, they provide the argument that decisions such as Cadbury Schweppes and Marks \& Spencer prohibit national efforts to tackle tax-avoidance practices. ${ }^{207}$ On the basis of these examples they argue that "rather than socially embedding the market, this line of ECJ case law undermines policies that aim at correcting market outcomes to achieve redistribution". 208

Scharpf and Höpner/Schäfer provide a compelling argument about the structural effects of these lines of cases from the Court of Justice. The Polanyian outlook they provide on this basis is grim $^{209}$

"The 'permissive consensus' of the past has given way to a 'constraining dissensus' and a widespread distrust of elite-driven integration. In particular, those who have been negatively affected by stronger competition and integrated markets have adopted more skeptical views of integration.... When the countermovementprotection against market forces - is not forthcoming at the EU level and is losing ground domestically, losers grow Euro-skeptical, endorse nationalism, and sometimes support extreme right parties".

I agree with Schapf and Höpner/Schäfer on the potential detrimental effects of the seemingly one-sided case law of the Court of Justice in terms of its social legitimacy. Their normative outlook is therefore shared in this thesis. This does, however, not apply to the assessment of the case law. Too often the case law of the Court of Justice is too selectively analysed and commented on without sufficient eye for detail. These accounts seem to underestimate the quite subtle balancing work and adjudicative techniques offered by the Court of Justice, which provide for a slightly more positive outlook. ${ }^{210}$ The next chapters shall substantiate this

Cases C-438/05, (Viking); C-341/05, (Laval), C-346/06, (Ruffert)

207 Cases C-196/04 (Cadbury Schweppes), C-446/03, (Marks \& Spencer)

${ }^{208}$ M. Höpner and A. Schäfer (no. 21 above), p. 445.

${ }^{209}$ Ibid., p. 450.

210 See for example analyses of D. Damjanovic, "The EU Market Rules as Social Market Rules: Why the EU Can Be a Social Market Economy," Common Market Law Review 6(2013) p. 1685-1717 and also de Witte above (no.53); Ashiagbor above (no. 29) at 317: 'What these cases reflect is the Court's attempt to grapple with an issue over which the political institutions are similarly engaged: how to 
statement further. This thesis therefore aims to complement such normative outlooks with a more complete analysis of the case law of the Court of Justice, if only because this study will include the important areas of competition law and state aid, which often are not mentioned in critical accounts of the case law of the Court of Justice but constitute two of the fundamental pillars of the internal market.

\section{Social legitimacy in the context of internal market adjudication: (e)valuation and the expressive function of internal market law as a dialogue of mutual responsiveness}

The foregoing sections have discussed social legitimacy in a rather broad sense, that is to say, without making the normative claims of social legitimacy specific to the context of adjudication. However, as was explained before, this thesis will specifically explore social legitimacy in the sphere of internal market adjudication and not cover legislation and other forms of internal market governance. ${ }^{211}$ This section shall discuss how the normative claims that were developed in the foregoing concretise in the adjudicative context. This will be explored specifically with respect to the areas of free movement, competition and state aid in the following chapters but the normative framework can be discussed here in slightly more abstract terms in order to set out the lens through adjudication will be approached in the following chapters.

The normative claim of social legitimacy in the context of the multilevel governance context of the EU and the internal market is that a reconciliation of local domestic social values within supranational market objectives requires a form of explicit responsiveness to the social context that is being adjudicated. Moreover, it was highlighted with reference to the historical analysis of Polanyi that in the context of market integration there is a risk that dominating market based rationales

promote market liberalization without undermining the social values that national governments are perhaps best placed to protect'.

${ }^{211}$ Although the following chapters will shortly touch on those dimensions where relevant. 
will ignore and crowd out alternative legitimate social purpose. In the context of adjudication these normative demands boil down to the issues of valuation in law and the related problems of indeterminacy and commensurability. ${ }^{212}$

For example, in its evaluation of a regulatory intervention that restricts the movement of economic actors, the Court of Justice may exclude valuable social practices that contribute to social cohesion and capital within Member States. An evaluative adjudicative method such a strict proportionality, applied in free movement adjudication, seeks the more efficient or less restrictive state measure; potentially excluding a relevant and genuine political compromise (further discussed in Chapter II). The efficiency based exemption criteria in competition law value competition restrictive sustainability initiatives in terms of the willingness of consumers to pay for a price increase; potentially excluding the inherent value of a sustainable environment (further discussed in Chapter III). The market based evaluative standards that state aid law introduces may nudge public bodies towards actions that are justified exclusively on the grounds of their commercial selfinterest; crowding out potential alternative visions regarding the appropriate role of public authorities and the direction that policy objectives take (further discussed in Chapter IV). The point is that these evaluative standards that are adopted in adjudicative contexts may translate social realities within a metric that risks doing violence to potentially genuine and worthwhile aspects of those objectives. This is the type of incommensurability that is central to the normative lens in the thesis. When the evaluative standard adopted by the courts results in a situation where objectives pursued by Member States cannot be aligned along the evaluative metric without doing violence to the potentially genuine and worthwhile aspects of those objectives.

The metric that is adopted in these examples points toward instances where the evaluative standard that is implicit in the adjudicative rationale applied by the court is reflective of a utilitarian consequentialist standard. An analogy can be drawn on this point with the argument of Majone who would argue that such market

${ }^{212}$ C.R. Sunstein, 'Incommensurability and Valuation in Law' Michigan Law Review 92(1994) at 779. 
enhancing rationalities are based on the idea that they improve overall welfare and hence "do not need a strong normative foundation" since they rely on output legitimacy. ${ }^{213}$ Instead rationales that would imply choices between social objectives "can only be legitimated by majority decisions and by virtue of that fact place too heavy a burden on the fragile normative foundations of a transnational polity"214. Moreover, these utilitarian standards are a, on first sight, clear and clean way of approaching otherwise obscure and complex objectives that are not easily translated into targets and means of achieving them. Therefore, the legal framework may well be willing to protect a particular nonmarket issue but also want a mechanism that allows the application of a clear and transparent standard of assessment. Thus, the use of a market rationale in order to evaluate a conflict between market integration and a particular regulatory choice may also partly just be about simplifying the application of the rules, rather than a way of saying that nonmarket issues only count if they can be perceived in terms of the market. ${ }^{215}$ For example, in state aid, there can be no room for the more subtle elements of the relationship between the state and a debtor in judicial review. There are good reasons for a purely functional, consequentialist evaluation of this relationship since recognising or allowing trust and informal considerations to rule the relationship between the state and its debtors would simply be too amorphous for judicial review to pick up and raise problems for the transparent application of the state aid rules. ${ }^{216}$ That is to say, trust and informality are just a step away from the granting of advantages for protectionist aims.

However, this argument does run into difficulty, as pointed out by Höpner and Schäfer, if it is clear that the valuation that is implicit in market derived standards

${ }^{213}$ G. Majone, Dilemmas of European Integration. The Ambiguities and Pitfalls of Integration by Stealth, (Oxford: Oxford University Press 2005) 191.

214 Ibid.

215 This is, as such comparable to the so-called type I or type II errors that recognizes the inevitable tradeoff involved in the design of any system that pursues justice. We may attempt to set our standards as high as we can, but somewhere a balance must be struck, lest the system will become unworkable by making it too difficult to e.g. pass sentence on the majority of wrongful offenders.

${ }^{216}$ G Davies, 'Democracy and Legitimacy in the Shadow of Purposive Competence' 21(2015) European Law Journal at p. 2. 
have a direct and potentially structural impact on a variety of social measures and identity within Member States. ${ }^{217}$ As was discussed before, the adjudication of the Court, becomes a form of social ordering in as fat as it sets the conditions under which certain policy within Member States is restrictive. ${ }^{218}$ It determines how the relationship between the social and economic sphere is to be governed and the adjudicative determinations of the Court regarding this relationship will normally enter in some degree into the future relationship between these two spheres in the internal market. Therefore, those who favour legal approaches based on unitary kinds of valuation must realise that this approach is only a means of overcoming institutional challenges and does not reflect a complete understanding of the nuances of the problems involved. ${ }^{219}$ A completely functional and under-socialised model of adjudication could threaten the social cohesions, solidarity or identity that a state pursues. A liberal society such as the EU aspires to be contains a diversity of social spheres - e.g. families, markets, politics, religious organizations - and (should) make, space for different kinds of valuation. ${ }^{220}$

As was discussed above, the literature on varieties of capitalism provides a further normative underpinning for the argument in favour of social diversity amongst Member States in the Union. In short, that literature demonstrates that institutions are shaped not only by a legal system. The informal rules or common knowledge that is acquired by actors on the basis of the history and culture of nations leads to a variety of capitalist organisation. ${ }^{221}$ The development of "institutional complementarities", i.e. the development of complementary institutions amongst different spheres means that the insertion of elements of one variety into the fabric of the other can have disintegrative effects. ${ }^{22}$ This builds on the idea that the diversity of preferences and orientations in the EU is the product of specific historical experiences, political contestation, societal learning and

17 M. Höpner and A. Schäfer (above no. 21), 445.

218 See Fuller and Winston above (no. 63) at 353.

219 See Sunstein above (no 212).

220 On social differentiation and valuation in law see also Sunstein above (no 212) at 782.

${ }^{221}$ P. A. Hall and D. W. Soskice above (no. 92); P.A. Hall above (no. 93), 1223-1243.

222 See Hassel above (no. 95). 
continuous political decision-making. ${ }^{223}$ Hence, consequentialist evaluations that demand a 'one-size-fits-all philosophy' are 'normatively flawed because of its disregard of the normative infrastructure of the economy,224. In this way the normative fabric of the economic orders within Member States can be seen as their "social acquis", which should be recognised within EU law. ${ }^{225}$

The above is to some extent reflected in the words of Court of Justice judge Koen Lenearts, "beyond a core nucleus of shared values where the ECJ must ensure uniformity, EU law cannot disregard the cultural, historical and social heritage that is part and parcel of national constitutional traditions. Beyond that core nucleus, the ECJ welcomes "value diversity",. ${ }^{226}$ However, the point where exactly that dividing line falls remains subject of much controversy. ${ }^{227}$ Clearly, a problem for adjudication and a commitment to social diversity within the multilayer governance context of the Union is that plurality may be bought at the price of allowing too much. Internal market adjudication therefore needs coherent approaches to avoid that social diversity turns into a carte blanche for communities who prefer their own values at the expense of other Member States.

However, if we indeed accept the argument that social diversity is a value that the EU internal market is committed to then market derived utilitarian standards are not appropriate means to adjudicate conflicts in every situation, despite the highlighted value of administrability. It can be discussed whether the fact that many restrictive Member State regulations perish within the evaluative framework of the Court is because Member States themselves do not really understand the functions

${ }^{223}$ As submitted by C. Joerges, 'Market Integration and Europeanisation of Private Law', Jean Monnet Project Conference Paper (May 2015), on file with author

${ }^{224}$ Ibid., p. 6.

${ }^{225}$ As defended by Scharpf, F.W. (2015). After the Crash: A Perspective on Multilevel European Democracy, European Law Journal 21 (2015), 384-405; M. Höpner and A. Schäfer, 'A New Phase of European Integration: Organized Capitalisms', 33(2010) West European Politics p. 344-368; W. Streeck, , 'E Pluribus Unum? Varieties and Commonalities of Capitalism”, (2010) Cologne: MPIfG Discussion Paper $10 / 12$.

${ }^{226}$ K. Lenaerts, "The Court's Outer and Inner Selves: Exploring the External and Internal Legitimacy of the European Court of Justice" in H. Clemens et al. (eds), Judging Europe's Judges : The Legitimacy of the Case Law of the European Court of Justice (Hart, 2013), p. 13-60.

227 S. Weatherhill, "The Court's Case Law on the Internal Market: 'A Circumloquacious Statement of the Result, Rather than a Reason for Arriving at It'?”, in H. Clemens et al. (eds), Judging Europe's Judges: The Legitimacy of the Case Law of the European Court of Justice (Hart, 2013), p. 104. 
of their own laws, nor defend them well, ${ }^{228}$ or whether the problem is in to the way the Court has chosen to frame things, for example in consequentialist, purposive terms ${ }^{229}$ which simply fails to capture and weigh the true social significance of some restrictive rules. It is probably a bit of both and this thesis will explore how the adjudicative rationale of the Court can be made consistently more responsive to accommodate Member State diversity and promote the objectives of the internal market; an integrated market that is responsive to a Member State's plural set of social contexts. ${ }^{230}$ Concomitantly, this approach will provide an answer to Somek's fundamental question and add to the constitutional debate based on the argument of transnational effects.

Another point is that utilitarian standards tend to obscure the commensurability issue by assuming that different values or objectives are commensurable and thereby fail to reveal what is at stake in many areas of internal market law. There is on this point an expressive function of internal market law that is potentially lost if utilitarian standards dominate the legal analysis. This is directly related to the previously submitted social purpose for EU internal market law. It was submitted that the social purpose is concretised in the respect and accommodation of social diversity amongst Member States, whilst promoting the objectives of the internal market by scrutinizing the internalization of the transnational effects of Member State social measures. The expressive function of internal market law is then to unveil normative conflicts in order to illuminate what is at stake in internal market conflicts. ${ }^{231}$ Questioning and demanding articulation of restrictive regulatory choices within legal frameworks may be an excellent starting point for a dialogue that aims to increase the distinct articulation and thereby assists in the identification of embedding organizational principles on the Member State level. The 'dialogue of

${ }^{228}$ See G. Davies above (no. 216) and G. Davies above (no. 19).

229 Ibid.

${ }^{230}$ This would be a rationale that is in tune with the Lisbon judgment of the German Federal Constitutional Court Case 2 BvE 2/08 et al Lisbon [2009] where it decided that EU law can be rejected i fit would limit the sovereignity of the state to an extent that it can no longer define the socio economic circumstances of its citizens.

231 On the expressive functions of law see also Sunstein (no. 210). Also on this M Dani, 'Rehabilitating social conflicts in European Public Law', (2012) 18 European Law Journal p. 621 
mutual responsiveness' is therefore based on the idea that internal market law is a means to start a conversation with Member States on the normative choices of restrictive laws and regulatory choices, which requires on one side a responsiveness within the application of internal market law and, on the other side, a clear understanding and articulation of restrictive objectives that are pursued on a Member State level. How responsiveness can be integrated within the legal framework of the internal market and what the proxies and requirements are for the articulation of regulatory choice shall be explored in the next chapters. The balance that needs to be struck therefore is to establish, with sufficient subtlety for the values at stake, which evaluative rationality is most suitable for the situation that is to be adjudicated. An understanding of problems of incommensurability within internal market adjudication will make it easier to see what is at stake and guide a court in its choice for an evaluative rationale that is congruent with the social context that is being adjudicated. The existence of a genuine norm conflict can guide the Court in choosing an evaluative rationale and instruct about the appropriateness of adopting an evaluative framework based on strict proportionality versus procedural proportionality; or instruct a categorisation definition regarding the pursuit of sustainability in terms of a restriction on competition; or, similarly, if the granting of selective regulatory advantages should qualify as state aid. ${ }^{232}$ Each of these choices has an effect on whether the evaluative framework of the Court is based on utilitarian standards that prescribe certain substantive outcomes or whether the evaluative rationale shifts to a more procedurally based test. ${ }^{233}$ In other words, each has an effect on the extent that diversity is tolerated in the internal market. This shall become clear in the following chapters that will discuss these choices and their effects extensively and more explicitly on the basis of case law of the European courts.

\footnotetext{
232 On balancing, categorization as adjudicative techniques adopted by the Court of Justice see E. Cloots, National Identity in EU Law, (Oxford: OUP 2015).

${ }^{233}$ On the latter also H. Schepel, The Constitution of Private Governance: Product Standards in the Regulation of Integrating Markets (Hart Pub 2005); H. Schepel, 'Delegation of Regulatory Powers to Private Parties under EC Competition Law: Towards a Procedural Public Interest Test' (2002) 39 Common Market Law Review 31.
} 
As such, the proposed normative-prescriptive model of adjudication seeks to serve various purposes. Above all, it seeks responsiveness to social context in the adjudicative model of the Court. However, in that process, the expressive value of internal market law will become apparent since the substantive scope and reach of the internal market will be established; to what extent the internal market can substantively accommodate social claims, and when objectives become inherently irreconcilable with the objectives pursuit on the basis of market integration. The basic point then is that adjudicative rationales should respond to such a finding of irreconcilability. The exercise of the Court to find this 'switch' between evaluative principles that are congruent with the underlying social context, without losing sight of internal market objectives, is coined as responsive adjudication and the studies in the following chapters will aim to trace fragments of such responsiveness in the case law of the Court. Subsequently the intention of this study is to consistently reconstruct that case law into a coherent model of social legitimacy in which the valuation that is reflected on the basis of an adjudicative rationale of the court interacts constructively and in congruence with the social context that is being adjudicated. This allows the Court of Justice to implement an 'operational rationale' whenever it has to adjudicate a conflict between the objectives of market integration and restrictive domestic (social) interests.

\section{Outlook for the thesis: the research agenda}

This chapter developed an argument that shall be unfolded further in the coming chapters of the thesis. Social legitimacy has been dissected as to its meaning and function in a multilevel context such as the EU. It can be concluded that social legitimacy, as a concept, has been introduced specifically to emphasize the reciprocal relationship between global market integration and the locality of the social. Tracing the concept back to Polanyi, the idea of social legitimacy becomes a necessity for a political sustainable project that seeks supranational market integration. The balance between the requirements from the EU internal market for Member States regulatory choices, whilst at the same time respecting the 
'fundamental structures' that exist in the Member States (article 4(2) TEU), through a recognition of a diversity of regulatory options, is one of the structural challenges faced by the internal market project. ${ }^{234}$ What is targeted in this thesis are the potential underlying fixed value choices that are implicit in the different modes of EU governance and may pull towards the adoption of rationalities in the evaluation of Member State action that disregards the social diversity and value pluralism that is inherent in the EU polity. This would not be in alignment with the current values and objectives structure of the EU that points towards the importance of institutionalising diversity. The quest for a combination of both an economic and social purpose for the EU has been there for a long time. It is argued that the 'key' of understanding this dynamic lies in terms of a dialogue of mutual responsiveness and it has a constitutional basis. The constitutional evolution has led to an obligation to integrate a rationale of responsiveness towards social diversity within the EU internal market governance mechanisms.

In a nutshell, within this context, social legitimacy places specific requirements on the selection and application of adjudicative rationales, depending on whether the objects of governance originate from different or within the same normative order(s) and provides a conceptualisation of a structural alternative model of internal market adjudication to account for social interests within an integrating European market. Social legitimacy can be derived from a rationale that manages to distinguish voices within Member States that are embedding a social fabric from the voices that are to be embedded within the EU internal market fabric. Social legitimacy is foregone when rationales apply an atomized, undersocialized conception of, for example, rational Member State action and discards complex social context that embeds economic activities.

Foremost, clarity in the framing of the economic and social purpose and potential incommensurable conflicts between these potentially conflicting aims is needed in order to instruct adjudication. The following chapters illustrate that it is

234 See on this point also A Somek, 'The social Question in a Transnational Context' LSE "Europe in Question” Discussion Paper series, June 2011. 
specifically the lack of this clarity that may undermine the required social legitimacy for the EU. In this way social legitimacy can be connected to the constitutional theory of transnational effects, which, as argued, derives the legitimacy of the internal market project from its ability to govern social diversity in a responsive manner, requiring explicit responsiveness both from Member States in view of their commitments to the internal market and from the internal market in the sense that it needs to be positioned within Member State's differing sets of social contexts. Indeed, implementing the idea of mutual responsiveness favours a constitutional conception of the EU legal system that is living, dynamic and a recognition that the EU constitution can and should grow and adapt to changing circumstances without losing its identity and retaining its social legitimacy. ${ }^{235}$

It has been argued that based on the social purpose of the EU internal market as one of providing an infrastructure for constructive interplay of norm conflicts, the idea of mutual responsiveness is an idea that should stand central to questions as regards the balance between market integration and social objectives. From the perspective of the supranational trade regime it is therefore necessary to answer the question what market integration can legitimately prescribe to Member States in terms of substantive outcomes, e.g. the less restrictive or more efficient measure and where the limit to that normative prescriptive power should be set and in what way in order to allow for social diversity. Conversely, social interests that are restrictive of the supranational trade interests will have to incorporate a certain responsiveness to integration objectives. The thesis is concerned with developing a model of social legitimacy for the Court to adjudicate such conflicts and to provide an 'operational rationale' under the heading of responsive adjudication

The following chapters of this thesis will look at the main areas of law of the EU internal market: free movement, competition and state aid. Each of these chapters shall identify how the social sphere manifests itself in that area of law and to what extent the supranational rules are able to accommodate social diversity and

235 See also M Dawson and F de Witte (2013) 'Constitutional balance in the EU after the Euro-crisis', Modern Law Review, 76 (2012), p. 817-844. 
to what extent they threaten it. Each chapter shall identify, with regard to the mentioned areas of law, deficiencies in the extent that the dialogue of mutual responsiveness takes place. Questioning and demanding articulation of restrictive regulatory choices within legal frameworks may be an excellent starting point for a dialogue that aims to increase the distinct articulation and thereby assists in the identification of embedding organizational principles on the Member State level. Each chapter shall also develop a rationale of mutual responsiveness for the area of law under investigation. Developing this rationale of responsiveness in internal market law will be of discursive, formative value for the EU project as a whole. In developing a rationale of responsiveness the substantive scope and reach of the internal market will be established. That is to say, to which point the internal market can accommodate social claims and from which point objectives become inherently irreconcilable. Therefore, the overarching ideas is the struggle between market integration and social locality should be cherished as a potential source of deliberative and formative potential for the expressive value of internal market law. ${ }^{236}$

${ }^{236}$ As argued also by Dani (above no. 231). 


\section{CHAPTER II}

\section{Social legitimacy in EU free movement law}

I. Introduction

II. Problematisation: Valuation, indeterminacy and incommensurability in free movement adjudication

A. The organizational principles of EU free movement law 80

$B$. The expedient 'rights inflation' proportionality model in EU free movement adjudication 84

i. The basic structure 84

ii. The unqualified market access test as a means to frame the free movement conflict 85

iii. The structure of proportionality 96

III. Responsiveness in the proportionality analysis of the Court in free movement 99
A. Introduction
B. Substantive efficiency model 100
C. The margin of discretion model 106
D. The procedural good governance model 109
E. Incoherence in the application of the different rationales $\quad 120$

IV. A dialogue of mutual responsiveness: the interplay of principles of substantive efficiency, margins of discretion and good governance in free movement adjudication 123

A. Between managerialism, margins of discretion and good governance: A responsive model

B. Reframing exemplary free movement cases within the proposed rationale

i. Volkswagen: valuing the "social acquis" of a Member State within the internal market

ii. Omega: the importance of mutual responsiveness in the pursuit of legitimate objectives 130

iii. Viking: resolving the fundamental tension of the internal market on the basis of a dialogue of mutual responsiveness 


\section{Introduction}

Chapter I discussed that Member States have committed themselves to market integration and that the main requirements of EU free movement law are clear, such as the textbook examples of the prohibition of quota's, custom duties and protectionist schemes, but a lot of contentions questions remain. A lot of these contentious issues originate from the significant expansion in scope of all the free movement provisions over the last two decades. ${ }^{1}$ Although Member States have been allowed to increasingly add substance to what can be considered as legitimate overriding objectives to rights of free movement, the Court of Justice has concomitantly been increasingly strict in the application of its proportionality analysis. ${ }^{2}$ Moreover, the increase in scope has led to an increase of controversial outcomes in the case law of the Court. ${ }^{3}$ In particular, the terms of the dialogue between the 'noneconomic social' and the requirements of market integration as set by the Court are increasingly contested. ${ }^{4}$ There is no apparent operational principle available to the Court to balance these types of conflicts, between Member States social objectives and the requirements of the internal market. ${ }^{5}$

It is on this point, specifically, that this chapter seeks to contribute. That is to say, through a perspective that goes beyond emphasizing either (i) the importance for EU law to respect the structures that are expressive of Member State choices, which embed the pursuit or protection of social objectives ${ }^{6}$ or (ii) the requirements

1 Generally good overview of issues in E. Spaventa, 'From Gebhard to Carpenter: Towards a (non-) economic European constitution' (2004) 41 Common Market Law Review, Issue 3, pp. 743-773 and in Francesco De Cecco, Chapter 2 'The Constitutional Framework', in State Aid and the European Economic Constitution (Oxford: Hart. Publishing, 2013)

2 Inter alia C. Barnard, "Derogations, Justifications, ad the Four Freedoms: is State Interest Really Protected?" in Barnard and Odudu (eds), The Outer Limits of European Union Law (Oxford, hart Publishing, 2009) 273.

3 E.g Nic Shuibhne, N Maci, 2013, 'Proving Public Interest: The Growing Impact of Evidence in Free Movement Case Law', Common Market Law Review, vol 50, no. 4, pp. 965-1005.

4 E.g. C Joerges and F Rödl, "Informal Politics, Formalised Law and the "Social Deficit" of European Integration: Reflections after the Judgments of the ECJ in Viking and Laval' (2009) 15 European Law Journal 1-19

5 See L Azoulai, 'The Court of Justice and the Social Market Economy: The Emergence of an Ideal and the Conditions for its Realization' (2008) 45 Common Market Law Review, p. 1335

6 Most clearly F Scharpf F.W, 'Negative and Positive Integration in the Political Economy of European 
for Member States to open up these embedded structures in order to develop towards a post-national constellation that remedies potential democratic deficits ${ }^{7}$. What is required and pursued, instead, is a holistic approach to the issue, recognising the interdependence of both central facets for the structure and development of the internal market in a mutually responsive manner. I discussed in the fist chapter that this exercise is endowed with constitutional relevance, reflected in Articles 3 and 4(2) TEU. Article 3 TEU sets out a dual commitment to both promote the objectives of the internal market and the objectives of sustainability, social inclusion/cohesion and a social market economy. The objectives of the internal market are supranational and require responsiveness from Member States, whilst objectives normally associated with sustainability, social inclusion/cohesion and a social market economy predominantly find their origin within Member State national identities and regulatory structures and are therefore by nature diverse. It is the latter that Article 4(2) TEU is particularly concerned with, by carving out the general commitment of the Union to 'respect' national identities of Member States that are inherent in their national, regional and local, fundamental political and constitutional structures. The rationale adopted in the legal review of objectives that are restrictive of market access may implicitly or explicitly pursue objectives that are incommensurable with the diversity of social context within Member States. It is in EU free movement law that this field of tension, between supranational market integration and local structures, reflective of social identity and diversity, comes to fore most clearly. As such, this chapter speaks to what can be considered a - if not the - central point of tension in EU free movement law adjudication.

Welfare States' in G. Marks, F.W Schaprf, P. Schmitter and W. Streeck (eds) Governance in the European Union (London Sage publication 1996) at p. 15; F.W. Scharpf, 'The asymmetry of European integration, or why the EU cannot be a "social market economy" (2009) 8, Socio-Economic Review, pp. 211-250 ;

Inter alia M Maduro, We the Court: the European Court of Justice and the European Economic Constitution (Oxford, UK and Evanston, Ill, Hart Publishing and Northwestern University Press, 1998), overview of this narrative and fundamental critique in A Somek, 'The Argument from Transnational Effects I: Representing Outsiders through Freedom of Movement' (2010) European Law Journal 315, referring to C. Joerges and J. Neyer, “Deliberative Supranationalism” Revisited', (2006) 2006/20 EUI Working Paper Law 2 as the 'inventors' of this perspective on EU free movement law. 
However, in the field of free movement adjudication, the EU internal market project has been a, seemingly, one-sided affair, primarily concerned with the question how social structures within Member States are required to accommodate market access rights that flow from the free movement rules. ${ }^{8}$ Exemplary of this relationship is the syntax of the Court in the area of free movement law that, on the basis of an unqualified market access test, captures most regulatory structures and social interests as potential restrictions, whilst requiring justifications of these structures and interests within a strict evaluative framework. As argued in the previous chapter, the normative claim of social legitimacy in the context of the multilevel governance context of the EU internal market is that a reconciliation of local domestic social values within supranational market objectives requires a form of explicit responsiveness to social context. The claims of social legitimacy were partly constructed on the basis of the ideas of Karl Polanyi, who's historical analyses of transformations in state-market-society relationships provides a normative foundation for the idea that an overly functional and under-socialised model of adjudication could threaten the social cohesion, solidarity or identity that a state pursues. A liberal society, such as the EU purports to be, contains a diversity of social spheres and (should) accordingly make, space for different kinds of valuation of those spheres. ${ }^{9}$ This chapter explores the adjudicative model(s) of the Court of Justice in free movement cases from this normative perspective. The exercise of the Court to find evaluative principles that are congruent with the underlying social context, without losing sight of internal market objectives, is coined as responsive adjudication. The intention of this study is to consistently reconstruct that case law into a coherent model of social legitimacy where the valuation that is reflected within the adjudicative rationales of the Court of Justice interacts constructively and is in congruence with the social context that is being adjudicated.

\footnotetext{
8 The scope of the chapter is limited to 'market origin rights' versus regulatory choices of Member States. That excludes individual based rights such as is citizenship and some free movement of persons and workers lines of case law from the scope of this chapter.

9 Chapter I section II.
} 
A short outlook for the chapter: Section II looks at the existing adjudicative template that the Court adopts in free movement adjudication and discusses how the 'valuation' of free movement conflicts within that template may lead to issues of incommensurability and consequent problems with the normative claims purported by social legitimacy. Section III looks more specifically at the current adjudicative techniques developed by the Court to govern this field of EU law in terms of ideal type models. It will be demonstrated that the Court has created different standards of evaluation towards restrictive social context but that responsiveness is currently lacking, in any coherent form, in the adjudicative models developed by the Court in EU free movement law. Section IV gathers these approaches and considers how they could be reconstructed into a model of adjudication that is more in tune with the normative claims of social legitimacy. It turns out that the essential features of the proposed alternative are visible in the case law of the Court but in order to adjudicate in a socially legitimate way the Court will have to fundamentally reconsider its model of adjudication. The chapter introduces a rationale of responsiveness that recognises norm collisions and instructs the selection and application of adjudicative models, depending on the absence or presence of an irreconcilable conflict between normative principles. ${ }^{10}$ On this basis the case law of the Court can be rationalised, restructured and become responsive to Member State diversity. The normative rationale of responsiveness leads to a restructuring of the case law on the basis of the notion that the social legitimacy of EU free movement law depends on a legal framework that does not suppress but allows a diversity of embedding organizational principles to exist and allows them to constructively interact within overarching legislative frameworks. Section $\mathrm{V}$ concludes that the development of an adjudicative rationale that manages to distinguish between normative organizing principles has the potential to contribute significantly to the social purpose of the EU internal market project.

10 Normative principles are understood in this context as justification narratives that reflect any system of rules and shared expectations governing a particular social context. See further J.Scott and G. Marshall, 'A Dictionary of Sociology', (OUP 2009). 


\section{Problematisation: Valuation, indeterminacy and incommensurability in free movement adjudication}

A. The organizational principles of EU free movement law

The supranational market rationale that EU free movement rules purport in its most simplistic form is concerned with an area without internal frontiers, in which the free movement of goods, persons and capital is ensured in accordance with the provisions of the Treaties (Art. 26 TFEU). Free movement rules pursue as much market access as possible and therefore set out to challenge obstacles to trade. However, the EU Treaties have always allowed national measures to take precedence over free movement when they serve important interests recognized by the Union, including national identity. In addition, the Court has developed a range of mandatory requirements (Cassis de Dijon ${ }^{l l}$ ) as 'public interest requirements' or 'objective justifications'. Free movement law recognizes explicitly that in the absence of EU harmonization and in so far as there are no national measures producing a protectionist effect, Member States enjoy leeway in safeguarding national interests, which are deemed fundamental to their identity. ${ }^{12}$ Beyond the "core nucleus of shared value", the Court "welcomes value diversity". ${ }^{13}$ However, controversy accumulates around the question where exactly that dividing line falls. $^{14}$

The social critiques that were discussed in the previous chapter mostly originate from this controversial case law in the area of EU free movement law. As was discussed in section II of the first chapter, these critiques tend to identify a structural bias of the Court in favour of market access and deregulation. It is true

11 Case 120/78, Rewe-Zentral AG v Bundesmonopolverwaltung für Branntwein [1979] ECR 649.

12 H. Clemens et al. (eds.), Judging Europe's Judges: The Legitimacy of the Case Law of the European Court of Justice (Hart, 2013).

${ }^{13}$ K. Lenaerts, "The Court's Outer and Inner Selves: Exploring the External and Internal Legitimacy of the European Court of Justice" in H. Clemens et al., Judging Europe's Judges : The Legitimacy of the Case Law of the European Court of Justice (Hart, 2013), p. 13-60.

14 S. Weatherhill, "The Court's Case Law on the Internal Market: 'A Circumloquacious Statement of the Result, Rather than a Reason for Arriving at It'?", in H. Clemens et al., Judging Europe's Judges : The Legitimacy of the Case Law of the European Court of Justice (Hart, 2013), p. 104. 
that in most cases before the Court, where there is found a restriction on free movement, pursuant to the pursuit of a regulatory objective, the conflict is decided in favour of the EU free movement objectives. Such claims are concretized on the basis of controversial free movement cases such as Centros, Überseering and Inspire $A r t^{15}$ that are critiqued for allowing companies to circumvent national codetermination procedures in Germany by establishing themselves in the UK or the Cadburry Schweppes type cases ${ }^{16}$ that would allow tax-avoidance practices by companies, and perhaps most prominently in the socially salient cases of Laval, Viking, Ruffert, Luxemburg and more recently Occupational pensions and Herron, 17 which have resulted in a strong believe that fundamental social interests are structurally valued as being subordinate to rights to free movement. ${ }^{18}$

The most obvious valuation bias is found to exist in the legal fact that restrictions on free movement of economic actors are applied so as to include almost all regulatory rules within Member States with a cross border interest, which then have to be justified and accompanied by an analysis of the appropriateness and proportionality of the measures and by specific evidence, substantiating the claims

15 Case C-212/97, Centros Ltd v Erhvervs- og Selskabsstyrelsen [1999] ECR I-01459; Case C-208/00, Überseering BV v Nordic Construction Company Baumanagement GmbH [2002] ECR I-09919; Case C-167/01, Kamer van Koophandel en Fabrieken voor Amsterdam v Inspire Art Ltd. [2003] ECR I10155.

16 C-196/04, Cadbury Schweppes [2006] ECR I-07995.

17 Case C-341/05 Laval un Partneri [2007] ECR I-11767; Case C-438/05 Viking Line [2007] ECR I10779; Case C-346/06 Rüffert [2008] ECR I-01989; Case C-319/06 Commission/Luxemburg [2008] ECR I-04323; Case C-271/08 Occupational pensions [2010] ECR I-07091; Case C-426/11 Herron [nyr].

18 A selection; C Barnard, 'Viking and Laval: An Introduction' (2007-2008) 10 CYELS 464; A Dashwood, 'Viking and Laval: Issues of horizontal Direct Effect' (2007-2008) 10 CYELS 525; A Davies, 'One Step Forward, Two Steps Back? Laval and Viking at the ECJ' (2008) 37 ILJ 126; S Deakin, 'Regulatory competition after Laval' (2007-2008) 10 CYELS 581; C Kilpatrick, 'Laval's Regulatory Conundrum: Collective Standard-Setting and the Court's New Approach to Postal Workers' (2009) 34 ELRev 844; C Joerges and F Rödl, 'Informal Politics, Formalised Law and the "Social Deficit" of European Integration: Reflections after the Judgments of the ECJ in Viking and Laval' (2009) 15 ELJ 1; J Malmberg and T Sigeman, 'Industrial Action and EU Economic Freedoms: The Autonomous Collective Bargaining Model Curtailed by the European Court of Justice' (2008) 45 CMLRev 1115; T Novitz, 'A Human Rights Analysis of the Viking and Laval Judgments' (2007-2008) 10 CYELS 541; S Sciarra, 'Viking and Laval: Collective Labour Rights and Market Freedoms in the Enlarged EU' (2007-2008) 10 CYELS 563; P Syrpis and T Novitz, 'Economic and Social Rights in Conflict: Political and Judicial Approaches to their Reconciliation’ (2008) 33 ELRev 411. 
made. ${ }^{19}$ The argument is made that, as a result of the trade bias, there exists a structural preference in favour of deregulation that is targeted against specific, or perhaps better described as claims to, social organizational forms at the Member State level, which challenge the legitimacy of the EU internal market project. ${ }^{20}$

The first chapter described how the argument from transnational effects (re)contextualizes this as a subtle and constructive means towards a new transnational democratic nation state, one that is particularly sensitive towards the interests of entities that fall outside of its direct political reach and procedures. Within this perspective, a wide interpretation of the scope of free movement provisions is adopted for the purpose of placing constitutional limits on State interventions in the market, not for the purpose of the market but for considerations related to the accommodation of interests that are not part of national democratic governance structures. ${ }^{21}$ In other words, the ambitions of the EU free movement rules are not 'market' oriented but aim to achieve integration amongst otherwise defunct national democracies. However, Somek highlighted that the conceptual apparatus to achieve this integration is based on economic due process or efficiency considerations, ${ }^{22}$ with the effect that social objectives within Member States may be forced to fit within a model that disregards their constituent features.

The balance that is arguably to be found in EU free movement adjudication is exactly the dividing line between those organizational principles within Member States that are embedding a social fabric from those that are to be embedded within the EU internal market fabric. The Polanyian rationale, as it was introduced in the first chapter, does not exclude the efficiency and liberty rationales of the market as an overarching framework to determine this. Questioning and demanding

19 N.N. Shuibhne, N Maci, 'Proving Public Interest: The Growing Impact of Evidence in Free Movement Case Law', Common Market Law Review, 50(2013), p. 965-1005.

20 See Joerges and Rödl (no. 18 above); S. Buckel and L. Oberndorfer, 'Die lange Inkubationszeit des Wettbewerbs der Rechtsordnungen - Eine Genealogie der Rechtsfälle Viking/Laval/Rüffert/Luxemburg aus der Perspektive einer materialistischen Europarechtstheorie' in A.F. Lescano, F. Rödl and C. Schmid (eds), Europäische Gesellschaftsverfassung. Zur Konstitutionalisierung sozialer Demokratie in Europa (Nomos 2009); see also Somek above (no.7).

21 See Maduro above (no. 7).

22 See Somek above (no. 7). 
articulation of restrictive regulatory choices within legal frameworks may be an excellent starting point for the dialogue of mutual responsiveness that aims to increase the distinct articulation and thereby assists in the identification of embedding organizational principles on the Member State level. There exists an expressive function for free movement law in this respect. However, the argument presented in this chapter posits that the absence of a clear rationale to find this dividing line is exactly what undermines social legitimacy of the EU internal market project because it fails to identify genuine norm conflicts in free movement cases. This point shall be further developed below.

The normative claim of social legitimacy, as it was developed in the previous chapter, in the context of the multilevel governance context of the EU and the internal market is that a reconciliation of local domestic social values within supranational market objectives requires a form of explicit responsiveness to the social context that is being adjudicated. Moreover, it was highlighted with reference to the historical analysis of Polanyi that in the context of market integration there is a risk that dominating market based rationales will ignore and crowd out alternative legitimate social purpose. In the context of adjudication these normative demands boil down to the issues of valuation in law and the related problem of commensurability. Evaluative standards that are adopted in adjudicative contexts may translate social realities within a metric that risks doing violence to potentially genuine and worthwhile aspects of those objectives. This is the type of incommensurability that is central to the normative lens in the thesis. When the evaluative standard adopted by the courts results in a situation where objectives pursued by Member States cannot be aligned along the evaluative metric without doing violence to the potentially genuine and worthwhile aspects of those objectives.

Therefore, although Member States need to accommodate out of state interests by committing themselves to the integrating supranational market, the internal market principles will need to accommodate Member State diversity. The latter means, rather subtly, that the evaluating models that the Court adopts should be responsive to Member State objectives that are legitimate but incompatible with 
the rationale of the normative principle that the internal market purports in a specific case. This responsiveness is to be found in the selection of an evaluative framework to come to a conclusion of a conflict and the explicit articulation of irreconcilable normative conflicts.

In the next sections I shall distil these principles from what can be seen as 'ideal type' models of adjudication that the Court has developed within this central field of tension, between market integration and social spheres within Member States, and classify the evaluative techniques the Court has developed. It will be demonstrated that the case law of the Court does not follow any particular settled adjudicative rationale to determine the more contested requirements that free movement law purports. ${ }^{23}$ Nor is there any ideological agenda or explicit bias at work. Before making sweeping statements about the effects of this case law or the agenda of the Court, it is important to look in some detail at the structural adjudicative techniques that the Court employs in EU free movement law to distil some continuing and current trends in the adjudicative techniques employed by the Court.

B. The expedient 'rights inflation' proportionality model in EU free movement adjudication

\section{i. The basic structure}

There is a certain inherent and continuing structure in the free movement case law of the Court that follows partly from the structure of the Treaty and partly from precedent based case law. ${ }^{24}$ The template of the Court of Justice consists of three separate steps: (i) is there a restriction on a free movement right?; (ii) is there a legitimate justification for the restriction?; (iii) can the restriction be considered proportionate with regard to its legitimate objectives? This template leads to a particularly characteristic syntax of the case law of the Court in EU free movement

23 Eg the 'centralised', ' competitive' and 'decentralised' models of Maduro above (no. 7).

24 As highlighted for example in L Azoulai, 'The Court of Justice and the Social Market Economy: The Emergence of an Ideal and the Conditions for its Realization' (2008) 45 CMLRev at p. 1335. 
law that is largely standardized, but only to the point that inherently conflicting objectives need to be evaluated and prioritised. Importantly, the starting point of the adjudicative model developed by the Court is to apply a broad and unqualified market access test for all free movement rights, ${ }^{25}$ which imposes jurisdiction over most Member State regulatory choices that can be considered restrictive to economic activities, and to then, in a second stage, resolve conflicts in the course of a proportionality exercise. Whilst originating from the area of goods, the Dassonville formula, "all trading rules enacted by Member States which are capable of hindering, directly or indirectly, actually or potentially, intra-community trade", ${ }^{26}$ applies to all other freedoms as well. ${ }^{27}$ Despite being concerned with the free movement of goods, the Keck approach provided for regulatory rules to fall outside of the reach of the free movement rules, in case they qualified as 'certain' nondiscriminatory 'selling arrangements' and did not completely prevent market access ${ }^{28}$ today all freedoms appear to be converging towards a rather unqualified market access test. ${ }^{29}$ Below I shall dissect the function of this test in the adjudicative model applied in free movement cases by the Court of Justice.

\section{ii. The unqualified market access test as a means to frame the free movement conflict}

The establishment of a restriction appears to be an important step in the adjudication of conflicts within free movement law, because as said, most

25 See for a recent analysis I. Lianos 'In Memoriam Keck: The Reformation of the EU Law on the Free Movement of Goods', (2015) 2 European Law Review, More discussion on this adjudicative tool in G. Davies, "Understanding Market Access: Exploring the Economic Rationality of Different Conceptions of Free Movement Law," German Law Journal 11, no. 7-8 (2010) p. 671-704; E. Spaventa, "Leaving 'Keck' behind?: The Free Movement of Goods after the Rulings in 'Commission v Italy' and 'Mickelsson and Roos," European Law Review 34, no. 6 (2009) p. 914-32; J.Snell, "The Notion of Market Access : A Concept or a Slogan?," Common Market Law Review 47, no. 2 (2010).

26 Case 8/74 Dassonville [1974] ECR 00837, para. 5.

27 For services in case C-76/90 Säger v Dennemeyer [1991] ECR I-04221; for workers in case C-415/93 Union royale belge des sociétés de football association and Others v Bosman and Others [1995] ECR I04921; for establishment in in case C-55/94 Gebhard v Consiglio dell'Ordine degli Avvocati $e$ Procuratori di Milano [1995] I-04165; for capital in Case C-367/98 Commission v Portugal [2002] ECR I-04731.

28 Joined cases C-267/91 and C-268/91, Keck and Mithouard [1993] ECR I-06097.

29 See amongst others Spaventa above (no. 25). 
regulatory rules that are tested within the traditional syntax tend not to fulfil the proportionality criteria that come later. The move of the Court towards the adoption of a rather unqualified market access have been frequently critiqued ${ }^{30}$ and the contributions seem to agree that the Court has now 'refined' its approach in Keck in favour of a market access test, although it seems that the Court in free movement of goods cases still uses part of its Keck rationale. ${ }^{31}$

In the two cases that have served as the main signalling point for the shift of the Court towards this market access test, what seems to have been decisive is the question whether the measures in question touched directly on cross border movement. In Commission v Italy (trailers) ${ }^{32}$ the Court decided that the prohibition of specific trailers constituted a restriction (although it could be justified by reasons of road safety). The Court stated that, in addition to the principles of nondiscrimination and mutual recognition, Article 34 TFEU reflects the obligation to "respect the principle of ensuring free access of union products to national markets". ${ }^{33}$ As a result of the Italian rules, which completely banned motorcycle trailers from the road, the consumer demand for such trailers did not exist in Italy and, consequently, their importation to the market was directly hindered. The same approach was adopted in the case Mickelsson. ${ }^{34}$ Here the Court stated that Swedish rules, regulating areas where jet skis could be used left only marginal opportunities

30 For example, C. Barnard and S. Deakin, 'Market Access and Regulatory Competition', in C. Barnard and J. Scott (eds.), The Law of the Single European Market, unpacking the premises (Hart, 2002); Spaventa, above (no. 25) at 914; Davies above (no. 25) at 671; Snell above (no. 25) at 437; M.S. Jansson and H. Kalimo, 'De Minimis meets "Market access": transformations in the substance - and the syntax - of EU free movement law?', (2014) 51, Common Market Law Review, at 523.

31 See Case C-108/09 Ker Optika 2010, referring to Keck in paragraph 51: "For that reason, the application to products from other Member States of national provisions restricting or prohibiting certain selling arrangements is such as to hinder directly or indirectly, actually or potentially, trade between Member States for the purposes of the case-law flowing from Dassonville, unless those provisions apply to all relevant traders operating within the national territory and affect in the same manner, in law and in fact, the selling of domestic products and of those from other Member States. The application of such rules to the sale of products from another Member State meeting the requirements laid down by that State is by nature such as to prevent their access to the market or to impede such access more than it impedes the access of domestic products. (emphasis added)"

32 Case C-110/05 [2009] ECR I-519.

33 Ibid., para 34.

34 Case C-142/05 [2009] ECR I-04273 
for their use. Consequently, the restrictions could have considerable influence on the behaviour of consumers and, consequently, these rules affected market access. ${ }^{35}$

As such, it can be argued that the Court does provide for some qualifications to market access. ${ }^{36}$ Indeed, it can be argued that the Court, to some degree, has focused on the directness of market access hindrance, as confirmed, for example, also in the field of services and workers. ${ }^{37}$ For example, in Bosman the Court considered that a football transfer fee system qualified as a restriction by making a reference to the direct impact of a player's access to the employment markets of other member states. ${ }^{38}$ In Apline Investments the Court of Justice evaluated the legality of a Dutch measure preventing financial service providers from cold calling potential clients. ${ }^{39}$ The regulation was defended on the basis of its nondiscriminatory nature and that it could consequently be qualified as a selling arrangement. The Court disagreed, describing the measure as directly affecting access to the market in services in the other Member States. AG Tizzano agreed with this approach in Caixa Bank where he argued that the freedom of establishment is violated only if a measure either discriminates or directly affects market access. Therefore, importantly, this reasoning would imply that it is insufficient if a measure's only effect is to reduce profit margins and the attractiveness of the pursuit of an activity. ${ }^{40}$ That is because the latter could be seen to mean that the market access test provides for unlimited economic freedom. Similarly, AG Tesauro argued in the case Hünermund that "Article 34 does not provide for a general freedom to trade or the right to the unhindered pursuit of commercial activities, but is aimed at restrictions on imports". ${ }^{41}$ AG Maduro built on this by arguing in Alfa Vita that:

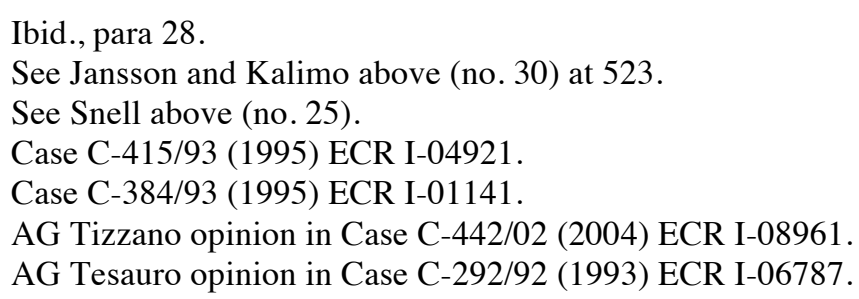


“...Community nationals cannot draw from this provision an absolute right to economic or commercial freedom. Indeed, the Treaty provisions relating to the free movement of goods aim to guarantee the opening-up of national markets, offering producers and consumers the possibility of fully enjoying the benefits of a Community internal market, and not to encourage a general deregulation of national economies....

...in the context of the establishment of an internal market, the fundamental objective of the principle of free movement of goods is to ensure that producers are put in a position to benefit, in fact, from the right to carry out their activity at a crossborder level, while consumers are put in a position to access, in practice, products from other Member States in the same conditions as domestic products. Such was the intention of the Treaty draftsmen; such has been the approach of the Court which has implemented it...

In such circumstances it is obvious that the task of the Court is not to call into question as a matter of course Member States' economic policies. It is instead responsible for satisfying itself that those States do not adopt measures which, in actual fact, lead to cross-border situations being treated less favorably than purely national situations". ${ }^{42}$

This opinion suggests that market access should be restricted in the sense that differences between regulatory regimes as such cannot lead to restrictions that trigger the free movement rules, unless they lead to cross border situations being treated less favourably than the national situation. However, recent case law demonstrates that when pressed, the notion is still likely to collapse into an very wide economic freedom assertion, much like the original Dassonville formula. ${ }^{43} \mathrm{~A}$ recent application in the case DKV Belgium explicitly illustrates the shortcomings of the market access test in this respect. ${ }^{44}$

The case concerned a Belgian authorization requirement for certain insurance premiums. According to Belgian law, insurers could only alter annually the premium on the basis of the consumer price index. If they would require higher premium increases, this could only be done after authorization from the banking, finance and insurance commission. These rules were aimed at protecting

42 AG Maduro opinion in joined cases C-158/04 and C-159/04 (2006) ECR I-08135.

43 Case 8/74 Dassonville, [1976] para. 5

44 Case C-577/11 DKV Belgium [2013] nyp 
consumers, particularly with a view to preventing them from being faced with sharp, unexpected increases in insurance premium rates. ${ }^{45} \mathrm{DKV}$ Belgium was denied an increase of its premium and challenged the system, alleging that it disproportionately infringed the free movement of services. Regarding the existence of a restriction the Court repeated the mantra that:

“the term 'restriction' within the meaning of Articles 49 TFEU and 56 TFEU covers all measures which prohibit, impede or render less attractive the freedom of establishment or the freedom to provide services". ${ }^{46}$

\section{However,}

"a measure applicable without distinction, such as the system of premium rate increases at issue in the main proceedings, may come within that concept, it should be borne in mind that rules of a Member State do not constitute a restriction within the meaning of the FEU Treaty solely by virtue of the fact that other Member States apply less strict, or more commercially favourable, rules to providers of similar services established in their territory..."

and

"the concept of restriction covers measures taken by a Member State which, although applicable without distinction, affect access to the market for undertakings from other Member States and thereby hinder intra-Community trade". ${ }^{4}$

The next logical step would now be for the Court to qualify the market access test since the mere fact that there exists a difference between regulatory regimes is clearly insufficient for that. The logical expectation would be to introduce some substantial criterion that would introduce differentiated impact, ${ }^{48}$ selectivity, ${ }^{49}$ de minimis ${ }^{50}$ or a perhaps even a return to a Keck type rule ${ }^{51}$ as a potential

45 Ibid., para. 9.

46 Ibid., paras. 31.

Ibid., paras. 32-33.

Snell above (no. 25) at 448 argues in favour of a differential impact test combined with market access.

49 Davies above (no. 25) at 685 offers selectivity as an alternative.

50 Jansson and Kalimo above no. 30) at 523.

51 P. Oliver, 'Of Trailers and Jet Skis: Is the Case Law on Article 34 TFEU Hurtling in a New Direction?', Fordham International Law Journal 33(2011), at 1469; see also P. Oliver, Free Movement of Goods in the European Community: under Articles 28 to 30 of the EC Treaty, (London: Sweet \& Maxwell 2003), 
qualification. However, the Court in this case seems to have been inspired mostly by the idea of AG Jacobs who argued in his opinion in the case Leclerc/Siplec, that the central concern of the treaty provisions on free movement is "to prevent unjustified obstacles to trade between Member States and if an obstacle to interstate trade exists, it cannot cease to exist simply because an identical obstacle affects domestic trade". 52 AG Jacobs argued that "restrictions on trade should not be tested against local conditions, which happen to prevail in each Member State, but against the aim of access to the entire Community market". ${ }^{53}$ This idea seems to have been the decisive one for the Court, which main consideration is worth citing in full:

"[...] a system of premium rate increases such as that at issue in the main proceedings is liable to dissuade insurance undertakings having their head office in a Member State other than the one which introduced such a system from opening a branch in that Member State or to offer their products there as part of the free movement of services. Those undertakings will not only have to change their terms and rates to meet the requirements imposed by that system, they will also have to determine their premium positioning and, therefore, their commercial strategy when they first set their premiums, with the risk that future premium rate increases will be insufficient to cover the costs with which they will be faced. It follows that insurance undertakings entering the market of a Member State which has introduced a system of premium rate increases such as that at issue in the main proceedings are obliged, if they want to be able to access that market under conditions which comply with the legislation of that Member State, to re-think their business policy and strategy [...]. In those circumstances, a system of premium rate increases such as that at issue in the main proceedings must be held to constitute a restriction on the freedom of establishment and the freedom to provide services". ${ }^{54}$ (emphases added)

The Court demonstrates here what unqualified market access entails and it is contradictory to the idea that regulatory differences as such do not entail, automatically, restrictions on freedom of movement as meant in the Treaty. ${ }^{55}$ Thus applied, any rule preventing profit maximizing behavior that an undertaking wishes

at 111. Also J.J.W. Weiler, "The Constitution of the Common Market Place: Text and Context in the Evolution of the Free movement of Goods", in P Craig and G De Burca (eds), The evolution of EU law (Oxford, OUP 1999) at 372.

52 AG Jacobs opinion in C-412/93 Leclerc-Siplec [1995] ECR I-179

53 Ibid. para. 40.

54 Case C-577/11 DKV Belgium [2013] nyr, paras 34-35.

55 To the same effect: C-543/08 European Commission Portuguese Republic [2010] ECR I-11241. 
to engage in, is likely to reduce 'profitability', which the Court considers the benchmark of the market access test. The Court considers that the basic fact that an undertaking will have to determine a commercial strategy that is 'specific to a Member State' and takes account of the differing regulatory circumstances in that Member State is sufficient to constitute a restriction on the freedom of establishment and the freedom to provide services. It is, thereby, automatically unfavorable towards the out of state trader. Interpreted in this way, market access is an open concept that will encompass all rules, which have an effect on an economic operators business policy and strategy, which are introduced as the substantial criterion of market access in this case. ${ }^{56}$ According to the Court, the issue is not whether the product can access the market at all but whether the measure is such as to make the offering of services less attractive because it reduces the possibilities or because it increases costs. In other words, the economic operator not only has a right to access the market, "it has a right to access as wide and cheap a market as possible". ${ }^{57}$ Somek's concerns would be validated on this basis since it would turn free movement law in an unrestricted economic due process test (see on this further Chapter I section II.C.). This reading has recently been confirmed by AG Bot:

"According to the formula now usually employed in the case-law, Article 34 TFEU reflects the obligation to comply with the principles of non-discrimination and of mutual recognition of products lawfully manufactured and marketed in other Member States, as well as the principle of ensuring free access of EU products to national markets. I infer from that standard formula that a national measure may constitute an obstacle not only when, as a selling arrangement, it is discriminatory, in law or in fact, but also when, irrespective of its nature, it impedes access to the market of the Member State concerned. It follows that, where an obstacle to market access is found to exist, there is no need to undertake a comparative examination between the situation of the domestic products and that of the imported products in

56 See also Spaventa above (no. 25) 914-32. See also case Case C-518/06 [2009] Commission v Italy ECR I-03491, paras 68-70, concerning an infringement action against Italy, in respect of regulatory rules on motor insurance. Insurance companies in Italy were required to provide insurance to any potential customer, under terms and rates the company had to publish in advance and there were limitations on the freedom of the companies to set their premiums. In the view of the Court this affected market access: "inasmuch as it involves changes and costs on such a scale for those undertakings, the obligation to contract renders access to the Italian market less attractive and, if they obtain access to that market, reduces the ability of the undertaking concerned to compete effectively, from the outset against undertakings traditionally established in Italy".

57 See Spaventa above (no. 25), at 924. 
order to establish the existence of a difference in treatment between them". ${ }^{58}$ (emphasis added)

This can of course be critiqued, and it has been by many commentators. ${ }^{59}$ Fore example Juka Snell notes that since the term 'market access' lacks a clear content, "the court may use it freely either to approve or to condemn measures that it happens to like or dislike. Market access may simply provide a sophisticated sounding garb that conceals decisions based on intuition". ${ }^{60}$ From the perspective of responsiveness, the potential danger of this method of adjudication is that the instalment of expedient concepts will lead to the quick disapplication of conflicting social objectives. ${ }^{61}$ As Barnard submitted, "the moment collective action is found to be a 'restriction' .... the 'social' interests are on the back-foot, having to defend themselves from the economic" ${ }^{62}$. It follows from the market access test that the assessment of the proportionality of a restriction to a right of free movement is triggered almost instantly and without any form of qualification as soon as access to potentially 'embedded' spaces of economic activities is restricted. As a starting point it is therefore important to emphasize that the framing of the conflict that is being adjudicated at the proportionality stage in EU free movement cases lacks the traditional conflict that is adjudicated by the proportionality principle through resolving 'embedded' prima facie rights. Instead, the conventional method applied in EU free movement law is reversed. Namely, to assess an embedded public policy concern, such for example a fundamental right, under the proportionality assessment versus an external right of free movement. At this point the restriction is seen as an exception to the fundamental Treaty principles and must be construed

58 Opinion AG Bot in Case C-333/14 The Scotch Whisky Association and Others $v$ The Lord Advocate [2015], nyr, para. 58.

59 See above (no. 25)

$60 \quad$ Snell above (no. 25) at 448.

${ }^{61}$ See also J.H.H. Weiler, 'Fundamental rights and fundamental boundaries', in The Constitution of Europe: 'Do the new clothes have an emperor' and other essays on European integration, (CUP 1999), p. 102-129; also J.H.H. Weiler, The Constitution of the Common Market Place: Text and Context in the Evolution of the Free Movement of Goods, in P. Craig, G. De Burca (eds.) The evolution of EU law (CUP 1999). See also B. de Witte, "Community law and national constitutional values", Legal Issues of European Integration, (1991) 19, p. 1-22.

${ }^{62}$ C Barnard, 'Social dumping or dumping socialism' (2008) 67 Current Law Journal, 262 at 264. 
narrowly and the Court has established that "...those grounds must...be interpreted strictly, so that their scope cannot be determined unilaterally by each Member State without any control by the Community institutions. ${ }^{163}$

A case in point is the Omega case concerning a prohibition imposed by the Bonn police authority on a game parlour at which players with the help of laser guns simulated killing each other. One of the reasons that was given by the authority for imposing this measure was the protection of public policy, which was qualified by the Bunderverwaltungsgericht to be protecting human dignity, a fundamental constitutional principle spelt out in Article 1(1) of the German Grundgesetz. Acknowledging that human dignity represented a fundamental societal interest, the Court nevertheless decided that human dignity would have to be justified as a derogation from the fundamental principle on the freedom to provide services, and thus interpreted strictly. The Court did not spend a lot of thought on the fact that in terms of hierarchy of norms, the freedom to provide services was considered, necessarily, as the higher norm since the protection of human dignity was able to 'restrict' the free movement right in this case. Although the Court in its subsequent assessment of the proportionality of the measures considered that human dignity was allowed to trump the free movement right, through a light substantive proportionality analysis, there remains something quite unsatisfactory with the way that the Court adjudicates these types of conflicts. This also seemed to be a concern of Advocate General Trstenjak who argued in Commission v. Germany (occupational pensions) that: ${ }^{64}$

"Such an analytical approach suggests, in fact, the existence of a hierarchical relationship between fundamental freedoms and fundamental rights in which fundamental rights are subordinated to fundamental freedoms and, consequently, may restrict fundamental freedoms only with the assistance of a written or unwritten ground of justification".

63 See eg, para. 17 in Case C-54/99 Eglise de schientologie [2000] ECR I-01335, para. 47 in case C503/99 [2002] ECR I-044809, para. 48 in Case C-483/99 and para. 72 in Case C-463/00 [2003] ECR I04581.

64 Opinion AG Trstenjak in Case C-271/08 [2010] ECR I-07091, para. 184. 
However, as pointedly commented on by Spaventa, whether this approach of the Court is truly problematic all depends on how the internal market is conceptualised: "The broadening of the scope of the Treaty could be seen as a contribution not so much to deregulation but rather to better regulation, through a process of continuous self-reflection and of continuous dialogue between regulators, traders and the Court". ${ }^{65}$ This view is reflective of the argument from transnational effects, which main rationale is the opening up of the discursive value of exactly this dialogue. A broadening of the market access test, thereby leads to a broadening of the dialogue and furthers the interests of European unity from that perspective. As aptly pointed out by Nic Schuibhne, "the justification framework has evolved over time to become the prime space within which public interest arguments are aired. It is where the multifaceted construction of the internal market ... is explored and contested" ${ }^{\prime 66}$. Indeed, the Treaty-permitted grounds for derogation from free movement rights ${ }^{67}$ have since a long time been extended with a very expansive approach in the case law, which allows the propagation of most policy arguments as 'imperative requirements' or 'overriding reason in the public interest' ${ }^{68}$ Member States are only barred from adopting 'economic' justifications so as to highlight that only public interest objectives can override free movement rights ${ }^{69}$ However, in practice the 'economic' justifications have been interpreted mostly as 'protectionist' aims, which are, prima facie, not accepted as an overriding reason in the public interest. ${ }^{70}$ Thus, the simultaneous increase of the reach and the

65 Spaventa above (no. 25), p. 925

66 N.N. Shuibhne, The Coherence of EU Free Movement Law (Oxford: Oxford University Press, 2013) at 26.

67 ' Public morality, public policy or public security; the protection of health and life of humans, animals or plants; the protection of national treasures possessing artistic, historic or archeological value; or the protection of industrial and commercial property' in Article 36 TFEU for quantitative restrictions on the free movement of goods. Public policy, public security or public health in Articles 45(3), 52 and 62 TFEU for free movement of workers, free establishment and free movement of services. For restrictions on free movement of capital specific restrictions are set out in Article 65 TFEU.

68 See J. Scott 'Mandatory or imperative requirements in the EU and the WTO', in C. Barnard and J. Scott, The Law of the Single European Market : Unpacking the Premises (Oxford: Hart, 2002) at p. 269.

69 Case C-141/07 Commission v Germany [2008] ECR I-6935, paragraph 60, Case C-444/05 Stamatelaki [2007] ECR I-03185

70 See AG JÄÄSKINEN in Joined cases C-105/12 to C-107/12 Essent nyp, who provides a compelling argument for interpreting the economic justification in this way in para. 89 and further 
potential justifications with regard to the free movement provisions can indeed be perceived as a tool to impose a view of good governance..$^{71}$ It may be argued that in this way, and on the basis of an unqualified market access standard a constitutional settlement is advanced in which the validity of all democratically enacted Member State legislation and regulatory regimes that restrict a free movement right are contingent on judicial approval through a proportionality standard.

Crucial for the argument advanced here is that, absent explicit responsiveness, and in the presence of normative evaluative frameworks, this adjudicative model of the Court would render the negotiation, compromise and agreement involved in the adoption of legislation and regulatory regimes on a Member State level potentially irrelevant. The model may lack social legitimacy because it will, in effect, recognize rights that may not be part of the constitutional or legislative contexts on the Member State level and instead require a justification for the existence of those contexts. As argued before, there are legitimate obligations that can be imposed on Member States constitutional, legislative and regulatory contexts, that derive from the commitment of being part of an integrating European market, however, Member State legislative context reflect choice and commitments of a political community that are significant and these choices must receive the explicit consideration of the judiciary. The 'culture of justification' for restrictions of economic activity as clearly purported by the Court of Justice on the basis of an unqualified market access test is therefore only acceptable within the confines of the embedding context of Member States that allow for economic activity to take place at all. ${ }^{72}$ Therefore, the unqualified market access test, as a means to structure

\footnotetext{
Spaventa above (no. 25)., p. 925.

72 See further more broadly D. Dyzenhaus 'Proportionality and Deference in a Culture of Justification' in Huscroft, Miller, and Webber (eds.), Proportionality and the Rule of Law: Rights, Justification, Reasoning (CUP 2014) 234-258. In the famous words of R. Cover, 'Foreword: Nomos and Narrative', Harvard Law Review 97[1983], p. 4-68: "no set of legal institutions or prescriptions exists apart from the narratives that locate it and give it meaning. For every constitution there is an epic, for each Decalogue a scripture. Once understood in the context of the narratives that give it meaning, law becomes not merely a system of rules to be observed, but a world in which we live. In this normative world, law and narrative are inseperably related. Every prescription is insistent in its demand to be located in discourse - to be supplied with history and destiny, beginning and end, explanation and purpose".
} 
free movement conflicts can only be socially legitimate if it is merely a prima facie way to structure the conflict at hand. In a next stage, responsiveness should become a core and explicit part of the proportionality analysis. By adopting a rationale of responsiveness, at a preliminary stage, it will be possible to streamline the choices of the Court for a particular model of evaluation and intensity of proportionality assessment in a way that guarantees the responsiveness of legal review. We shall now move on to look at proportionality analysis from this angle.

\section{iii. The structure of proportionality}

The three stages of proportionality assessment are standardized and consist of an inquiry into (i) whether a measure was suitable to achieve the desired end (in the form of a rational connection between means an end); (ii) whether it was necessary to achieve the desired end (in the form of a test if there was a less restrictive measure available); and (iii) whether the measure imposed a burden on the individual that was excessive in relation to the objective sought to be achieved (proportionality stricto sensu). The third part of the test is often not applied by the Court and, as Paul Craig has noted, the Court will normally only consider part three when an applicant explicitly addresses an argument concerning this stage of the inquiry. ${ }^{73}$ Otherwise the Court tends to resolve the assessment on the basis of the first two stages of the proportionality assessment.

The function of proportionality in a democracy based on the rule of law, traditionally perceived, incorporates some important elements of responsiveness. Traditionally perceived the connection between proportionality and democracy is "to secure government not only by the people through representation but to secure it in a way that a common good can be advanced in recognition of which everyone can, in principle, collaborate by obedience to a legitimate regime of law" ${ }^{74}$ For such a regime it is important to have the law function in a way that a legal subject's

\footnotetext{
P. Craig and G. de Burca, EU Law text, cases and materials (Oxford University Press, 2011), p. 551.

74 T.R.S. Allan, 'Democracy, Legality, and Proportionality' in Huscroft, Miller, and Webber (eds.), Proportionality and the Rule of Law: Rights, Justification, Reasoning (CUP 2014) 205-233 at 209.
} 
treatment by the law must be capable of a justification that explicitly articulates a conception of the 'public good' that is context specific, dynamic and therefore open to debate and criticism. ${ }^{75}$ Implicit in this conception is that the burdens that flow from the law must be measured with respect to the advancement of that public interest and that the social legitimacy of a legal regime is, in part, obtained through a process of reasoned deliberation through which abstract principles of law become concrete and constitutive in the course of application to specific situations. ${ }^{76}$ From this perspective, the idea of proportionality can be perceived as a technique that considers that the resolving of conflicts between rights and general public interest is best resolved by responsiveness to context, allowing reasonable solutions to be found that are sensitive to all the relevant contextual considerations. ${ }^{77}$

Importantly, on the basis of the previously discussed unqualified market access test, the adjudicative model of the Court resembles what can be termed as a "rights inflation" proportionality model. ${ }^{78}$ The rationale behind this model is that the existence of a hierarchical relationship between competing objectives is purely functional and that proportionality, applied in this way, indeed merely structures the conflict in a prima facie way so that legitimate rights and policies can actually be established. For example, in the extreme, proponents expounding a wide understanding of rights in proportionality analysis may include murder at a prima facie stage as a potential right or interest, but there is no doubt that there are reasons of sufficient weight in favour of a prohibition of that prima facie right, which are to be taken into account at the justification stage. In fact, it may be argued that proportionality is ideally suited to conduct such an inquiry as it is an approach that acknowledges first, that there is a right to murder and subsequently, at the justification stage, deals with the permissible limitations of this right, addressing all

\footnotetext{
75 Further D. Dyzenhaus 'Proportionality and Deference in a Culture of Justification' in Huscroft, Miller, and Webber (eds.), Proportionality and the Rule of Law: Rights, Justification, Reasoning (CUP 2014) 234-258.

76 Allan above (no. 74).

77 Further, ibid. at 211.

78 As in K. Moller 'Proportionality and Rights Inflation', in Huscroft, Miller, and Webber (eds.), Proportionality and the Rule of Law: Rights, Justification, Reasoning (CUP 2014) 155-172 .
} 
morally relevant considerations in order to reach the right conclusion. ${ }^{79}$ Similarly, free movement rights are placed as a prima facie right above a public interest concerns such as human dignity, merely to then at the justification stage, deal with all the permissible limitations of the free movement right on the basis of human dignity, and in that stage address all the morally relevant considerations to come to a conclusion of the conflict. ${ }^{80}$ The prima facie structuring of EU free movement conflicts in this way is a crucial part of the adjudicative model of the Court, as indicated before, allowing it to engage with a range of regulatory contexts and, as explained before within the constitutional construct of the internal market, to initiate a dialogue with Member States that purports internal market integration. However, as was argued, to avoid problems of social legitimacy, this model depends crucially on responsiveness and can only be perceived as an adequate and acceptable technique if, eventually, conflicts between rights and general public interest are resolved on the basis of responsiveness to context, which incorporates a type of valuation that is able to respond to all the relevant contextual considerations. The basic adjudicative free movement framework of the Court requires, from the perspective of social legitimacy, determinacy on the basis of an identification of normative conflicts between complete market access and restrictive social context. In so far as genuine normative conflicts are resolved within a metric that too easily presumes that conflicting objectives are commensurable within a single metric, social legitimacy issues will arise. To see to what extent this applies in free movement adjudication we need to explore, in more depth, the actual evaluative rationales that the Court incorporates in its proportionality assessment. I turn to this in the next section.

79 As argued for example by K. Moller (no. 78 above). See also M. Kumm, "The idea of Socratic contestation and the right to justification: The point of rights-based proportionality review", 4 Law \& Ethics of Human Rights (2010), 157.

80 For a critique on this see J.H.H. Weiler and N.J.S. Lockhart, "'Taking Rights Seriously' seriously: The European Court of Justice and its fundamental rights jurisprudence', (1995) 32 Common Market Law Review at p. 593 who challenge the rights denigration argument as an 'unjustified leap from a lexical equivalence to normative equivalence.' 


\title{
III. Responsiveness in the proportionality analysis of the Court in free movement
}

\author{
A. Introduction
}

In recent contribution, increasing reference has been made to the emergence of two 'separate' versions of proportionality within the case law of the Court. ${ }^{81}$ One version is considered substantively oriented and the other oriented more towards assessing the procedural context in which the measures were taken. It seems, however, that these are not so much separate tests but rather instances where the Court has either put more emphasis on whether a measure is suitable to achieve the desired end, or on the question as to whether a measure is necessary to achieve the desired end. ${ }^{82}$ Importantly, the criterion that stands behind the decision of the Court to put emphasis on procedural context or substantive rationality is largely unclear and, as will be discussed, mostly arbitrarily applied. Indeed, the Court will sometimes engage in a comparative review of measures adopted in other Member States on the basis of the principle of mutual recognition. ${ }^{83}$ Then again, it has also often been held that "the fact that one Member State imposes less strict rules than another Member State does not mean that the latter's rules are disproportionate" ${ }^{84}$ At times, the Court protects a space for Member State difference by referring to "the circumstances of law and of fact, which characterize the situation in the Member State concerned" 85 and defers the proportionality assessment completely to the national court. ${ }^{86}$

81 E.g. D. Damjanovic, "The EU Market Rules as Social Market Rules: Why the EU Can Be a Social Market Economy," Common Market Law Review 50, no. 6 (2013): 1685-1717; F. de Witte, "Sex, Drugs \& EU Law: The Recognition of Moral and Ethical Diversity in EU Law," Common Market Law Review 50, no. 6 (2013): 1545-78.

82 See also G. Mathisen, "Consistency and Coherence as Conditions for Justification of Member State Measures Restricting Free Movement," Common Market Law Review 47, no. 4 (2010): 1021-48.

83 E.g. Case C-333/08 Commission v France [2010] ECR I-00757, para. 105.

84 E.g. Case C-141/07 Commission v Germany [2008] ECR I-06935, para. 51; Case C-36/02 Omega Spielhallen v. Oberbü̈germeisterin derBundesstadt Bonn [2004] ECR I-9609, para 108.

85 E.g. Case C-434/04 Criminal proceedings against Ahokainen and Leppik, [2006] ECR I-9171, para 40.

86 E.g. Case C-405/98, Konsumentombudsmannen (KO) v. Gourmet International Products AB (GIP), [2001] ECR I-1795, paras. 21-22 
However, when looking at these seemingly incoherent techniques of the Court to adjudicate free movement conflicts it is possible to distil three 'ideal type' models, which will be discussed in the next sections, whilst highlighting the valuation that is inherent in these models and the impact that may have on contextual responsiveness. By unveiling the implicit rationale that is inherent is these adjudicative rationales of the Court it becomes possible to submit such choices to a normative assessment (in section IV).

B. Substantive efficiency model

The first model can be labelled the substantive efficiency model and comes to the conclusion of a conflict by way of questioning whether a measure is necessary to achieve the desired end. If there exists a less restrictive measure then the test is failed. As demonstrated by Nic Shuibhne and Maci, there is a high degree of variety in the way that the Court has formulated the substantive standards of its assessment. ${ }^{87}$ The most standardised version is the one where the Court stipulates that " $i$ i]f $a$ Member State has a choice between various measures to attain the same objective it should choose the means which least restricts [free movement]" ${ }^{88}$ In goods cases the Court has seen labelling as the least restrictive instrument in many cases. Exemplary here is the Beer Purity case where the Court decided that informing consumers through linking the name 'Bier' only to products brewed with malted barley, hops, yeast and water could equally well be achieved "by means which do not prevent the importation of products which have been lawfully manufactured and marketed in other Member States and, in particular, by the compulsory affixing of suitable labels giving the nature of the products sold" ${ }^{89}$

This substantive oriented variant of the proportionality test is prescriptive of the content of national choices and the legality of a particular measure, which will depend on the absence of "policy alternatives that are less restrictive of the rights of

\footnotetext{
See Shuibhne and Maci above (no. 3) p. 965-1005.

88 Case 261/81, Walter Rau Lebensmittelwerke v. De Smedt PVBA, [1982] ECR 3961, para 12.

89 Case 178/84 Commission v. Germany [1987] ECR 01227, para 36.
} 
mobile actors. It allows such actors to demand that Member State policies are reassessed in light of less restrictive choices made by other Member States". 90 Whenever the Court applies this model of substantive efficiency, it pursues the idea that there is a single normative principle at work and that all the interests in the conflict are therefore necessarily compatible, by insisting that the diversity of options that have led to a restriction of trade can be subject to one rational judgment according to their weight and rankings. The functioning of the model is clearly illustrated in a case concerning Austrian restrictions on road transport for environmental reasons, where the Court stated that:

\begin{abstract}
"Without the need for the Court itself to give a ruling on the existence of alternative means, by rail or road, of transporting the goods covered by the contested regulation under economically acceptable conditions, or to determine whether other measures ... could have been adopted in order to attain the objective of reducing emissions of pollutants in the zone concerned, it suffices to say in this respect that, before adopting a measure so radical as a total traffic ban on a section of motorway constituting a vital route of communication between certain Member States, the Austrian authorities were under a duty to examine carefully the possibility of using measures less restrictive of freedom of movement, and discount them only if their inadequacy, in relation to the objective pursued, was clearly established."91
\end{abstract}

The Court eventually held that:

"it has not been conclusively established in this case that the Austrian authorities ... sufficiently studied the question whether the aim of reducing pollutant emissions could be achieved by other means less restrictive of the freedom of movement and whether there actually was a realistic alternative for the transportation of the affected goods by other means of transport or via other road routes". ${ }^{2}$

When the Court chooses to apply this substantive efficiency test it advances a normative principle of technocratic managerialism ${ }^{93}$ and assumes a regulatory

F. De Witte (no. 81 above) at p. 1568.

91 Case C-320/03 Commission v. Austria [2005] I-09871, para. 87.

Ibid., para. 89.

93 A term coined in W. Enteman, Managerialism: The Emergence of a New Ideology (WIsconsin: University of Wisconsin Press, 1993). 
context where a rational assessment of a problem, involving the gathering and collating of information, listing options, calculating the costs of each option, evaluating consequences and choosing the best course of action is actually available. The main problem of this model is that, as an evaluative framework for Member State regulatory choice, it can only be applied where the context is actually managerial and hence leads to a problem of incommensurability if applied to adjudicate a social context that does not fit within the utilitarian standard of the least or less restrictive measure. In other words, the model is unable to take account of the potential systemic effects of certain policy choices in Member States. That is to say, many legislative, regulatory choices and governance schemes are the product of a compromise between different interests. Hence, such choices can often be criticized for being inefficient. ${ }^{94}$ However, if these choices reflect essential points of compromise that, for example, secured the necessary political capital for a specific regulatory choice, then a blanket substantive review may forego the underlying social context that is embedded within a particular regulatory scheme. As was highlighted in the previous section, adjudicative rationalities need to be responsive to such context and not forego relevant social compromises on the basis of an undersocialised rationale of technocratic managerialism.

If we accept the argument that social diversity is a value that the EU internal market is committed to then this market derived utilitarian standard is not an appropriate means to adjudicate conflicts in every situation, and may inhibit choices for the underlying normative infrastructure of the economy within Member States. Moreover, the use of this utilitarian standard tends to obscure the commensurability issue by assuming that different values or objectives are commensurable and thereby fails to reveal what is at stake in many areas of internal market law. ${ }^{95}$ There is, in other words, an expressive function of free movement law that is potentially lost. By way of illustration reference can be made to the recent Scottish minimum

94 See for example G Monti, 'EU Competition Law from Rome to Lisbon' in C Heide-Jorgensen et al (eds), Aims and Values in Competition Law (Copenhagen, DJOF Publishing, 2013).

95 G. Davies, 'Democracy and Legitimacy in the Shadow of Purposive Competence' 21(2015) European Law Journal at p. 2. 
alcohol pricing case. ${ }^{96}$ The Scottish Parliament passed a law in order to reduce the consumption of alcohol, specifically to create disincentives for lower income groups, which were considered to constitute a majority of 'hazardous drinkers'. The law prohibited the sale of alcohol at a price below a minimum price that was to be calculated on the basis of the content in alcohol. The law was challenged and it was argued, inter alia, that the minimum pricing restricted access to the Scottish alcohol market because it factored out the potentially lower cost structures and the comparative advantages that existed in other Member States. AG Bot considered that the proportionality assessment boiled down to the question whether taxation could not be used as a 'more effective and less trade restrictive measure' ${ }^{97}$ AG Bot considered that on the basis of the principle of 'free formation of prices' an objective such as "increased taxation that is less restrictive of trade while enabling the objective pursued to be attained must be preferred to a measure fixing a minimum price, which gives rise to a greater obstacle" $"$. AG Bot was of the opinion that this alternative would present a better "cost-benefit outcome" than the setting of a minimum price. The consequentialist rationale that is implicit in the utilitarian standard adopted by the $\mathrm{AG}$ in this case juxtaposes a measure of minimum pricing with general taxation without considering to what extent the social context allows such a cost-benefit choice for the legislator. In fact, for the Scottish authorities, there was no apparent alternative available to seek a normative choice for the regulation of alcohol consumption, since general alcohol taxation is controlled by the UK government. Therefore, underlying the cost-benefit analysis is a fundamental question regarding the balance of constitutional taxation powers between the UK and Scotland and the question to what extent Scotland has the ability to define the normative infrastructure of its own economy. This dimension of the conflict is obscured by the consequentialist analysis, which reduces such social complexities to a question of thinking in terms of the 'less restrictive'

\footnotetext{
96 Opinion AG Bot in Case C-333/14 The Scotch Whisky Association and Others $v$ The Lord Advocate, [2015] nyr.

97 Ibid., para. 146.

98 Ibid., para. 148.
} 
measure. This is directly related to the previously submitted social purpose of EU internal market law. It was submitted that the social purpose is concretised in the respect and accommodation of social diversity amongst Member States, whilst promoting the objectives of the internal market by scrutinizing the internalization of the transnational effects of Member State social measures. The expressive function of internal market law is then to unveil normative conflicts such as these in order to illuminate what is at stake in internal market conflicts. ${ }^{99}$

Another case in point is the 2013 Libert case in which the Court ruled that social housing regulation in Belgium, which restricted access to housing in certain situations to those with a "sufficient connection" to the geographical area and required land developers to meet social housing obligations. ${ }^{100}$ The objective of the housing regulation was to ensure access to housing in certain areas for low-income or otherwise disadvantaged sections of the local population, a measure designed to combat the increasingly unstoppable phenomenon of gentrification. ${ }^{101}$ However, the Court considered after listing the restrictions on movement of capital, services and establishment that there were other means of pursuing Flanders' socio-economic objectives, which were less restrictive of free movement and provided the example of offering "subsidies for purchase or other subsidy mechanisms specifically designed to assist less affluent persons" ${ }^{102}$. In taking this position, the Court did not take into account potential political compromises or budgetary restrictions but assumed a regulatory context where calculating the costs, evaluating economic consequences and choosing the least costly course of action was possible and realistic. Perhaps it was, but is more than likely that it was not. ${ }^{103}$ Moreover, the issue of gentrification in light of the potential it has to undermine social cohesion

99 On the expressive functions of law see also C. Sunstein, 'Incommensurability and Valuation in Law' Michigan Law Review 92(1994) at 779). Reference on this point can also be made to Dani in 'Rehabilitating social conflicts in European Public Law', (2012) 18 European Law Journal 621 who similarly argues against the consensus reasoning that is inherent in the way conflicts are resolved by the Court of Justice.

100 Case C-197/11 Libert e.a. [2013] nyr.

101 Ibid., para. 23.

102 Ibid., para. 56.

103 See S. Reynolds, 'Housing policy as a restriction of free movement and MSs discretion to design programmes of social protection: libert' Common Market Law Review 52(2015) p 259-280, 
and the relationship with the free movement of capital and services of real-estate development was not discussed. ${ }^{104}$ From the perspective of social legitimacy, the valuation that is implicit in the evaluative rationale of substantive efficiency can have a structural impact on a variety of social measures and identity within Member States. ${ }^{105}$ This type of valuation is at risk of denying that the diversity of preferences and orientations in the EU is the product of specific historical experiences, political contestation, societal learning and continuous political decision-making. ${ }^{106}$ As such, the first chapter discussed that despite globalizing trends, Member States vary deeply in terms of institutional preferences and structural policy differences. ${ }^{107}$ The evaluative standard that is used by the Court of Justice in these cases is not able to express and acknowledge those differences.

However, in other cases the Court does find itself granting a definite margin of discretion. Contrast the above findings with the Court's analysis in the Trailer's case on road safety measures, where less restrictive measures had been brought forward by AG Bot but the Court nevertheless granted a wide margin of discretion to the Member State: ${ }^{108}$

"[I]n the field of road safety a Member State may determine the degree of protection which it wishes to apply in regard to such safety and the way in which that degree of protection is to be achieved. Since that degree of protection may vary from one Member State to the other, Member States must be allowed a margin of appreciation ... [T] he Italian Republic contends, without being contradicted on this point by the Commission, that the circulation of a combination composed of a motorcycle and a trailer is a danger to road safety ... Although it is possible, in the present case, to envisage that measures other than the prohibition laid down ... could guarantee a

104 E.g. S. Sassen, "On concentration and centrality in the global city" in P. Knox, L.Taylor, J. Peter (eds.), World Cities in a World-System. (Cambridge UP 1995), p. 63-75.

105 M. Höpner and A. Schäfer, "Embeddedness and Regional Integration: Waiting for Polanyi in a Hayekian Setting” 66(2012) International Organization 429 at p. 445.

106 As submitted by C. Joerges, 'Market Integration and Europeanisation of Private Law', Jean Monnet Project Conference Paper (May 2015), on file with author

107 These can for example be classified in benefit structures, methods of financing, service intensity, family policy, employment regulation, logic of governance and the regulation of industrial relations in A. Hemerijck, 'The Self-Transformation of the European Social Model(s)', in G. Esping Andersen (ed.), Why we need a Welfare State (Oxford: OUP, 2002) 178. See also P. Beramendi, 'Inequality and the Territorial Fragmentation of Solidarity', International Organization $(2007,4)$ p. 783-820.

108 Case C-110/05, Commission v. Italy (Trailers), [2009] ECR I-519, paras. 65-66. 
certain level of road safety ... such as those mentioned in point 170 of the Advocate General's Opinion, the fact remains that Member States cannot be denied the possibility of attaining an objective such as road safety by the introduction of general and simple rules which will be easily understood and applied by drivers and easily managed and supervised by the competent authorities." (emphases added)

However, such simplicity was not valued to the same degree in the invalidation of the Swedish monopoly system for the import of alcohol by persons younger that 20 years of age, on the basis of suggestions made by the Commission for less restrictive measures:

"the age check could be carried out by way of a declaration in which the purchaser of the imported beverages certifies, on a form accompanying the goods when they are imported, that he is more than 20 years of age" ${ }^{109}$

As such, there is a degree of variety in the application of the substantive part of the proportionality assessment by the Court, which is not directly clarified or justified in the case law. A strict application of the substantive proportionality assessment invalidates the measure before the Court immediately as in the Beer purity measures in Germany, the environmental measures of Austria and the import monopoly on alcoholic beverages in Sweden. The deferential version of the substantive review test allows for more discretion for the Member States in the selection of protective measures such as in the Trailers case and often involves a referral back to the national court to make the final assessment. This referral will then often be provided with more or less guidance as to the way that this assessment should take place. Suffice to say for now that the extent and the degree to which the substantive proportionality test is applied by the Court is not obviously consistent and appears to depend to some degree on the 'sensitivity' of the measure that is under review.

\section{The margin of discretion model}

${ }^{109}$ Case C-170/04 Klas Rosengren and Others v Riksåklagaren, [2007] ECR I-04071 para. 56. 
Arguably, the second 'ideal type' model could address this concern. This model can be termed the margin of appreciation model and has been heralded as being of the highest significance for EU internal market law. ${ }^{110}$ The model is based on granting a margin of discretion to Member States as soon as the restriction at stake is to be considered 'sensitive' and is mostly applied in cases where fundamental rights or values are at stake at the Member State level. ${ }^{111}$ The more sensitive the matters advanced in the context of justifications are, the more generous the scope for justification becomes, as do the breadth of the margin of appreciation enjoyed by the regulator. ${ }^{112}$ The normative principle at work in this model is that free movement rules will scrutinise Member State restrictions on free movement rights, in so far as justifications are not sensitive and allow a 'definite margin of discretion' to Member States in the pursuit of objectives, when the interest at stake is for some reason considered to be sensitive. ${ }^{113}$ The obvious shortcoming of the model is that there is no rationale for when an interest is to be considered sensitive, other than the vague notion that the further removed from 'trade' the interest is, the more leeway is provided to Member States. However, the model points in a promising direction in terms of responsiveness to the social context of a conflict. That is to say that the normative principle of the internal market, narrowly perceived as purporting technocratic managerialism, is related to trade interests and that Member State objectives which clearly fall outside of this 'trade sphere' will not be reviewed within a model of substantive efficiency that looks for a less restrictive measure. However, is the internal market then to be considered as forwarding only the narrow aims of substantive efficiency? This

${ }^{110}$ S Weatherhill, 'Viking and Laval: the EU internal market perspective' in M Freedland and J. Prassl (eds.), Viking, Laval and Beyond, (Hart 2014), p. 32. Also J.H.H. Weiler, (1999), 'Fundamental rights and fundamental boundaries', in The Constitution of Europe: 'Do the new clothes have an emperor' and other essays on European integration, Cambridge, CUP, pp. 102-129, at p. 104.

111 See N. Nic Shuibhne, "Margins of Appreciation: National Values, Fundamental Rights and EC Free Movement Law", European Law Review, 32(2009), p. 230-256.

112 Ibid.

113 For example C-112/00 Schmidberger, [2003] ECR I-5659 and Case C-36/02 Omega Spielhallen- und Automatenaufstellungs-GmbH v Oberbürgermeisterin der Bundesstadt Bonn [2004] ECR I-9609. See generally, J. Morijn, 'Balancing fundamental rights and common market freedoms in union law: Schmidberger and Omega in the light of the European constitution', (2006) 12 European law Journal 15-40. 
would imply that any interest, which is considered sensitive falls outside of the reach of the internal market, regardless of its transnational effects and potential democratic deficiencies. Interpreted in this way, the two models combined would take the mutuality out of the responsiveness that is required for a model of embedded liberalism to succeed. The Court of Justice provides an answer to this in Schmidberger. In Schmidberger the Court acknowledged a wide margin of discretion to Austria to decide whether or not to ban a demonstration, which resulted in the closure of a major transit route and hence restricted the free movement of goods but then proceeded to investigate how it came to that decision, noting that

"various administrative and supporting measures were taken by the competent authorities in order to limit as far as possible the disruption to road traffic. Thus, in particular, those authorities, including the police, the organisers of the demonstration and various motoring organisations cooperated in order to ensure that the demonstration passed off smoothly. Well before the date on which it was due to take place, an extensive publicity campaign had been launched by the media and the motoring organisations, both in Austria and in neighbouring countries, and various alternative routes had been designated, with the result that the economic operators concerned were duly informed of the traffic restrictions applying on the date and at the site of the proposed demonstration and were in a position timeously to take all steps necessary to obviate those restrictions. Furthermore, security arrangements had been made for the site of the demonstration" $" 114$.

The Court, after acknowledging a wide margin of discretion for Austria to determine the best course of action in this situation, proceeded to investigate whether Austria respected basic "good governance principles" in the decision to allow for the protests to take place. ${ }^{115}$ As such, the Court granted a margin of discretion but introduced also another standard of evaluation, which can be seen as the third 'ideal type' model of the Court.

114 C-112/00 Schmidberger, [2003] ECR I-5659, para. 87.

115 See also W. Sauter and H.Schepel, State and market in European Union law: the public and private spheres of the internal market before the EU Courts, (Cambridge University Press 2009), at p. 99; also D. Chalmers, G. Davies, and G. Monti, European Union Law; Cases and Materials (second edition, Cambridge University Press 2010), at p. 760. 
D. The procedural good governance model

The third 'ideal type' type model of the Court can be coined as the good governance model. This section shall discuss the emergence of this model and the requirements that flow from it. This concerns a line of case law that focuses nearly exclusively on the suitability of procedural context surrounding specific regulatory choices of Member States. Conventionally, suitability in the proportionality test looks at the existence of a 'rational connection' between the measure and its objective. In the case Hartlauer ${ }^{116}$ the Court formulated what can be coined as the 'external suitability' of a measure. Not only must there be a rational connection between the measure and the objective, such as for example in Bosman ${ }^{117}$, there must also be a rational connection between the measure and its broader regulatory context. In Bosman the Court held that transfer fee rules were not an adequate means of maintaining financial and competitive balance in football leagues because they neither precluded the richest clubs from securing the services of the best players nor did they prevent the availability of financial resources from being a decisive factor in competitive sport. As such, there did not exist a sufficiently deducible rational connection between the means and the end. This form of application of the suitability test can be seen as the 'inherent suitability' of a measure. In other words, there should be an inherent rational connection between the measure and the concerned objective. Then, in Hartlauer, a measure that made the right to operate a certain category of dental clinics subject to a prior authorisation, while another category of dental clinics was not subject to any such requirement, was considered unsuitable. The Court could not identify any rational basis for the disparate treatment of the two classes of establishment and, accordingly, dismissed the justification plea that the legislation was justified on public health grounds. ${ }^{118}$ In other words, the measure did not make any sense in the wider regulatory context in which it operated. This 'externally oriented' suitability

116 Case C-169/07 Hartlauer [2009] ECR I-01721.

117 Case C-415/93 Bosman [1995] ECR I-04921.

118 Case C-169/07 Hartlauer [2009] ECR I-01721, paras 55-63. 
test has been developed by the Court in detail in various strands of case law and has crystallized in various requirements that can be placed on how Member States design their regulatory frameworks in a wider sense. ${ }^{119}$

The Court provided somewhat of an underlying rationale for looking at procedural context instead of on the substantive measure itself in the Schindler case regarding a UK ban on large-scale lotteries: ${ }^{120}$

"Even if the morality of lotteries is at least questionable, it is not for the Court to substitute its assessment for that of the legislatures of the Member States where that activity is practices legally. [...], lotteries involve a high risk of crime or fraud, given the size of the amounts which can be staked and of the winnings which they can hold out to the players, particularly when they are operated on a large scale. [...] they are an incitement to spend which may have damaging individual and social consequences. A final ground which is not without relevance, although it cannot in itself be regarded as an objective justification, is that lotteries may make a significant contribution to the financing of benevolent or public interest activities such as social works, charitable works, sport or culture. Those particular factors justify national authorities having a sufficient degree of latitude to determine what is required to protect the players and [...] it is for them to assess not only whether it is necessary to restrict the activities of lotteries but also whether they should be prohibited, provided that those restrictions are not discriminatory". ${ }^{121}$ (emphases added)

The Court explicitly considers in Schindler the high risk of crime or fraud, damaging individual and social consequences and the link to public interest activities as reasons not to substitute the assessment of the Court with that of the legislature. As a result, the Court, did not refer at all to the possible existence of equivalent substantive safeguards in the Member State where the service provider was established - safeguards which AG Gulmann thought were sufficient in this case. ${ }^{122}$ On various other occasions, whilst reviewing regulatory contexts surrounding gambling, the Court has stated explicitly that a system of protection that is less restrictive compared to the one that is adopted by other Member States

119 See, generally, Van den Bogaert and Cuyvers, "Money for nothing: The case law of the EU Court of Justice on the regulation of gambling", 48 CML Rev. (2011), at 1175; also J Mulder, 'A New Chapter in the European Court of Justice Gambling Saga: A Stacked Deck?' 38(2011) Legal Issues of Economic Integration, p. 243-262.

${ }^{120}$ C-275/92 Schindler ECR [1994] I-01039.

121 Ibid., paras. 60-61.

122 Opinion AG Gulmann in C-275/92 Schindler ECR [1994] I-01039. 
cannot affect the proportionality of the system of protection that was implemented. ${ }^{123}$ Instead, it matters in these cases whether or not a Member State policy reflects a genuine concern to limit gambling opportunities. The criteria to assess this will differ according to the system for which a Member State opts and results in what the Court itself has coined a 'global assessment', in the Läärä case, where the Court held that a system of protection must be assessed as a whole. ${ }^{124}$

As explained, the criteria to assess this will respond to the system for which a Member State opts. As described before, it is standard case law that whether some types of games of chance are subject to a public monopoly whilst others are subject to a system of licenses issued to private operators is not in itself capable of affecting the suitability of a public monopoly for achieving the objective of preventing citizens from being incited to squander money on gambling and of combating addiction. ${ }^{125}$ Member States are free to disregard other Member States' systems of protection when choosing the level of protection they want to ensure in their territories. The Court made this very explicit in Stoss and others:

"[...] having regard to the discretion which Member States enjoy in determining the level of protection for consumers and public order which they intend to ensure in the gaming sector, it is in particular not necessary, with regard to the criterion of proportionality, that a restrictive measure decreed by the authorities of one Member State should correspond to a view shared by all the Member States concerning the means of protecting the legitimate interest at issue”. ${ }^{126}$ (emphases added)

Hence, a system of protection must solely be assessed by reference to the objectives pursued by the Member State and the level of protection the Member State concerned intends to provide. The Court has kept to this intention in all but two subsequent rulings concerning gambling holding that: ${ }^{127}$

"moral, religious or cultural factors, as well as the morally and financially harmful consequences for the individual and for society associated with betting and gaming,

${ }^{123}$ For example, Case C-124/97, Läärä ECR [1999], I-6067.

124 Ibid. paras 35-36.

125 As in Case C-124/97, Läärä ECR [1999], I-6067.

126 Joined Cases C-316/07, C-358/07 to C-360/07, C-409/07 and C-410/07, [2010] ECR I-08069 (Stoss and Others), para. 80.

127 Ibid., para. 76 See for the incoherency Case C-243/01, Gambelli [2003] ECR I-13031 and Case C243/01 Placania [2007] ECR I-01891, where the Court did apply a light necessity test. 
may serve to justify a margin of discretion for the national authorities, sufficient to enable them to determine, in accordance with their own scale of values, what is required in order to ensure consumer protection and the preservation of public order." (emphases added)

The Court considers that 'in the specific area of the organisation of games of chance' ${ }^{128}$ national authorities enjoy a 'measure' of discretion to enable them to determine what is required in order to ensure consumer protection and the preservation of order in society and it is then for each Member State to assess whether, in the context of the legitimate aims which it pursues, it is necessary to prohibit betting and gaming wholly or in part or only to restrict them and, to that end, to lay down more or less strict supervisory rules. There is in these cases a role for mutual recognition only where a system under review concerns a 'hybrid' policy. For example, in the Gambelli case the Italian government pursued a policy based partly on exclusive - monopoly - licensing and partly on an expanding liberal licensing policy. ${ }^{129}$ The Court takes the position that such 'hybrid' systems of protection can be tested on their necessity, taking into account principles of mutual recognition, if the supplier of the service is subject in his Member State of establishment to completely comparable regulations entailing controls and penalties. In contrast, policies that are based on a monopoly system sec can only be assessed on the basis of their own merits and potentially inconsistent policy objectives. This was explicitly confirmed by the CJEU in Stoss and others:

"[...] where a public monopoly in the area of games of chance has been established in a Member State and it appears that that measure satisfies the various conditions permitting it to be justified having regard to the legitimate public interest objectives allowed by the case-law, any obligation to recognise authorisations issued to private operators established in other Member States is, ex hypothesis, to be excluded, simply by virtue of the existence of such a monopoly". ${ }^{130}$

It is certainly true that gambling in particular is subject to very different degrees of regulation between the Member States; a business practice classified as

\footnotetext{
${ }^{128}$ Case C-390/12 Pfleger [2014] nyr, para 45

129 Ibid., para. 73.

130 Ibid., para. 109.
} 
lawful in some Member States is liable to criminal prosecution and penalties as severe as imprisonment in others. ${ }^{131}$ As a result, the Court has in these gambling cases mostly chosen to not apply the necessity test at all and instead focused at the procedural context of the measures, promoting a 'global assessment' of the circumstances in which legislation has been adopted and implemented. The idea of a global assessment originated in the Läärä case where the Court held that a system of protection must be assessed as a whole. ${ }^{132}$ The Court considered that the mere fact that some games of chance were not prohibited is insufficient to show that the national legislation is not in reality intended to achieve the public interest objectives at which it is aimed. It was considered that a limited authorisation of such games on an exclusive basis has the advantage of confining the desire to gamble and the exploitation of gambling within controlled channels. ${ }^{133}$ Since the objective of protecting consumers from gambling addiction is, in principle, difficult to reconcile with a policy of expanding games of chance characterized, inter alia, by the creation of new games and by the advertising of such games:

"[...] such a policy cannot be regarded as being consistent unless the scale of unlawful activity is significant and the measures adopted are aimed at channelling consumers' propensity to gamble into activities that are lawful". ${ }^{134}$ (emphases added)

This illustrates the 'global assessment' that the Court can make in these cases. In this type of assessment the Court will look whether legislation actually pursues the objective of protecting gamblers or fighting crime and does so 'genuinely' and in a consistent and systematic manner. A global assessment involves a thorough evaluation of legislative context and intentions in order to reveal if the intentions of Member States are genuinely concerned with the objectives that are claimed to be pursued and the Court has on various occasions considered that Member State legislation lacked such genuine intentions through unveiling inconsistencies in the activities of the authorities concerned with the supervision:

\footnotetext{
131 Case C-67/98 Zenatti [1999] ECR I-7289, para. 36.

132 Case C-124/97, Läärä ECR [1999], I-6067.

133 Ibid., para. 37.

134 Ibid., para. 30.
} 
"In so far as the authorities of a Member State incite and encourage consumers to participate in lotteries, games of chance and betting to the financial benefit of the public purse, the authorities of that State cannot invoke public order concerns relating to the need to reduce opportunities for betting in order to justify measures such as those at issue in the main proceedings." 135

In relation to monopoly systems the Court in Stoss and others decided that:

"[...] the establishment of a measure as restrictive as a monopoly, which can be justified only in order to ensure a particularly high level of consumer protection, must be accompanied by a legislative framework suitable for ensuring that the holder of the said monopoly will in fact be able to pursue, in a consistent and systematic manner, the objective thus determined by means of a supply that is quantitatively measured and qualitatively planned by reference to the said objective and subject to strict control by the public authorities". ${ }^{136}$ (emphases added)

A choice for a monopoly-based policy has to be embedded in a general policy that is aimed at a high level of consumer protection. In addition, the choice for a monopolist is only genuine if the legislative framework that establishes a monopolist suitably (qualitatively) equips and limits the activities (quantitatively) of the monopolist in a way that genuinely reflects the chosen policy of a high level of consumer protection. This strand of case law of the Court makes clear that the fundamental choice for a system of protection affects the assessment of Member State policy along the consistency yardstick of the Court. As such, the Court has developed a number of concrete guiding principles that clearly illustrate when a Member State is genuine and when a Member State is hypocritical in its intentions to limit gambling opportunities. Stoss and others and Carmen Media best illustrates how far such an analysis can go. For example, advertising issued by the holder of a public monopoly has to remain measured and strictly limited to what is necessary in order to channel consumers towards authorised gaming networks. In Stoss and others the Court limited the possibilities for advertisement, within a system of protection aimed at a high level of consumer protection, significantly:

"[...] any advertising issued by the holder of a public monopoly remain measured and strictly limited to what is necessary in order thus to channel consumers towards

\footnotetext{
${ }^{135}$ Case C-243/01, Gambelli [2003] ECR I-13031, paras 67, 69.

136 Ibid., para 83.
} 
authorised gaming networks. Such advertising cannot, however, in particular, aim to encourage consumers' natural propensity to gamble by stimulating their active participation in it, such as by trivialising gambling or giving it a positive image due to the fact that revenues derived from it are used for activities in the public interest, or by increasing the attractiveness of gambling by means of enticing advertising messages depicting major winnings in glowing colours". ${ }^{137}$ (emphases added)

The referring courts in Stoss and others and Carmen Media also noted, in relation to casino games and automated games, that the public authorities had been developing or tolerating policies of expanding supply despite the fact that the concerned forms of gambling (as follows from the judgment) presented a higher potential risk of addiction. Possibilities of casino games on the internet were tolerated and automated games could be exploited in a lot of establishments other than casinos, gaming arcades, restaurants and cafes. ${ }^{138}$ These circumstances led the Court to conclude that the German courts:

"[...] may legitimately be led to consider that the fact that, in relation to games of chance other than those covered by the public monopoly at issue in the main proceedings, the competent authorities thus conduct or tolerate policies aimed at encouraging participation in those other games rather than reducing opportunities for gambling and limiting activities in that area in a consistent and systematic manner, has the effect that the objective of preventing incitement to squander money on gambling and combating addiction to the latter, which was at the root of the establishment of the said monopoly, can no longer be effectively pursued by means of the latter, so that the latter can no longer be justified having regard to Articles 43 EC and 49 EC". ${ }^{139}$ (emphases added)

Within this evaluative framework Member States are free to disregard other Member States' systems of protection when choosing the level of protection they want to ensure in their territories. ${ }^{140}$ The Court considers in these cases that national authorities enjoy a 'measure' of discretion to enable them to determine what is

\footnotetext{
137 Ibid., para. 103.

138 Cases C-316/07, C-358/07 to C-360/07, C-409/07 and C-410/07, 07 Stoss and Others [2010] ECR I08069, paras 100 and 106 and case C-46/08 Carmen Media [2010] ECR I-08149, paras 67 and 68.

139 Joined Cases C-316/07, C-358/07 to C-360/07, C-409/07 and C-410/07 Stoss and Others [2010] ECR I-08069, para. 106 and judgment of 8 September 2010 in case C-46/08, Carmen Media [2010] ECR I08149, para. 68.

140 Ibid., (Stoss and Others), para. 80.
} 
required in order to ensure the level of protection they want and the means to pursue them. It will then, however, scrutinize the measures as to their genuine nature, systemacy and coherence in a global assessment of the regulatory context. The normative principle that is inherent in this model is that Member States enjoy the freedom, with respect to legitimate interests, to choose levels of protection as well as the substantive content of them as long as the measure fulfils a standard of good governance.

Another standard of good governance can be traced back to the $1980 \mathrm{~s} .{ }^{141}$ The Court started formulating procedural guarantees, which had to be satisfied in relation to restrictive Member State measures. They related to judicial review and standards to be met by administrative procedures, which resulted in the granting or refusing an authorization or a license. For example in the Medien Vertriebs case the Court considered that the procedure governing access "must be one which is readily accessible, can be completed within a reasonable period, and, if it leads to a refusal, the decision of refusal must be open to challenge before the courts". ${ }^{142}$ These types of requirements are reminiscent of a series of Court rulings that have established that, when awarding a services concession, a public authority is subject to EU Treaty principles of non-discrimination and equal treatment and that these principles imply an "obligation of transparency". ${ }^{143}$ That obligation means that, before their award, services concessions must be subjected to a degree of advertising, which is sufficient to open them to competition. Small exceptions to these transparency requirements are allowed if:

“[...] the Member State concerned decides to grant a licence to, or renew the licence of, a public operator whose management is subject to direct State supervision or a private operator whose activities are subject to strict control by the public authorities". ${ }^{144}$ (emphases added)

141 See also S. Prechal, 'Free Movement and Procedural Requirements: Proportionality Reconsidered', (2008) 3 Legal Issues of Economic Integration at 201

${ }^{142}$ Case C-244/06 Medien Vertriebs [2008] ECR I-00505, par. 50

143 See for example case C-324/98 Telaustria and Telefonadress [2000] ECR I-10745, paragraphs 60 to 62; Case C-206/08 Eurawasser [2009] ECR I-0, para. 44; and Case C-91/08 Wall [2010] ECR I-0, para. 33

${ }^{144}$ Case C-203/08, Betfair [2010] ECR I-04695, para. 59. 
Similar cases are cases like Radlberger v Land Balden-Wuterrtemberg where legislation was held to run counter to the principle of proportionality on the grounds that traders were given insufficient time to adapt to it. ${ }^{145}$ Similarly, the Court held in Commission v Austria (a case that preceded the other traffic ban of Austria on the Brenner pass discussed above) that:

"a transition period of only two months between the date on which the contested regulation was adopted and the date fixed by the Austrian authorities for implementation of the sectoral traffic ban was clearly insufficient reasonably to allow the operators concerned to adapt to the new circumstances". ${ }^{146}$

The same kind of requirement applies to administrative authorization schemes, which must be based on "objective, non-discriminatory criteria known in advance, in such a way as adequately to circumscribe the exercise of the national authorities' discretion". ${ }^{147}$ Laval can be seen as, partly, imposing a similar obligation on collective action that is restrictive towards foreign service providers and:

"cannot be justified in the light of the public interest [...], where the negotiations on pay, which that action seeks to require an undertaking established in another Member State to enter into, form part of a national context characterized by a lack of provisions, of any kind, which are sufficiently precise and accessible that they do not render it impossible or excessively difficult in practice for such an undertaking to determine the obligations with which it is required to comply as regards minimum pay". ${ }^{148}$ (emphases added)

Another good example is Commission v Spain where the Court assessed regional measures in Catalonia that regulated the setting up of large retail establishments. Retail establishments of a certain size were subject to a system of prior authorization. ${ }^{149}$ Spain argued that the provisions related to town and country planning and environmental protection. By confining the location of large retail

\footnotetext{
145 Case C-309/02 Radlberger v Land Baden-Wurttemberg [2004] ECR I-11763, similar reasoning with regard to the fulfilment of proportionality is applied in cases such as C-463/01 Commission v Germany [2004] ECR I-11705, paras 79-80

${ }^{146}$ Case C-320/03 Commission v. Austria [2005] ECR I-09871, para. 90.

147 For example, case C-367/12 Sokoll-Seebacher [2014] np, para. 27, case C-169/07 Hartlauer [2009] ECR I-1721 paragraph 64.

148 Case C-341/05, Laval [2007] ECR I-11767, para. 110.

149 Case C-400/08 Commission v Spain [2011] ECR I-01915.
} 
establishments to 'population centers', where the demand would be greatest, and by limiting the size of establishments in less populous areas, the legislation was seeking to avoid polluting car journeys, to counter urban decay, to preserve an environmentally integrated urban model, to avoid new road building and to ensure access by public transport. The Court first established that:

"taken as a whole, those specific restrictions laid down in the contested legislation significantly affect the possibility of opening large retail establishments on the territory of the Autonomous Community of Catalonia. In such circumstances, the reasons which may be invoked by a Member State in order to justify a derogation from the principle of freedom of establishment must be accompanied by an analysis of the appropriateness and proportionality of the restrictive measure adopted by that Member State, and by precise evidence enabling its arguments to be substantiated". ${ }^{150}$ (emphases added)

The Court then considered that the introduction of preventative and therefore prior measures must be regarded as appropriate means of achieving the objective of environmental protection. A rational connection was established since the adoption of measures a posteriori, if the setting up of a retail establishment already built should prove to have a negative impact on environmental protection, would certainly be less effective and more costly as compared to a system of prior authorization. However, then the Court investigated the procedural criteria and found that they required the application of ceilings as regards the market share and the impact on existing retail trade that the Retail Facilities Committee, which codecided on the authorization, was composed of potential competitors of the economic operator wishing to set up a new large establishment in Catalonia and that the only sectoral interest represented in that committee was that of the existing local trade and without representation of environmental or consumer interests. ${ }^{151}$ As such, even though the substantive measures themselves were considered appropriate, the design of the authorisation procedure was considered misconstrued.

Floris de Witte has commented that the procedurally oriented version of proportionality, when correctly applied, could allow for the rationalization of the

150 Ibid., paras $81-82$
151 Ibid., paras $109-111$ 
implementation of national policy and argues that it is the ideal tool to be used by the Court to ensure the absence of discrimination and protectionism and to adjudicate conflicts between moral/ethical choices of Member States and the interests of free movement law. ${ }^{152}$ One of the reasons being that the procedural proportionality test would respect the substance of national moral and ethical choices and instead focuses on "teasing out discriminatory or protectionist biases" focusing on "the normative coherence of national policies, the consistent application of sanctions, and legislative transparency"153.

The argument that is developed in this chapter is, on this point, largely in alignment with the conceptualisations of De Witte. It is, however, important to note that the orientation on procedure can have important and structural effects on the way that policy objectives come into existence on a Member State level. In the said gambling cases the Court, in addition to teasing out discriminatory or protectionist measures, also positively implements procedural due care obligations that are to be followed by the Member States. This goes further than teasing out discriminatory or protectionist measures. According to Barnard it is in fact a sign of the excessively rigorous scrutiny that the Court adopts in its evaluation of restrictive measures. ${ }^{154}$ It is argued here that the procedural due care obligations, as well as the rationalization and transparency requirements that the Court purports are part of an emerging internal market principle of "procedural good governance' ${ }^{155}$. Indeed, it is the way in which legislation is adopted or implemented that is becoming increasingly important in determining the compatibility of national rules with the Treaty. The rise of this interpretation of the principle of proportionality appears to reflect a shift towards a culture of justification, of the giving of reasons in due course within a framework that is transparent and calculable. However, it is correct that the "global assessment" approach that the Court purports in these cases allows for more social

\footnotetext{
152 Floris de Witte see above (no. 81) at 1551.

153 Ibid., p. 1573.

154 C. Barnard, "Derogations, Justifications, ad the Four Freedoms: is State Interest Really Protected?" in Barnard and Odudu (eds), The Outer Limits of European Union Law (Oxford, Hart Publishing, 2009) 273.

155 Similarly, see Prechal above (no.141) 201.
} 
diversity in the internal market since it acknowledges that the normative infrastructure of gambling markets differs amongst Member States and shifts the analysis to the procedural soundness and away from guiding the normative choices that a Member State makes.

As to its shortcomings, as in the margins of discretion model, the granting of a definite margin of discretion to the Member States appears loosely connected to the 'sensitivity' of the measure that is being evaluated. This has, however, not been connected to an adjudicative rationale that sets out when this rationale is to be applied by the Court. It is unclear for example why the Court has chosen in the majority of the gambling cases not to apply a necessity test at all, whereas it does do so in cases where regulatory differences between Member States exist, arguably to the same degree, on the basis of, e.g. cultural, historical and regulatory differences. ${ }^{156}$ Although the Court, in these cases also decides that the Member States, from an EU perspective, have 'a degree of latitude' to determine national policy objectives and consequent levels of protection they want to ensure, it will still apply a 'light' or deferential version of the necessity test, noting only the fact that other Member States have established systems of protection that restrict free movement to a lesser degree is of no consequence.

E. Incoherence in the application of the different rationales

Summarising the previous sections, the ideal type models developed by the Court are threefold: (i) the substantive efficiency model, which is concerned with the inherent rationality of a measure and its necessity that purports a normative principle of technocratic managerialism, (ii) the margin of appreciation model that balances conflicts through the allocation of a margin of discretion as soon as the interests at stake are to be considered removed from trade and valued as 'sensitive', and (iii) the good governance model that looks at the measure in its

156 Compare for example with judgment case C-244/06 Medien Vertriebs [2008] ECR I-00505 in relation to the level of protection for which the German government opted in relation to minimum age requirements for watching Japanese Manga movies that were in free circulation in the UK. 
procedural and governance context and advances principles of transparency, coherence and consistency. In the application of each of these 'ideal type' models, the Court seems to be without a clear rationale as to when a definite margin of discretion is explicitly granted to Member States, when interests are to be considered sensitive ${ }^{157}$ and when a focus on procedural context is more appropriate than an evaluation of the necessity of the substantive measures themselves. ${ }^{158}$

For example, in Medien Vertriebs the Court decided with respect to the level of protection for which the German government opted in relation to minimum age requirements for watching Japanese Manga movies that were in free circulation in the U.K. that:

\begin{abstract}
"it is not indispensable that restrictive measures laid down by the authorities of a Member State to protect the rights of the child, [...], correspond to a conception shared by all Member States as regards the level of protection and the detailed rules relating to it $[\ldots]$. As that conception may vary from one Member State to another on the basis of, inter alia, moral or cultural views, Member States must be recognised as having a definite margin of discretion." 159 (emphases added)
\end{abstract}

However, the Court then moved on to evaluate the substantive scope of the prohibition, by establishing that the concerned measure did not preclude all forms of marketing of unchecked image storage media, considering that in the light of those factors, the protective rules did not go beyond what is necessary to attain the objective pursued. Its assessment was oriented on the substance of the measures. Equally, in Omega the Court considered that, despite, again the existence of a 'definite margin of discretion' ${ }^{160}$ for Member States to define how economic activities should be exercises in a manner that respects human dignity, the justification for a derogation from the fundamental freedom to provide services, must be interpreted strictly and considered justified "only if they are necessary for

\footnotetext{
157 Compare also with Case C-137/09 [2010] Josemans ECR I-13019 for example where there was no explicit mention whatsoever of a margin of discretion despite similarly intensity in differences in regulatory contexts between Member States as to the regulation of soft drugs.

158 See on this also Damjanovic,( above no. 81).

159 C-244/06 Medien Vertriebs [2008] ECR I-00505, para 44

160 Case C-36/02 Omega [2004] ECR I-9609, para. 31.
} 
the protection of the interests which they are intended to guarantee and only in so far as those objectives cannot be attained by less restrictive measures". ${ }^{161}$ The Court then considered very briefly that by prohibiting "only the variant of the laser game the object of which is to fire on human targets" and thus "play at killing' people, the contested order did not go beyond what is necessary in order to attain the objective pursued by the competent national authorities. ${ }^{162}$

As regards the suitability of the measure, the Court did in these cases not engage in any 'global assessment' of the regulatory context within which the measures were taken. I mention this merely to illustrate that the Court has not been willing or able to formulate an approach that can be considered coherent or consistent in cases where Member States are granted a definite margin of discretion in the formulation of their policy objectives. ${ }^{163}$ In this respect Davies has submitted that

"The rules and principles stated by the Court are far better understood as embodying a series of compromises, perceptions of fact, and pragmatic approximations which aim to deal with the problems of evidence, workload, and legal clarity, rather than as an ongoing monologue about market philosophy. Looking in the case law for a coherent framework addressing these classical judicial concerns is ... quite fruitful. Looking in the case law for clear or consistent guidance about the conceptual foundation of economic integration is, as internal market lawyers know, a hopeless cause". ${ }^{164}$

According to Davies the Court is unable or uninterested in defining a coherent approach in its case law. ${ }^{165}$ However, the foregoing analysis has demonstrated that, if perceived as ideal types, there are certain clear trends in the rationales the Court adopts in adjudicating free movement conflicts, which allows the formulation of a normative critique that aims to reconstruct this case law into a more coherent and consistent model of adjudication. It will be argued that this can

161 Ibid., para 36 .

162 Ibid., para 39.

163 See Shuibhne above (no. 66) at p 31 et seq for potential explanations for this incoherence.

164 G Davies, 'The Court's jurisprudence on free movement of goods: Pragmatic presumptions, not philosophical principles' (2012) 2 European Journal of Consumer Law 25 at 27.

165 In contrast see K. Lenaerts, "The Court's Outer and Inner Selves: Exploring the External and Internal Legitimacy of the European Court of Justice" in H. Clemens et al., Judging Europe's Judges : The Legitimacy of the Case Law of the European Court of Justice (Hart, 2013), p. 13-60. 
be achieved on the basis of a rationale of mutual responsiveness. The analysis will now start to move in that direction.

\section{A dialogue of mutual responsiveness: the interplay of principles of substantive efficiency, margins of discretion and good governance in free movement adjudication}
A. Between managerialism, margins of discretion and good governance: A responsive model

The ideal type models reveal the three main evaluative principles that are advanced in EU free movement law to test member States' regulatory choices and accommodate social diversity: the principles of technocratic managerialism, margins of discretion and procedural good governance. The model of embedded liberalism requires that these evaluative principles are to be applied dynamically, responsive to the presence or absence a conflict between normative principles in free movement cases.

This section argues that the dividing line between the identified main organisational principles advanced through EU free movement law should find its basis in the identification of the nature of a conflict in terms of normative principles. It was argued previously that the compromise of 'embedded liberalism', which the basic constitutional infrastructure of the internal market reflects, depends on the constructive interplay between the objectives of market integration with domestic public interests. In its ideal form the principle of embedded liberalism would therefore in a first stage 'use' the narrow normative framework of free trade objectives to tease out and understand regulatory choices that restrict free trade objectives and in a second stage adopt an evaluative principle that is congruent with the regulatory context that gave rise to the restriction. In this way domestic social values can be recognised within a supranational market integration rationale.

It was discussed that the substantive efficiency model of proportionality, implements a utilitarian approach. In addition to denying a governing principle (such as the utility principle), incommensurability in the context here developed 
holds that there cannot be a priority rule in genuine conflicts between organizational principles (that is, no value always has priority over another). One of the key points of the case law of the Court in the discussed gambling saga is that a system of protection that a Member States installs has to be embedded by ex ante conditions justifying the Member State choices. If systems of protection are coherently and systematically part of an existing infrastructure that is tailored towards the level or protection that it seeks to protect, these systems of protection are provided with a margin of discretion and unlikely to be struck down by EU law. In other words, Member States systems of protection need to be transparent, systematic and internally coherent but if these conditions are taken into account then the level of protection and the means through which this level of protection is sought remains largely at the discretion of the Member States. Inherent in the approach that the Court has taken in this area is the notion that there is no common standard through which to assess the levels of protection that Member State's opt for. Instead, the adjudicative evaluation focuses on how the regulatory context is designed and whether that design conforms to a certain idea of good governance.

The type of responsiveness that is meant here is, to an extent, visible, for example, with regard to the application of the EU competition rules, where the Court has established in some cases that social structures on a Member State level, designed on the basis of the principles of solidarity, are incompatible with the functioning of a sector on the basis of a normative principle of capitalisation. ${ }^{166}$ Therefore, as will be further discussed in chapter III, EU competition rules do not apply in full to sectors that are primarily organised on the basis of solidarity principles, provided that there are some guarantees of institutional design that guarantee transparency and a coherent, active form of state supervision. ${ }^{167}$ In these cases, the Court explicitly recognises legitimate normative principles on a Member State level that do not 'fit' within the normative order of the competition rules, on

\footnotetext{
166 See for an overview T. K. Hervey 'Social solidarity: a buttress against internal market law' in J. Shaw (ed.), Social Law and Policy in an Evolving European Union (Hart Publishing 2000) p. 31-47.

167 Case law starting with case C-159/91 and C-160/91 Poucet Pistre 1993 ECR I-00637.
} 
the basis of a rationale that is arguably based on a recognition of conflicting normative principles.

The identification of a conflict along the lines of this reasoning can be further illustrated on the basis of the case Commission $v$ Germany (occupational pensions). ${ }^{168}$ The Commission consider that Germany failed to respect the public procurement Directives. A collective agreement between an association of employers and a trade union reserved pension services to three specific groups of service providers and excluded a large number of insurance companies from the market, thus, the Commission argued, reducing competition and increasing the price for the service. The German authorities had argued that the procurement directives could not apply because the social objectives pursued, by virtue of the process of a collective agreement, in favour of certain pension schemes, necessitated reduced competition and, hence, justified the exclusion of the procurement rules. The German system deprived employers from their authority to select by replacing it with "a consensual solution arrived at by the social partners". Therefore, the selection of the pension scheme providers was, in itself, by virtue of the process, the relevant social concern. The Court did not accept this argument on the basis of an illuminating rationale. The Court demanded a revisit of these objectives by looking specifically at the concrete objective that was sought within the German system of governance. For this purpose, the Court assessed specifically whether the two central aims - the social objectives versus procurement - were indeed 'inherently irreconcilable' with each other in this specific instance and found that

"the pooling of risks, upon which any insurance activity is based, can be ensured by
a body or undertaking that provides pensions which is selected following a call for
tenders at European Union level. Nor is there anything in the public procurement
directives to preclude a local authority employer from specifying, in the terms of the

${ }^{168}$ Case C-271/08, Occupational pensions [2010] ECR I-07091. See on the potential of this case also S. Deakin "The Lisbon Treaty, the Viking and Laval judgments, and the financial crisis: in search of new foundations for Europe's 'social market economy'" in N. Bruun, K. Lörcher and I. Schömann (eds), The Lisbon Treaty and Social Europe (Hart Publishing 2012), p. 19-43. Also P. Syrpis, 'Reconciling Economic Freedoms and Social Rights-The Potential of Commission v Germany (Case C-271/08, Judgment of 15 July 2010), Industrial Law Journal 40(2011) at 222-229. 
call for tenders, the conditions to be complied with by tenderers in order to prevent, or place limits on, workers interested in salary conversion being selected on the basis of medical grounds." 169

In other words, although it was argued that there was in this case a conflict between normative principles, between principles of solidarity and the market, the Court found that there was in fact, in concreto, no such conflict. That is to say, that the actual objective of the collective agreements could be achieved within the ambit of the procurement rules, without inhibiting the actual, specific, social objective. As such, the Court in this case set out a 'compatibility agenda' on the basis of an adjudicative 'inherently irreconcilable' rationale. ${ }^{170}$ Concomitantly, the Court demonstrates a means to think about the two identified main normative principles of the internal market, between substantive efficiency and procedurally oriented good governance evaluations.

The choice for either of these models can be instructed by the identification of the nature of conflicting objectives as being 'inherently irreconcilable'. On the basis of a prima facie structuring of a conflict based on the 'narrow' aims of market based substantive efficiency, the Court could first assess whether the restrictive aims, which are pursued by Member Sates are inherently irreconcilable with substantive efficiency objectives of the internal market. In the case at hand, the Court found the objectives to be reconcilable and, consequently, the focus on substantive efficiency was, within the model proposed, acceptable. In contrast, if found to be irreconcilable, the Court would have had to switch to an assessment of the wider procedural context of the measures. This is a model that is mutually responsive and provides an operational principle of embedded liberalism to be incorporated in an adjudicative rationale; inherently irreconcilable local domestic values will be separated within a rationale of supranational market integration and vice versa market integration objectives are pursued on the basis of the infusion of procedural unity, transparency, consistency and coherence within those local

169 Case C-271/08, Occupational pensions [2010] ECR I-07091, para. 58.

${ }^{170}$ See also the Opinion of AG Wahl delivered on 30 April 2014 in case C-113/13 Azienda sanitaria locale [2014] $\mathrm{np}$. 
structures. This approach will allow the Court to recognise legitimate normative principles on a Member State level that do not 'fit' within the utilitarian normative order of the free movement rules and accordingly guide the Court in its adoption of an evaluative rationale.

It is submitted that the starting point of a more responsive adjudicative model therefore requires a clear understanding of the normative principles and rationales at work in EU free movement law. Such an understanding will also clarify what it means for the Member States to commit themselves to an integrating market. This commitment shifts between the implementation of organisational principles based on substantive efficiency and good governance.

If the previously identified ideal type models are used as building blocks, a coherent adjudicative model can be constructed on this basis, which meets the normative claims of social legitimacy. This shall be highlighted in the following section, which reframes some exemplary cases within the proposed rationale with an emphasis on how the irreconcilability test can improve the selection of an evaluative rationale that is responsive to social context and through an articulation of a potential conflict of norms improve the expressive value of free movement law.

B. Reframing exemplary free movement cases within the proposed rationale

The functioning of the proposed inherently irreconcilable test and the consequent choice for an evaluative model can be illustrated by shortly reframing three paradigmatic cases within the proposed model: Volkswagen, Omega and Viking. ${ }^{171}$

i. Volkswagen: valuing the "social acquis" of a Member State within the internal market

171 Case C-112/05, Commission v. Germany, [2007] ECR I-8995, Case C-438/05 Viking Line [2007] ECR I-10779, Case C-36/02 Omega [2004] ECR I-9609. 
Volkswagen is a paradigmatic case mainly because it showcases a free movement case where there is a conflict between a supranational rationale of free capital exchange with shareholder primacy and a local governance model, which is exemplary of the German social economic system of negotiated solutions and contrary to shareholder primacy. ${ }^{172}$ The case demonstrates in principle how the adjudicative model of the Court is capable to value different normative orientation within economic systems of Member States.

Porsche had set out to take over Volkswagen but found its plans blocked by the control mechanisms that existed in the Volkswagen company, Volkswagenwerk, for the reason of safeguarding the interests of all affected stakeholders. Importantly, the Land of Lower Saxony had a blocking $20 \%$ shareholder vote on the basis of the Volkswagengesetz (VW Law) that, inter alia, capped voting rights at 20 percent for all shareholders. The VW Law has a complex and interesting history. ${ }^{173}$ The law had been adopted in 1960 to put an end to the disputes between various groups of persons who had laid claim to private rights over the limited liability undertaking, which had basically become ownerless after the Second World War. The Commission brought proceedings against the VW Law for infringing the rules on the free movement of capital. The Court agreed with the Commission that the controlling rights in the VW Law derogated from general German company law and provided the Land of Lower Saxony to exert considerable influence on Volkswagen, beyond that which it could exert under general company law. That considerable influence was liable to deter investors from other member states. ${ }^{174}$ Germany was unable to provide convincing arguments that demonstrated in concreto why the control mechanisms were necessary to protect the interests of

172 See C. Gerner-Beuerle, "Shareholders between the Market and the State: The VW Law and Other Interventions in the Market Economy," Common Market Law Review 49, no. 1 (2012): 97-144. Also J. Snell, "Varieties of Capitalism and the Limits of European Economic Integration," Cambridge Yearbook of European Legal Studies 13 (2011): 415-34 and F. De Cecco, State Aid and the European Economic Constitution (Oxford: Hart Pub., 2013), 24 (chapter on the limits of constitutional adjudication).

173 See the opinion of Advocate General Colomer in Case C-112/05, Commission v. Germany, [2007] ECR I-8995.

174 Case C-112/05, Commission v. Germany, [2007] ECR I-8995, para. 60. 
workers and minority shareholders against the whims of a single shareholder, and how a company as big as VW could affect the general interest. ${ }^{175}$

After a similar prima facie structuring of the conflict, the preliminary step in the proposed responsive model of adjudication would ask whether the conflicting normative principles at hand were 'inherently irreconcilable'. Essentially, at the centre of the case stand two competing models of governance; shareholder primacy and free capital movement versus a model that negotiates stakeholder interests. The rationale of shareholder primacy and capital movement requires a governance model that puts shareholder interests as a first priority relative to other corporate stakeholders, including the power to intercede directly and frequently in corporate decision-making (one share, one vote). The stakeholder interest model is irreconcilable with this model since it broadens the scale of interests that are relevant for the company and pulls the corporate-decision making process away from a model, which can be validated purely on the basis of shareholder value towards a framework of nonmarket mechanisms of negotiated compromise. After the identification of these competing normative principles, and establishing that a governance model as pursued by the German authorities is a legitimate objective, the evaluative principle to be used in order to scrutinise the German governance model would be based on principles of good governance, as highlighted above, and not substantive efficiency. This would not necessarily lead to another outcome of the case but the object of the evaluation would be radically different. The scrutiny would concern the choice for the governance model; the coherence and transparency of the decision making process; the availability of an appeal process and the broader coherence with the policy objectives of the German authorities. Moreover, the veto power of the Land would have to be specifically embedded within and limited as to the protection of the general public interests at stake; the use of a veto would have to be articulated in a reasoned and open fashioned as to what the justifications were; involve explicit consideration of alternatives; and all stakeholder interests would have to be considered. As such, the advantage of the

175 Ibid., paras 72-82. 
responsive model is that it allows diverging governance models to exist in accordance with good governance principles, which explicitly allow regulatory diversity, yet stimulate EU wide procedural unity in these matters that can clearly be connected to the supranational market integration objectives (transparency, consistency and contemporaneousness).

\section{ii. Omega: the importance of mutual responsiveness in the pursuit of legitimate objectives}

Another exemplary case to illustrate the responsiveness model is Omega. ${ }^{176}$ The Omega case is often referred to as an example where the Court has been explicitly sensitive towards specific Member State context since it restricted the market freedoms in favour of a fundamental right. ${ }^{177}$ However, the proposed model would find the approach of the Court of Justice in Omega lacking from the perspective of mutual responsiveness. In Omega, the conflict at stake concerned the values of a local community that opposed the establishment of a British based laserdome venue, where people would be making fun of shooting each other with laser guns. The police of the German state North Rhine-Westphalia ordered a prohibition of these games as they constituted a danger to public order. It was considered that acts of simulated homicide and the trivialization of violence were contrary to the fundamental values prevailing in public opinion. Omega argued instead that the order was contrary to EU law, in particular the free movement of services. The Court established first that

"the Community legal order undeniably strives to ensure respect for human dignity as a general principle of law. There can therefore be no doubt that the objective of protecting human dignity is compatible with Community law, it being immaterial in that respect that, in Germany, the principle of respect for human dignity has a particular status as an independent fundamental right". ${ }^{178}$

176 Case C-36/02 Omega [2004] ECR I-9609.

177 For example Weatherhill (above no 110).

178 Case C-36/02 Omega [2004] ECR I-9609, para. 34. 
The Court considered that despite the existence of a 'definite margin of discretion' for Member States to define how economic activities should be exercised in a manner that respects human dignity, the justification for a derogation from the fundamental freedom to provide services, was to be interpreted strictly and could be considered justified, "only in so far as those objectives cannot be attained by less restrictive measures". ${ }^{179}$ The Court then considered, albeit briefly, that by prohibiting "only the variant of the laser game the object of which is to fire on human targets", the contested order did not go beyond what is necessary to attain the objective pursued by the national authorities. ${ }^{180}$ As such, the Court applied a light substantive review of the restriction.

On the basis of the model of responsiveness as a first step, the Court would assess whether the economic activity that was sought in this case was inherently irreconcilable with the legitimate public interest concerning human dignity as expressed by the local authorities. The answer to this question would be "yes", since the legitimate measure in question was supposed to be a reflection of local values, which opposed and specifically targeted the activity in question, and as such, was inherently irreconcilable with the principle of market access. The two objectives were, in that sense, incommensurable. Within the model proposed, that finding would then guide the Court in its choice for the subsequent evaluative principle. The incommensurability of the objective of market access with local values would guide the Court towards an application of good governance principles, which would assess the measure in its broader regulatory context. It would then be scrutinized whether the decree from a local police authority was sufficiently transparent, to determine whether the activity in question was genuinely contrary to fundamental values prevailing in public opinion, and whether it was a coherent policy response, or rather, an arbitrary process risking the complete exclusion of an assessment of transnational interests. Again, the advantage of this reasoning over the margin of appreciation model that the Court applied in this case

\footnotetext{
179 Ibid., para. 36.

180 Ibid., para. 39.
} 
is that local values are accommodated within a supranational market integration rationale, instead of a rationale that excludes such measures from the internal market dialogue completely.

\section{iii. Viking: resolving the fundamental tension of the internal market on the basis of a dialogue of mutual responsiveness}

In Viking, the Court was required to balance the right to strike of trade unions with the right to reflag a ship for the purpose of acquiring lower wage employees. ${ }^{181}$ As is well known, it is considered to be the paradigmatic case, demonstrating the Court of Justice's preference for free trade over social concerns. In simple terms, the normative principles that clashed in this case concerned the economic principle of market access with the lowest cost possible and the social principle reflected in the decision to strike, as a means for workers to protect their interests within that dynamic. Once more, within the adjudicative model proposed, the preliminary question asked is whether the exercise of the right to strike was inherently irreconcilable with the exercise of the economic activity in question. In the Viking case, this question would have to be resolved by asking the question as to whether the action at stake essentially fulfilled a market enabling function. Arguably, a number of labour market rules fulfil exactly this function by reducing transaction costs and information asymmetries in wage setting, and, consequently, they do not originate from another normative sphere than the one advanced by the market. In other words, they support a rationale that follows the allocative logic of market supply and demand. ${ }^{182}$ However, a set of rules that would delegate components of wage-setting and features of industrial relations to an institutional domain beyond this market enhancing logic qualifies as a factor that originates from another normative principle, as they explicitly shield employee interests from market

${ }^{181}$ Case C-438/05 Viking Line [2007] ECR I-10779, para. 32.

182 Further on this A. Ebner, 'Transnational Law and the Polanyi Problem', in C. Joerges and J. Falke, Globalisation and the Potential of Law in Transnational Markets (Hart Publishing Limited, 2011). p. 28. 
conditions. ${ }^{183}$ The difference is nuanced but important. The former includes the social within the market sphere by turning it into a manageable and, arguably, even a beneficial constraint. The latter is concerned with a protective shield against an dis-embedding market rationale and seeks to decommodify the workers interest. In Viking, this (the latter) seems to be exactly the interest that was at stake. The economic order required the facilitation of a transfer to lower wage employees and subsequent market access, whereas the social sphere reserved the right to block that movement and access, as a preventive and safeguarding measure for workers rights that would otherwise be discarded. The strike was aimed to elevate the conflict to an institutional domain beyond this market enhancing logic. This contextualization of the conflict would be responsive to the underlying social context and imply that the evaluative framework of the Court applied to such a conflict could not be concerned with the question as to whether there was a less restrictive substantive measure available. This responsiveness was lacking in the analysis of the Court, which was one-dimensional and only recognised the strike as having "the effect of making less attractive, or even pointless, [...], Viking's exercise of its right to freedom of establishment" ${ }^{\prime 184}$. As such, the Court disregarded the social reality in which the conflict arose and undermined the social purpose of the right to strike within the specific regulatory context in Finland. Within the proposed model the evaluative framework of the Court would, after concluding irreconcilability between market access and the right to strike, move toward the evaluative model of good governance. This would involve an assessment of the concreteness of the employee interests at stake, the coherence and consistency of the protection of this interest within its regulatory context, and the transparency of the system itself.

Paradoxically, it seems, in fact, that in its analysis the Court was mainly concerned with this question. In its referral, the Court indicated that the necessity of collective action was significantly hampered on the basis of the fact that the policy rules combating the use of flags was misconstrued. The design of the policy rules

\footnotetext{
183 Ibid., p. 28.

${ }^{184}$ Case C-438/05 Viking Line [2007] ECR I-10779, para. 72.
} 
would, if triggered by one of its members, always lead to solidarity action against the owner of a vessel, irrespective of whether or not that owner's exercise of its right of freedom would actually be liable to have a harmful effect on the work or conditions of employment of its employees. ${ }^{185}$ In other words, the design of the system of collective action was flawed, making the measure inappropriate as a genuine means of worker protection in its broader regulatory context. Therefore, the Court applied a procedural review of the regulatory framework that led to the restriction. However, it came to that conclusion on the basis of a flawed framing of the conflict, which undermined the responsiveness to the underlying social context, because the rationale that was applied by the Court necessarily subordinated social rights to market freedoms.

\section{Conclusion}

The first chapter pointed out that it can be discussed whether the fact that many restrictive Member State regulations perish within the evaluative framework of the Court is because Member States themselves do not really understand the functions of their own laws, nor defend them well, or whether the problem concerns the way that the Court often chooses to frame things, in consequentialist, purposive terms ${ }^{186}$ which simply fails to capture and weigh the true social significance of some restrictive rules. However, one thing that is clear is that the culture of justifications that the Court of Justice pursues in its proportionality model requires a clearer articulation of the requirements and the limits of market integration. Social legitimacy requires the Court to be consistently responsive to accommodate Member State diversity and promote the objectives of the internal market; an integrated market that is responsive to a Member State's differing sets of social contexts. $^{187}$

\footnotetext{
${ }^{185}$ Ibid., paras 87-90.

186 Ibid.

187 Moreover, this would be a rationale that is in tune with the Lisbon judgment of the German Federal Constitutional Court Case 2 BvE 2/08 et al Lissabon [2009] where it decided that EU law can be
} 
The balance between the requirements from the EU internal market for Member States regulatory choices, whilst at the same time respecting the 'fundamental structures' that exist in the Member States, through a recognition of a diversity of regulatory options, is one of the structural challenges faced by the internal market project. ${ }^{188}$ The different ways in which the Court has balanced these conflicts in the area of free movement, by granting margins of discretion in some cases and not in others, and by focusing exclusively on procedural context in some cases and not in others, demonstrates how the Court is struggling and in need of an operational principle. This need is clearly related to the social legitimacy question that stands central in this thesis. Looking through the lens of social legitimacy at EU free movement adjudication tells a mixed story. On the one hand there is clearly a responsiveness, which shows a concern for diversity and respect for local social context. On the other hand there are plenty of cases where the Court foregoes social context and pushes a normative perception of the way in which social objectives and market integration relate to each other. What is identified in the chapter as lacking is a consistent use of the ideal type proportionality rationales by the Court that move between principles of managerialism and good governance. Again, in the application of each of these 'ideal type' rationales, the Court seems to be without a clear rationale as to when a definite margin of discretion is explicitly granted to Member States, when interests are to be considered sensitive and when a focus on procedural context is more appropriate than an evaluation of the necessity of the substantive measures themselves. This incoherence threatens the application of mutual responsiveness and thereby social legitimacy. On the one hand a normative metric of evaluation may be adopted that is unresponsive to legitimate social context within a Member State. On the other margins of discretion may be granted to Member States whereas regulatory measures could have potentially been implemented in a more Union friendly way.

rejected i fit would limit the sovereignity of the state to an extent that it can no longer define the socio economic circumstances of its citizens.

188 See on this point also A Somek, 'The social Question in a Transnational Context' LSE “Europe in Question” Discussion Paper series, June 2011. 
The rationality of responsiveness in the adjudicative model of EU free movement law is to find the societal basis of a conflict through a discursive process that allows market rationality to question Member States protective organizations but allows nonmarket rationales to exist and remain an embedding fabric on the Member State level. The social purpose of the internal market is not to condition choices that require market to trump social or its opposite. The approach suggested in this chapter purports a more holistic idea that conceives the market and the social sphere as 'communicating vessels'. Market derived evaluative standards serve as a tool to tease out discriminatory, disingenuous regulatory choices within Member States but allow for genuine social objectives to exist in accordance with good governance principles that focus on the quality and systemacy of a governance process instead of on the rationality and efficiency of its outcome. In this way there is neither a sacrifice of the market or a sacrifice of the social and, instead, both social diversity and market integration are accommodated within the internal market.

There are a few clear advantages in the proposed model of adjudication that adopts an inherently irreconcilable test as a means of a preliminary qualification of the nature of a conflict before the Court of Justice. First, by 'using' the market access restriction in this way the Court avoids subsequent narratives that assert that the Court is engaged in the pursuit of a neo-liberal biased agenda. A finding of 'reconcilability' will guide the subsequent evaluation on the basis of an assessment of the less restrictive measure. A finding of 'irreconcilability' will guide the subsequent evaluation on the basis of an assessment of the wider coherence and consistency of the procedural context. Consequently, the requirements flowing from the integrating European market will be more explicitly articulated, leading to more unity in the interpretation of these requirements. ${ }^{189}$ It should be noted that, as a result, a particular measure may be considered as illegal in one country,

189 Instead of as was the case in the aftermath of the Viking case which led to various and widely differing national responses as highlighted in M. Blauberger's analysis, 'With Luxembourg in mind...the remaking of policies in the face of ECJ jurisprudence' 19(2012) Journal of European Public Policy, 109-126. 
depending on whether it is embedded in principles of good governance but not in another and during a certain period but not during another. Consequently, each case will need to be decided individually, on its own merits. The clear normative preference here is therefore to further context sensitivity over legal certainty in EU adjudication. ${ }^{190}$ Such context-specificity is a requirement of the Treaties that stands higher than mere legal certainty and will lead to more unity in understanding what is in fact required from an integrating European market.

As such, the proposed normative-prescriptive model of adjudication seeks to serve various purposes. Most of all, it seeks responsiveness to social context in the adjudicative model of the Court. However, in that process it will also establish the substantive scope and reach of the internal market. That is to say, to which point the internal market can accommodate social claims and from which point objectives become inherently irreconcilable. Therefore, the struggle that the Court faces in determining this balance should be cherished as a potential source of deliberative and formative potential for both the EU internal market and the Member States. The process of determining whether objectives are inherently irreconcilable will necessarily lead to a clearer articulation of what is required from Member States in the organization of their regulatory concerns. That is to say, the model will result in the creation of a discursive field that allows for the articulation of Member State prerogatives and the requirements flowing from European integration. This more context-specific model of adjudication will, as an effect, also provide for a clearer instruction to Member States to follow specific good governance principles. It is a model that is sensitive to the problem of judicial review in order to take account of the potential systemic effects of certain policy choices and stimulates a clearer articulation of what is required from Member States in the organization of their regulatory concerns. As such it will improve awareness, identity and importantly, dialogue regarding EU relevant matters not just before the EU courts, but also

${ }^{190}$ For the reverse argument see J. Snell, 'The notion of market access: a concept or a slogan?', (2010) 47 Common Market Law Review at 437 
Chapter II - Social legitimacy in EU free movement law

within the political arenas of the Member States. Concomitantly, interests and values will be better articulated, voiced and hopefully picked up by the Court. 


\section{CHAPTER III}

\section{Social legitimacy in EU competition law}

I. Introduction

II. Problematisation: Valuation, indeterminacy and incommensurability in EU competition law

A. Organizational principles in EU competition law: the debate on valuation 145

i. Goals of competition law $\quad 145$

ii. Non-competition interests within competition law assessments 148

iii. The problem of indeterminacy and the expressive value of competition law $\quad 153$

iv. Competition law as a platform for societal dialogue 162

B. Introduction to the case studies 163

i. The Friesian Horse: the legitimacy of private led public interest objectives 166

ii. The Energy Agreement for Sustainable Growth: the societal relevance of the process or

the rationality of its outcome? 168

iii. The Chicken of Tomorrow: the market rules when the state retracts? 172

III. Responsiveness in the case law of the Court of Justice $\quad 177$

A. Responsiveness to social context in Albany, Poucet Pistre and Wouters 178

i. The Albany building block: valuation of different social spheres 178

ii. Poucet and Pistre building block: a rationale for the alternative valuation of a noneconomic social sphere (part one) 182

iii. Wouters: a rationale for the alternative valuation of a noneconomic social sphere (part

two) 189

B. The requirements of mutual responsiveness in Arduino, Cipolla and Mauri 195

IV. A dialogue of mutual responsiveness: the interplay of principles of substantive efficiency, margins of discretion and good governance in competition law 200

A. A framework of mutual responsiveness 200

B. A return to the case studies on the basis of mutual responsiveness 203

i. Mutual responsiveness in the Friesian Horse case 203

ii. Mutual responsiveness in the Energy Agreement for Sustainable growth 206

iii. Mutual responsiveness in the Chicken of Tomorrow case 207

$\begin{array}{ll}\text { V. Conclusion } & 208\end{array}$ 


\section{Introduction}

The normative claims of social legitimacy that were developed and applied in the previous chapters can be pointedly summarized as follows. Taking as a point of departure the compromise of embedded liberalism, the argument has been submitted that the social purpose of the EU internal market is to provide an infrastructure for the conflict of norms within the Union that arise through the interaction between principles of economic integration and the pursuit of social interests on a Member State level. In turn, this conceptualisation has allowed for the development of a model of social legitimacy that provides normative instructions to the Court of Justice in order to adjudicate conflicts within the internal market infrastructure in tune with a variety of social contexts.

With regard to the application of the competition rules this concerns the extent to which the 'competition interest' that is advanced through the competition rules can be prescriptive with respect to the social interests that are worth pursuing, without inhibiting social diversity and accommodating the constructive interplay of norm conflicts within the Union at the same time. Until late in the 1990s the competition rules were not deeply embedded within the Member States. The Netherlands, for example, was considered as a 'cartel paradise' and there were cartels in all sectors and branches of the economy until the introduction of more stringent legislation in 1998, which only then could be considered to be in closer proximity to the objectives of the EU competition rules. However, the principle of competition has rapidly become one of the principal departure points of public policy and, as Whish and Bailey note

"competition laws will be found in all continents and in all types of economies large, small, continental, island, advanced, developing, industrial, trading, agricultural, liberal and post-communist. Quite apart from its geographical growth, competition law is now applied to many economic activities that once were regarded as natural monopolies or the preserve of the state: telecommunications, energy, transport, broadcasting and postal services, to name a few obvious examples, have become the subject of competition law scrutiny"1.

R. Whish and D. Bailey, 'Competition Law', (OUP, Oxford 2012), at 1. 
Although the competition rules require, in relative comparison to the EU free movement rules, a clear commitment from both Member States and economic operators, the effects of this normative order on social contexts, which are not blatantly contrary to competition objectives, soon becomes potentially problematic from a social legitimacy perspective. In comparison with EU free movement, the competition rules more directly value social relations in a particularly formative manner. As will be discussed further below, the competition rules, in particular 101 TFEU, place emphasis on the benefits that consumers accrue from the process of competition. Solely by virtue of this fact, social relations between producers, which collectively pursue interests on that level, are on the back footing. This amounts to a significant formative effect of the competition rules with regard to social relations in countries that, traditionally, have a more 'producerist' orientation. ${ }^{2}$ Moreover, an important facet of the competition rules is the obligation for subjects of competition law (undertakings) to self-assess their competition law status on the basis of the numerous position and guidance papers that are issued by (national) competition authorities on the basis of, inter alia, the case law of the Court of Justice. In this way competition law becomes, covertly, formative of social context, particularly when guidance is issued on the way that companies should (jointly) pursue social interests, such as sustainability initiatives. These formative effects will become clearer in the case studies that are discussed throughout the chapter.

The question from the perspective of social legitimacy is to what extent such formative valuation carries the risk of disregarding social context that pursues objectives, which are in themselves worthwhile. Should competition in all cases prevail? For example, the Court of Justice brands Irish beef producers that collectively aim to reduce the overcapacity in their sector in order to create an economic climate in which their businesses will be able to survive as measures with the object to restrict competition, which exposes them to significant sanctions. ${ }^{3}$ On

See J. Whitman 'Consumerism versus Producerism: A study in Comparative Law' (2007) Yale Law Journal at 340

3 Case C-209/07 BIDS [2008] ECR I-08637. The starting point for the fine is the percentage of a company's annual sales of the product concerned in the infringement (up to $30 \%$ ). This is then multiplied by the number of years and months the infringement lasted. In cartel cases, the fine is 
the other hand, associations of lawyers that prohibit cooperation between accountants and lawyers and thereby restrict competition in order to protect the integrity of the profession are granted a certain leeway to do so. ${ }^{4}$ On the basis of what principles should the Court of Justice decide to impose a normative view of competition on social contexts that are governed by other normative choices, such as sustainability, animal welfare and deontological principles within the 'free' professions? Particularly, if such principles are embedded within a context that is expressive of a Member States' social/cultural identity. To what extent should and can such context be recognized and 'respected' within the EU competition rules?

Adam Smith famously prophesised that

"people of the same trade seldom meet together, even for merriment and diversion, but the conversation ends in a conspiracy against the public, or in some contrivance to raise prices. It is impossible indeed to prevent such meetings, by any law, which either could be executed, or would be consistent with liberty and justice. But though the law cannot hinder people of the same trade from sometimes assembling together, it ought to do nothing to facilitate such assemblies; much less to render them necessary" .

It is, however, a fact that undertakings do meet and sometimes are also necessitated by national governments to meet, particularly in economies with a producerist orientation, and set standards for the pursuit of social objectives. ${ }^{6}$ This happens for environmental reasons, labour conditions, minimum trade standards and so forth. Agreements that flow forth from the pursuit of such objectives may restrict competition, for example through output restrictions, pricing agreements and prohibitions to trade in products that have been produced beneath certain trade

increased by a one-time amount equivalent to $15-25 \%$ of the value of one year's sales as an additional deterrent. The maximum level of fine is capped at $10 \%$ of the overall annual turnover of a company.

4 Case C-209/07 Competition Authority v Beef Industry Development Society Ltd and Barry Brothers (Carrigmore) Meats Ltd. [2008] ECR I-8637, paras 34-36 and Case C-309/99 Wouters [2002] ECR I1577

5 A. Smith, An Inquiry into the Nature and Causes of the Wealth of Nations (London, UK: George Routledge \& Sons, 1776; reprint, 1893), p.137.

6 See e.g. L. Ankersmit, 'Globalization and the Internal Market: Process-based Measures Within the EU Legal Order' (2015, PhD thesis, Vrije Universiteit Amsterdam); Also H. Schepel, 'The constitution of private governance: product standards in the regulation of integrating markets', (Oxford, Hart Publishing, 2005). 
standards. ${ }^{7}$ From a 'traditionalist' based understanding of competition law such private led initiatives may raise issues since they are likely to restrict the independent operation of the undertakings in the markets concerned. ${ }^{8}$

The diversity of objectives and the requirement for competition law to accommodate the pursuit of diverse social objectives by members of the same trade leads to specific challenges. The chapter finds that the application of the EU competition rules by the Court of Justice and, concomitantly, competition authorities is insufficiently developed to accommodate the pursuit of a diversity of social objectives. ${ }^{9}$ Consequently, on the basis of the normative framework that was introduced in Chapter I they are liable to impede the social legitimacy of EU competition law. This chapter shall develop this finding on the basis of three case examples in the Netherlands, which demonstrate how competition based rationalities carry the inherent risk to exclude social context or translate the social objectives at stake within an efficiency based context but without its fundamental constituent elements.

As was discussed in the first Chapter, there exists an analogy on this point with regard to the formative relationship between law and social norms. Roughly two ideas dominate the debate on the interaction between social norms and the law. One concerns the idea that 'custom' or norm based rules lack the flexibility and rational control that is considered desirable for some higher order reason - in this case competition. Law then could become the means to reform such 'old-fashioned' social norms. Some social norms may not be desirable from a particular rational perspective, and law can then improve the situation by regulating the concerned behaviour in congruence with the desired rationally and correcting undesirable phenomena, such as price agreements between competitors. As was discussed in the Chapter II, this is somehow reflected in the core nucleus of EU law where there

7 Ibid.

8 G. Monti, EC Competition Law (Cambridge UP 2006) p 20-52; R. Nazzini, 'Article 81 EC Between Time Present and Time Past - A Normative Critique of "Restriction of Competition" in EU law' (2006) 43 Common Market Law Review 497-536; G. Monti, 'Article 81 EC and Public Policy' (2002) 39 Common Market Law Review 1057-1099.

9 This Chapter necessarily extends these normative views on competition authorities in their capacity as 'quasi' like adjudicators. 
are some interests (however social they may be) that are simply not part of the accepted EU internal market values scheme and will therefore always have to give way to the objectives of market integration and competition. Outside of the core nucleus of mutually shared values, the balance between market integration and social interests that are restrictive of competition interests becomes more complex and in need of a more subtle rationale. To refer back to the previous analogy, this is the idea that legal and social norms do their job in the 'best' way when they are somehow aligned. The idea here is that law and social norms should in a way complement each other. This position harbours more challenges, in finding the right interplay between social norms and enforcing a 'dynamic' and flexible rationality through law. What underlies it is the idea that law should not be alien to society but instead that there should be some form of mutual communication between law and society. This reflects the basic point of the normative claim of social legitimacy, which is to say that if law is completely alien it risks loosing its legitimacy and become irrelevant. As such, the supranational EU law rules have to some extent to align with social contexts within Member States and built in mechanisms of responsiveness in order to retain its legitimacy. Since the application of the EU competition rules is mostly decentralised and applied within Member State contexts and institutional structures, it would seem that responsiveness is more easily obtained. This chapter reflects on these questions in the area of the competition rules from the perspective of social legitimacy.

The outline of this chapter is as follows. In section II, I will discuss the related issues of valuation, indeterminacy and incommensurability in the application of the EU competition rules. This section starts with a discussion on how these issues speak to the existing literature in EU competition law that deals with the objectives of competition law and to what extent competition rules should or can incorporate 'non-competition' interests. Three case studies will be discussed in this section that problematize the application of EU competition law in view of the social legitimacy requirement. Section III gathers and discusses the case law where the Court has demonstrated responsiveness to social context. Section IV reconstructs this case law into a coherent model of social legitimacy and 
demonstrates how this approach will be able to accommodate social diversity within the Union on the basis of the highlighted case studies. Section V concludes.

\section{Problematisation: Valuation, indeterminacy and incommensurability in EU competition law}

A. Organizational principles in EU competition law: the debate on valuation

\section{i. Goals of competition law}

The EU competition rules set out a strong and seemingly clear normative framework. ${ }^{10}$ Article 101(1) TFEU prohibits "all agreements between undertakings, decisions by associations of undertakings and concerted practices which may affect trade between Member States and which have as their object or effect the prevention, restriction or distortion of competition within the internal market". As an exception to this rule, Article 101(3) TFEU provides that the prohibition contained in the first paragraph may be declared inapplicable in case of agreements which contribute to improving the production or distribution of goods or to promoting technical or economic progress, while allowing consumers a fair share of the resulting benefits, and which do not impose restrictions which are not indispensable to the attainment of these objectives and do not afford such undertakings the possibility of eliminating competition in respect of a substantial part of the products concerned. Article 101(3) TFEU is generally applied by national competition authorities, in congruence with the guidelines of the Commission, which implement the 'more economic approach' in competition law, in a way that only 'economic efficiencies' or 'pro-competitive effects' of restrictive agreements are accepted in order to fulfil the first condition. ${ }^{11}$ Decisive value is attached to the objective qualification and concretization in economic terms of the

10 As discussed further below the objectives associated with EU competition law are nevertheless often considered as plural: economic efficiency, consumer welfare, 'fair' competition, market integration, innovation, economic freedom etc.

11 Guidelines on the application of Article 81(3) of the Treaty [2004] OJ C101/ 97; Guidelines on the applicability of Article 101 of the Treaty on the Functioning of the European Union to horizontal cooperation agreements [2011] OJ C11/1. 
claimed benefits that may be effectuated by restrictive agreements in order to qualify for an exemption. ${ }^{12}$ Next, Article 102 TFEU prohibits "any abuse by one or more undertakings of a dominant position within the internal market". The actual goals of these two articles have been subject to a very rich debate. ${ }^{13}$

These debates are vast and wide and the intention of this section is not to provide a very nuanced overview of all strands and perspectives. For the purpose of this Chapter the debates can instead be roughly split in two categories. One line of debate looks inward and asks what competition law, as an insulated autonomous field of law aims to achieve. Here different goals are conceived, such as consumer welfare; total welfare; the process of competition; the protection of competitors; consumer protection; innovation; economic freedom and redistribution of power. Each of these goals is then in itself, again, subject to debate since some economists may for example view consumer welfare so as to encompass not just merely low prices but as the product of a well functioning overall process of competition. The latter is in that case perceived as a necessary means to achieve total welfare, innovation and economic freedom. Regarding the idea of 'welfare', questions arise

12 Whish and Bailey above (no.1); Commission Guidelines on the application of Article 81(3) of the Treaty [2004] OJ C101/97; Commission Guidelines on the applicability of Article 101 of the Treaty on the Functioning of the European Union to horizontal co-operation agreements [2011] OJ C11/1; L. Kjølbye, 'The New Commission Guidelines on the Application of Article 81 (3): an Economic Approach to Article 81'(2004) 25 European Competition Law Review, 566-577.

13 To give an indication of the sheer volume of contributions to this topic over the years, just a selection: "P. Akman, 'Consumer Welfare and Article 102 EC: Practice and Rhetoric', World Competition 32(2009), p. 71-90; P. Akman, 'Searching for the Long-Lost Soul of Article 82 EC', Oxford Journal of Legal Studies 29(2009), p. 267-303; O. Andriychuk, 'Dialectical Antitrust: An Alternative Insight into the Methodology of the EC Competition Law Analysis in a period of Economic Downturn', European Competition Law Review, 31(2010), p. 155-164; O. Andriychuk, 'Rediscovering the Spirit of Competition: On the Normative Value of the Competitive Process' European Competition Journal 6((2010)), p. 575-610; E. Buttigie, 'Competition Law: Safeguarding the Consumer Interest. A Comparative Analysis of US Antitrust Law and EC Competition Law'in J. Drexl, W. Kerber, R. Podszun, (eds.), Competition Policy and the Economic Approach - Foundations and Limitations, (Cheltenham: Edward Elgar 2010); I. Liannos, 'Some reflections on the question of the goals of EU Competition Law', (2013) CLES Working Paper Series 3/2013; Monti above (no. 8); P. Nihoul, 'Freedom of Choice': The Emergence of a Powerful Concept in European Competition Law' Concurrences 3(2012), p. 55-70; L. Lovdahl-Gormsen, 'The Conflict Between Economic Freedom and Consumer Welfare in the Modernization of Article 82 EC' European Competition Journal 3(2007), p. 329-344; O. Odudu, 'The Wider Concerns of Competition Law' Oxford Journal of Legal Studies 30(2010), p. 599-613; C. Townley, Article 81 EC and Public Policy, (Oxford: Hart 2009); B. van Rompuy, Economic Efficiency: The Sole Concern of Modern Antitrust Policy? Non-Efficiency Considerations under Article 101 TFEU, (Kluwer 2012); D. Zimmer (ed.), The Goals of Competition Law, (Cheltenham: Edward Elgar 2012)". 
to what extent 'economic welfare' should be central and which rules are the best to advance welfare. Here there is debate on issues such as the extent that total welfare should be the objective or only consumer welfare should count. ${ }^{14}$ Should issues of regional policy or unemployment be allowed to play a role and in what way? ${ }^{15}$ The inward debate is largely undecided and in flux. Importantly, one can find emanations of different goals in different lines of case law and areas of competition law. For example, Article 101 TFEU can be said to be concerned mostly with consumer welfare since agreements that restrict competition can only be exempted on the basis of the criteria in 101(3) TFEU if there are tangible positive effects for consumers. ${ }^{16}$ Article 102 TFEU can be said to be mostly concerned with protecting the process of competition and, specifically, competitors since certain lines of case law restricts dominant undertakings in engaging in behaviour that may exclude smaller, less efficient competitors. ${ }^{17}$

The second line of debate is more outwardly oriented and asks what the goals of competition law are in the wider context of the world and, in the EU, with respect to European integration, specifically, what the relationship is or can be between competition and the social objectives pursued in the Lisbon Treaty. ${ }^{18}$ Is competition law a threat to these objectives, which should lead to the exclusion of competition law in certain areas of social life within the Member States? ${ }^{19}$ Can competition law contribute as a means to the achievement of the wider objectives of market integration? ${ }^{20}$ These questions speak to a line of literature within

14 E.g. Bork approaches consumer welfare and total welfare as being the same thing and serving the same objectives: R.H. Bork, The Antitrust Paradox: A Policy at war with itself (New York, Basic Books 1978). For a recent critique see D.A. Crane, 'The tempting of Antitrust: Robert Bork and the goals of Antitrust Policy', Antitrust Law Journal 79(2014) at 835-53.

15 Whish and Bailey above (no. 1), p. 23.

16 Also Buttigieg above (no. 13).

7 Also Akman above (no. 13).

18 E.g. G. Monti, 'EU Competition Law from Rome to Lisbon - Social Market Economy' in Caroline Heide-Jorgensen, Christian Bergqvist, Ulla Neergaard \& Sune Troels Poulsen (eds), Aims and Values in Competition Law (DJØF Publishing 2013); N. Dhondt, Integration of environmental protection into other EC policies: legal theory and practice (Europa Law Publishing 2003); D. Casey, 'Disintegration: Environmental Protection and Article 81 EC' (2009) 15 European Law Journal, 362-381; H. Vedder, Competition law and environmental protection in Europe: towards sustainability? (Europa Law Publishing 2003)

19 Case C-67/96 Albany [1999] ECR I-5751

20 See D. Ehlermann 'The Contribution of EC Competition Policy to the Single Market' (1992) 29 CML 
competition law that concerns the issue if, to what extent, and how so-called noncompetition or non-efficiency interests have a role to play within the legal framework of the competition rules. It is on this point of the discussion that this chapter seeks to contribute. More specifically, the remainder of the Chapter will be concerned with this question in the context of the application of Article 101 TFEU. Article 101 TFEU promotes the idea that the relationship between undertakings including the actions of associations of undertakings, such as for example guilds or sector-based organisations, should be governed on the basis of competition. Moreover, as was highlighted in the introduction, the modernisation process of the competition rules incorporated the obligation for subjects of competition law (undertakings) to self-assess their competition law status on the basis of the numerous position and guidance papers that are issued by (national) competition authorities. ${ }^{21}$ As such, I consider the application of 101 TFEU as the most relevant part of competition law from the perspective of the potential effects on the social sphere and the social diversity amongst the Member States. ${ }^{22}$

\section{ii. $\quad$ Non-competition interests within competition law assessments}

The discussion on the issue if, to what extent, and how so-called noncompetition or non-efficiency interests have a role to play within the legal framework of the competition rules exists within a spectrum where different

Rev 257; Cases C-403/08 and C-429/08 Football Association Premier League Ltd v QC Leisure, [2011] ECR I-000 and Case C-439/09 Pierre Fabre Dermo-Cosmétique SAS v Président de l'Autorité de la Concurrence, [2011] ECR I-000.

21 R. Wesseling, The Modernisation of EC Antitrust Law (Oxford, Hart Publishing 2000), at 20.

22 That is not to say that 102 TFEU or mergers have no relevance for his issue. Big corporations such as Google have of course a huge social impact and perhaps sometimes will restrict competition for the self-proclaimed advancement of a public interest (compare with Case T-30/89 Hilti AG v. Commission [1991] ECR II-1439). The enormous Google project on the digitalisation of books is a real-life example of this. Moreover, merger policy can be discussed from a perspective of social legitimacy. For example, are hospital mergers to be assessed only from a narrow perspective of efficiency benefits? Such questions are however excluded from the scope of this chapter, if only for reasons of space. It is however also not necessary to include these interesting examples, which will be reserved for later research projects, in this chapter for the more theoretical argument to stand on its own feet. That is the wider discussion of the role and function of competition in society and the chapter proceeds to make a normative claim about this on the basis of a discussion of 101 TFEU only (a normative claim that can also be transposed to other areas of competition law). 
arguments move between one of two seemingly opposing positions. On one side of the spectrum stand those who argue that non-competition interests can only play a role within a competition law framework if those interests can be translated and measured in strictly economic terms and, as such, can only override a competition interest if they contribute to consumer welfare. ${ }^{23}$ This line of argumentation perceives the function of competition law in narrow terms and as exclusively relevant for the advancement of consumer interests and efficiency. 'True' noncompetition or non-efficiency interests will fall completely outside of the reach of the competition rules and have to be discussed and addressed within a political context. Roughly, the line of argumentation here is that the competition rules are insufficiently equipped to be applied to a broad range of societal issues and that the added value of competition law as an instrument for the promotion of consumer welfare will be inhibited and obscured if non-competition interests would play a prominent role in the application of the competition rules. Importantly, this view is advanced by the European Commission, which also makes sure that national competition authorities will approach this issue in the same way. According to the Commission, the purpose of the exemption provision of article 101 (3) TFEU "is to provide a legal framework for the economic assessment of restrictive practices and not to allow application of the competition rules to be set aside because of political considerations". ${ }^{24}$ As a result, public interest goals "pursued by other Treaty provisions can be taken into account" but only in so far as they can be subsumed under the four conditions of Article 101(3) TFEU "by using the economic

23 For example G. Amato in 'Antitrust and the Bounds of Power', (Hart Publishing, 1997) at 117; O. Odudu in 'The Boundaries of EC Competition Law: The Scope of Article 81 (Oxford University Press, 2006), at 7;. L. Kjølbye, 'The New Commission Guidelines on the Application of Article 81(3): an Economic Approach to Article 81'(2004) 25 European Competition Law Review, 566; P. Lugard and L. Hancher, 'Honey, I Shrunk the Article! A Critical Assessment of the Commission's Notice on Article 81(3) of the EC Treaty' (2004) 25 European competition law review, at 410; A.C. Witt, 'Public Policy Goals under EU Competition Law: now is the Time to set the House in order'(2012) 8 European Competition Journal, at 443. For a comparable argument also K. Mortelmans, "Towards Convergence in the Application of the Rules on Free Movement and Competition?" 38(2001) Common Market Law Review at 613'.

24 Guidelines on the application of Article 81(3) of the Treaty [2004] OJ C101/ 97; Guidelines on the applicability of Article 101 of the Treaty on the Functioning of the European Union to horizontal cooperation agreements [2011] OJ C11/1 
methodology employed by it",25. The case studies that will be discussed later shall demonstrate how this narrow view is liable to exclude valuable social content from the framework of analysis.

This line of literature does not argue that other, wider, social interests do not matter. The argument is merely made that competition law exists as a separate field and competition authorities are specialised and independent authorities, above all, with the purpose to ensure the competition rules and it is not the competition authority but another (specialised or politically legitimised) entity that would have to make the assessment if non-competition interests would become crucial in a balancing process. If the interest at stake does not qualify as an efficiency concern, an alternative evaluative rationale should allow for the inclusion of a public interest decision by an actor with political legitimacy (for example within a deliberative governance model). ${ }^{26}$ For example, in mergers raising certain public interest considerations in the UK, the Secretary of State for Business, Innovation and Skills may intervene. ${ }^{27}$ Such intervention enables the Secretary of State to assume responsibility for determining whether or not to refer a merger to the Competition Commission and to take the ultimate decision in respect of mergers when defined public interest considerations are potentially relevant. In these cases there is no longer a competition assessment rationale at play but instead the assessment made is confined to the relevant public interest consideration within a political and democratically legitimated arena. Some consider this as a choice in terms of jurisdictional conflicts between policy areas that can be solved through a procedural test. For example, Lavrijssen qualifies non-competition interests as 'aimed at the promotion of horizontal and flanking policy interests and sectorspecific public service interests, such as the quality of healthcare ${ }^{28}$ Similarly,

25 Ibid., para 42.

26 Anna Gerbrandy has recently made suggestions to include more public stakeholders within the competition law procedure (in stead of the analysis) in order to increase the legitimacy of competition law decisions to take account of non-competition objectives in A. Gerbrandy, 'Addressing the Legitimacy Problem for Competition Authorities Taking into Account Non-Economic Values: The Position of the Dutch Competition Authority', European Law Review 40(2015) at 770.

27 R. Whish and D. Bailey above (no. 1), at 728.

28 S. Lavrijssen, 'The Protection of Non-Competition Interests; What Role for Competition Authorities 
Monti has argued for the addition of an Article 101(4) TFEU enabling public policy considerations to be integrated, separately, in the competition law assessment. ${ }^{29}$

What could be considered an opposing view argues that non-competition interests do (have to) play a prominent role within the competition law framework and are also able to set aside competition objectives if certain conditions are fulfilled. ${ }^{30}$ This line of argumentation is in favour of an approach whereby a quantifiable value is attributed to a non-competition interest. The latter would then involve a calculation of some sort to determine, within the exemption criteria, whether the balance should turn out in favour of the competition or noncompetition interest. ${ }^{31}$ This approach may use a plethora of economic methodologies to quantify and place a value on both the costs and benefits of restrictive agreements. ${ }^{32}$ The approach that assigns a quantifiable value to a noncompetition interest, which then allows a subsequent balancing within the exemption criteria is perhaps most clearly developed by Townley, who proposes that all interests (being competition or non-competition) can be assigned a money value. ${ }^{33}$ The difference between this position and the line of argumentation that was firstly introduced is that the quantification method would disagree with the idea that there are interests that are not quantifiable for the purpose of a competition analysis, whereas the former acknowledges that there are simply some non-efficiency interests that can override competition objectives on the basis of societal/political priorities but turns that into a political decision, which has to be legislated.

after Lisbon?', European Law Review 5(2010) at 635.

29 See Monti above (no. 8) at 1096.

30 For example S. Kingston, 'Integrating Environmental Protection and EU Competition Law: Why Competition Isn't Special' in European Law Journal, 6(2010) at 790; S. Kingston, Greening Competition Law and Policy (Cambridge 2012); Townley above (no.13); Casey above (no. 18) 362; A. Gerbrandy, 'Competition Law and Private-Sector Sustainability Initiatives' in A.L.B. Colombi Ciacchi and others (eds) Law \& Governance - Beyond the Public-Private Divide? (Eleven International Publishing 2013), 81; Wesseling above (no. 21) at 173; S. van Hees, A sustainable competition policy for Europe. - A research on how the European cartel rules can make a stronger contribution to Europe's sustainable development goals (Utrecht University, Utrecht 2013).

31 Townley above (no. 13); Kingston above (no. 30).

32 The use of environmental and ecological economics is a prominent example of such an approach, which goes beyond the use of a narrow welfare analysis. See Kingston above (no. 30) 163-193.

33 Townley above (no. 13). 
In summary, the first approach as discussed above resolves the integration of non-competition objectives on the basis of a rationale of 'exclusion'. The approach is static and wider objectives are not integrated in the substance of the competition law assessment. Instead, a conflicting interest will trump Article 101 TFEU completely or vice versa. The second approach that was discussed aims to resolve a potential conflict with wider objectives within Article 101(3) TFEU and, as such, they become an inherent part of the competition law assessment by virtue of a quantification approach, which allows for a concretisation of the advancement in the production or distribution of goods or to promoting technical or economic progress and are necessary proportionate to the attainment of those objectives. ${ }^{34}$

Somewhere in between these two positions, leaning more towards the exclusion than the quantification reasoning lies another approach, which excludes restrictive agreements from the scope of article 101(1) TFEU, if they can be considered necessary for the pursuit of a public interest goal, primarily based on the seminal cases of Wouters and Albany. ${ }^{35}$ This approach leans more towards the first position because it is also based on a rationale of exclusion. It differs mostly from the quantification approach because consumers do not require a 'fair share' of the benefits of the agreement, and instead is based on a more proportionality type of reasoning in stead of the cost-benefit analysis which is the basis of the quantification approach in article 101(3) TFEU. As such it will be discussed further below that this approach is most closely related to the normative claim of social legitimacy, which requires adjudicative rationales to be context specific. However, there are some important shortcomings of this approach, which are not fully addressed in the case law or the literature. These can be addressed on the basis of the idea of mutual responsiveness as will be further discussed below. For now the potential and shortcomings of this approach are parked. I will return to them in section III.

\footnotetext{
34 See van Rompuy above (no. 13) at 218.

35 Cases C-309/99 Wouters [2002] ECR I-1577 and C-67/96 Albany [1999] ECR I-5751.
} 


\section{iii. The problem of indeterminacy and the expressive value of competition law}

This debate and the positions that were introduced above are closely related to the problem of incommensurability and the expressive value of competition law. It was discussed in section $\mathrm{V}$ of Chapter I that certain evaluative standards carry the risk of excluding or wrongly valuing social context. In free movement it was discussed that this risk materialises, for example, in the application of strict proportionality to a social context, which cannot be completely captured in terms of the less restrictive measure. The normative concern is that evaluative standards may translate social realities within a metric that risks doing violence to potentially genuine and worthwhile aspects of those objectives. Moreover, an additional point of normative concern is that where an evaluative standard adopts a unitary metric, the balancing of competing values becomes simply a matter of calculation. This is not to say that the calculations will be a simple one, but to indicate that the nature of the problem is fundamentally transformed into one of quantification. ${ }^{36}$ Thereby, in situations where there is a manifest irreconcilability between normative orders, quantification risks loosing the expressive value that is inherent in a normative conflict and the consequent potential for social learning that arises from it. It foregoes the question when competition objectives and non-competition objectives are actually and genuinely irreconcilable. It is submitted that the answer to this question matters because it provides instruction as to how evaluative rationales should deal with the interaction between competition and non-competition concerns. It answers the question, in simple terms, whether a non-competition interest can be incorporated within Article 101(3) TFEU or not.

However, the framing of competition concerns on the one side and wider social objectives on the other is underdeveloped and basically fails to discuss what is at stake when potential genuine norm conflicts arise. It was discussed in the first chapter that social interests are often constructed and pursued as enabling market

36 See on this also B. G. Scharffs, 'Adjudication and the Problems of Incommensurability', (2001) 42 Wm. \& Mary L. Rev. at 1367 
interests. That is to say that the social interest concerned is often (more or less covertly) voicing a market related interest. Such 'economic' social interests can be achieved on the basis of a market-based model based on the allocative logic of supply and demand and also would, for example, not necessarily conflict with the efficiency driven exemption criteria of Article 101(3) TFEU. In those situations there is no genuine normative conflict between a competition and non-competition objective. For example, the CECED case is often discussed in terms of a demonstration of the incorporation of non-competition objectives within the competition law framework of 101(3) TFEU. ${ }^{37}$ The European Committee of Domestic Equipment manufacturers (CECED) case concerned the evaluation by the Commission of an agreement amongst European dishwasher manufacturers to stop producing or importing high electricity-consuming appliances. ${ }^{38}$ Since this affected 63 per cent of all dishwashers manufactured in Europe and would involve a price increase of up to 14 percent in order to improve the energy-efficiency, it was considered as a restriction on competition. ${ }^{39}$ However, the Commission considered that the restriction could be exempted on the basis of 101(3) TFEU partly because "the new electric water heaters and dishwashers will be more efficient and enable consumers to reduce their energy bills. Moreover, lower electricity consumption will indirectly help the Union achieve its environmental objectives". 40

The case is often discussed as an example of how 101(3) TFEU has been used to incorporate non-competition, non-efficiency or non-economic considerations. ${ }^{41}$ However, looking at the interests that were pursued in this case it does not appear that it is appropriate to frame it in terms of a case where the competition law framework was stretched to accommodate non-competition interests. In fact, the main objective of the agreement in question was to pursue the efficiency of

37 E.g. A.P. Komninos, 'Non-competition Concerns: Resolution of Conflicts in the Integrated Article 81 EC' (2008) The University of Oxford Centre for Competition Law and Policy Working Paper (L) 08/05; Whish and Bailey above (no. 1) at 158.

38 CECED (Case IV.F.1/36.718) Commission Decision 2000/475/EC [2000] OJ L187/47

Ibid, para 34

40 Commission Press Release IP/01/1659, 26 November 2001. As such the Commission recognised the environmental benefits of the agreement in a broad sense.

41 E.g. Komninos above (no. 37) and Whish and Bailey above (no. 1) at 158. 
washing machines and nothing of those objectives was lost or translated within the exemption framework of 101(3) TFEU in a way that would disregard fundamental aspects of those objectives. Instead the Commission assessed, on the basis of the exemption framework, the extent to which such efficiencies would materialise and, subsequently, benefit consumers.

Hence, when one speaks about norm conflicts between economic and social policies, this is not necessarily a conflict of different normative orders but, rather, reflects a disagreement with respect to the best design of one largely economic issue. ${ }^{42}$ Often, in the use of terminology such as the 'economic versus the social' or 'competition versus non-competition' there is no conflict of irreconcilable normative orders. Therefore, a better conceptual understanding of the noncompetition interest may solve or render more understandable some of the apparent problems within competition and non-competition balancing by clarifying whether a true conflict is actually present. A disentanglement of this kind could show more clearly when there is no real conflict of norms but rather a disagreement over the construction of one norm or when there is actually a conflict of different normative orders and hence indicate the need to adopt an evaluative legal rationale that does justice to pluralistic normative order conflicts.

To different degrees then, against this background, both previously discussed positions on the integration of non-competition objectives within the competition law assessment harbour some problems that are related to the lack of a clear understanding on the potential for norm conflicts between competition and noncompetition objectives. It is striking that there has been hardly any serious attempt in academic literature to address this lack of clarity even though the most advanced terminological debate on the market versus noneconomic objectives debate within EU law has been developed primarily within the area of EU competition law and specifically with respect to the question of what concerns an economic activity and

42 See e.g. C. Kaupa Maybe not activist enough? On the Court's alleged neoliberal bias in its recent labor cases', in Witte, Muir, and Dawson (eds), Judicial Activism at the European Court of Justice (Elgar 2013) p. 56-75. 
the legitimate reach of the EU competition law provisions, ${ }^{43}$ or the way that EU competition law should deal with public policy concerns that limit competition ${ }^{44}$. These narratives are unfulfilling because of the lack of any serious attempt to clarify the key terms that play the most important role in the evaluation of conflict situations as introduced above. The 'nature' of such conflicts, i.e. the question where competition starts and non-competition begins, is therefore, purely conceptually, relatively untouched. ${ }^{45}$ However, the key academic contributions that aim to provide a better understanding of how non-economic interests can and should be dealt with in competition law lack this discussion as a starting point to frame the issue. Key contributions in this area interchangeably use the terms public or social interest as representing noneconomic, nonmarket or noncompetition interests. $^{46}$

The point is that many proclaimed non-competition interests such as the environment, consumer protection, quality and fair trade are quickly qualified as non-competition or public interests but can, from the perspective of a competition perspective, be perfectly translated in terms of a competition rationale since they may be factors that allow for a certain singularity in the market. The setting of a collective standard by retail stores to exclusively buy fair trade products eliminates a competitive factor amongst those retailers. In this sense fair trade is something to compete with and it qualifies as a competition relevant benchmarks, which can be quantified in terms of efficiencies. ${ }^{47}$ Therefore, when an environmental interest is pursued and competition is concomitantly restricted in the relevant market, it is not given that this concerns a normative conflict between a competition and non-

43 E.g. O. Odudu, 'Interpreting Article 81(1): object as subjective intention' 26(2001) European Law Review 60-75; Odudu above (no. 13).

44 E.g. F. Kieran, 'A Separation of Powers Approach to Non-efficiency Goals in EU Competition Law' European Public Law 19(2013) at 189; I. Colomo, 'Market failures, transaction costs and Article 101(1) TFEU case law' European Law Review 37(2012) at. 541; Townley see above (no.13).

45 But see B. de Witte, "Non-market values in internal market legislation" in N. Shuibhne (ed.), Regulating the internal market (Elgar 2006), at 63, who uses nonmarket for interests that may have economic effects but whose driving power is not economical and C. Kaupa above (no. 42).

46 See e.g. Townley (no. 13), Odudu (no. 13), Monti (no. 8) and T. Prosser, The limits of competition law (Oxford UP 2005).

47 For example General Court T-34-92 Fiatagri and New Holland Ford [1994] ECR II-00905 and General Court T-35-92 John Deere [1994] ECR II-00957, paras. 52 en 81 (confirmed by the Court in C-7/95P [1998] ECR I-03111). 
competition interest. The risk of such indeterminacy in the framing of competition versus non-competition interests is that a conflict of different norms is suggested, whilst in reality there is only one norm at play (false conflict) or vice versa (true conflicts). The first position introduced above, that advances a strict and static application of the competition rules, is problematic because it more or less assumes a distinction between competition and non-competition interests, and submits that questions of priority between the two require different fora. The second, quantification, position that was introduced is problematic because there exist social interests that may get lost when they are quantified to easily within an efficiency rationale. Moreover, by artificially replacing the conflict between normative spheres through a process of quantification, a potential platform for societal learning and discussion concerning the (manner of) pursuit (of) worthwhile societal interest is removed from the table too quickly and without sufficient deliberation. It is submitted that, it is exactly on the intersection between market and non-market or competition and non-competition that it becomes possible to discover which societal interests matter and how they matter specifically. ${ }^{48}$

Again, if sustainable environmental objectives are pursued by lowering the output of an industry then, seemingly, there is no manifest conflict between normative principles. That is to say, the restriction on competition that follows from a collective and coordinated lowering of output can be measured against the efficiency valuation that is set out by the competition law framework. An efficiency rationale could be used to evaluate whether the lowering of output can be justified in terms of the effects it has on competition, without, on first sight, doing harm to the wider environmental objectives underlying the lowering of output. Both the problem and the solution can be quantified. However, if the same objective is

48 As discussed in Chapter one section V. Compare also with the elegant suggestion of Hervey in Marise Cremona, 'Market Integration and Public Services in the European Union' (Oxford University Press 2011) at 310: "EU law is no more (if it ever has been) simply, or even essentially or fundamentally about markets, leaving 'the social' to the Member States and national law. The roles of EU internal market and competition law are no longer (if they ever were) simply a means to achieve movement between markets, opening markets, and preventing nationality-based discrimination. Rather, EU free movement and competition law should become (or have become) a locus within which we collectively determine the balance of values, between (economic) freedom and (social) security; between competition and solidarity". 
pursued on the basis of a society wide compromise, without a clear rational basis, then an efficiency evaluation may not be the most appropriate framework to structure and decide on the conflicting societal objectives that are at stake. The first situation may be properly characterised as technocratic or managerial in nature and does not require a political instruction on the priority of objectives. This may be different in the second scenario. The problem is how to distinguish one social reality from the other. I will return to this problem further below in section IV.

The normative demands of social legitimacy therefore require a mechanism within the competition law assessment to single out the non-competition interest. It is submitted that the non-competition interest is concerned with objectives that fall outside of concerns that are related with the efficient functioning of markets - it is in this sense residual and defined through a process of opposition within the competition law analysis. ${ }^{49}$ Indeed, this approach accepts the primacy of competition but creates a 'responsive' space for the non-competition interest to be identified as a residual and conflicting objective. ${ }^{50}$ It opens up a dialogue concerning the regulatory choices of Member States. There is therefore an implicit understanding that non-competition interests are dynamic because the underlying fabric can develop and evolve. This is reflective of the idea that competition law does not exist in a vacuum but should be able to respond to the current values and aims of society and is as susceptible to change as political thinking and social objectives are generally. Because views and insights shift over a period of time, competition law is infused with the need to move and adapt towards developing notions of what is to be perceived as a noncompetition interest. ${ }^{51}$ For example,

49 The primary purpose of an exercise that tries to clarify the noneconomic objective is therefore to provide an operational conceptualisation that allows elemental social fabric to be distinguished from market objectives. See also H. Putnam, 'Meaning and Reference' 70(1973) The Journal of Philosophy at 699: "no operational definition does provide a necessary and sufficient condition for the application of any such word. We may give an "operational definition" [...] but the intention is never "to make the name synonymous with the description". Rather "we use the name rigidly" to refer to whatever things share the nature that things satisfying the description normally possess".

50 This comes close to the perspective that Colin Crouch develops around the idea of 'assertive social democracy' that accepts the value and priority of markets in the economy, but is aware of their limitations and deficiencies as inappropriate in other areas of life. C Crouch, Making Capitalism Fit for Society (Cambridge-Malden MA, Polity Press, 2013) at p 37.

51 Whish and Bailey (no. 1) p, 21. 
technological advances or new theoretical insights regarding theories of market failure and state failure can influence the idea of the non-economic. ${ }^{52}$ The EU case in point here is Corbeau where the Court reviewed the Belgian postal monopoly created by laws in the $1950 \mathrm{~s}$ and $1970 \mathrm{~s} .{ }^{53}$ Demand for the courier service offered by Corbeau did not exist to the same extent then. In 1993 societal developments had outgrown the basis for the law at that time. Similarly, in Albany, certain individuals were concerned that they would be forced to join compulsory industrial pension schemes, despite the fact that the free market offered better deals. ${ }^{54}$ The point here is that institutions and schemes introduced in the post-War period as a formulation of solidarity and common identity amongst workers are not necessarily viewed in the same light any more.

It follows from these considerations that the non-competition interest is far from a fixed idea that can be determined ex ante or on the basis of a form of dominance reasoning. That is to say a type of reasoning which says that as ' $\mathrm{x}$ is better than $\mathrm{y}$ in all respects', if conflicts arise in practice, $\mathrm{x}$ will always have priority over y. Instead, the non-competition interest is a dynamic and residual concept that forces an open and inclusive outlook within competition law assessments. Therefore, it is suggested that a conceptual clarification may prove beneficial for the qualification of a conflict as a true normative conflict or a false normative conflict. ${ }^{55}$ Both require different responses, both from the judiciary and the competition authorities. This will be the central theme running through the case studies that will be discussed further below.

For example, one of the case studies will discuss the Dutch competition authorities' (ACM) approach to a sector-wide and supply-side coordinated decision to no longer sell chicken in the supermarkets that is produced under conditions that are considered unacceptable from an animal welfare perspective. The measure specifically targeted so called 'plofkip', which is a name to describe chicken that is

52 P. Behrens, 'Public service and the internal market', in T. Einhorn (ed.), Spontaneous order, organization and the law. Roads to a European Civil Society (The Hague Asser Press 2003) at p. 43.

53 Case C-230/91 Corbeau [1993] ECR I - 2534.

54 Case C-67/96 Albany [1999] ECR I-5751.

55 W. Hohfeld, 'Some fundamental legal conceptions as applied in judicial reasoning' (1913) 23 The Yale Law Journal 16-59. 
made to grow unusually fast so as to speed up meat production (broiler chicken). The ACM considered animal welfare as a competition interest that was to be quantified by consumers. Only if consumers would be willing to pay for the removal of broiler chicken, then the measures would be considered legitimate from a competition law perspective. As such, the pursuit of animal welfare was put in the hands of the consumer and conceptualised as a monetary consideration. This is problematic for several reasons. In view of what was discussed before, mostly because societal interests are placed in the hands of consumers without proper societal deliberation. Is it desirable to have consumers place a number on the welfare of chickens or the way environmental objectives are pursued $?{ }^{56}$ Is consumer indifference in their purchasing decisions towards social and environmental attributes of the products concerned overriding ? $^{57}$ If we accept that effective competition constitutes an important public interest, but only one of the worthwhile interests in society, forming part of a range of other interests that are worth pursuing, we should ask the question if effective competition and 'broader' societal interests can be aligned harmoniously within an evaluative framework that requires the 'net efficiency result' to be positive.

This argument becomes more pressing if perceived in the context of European integration. As was argued in the first chapter, European integration is committed to value diversity. A liberal society contains a diversity of social spheres and (should) make, space for different kinds of valuation. ${ }^{58}$ Therefore, a competition law framework that lacks the tools to deal with social differentiation may lack social legitimacy. The case studies will demonstrate that this boils down, mostly, to a question of institutional design.

\footnotetext{
56 M. Sandel, 'What Money Can't Buy' (Farrar, Straus and Giroux 2012), p. 202: 'People disagree about the meaning of books, bodies, and schools, and how they should be valued. In fact, we disagree about the norms appropriate to many of the domains that markets have invaded - family life, friendship, sex, procreation, health, education, nature, art, citizenship, sports and the way we contend with the prospect of death. But that's my point: once we see that markets and commerce change the character of the goods they touch, we have to ask where markets belong - and where they don't. And we can't answer this question without deliberating about the meaning and purpose of goods, and the values that should govern them.'

See furhter on this issue also Ankersmit above (no. 6)) at p 247 and further.

58 See section V of Chapter I.
} 
This social legitimacy problem is not recognised nor addressed within the discussed academic narratives on the integration of non-competition interests within EU competition law. Supporters of a strict application of competition law would argue that this is 'simply' a competition issue or not. The legislator can address and prioritise the issue of e.g. animal welfare on the basis of legislation. On that basis the issue of animal welfare is kept outside of the 'competition sphere' and will be addressed within a democratically legitimate framework. In other words, lacking a clear political instruction, animal welfare as a non-competition interest is not able to overrule competition interests. My objection to this approach is that the black-white approach that is reflected in it is too simple. As said, I think the competition platform is well suited as a starting point for societal dialogue and exactly because of the struggle that takes place between competition and noncompetition interests, societal preferences are articulated more 'sharply' because one or the other needs to justify itself. This requires a clear articulation of the interests at stake. ${ }^{59}$

The quantification approach would argue in favour of a monetary value to be attached to the objective of animal welfare in order to allow for measurement and the ordering of objectives within the competition law framework. This approach carries, in a similar way, the risk of a removal of deliberation and conflict between different normative objectives by a direct translation of the objectives at stake within a language and grammar that may be unsuitable for the objectives at stake. The approach is more problematic because of the previously mentioned system of self-assessments that is part of all competition law regimes across Europe. On this basis economic operators are compelled to reason in the one-dimensional language that a monetarisation approach entails also in the pursuit of, for example, sustainability initiatives and animal welfare.

59 For further reading on social theory insights on the value of social interest conflicts: G. Simmel, 'The Sociology of Conflict. I', 9(1904) American Journal of Sociology 491; R. Dahrendorf, The Modern Social Conflict: An Essay on the Politics of Liberty (London: Weidenfeld and Nicolson 1988), at 25; L. Coser, The Functions of Social Conflict (New York: The Free Press, 1956); A.O. Hirschmann, 'Social Conflicts as Pillars of Democratic Market Society', (1994) 22 Political Theory 206-209, A. Somek, 'The social question in a transnational context', LSE Discussion Paper June 2011, at 27. 


\section{iv. Competition law as a platform for societal dialogue}

The alternative perspective that is proposed can be seen as a requirement in competition law to incorporate a close and context-specific assessment with respect to the potential normative plurality that is rooted within the different objectives that are pursued and are in potential conflict with competition interests. Importantly, the potential for competition law as a platform for societal development is underrecognised in both positions that were introduced above. To contextualise competition law from a perspective of societal learning is related to its constitutional meaning within internal market integration. As was submitted in Chapter I, the social purpose of the internal market is to provide for an infrastructure for the conflict of norms within the Union that arise through the interaction between principles of economic integration and the pursuit of social interests on a Member State level. ${ }^{60}$ In this respect, the competition rules are a tool for social dialogue because of the expressive value that is unlocked with the potential conflict between competition and non-competition interests. As said, within this dynamic societal preferences are both tested and newly articulated.

From this perspective, the function and potential pitfalls of competition law within the Union has been helpfully described by former Commissioner Monti who explained the liberalisation policy of the Commission with respect to liberal professions

"The present level of rules and regulation of liberal professions owe some debt to historical convention. How many are still needed in the modem world? Do they hinder or favour the development of the sector? Let me be provocative: Do they protect the consumers or the professionals? I propose to assess whether existing rules and regulations, which, remember, were devised and enacted in a very different economic context to that which exists today, continue to serve the legitimate purposes of the protection of the public interest. I would also like to assess whether they are the most efficient mechanisms available in the current market situation. It is clear that across the [European Union] there are different regulatory mixes. As the study shows, different regulatory choices produce different outcomes in the market and it is possible that some regulatory mixes have more beneficial market outcomes

60 See section III of Chapter I. See also K.H. Ladeur, "“Conflicts Law as Europe's Constitutional Form” ... and the Conflict of Social Norms as Its Infrastructure' [2014] in (C. Joerges and C. Glinski eds.), European crisis and the transformation of transnational governance : authoritarian managerialism versus democratic governance, at 383 . 
than others. It should be difficult to argue against those that have the least distorting effect on the workings of the market, while delivering the same, or even higher, turnover."

On the one hand, in the first part of the speech, competition law is perceived as a tool for societal dialogue, testing old conventions and requiring renewed articulation of the pursuit of public interests. On the other hand, in the second part of the speech, there is the emergence of the idea that regulatory systems should be tested on the basis of their 'efficiency' merits: "It should be difficult to argue against those that have the least distorting effect on the workings of the market, while delivering the same, or even higher, turnover". This is the potential pitfall of the application of competition law. Efficiency dominated thinking threatens the idea that a diversity of social spheres requires space for different kinds of valuation. Therefore the challenge is to combine the function of competition law - properly conceived - within the Union, in terms of its potential to serve as a tool for societal dialogue, with the need to allow for social diversity. It is exactly on this point that the dialogue of mutual responsiveness that is developed in this chapter, at the intersection of competition and non-competition interests, will add to the on-going debate.

B. Introduction to the case studies

The three case studies that will be discussed in this section aim to further concretise the slightly abstract issues that were discussed in section two. The three case studies originate from the Netherlands. As was briefly indicated before, competition law in the Netherlands was introduced relatively late, in 1998. The competition law that was then introduced is fully based and informed by the EU competition rules. Although originating within the Netherlands, the case studies allow generalisation with regard to the theoretical issue of combining competition

61 M. Monti, Commissioner for Competition: European Commission, Competition in Professional Services: New Light and New Challenges, For Bundesanwaltskammer Berlin (2003) available at http://europa.eu/rapid/press-release_SPEECH-03-149_en.htm (accessed 10-12-2015). 
and non-competition interests within competition law assessments as it was introduced in the previous section.

The cases illustrate concretely how specific approaches can inhibit the emanation of social objectives within competition rationales and thereby serve the function of problematisation. The political and institutional context in the Netherlands provides good examples of how competition law frameworks may struggle to incorporate social differentiation. Historically, the Dutch system of social and economic policy making has always been seen as heavily consensus based, coined as the 'polder model'. ${ }^{62}$ Consensus has always been institutionalised in the Netherlands, which is reflected in a plurality of advisory and consultative bodies that exist on all levels of policy making. The polder model is best characterised by the cooperation between employers' organizations, labour and the government. These talks are institutionalised within the Social Economic Council (SER). The SER is the central forum to discuss labour issues and, again, completely consensus based. It is acclaimed to have defused labour conflicts and avoiding strikes.

Moreover, the consensus based policy making used to be reflected in socalled 'product boards' that would include all interested parties in a production chain within a public institutional framework and would be involved directly in the development of social and economic policy making, relevant to the economic sector involved. As such, policy concerning livestock would involve the product board for livestock, meat and eggs as an intermediary between government and industry to ensure a smooth transition between politics and industry. Recently, as part of a government program to reduce administrative control and tax cuts for industry, the product boards have been cancelled. However, consensus based policy-making remains a central feature of Dutch politics, which is reflected in all of the case studies. The implication of this institutional background is that the Netherlands is characterised by a high degree of quasi public-private governance settings. As will

62 J. Woldendorp, The Polder Model: From Disease to Miracle? Dutch Neo-corporatism 1965-2000 (2005 $\mathrm{PhD}$ thesis, Vrije Universiteit Amsterdam), p. 267-269. Also B. Bouwens and J. Dankers, Competition and Varieties of Coordination in K. Sluyterman (ed.), 'Varieties of Capitalism and Business History The Dutch Case', (Routledge 2015) at 103 and further. 
be demonstrated in the case studies, this leads to challenges for the application of competition law that are directly related to the issue of social differentiation and valuation in competition law. Therefore, although the Netherlands has a governance context that can be considered quite singular, the issues that will be discussed further below are relevant for the broader theme of the thesis since it is a concrete example of how the legal framework of the competition rules is able to integrate social context and provide for a constructive interplay of norms without harming social objectives that are worth pursuing.

This is the recurring theme in the case studies. The first case study is an example of the quasi public-private context for policy making based on the old product board institutional context and focuses on the judicial review of rules of a studbook. These rules were aimed at the health of the horses within the studbook but restricted stud-owners in the amount of offspring they could produce. A classic output restrictions case from the perspective of a competition rationale. The second and third case-study concern government induced but privately led sustainability initiatives that resulted in restrictions on competition. These two latter case studies are interesting because of the clear approach the ACM has taken in these cases towards the issue of integrating non-competition interests in the competition law framework, which is part of a broader programmatic objective of the ACM to instruct undertakings how to pursue sustainability initiatives. ${ }^{63}$ In a nutshell, the position taken by the ACM, based on legislative instructions, ${ }^{64}$ is that of a

63 These guidelines are all in Dutch: ACM Visiedocument Mededinging \& Duurzaamheid, mei 2014, www.acm.nl/nl/publicaties/publicatie/12930/Visie-mededinging-en-duurzaamheid (accessed 10-122015). This policy and resulting cases from the ACM are part of an on-going discussion in Dutch competition law literature: e.g. L. Ankersmit, 'Het einde van de kiloknallers? De grenzen aan zelfregulering van duurzaam vlees onder het kartelverbod' Actualiteiten Mededingingsrecht (2011) 149155; Gerbrandy above (no. 26); A. Gerbrandy, 'Duurzaamheidsbelangen in het mededingingsrecht', NtEr 2013/9, p. 326-333; H. Pijnacker- Hordijk, 'Beoordeling van duurzaamheidsinitiatieven onder het mededingingsrecht', Markt \& Mededinging 2013; J. Mulder, 'Op het snijvlak van onafhankelijkheid en openheid :wat is de rol van de ACM in een duurzamemaatschappij?', SEW 2014, p. 565-578; J Mulder, 'Een duurzame maatschappij, wat mag dat kosten?', NJB 2015/1400 1912-1920.

Besluit van de Minister van Economische Zaken van 6 mei 2014, nr. WJZ / 14052830, houdende beleidsregel inzake de toepassing door de Autoriteit Consument en Markt van art. 6 lid 3 Mededingingswet bij mededingingsbeperkende afspraken die zijn gemaakt ten behoeve van duurzaamheid. At the time of writing there was a public consultation pending with new legislative instructions for the competition law assessment of sustainability initiatives, accessible at https://www.internetconsultatie.nl/mededingingenduurzaamheid (accessed 14-01-2016). This new 
monetarisation approach, quantifying all objectives in order to balance them with restrictions on competition, whilst taking the position that there should be a strict difference between legislation and the market. That is to say that if the legislator would want to prioritise certain objectives over competition, it can do this on the basis of legislation. In the absence of legislative prioritisation, everything falls in 'the market sphere' and needs to be quantifiable for the purpose of an efficiency analysis to determine the balance of objectives. The following subsections set out the case studies in more detail. Section IV returns to them on the basis of a rationale of mutual responsiveness.

\section{i. $\quad$ The Friesian Horse: the legitimacy of private led public interest objectives}

The Friesian horse case demonstrates some of the difficulties that arise in the context of the pursuit of social objectives in a private context if the pursuit of those objectives is liable to restrict competition in the relevant market.

The Friesian is a horse breed originating in a province, Friesland, in the Netherlands. It is easily recognized by its black coat colour and long, thick mane and tail, wavy, and "feathers"-long, silky hair on the lower legs, deliberately left untrimmed. The breed has faced extinction many times and is considered one of the oldest breeds ever to be recorded. The Friesch Paarden-Stamboek (Friesian Horse Studbook) is traced as far back as $\mathbf{1 8 7 9}$. Cross breeding is not allowed and only the off-spring of approved stallions can be entered into the main studbook registry. Stallions must be approved for breeding in order for their off-spring to be eligible for registration with the Friesian Horse Studbook (FPS). A stallion's breeding approval is always conditional. The FPS was, at the time that the concerned measures were reviewed, recognised as an 'official pedigree' by the previously

legislative instructions was created in response to the cases, discussed further below, where the ACM rejected sustainability initiatives from companies and the academic response referred to in the previous note. Within the new instructions, inter alia, future assessments of the ACM are to take account of 'long terms interests', 'measures as a whole' and potential broad 'societal interests'. The methodology to calculate these benefits remains, however, largely quantitative and based on consumer behaviour based and 'willingness to pay' assessments. 
highlighted product board for livestock, meat and eggs. Within this context FPS had to adhere to requirements that were set for 'official' pedigrees across the Netherlands and this included the organisation of a pedigree in a way that would ensure that the preservation of the breed would be guaranteed on the basis of concrete breeding improvement programs, to be determined by the FPS.

Historically, the Friesian horse has issues with inbreeding because the population of the Friesian went through a few so called 'bottle necks' where the impact of just a few male horses was very big in the growth of the population. The FPS therefore strictly regulated the number of inseminations that the approved studs were allowed and forbids them to go above 180 per year until the offspring has been approved by the FPS. Members that would go above the 180 per year were liable to be sanctioned. In 2006, two of the approved studs that were owned by the same party, were particularly popular and surpassed the offspring limitation by 156 inseminations. The owner objected to the sanctions that were imposed on him, arguing that the restrictive pedigree rules qualified as output restrictions. Output restriction are generally considered as so called 'hardcore' competition law infringements that are unlikely to be justified on the basis of article 101(3) TFEU (and its Dutch equivalent). The question put on the table of an appellate court in the Netherlands was whether the FPS had indeed unduly restricted competition of its members by setting limits to the output of approved studhorses on the basis of concerns related to the health of the animal. ${ }^{65}$

More specifically, the question before the court was whether the health of the Friesian horse could be qualified as a restriction of competition that had to fulfil the efficiency requirements of 101(3) TFEU. The appellate court focussed on the 'legitimacy' question and posited in that respect that the nature of the noncompetition interest at stake in this case could not be considered as a 'weighty public interests' and therefore it could not 'justify' an infringement on the competition rules without fulfilling 101(3) TFEU. The pursuit of the health of the Friesian horse could not be considered as a sufficiently 'special' public interest to

65 Appellate Court of Arnhem 10-03-2010, Case nr. 200.002.794. 
be excluded from the scope of the competition rules. Hence, it had to fulfil the exemption criteria of article 101(3) TFEU. Therefore, implicitly the appellate court valued the restrictions as falling within the competition-dominated sphere, which therefore had to be exempted on the basis of the potential efficiencies, which they produced. On this point lies the judgment's interest, specifically with respect to the question of the valuation of the restrictions as insufficiently 'weighty'. Which interests do qualify as sufficiently weighty or worthy and how should they be pursued? Apparently, the quasi public-private governance context did not provide the measures with sufficient public interest weight. The appellate court did not expand on its reasoning and this makes the judgment weak but the judgment's interest lies exactly in this weakness as it indicates the clarification that is needed on this point and raises the issue of how private parties can pursue objectives that restrict competition but, concomitantly, potentially qualify as a genuine social objective.$^{66}$ This issue is further explored below in the following two case examples and section IV returns to it specifically from the perspective of mutual responsiveness.

\section{ii. The Energy Agreement for Sustainable Growth: the societal relevance of the process or the rationality of its outcome?}

The Energy Agreement for Sustainable Growth (EASG) is an example of Dutch consensus based policy-making and involved more than forty organisations in the definition of an energy and climate policy. ${ }^{67}$ They include central, regional and local government, employers' associations and unions, nature conservation and

66 See on this issue specifically inter alia H. Schepel, 'Delegation for regulatory powers to private parties under EC competition law: towards a procedural public interest test', Common Market Law Review (2002) 39, 31-51. Also Gerbrandy above (no. 30) at 83; .Gerbrandy above (no. 26) at 770; J. Mulder, 'Finding the public interest and the case of the Friesian horse', 2013 ACLE Conference Paper http://acle.uva.nl/events/competition--regulation-meetings/conference-papers-9th-cr-meeting-2013.html (accessed 10-12-2015); Also see Ankersmit above (no. 6) at p 290 and further.

67 The plan can be found at www.ser.nl/nl/publicaties/overige/2010-2019/2013/energieakkoord-duurzamegroei.aspx (accessed 10-12-2015). See for the preliminary competition law assessment by the Dutch competition authorities ACM: ACM, 'Notitie ACM over sluiting 5 kolencentrales in SER Energieakkoord' www.acm.nl/nl/publicaties/publicatie/12033/Notitie-ACM-over-sluiting-5kolencentrales-in-SER-Energieakkoord/ (accessed 10-12-2015) 
environmental organisations, and other civil society organisations and financial institutions. The interest wide agreement was intended to offer long-term sustainable prospects and create trust and involvement on the part of individuals, businesses, and civil society organisations.

The problematic part of the agreement concerned the closing down of coal power plants from the 1980s as part of an incentive path that would encourage the development of more sustainable energy sources. The trade association of the Dutch energy industry, Energie Nederland (EN) asked for an analysis from the $\mathrm{ACM}$ on whether the planned agreement on closing down of the coal power plants could be reconciled with Article 101 TFEU (and its equivalent in Article 6 of the Dutch competition act). The subsequent analysis of the ACM was quasi-informal but nevertheless created a situation that fundamentally challenged the EASG in its totality. ${ }^{68}$ The analysis of the ACM focussed on the closing down of the coal plants in isolation because the parties to the agreement were 'able to decide for themselves whether or not to include the agreement in the accord, subject to the competition rules'. The ACM considered that since the proposed agreement was a result of discussions between producers within EN and put forward by EN during the negotiations about the Energy Agreement that this qualified as an agreement between undertakings within the meaning of the competition rules.

The case of the EASG demonstrates the challenges for competition law frameworks in the valuation of a social interest, which is not necessarily quantifiable and, mostly, unveils a lacking institutional framework for the pursuit of social objectives by private parties. The interest at stake in this case, which cannot be valued completely within the competition law framework, concerns the process that has led to a specific organisational structure and brought together various societal actors in a way that has made them somehow co-responsible for these objectives, thereby, creating mutual obligations to ensure that they operate according to the social value attached to these objectives. As was discussed in

${ }^{68}$ As can be gathered from various news reports: E.g. http://www.energieoverheid.nl/2013/09/30/acmbreekt-pijler-energieakkoord-af-sluiting-kolencentrales-nadelig-voor-consument-en-milieu (accessed 10-12-2015) 
Chapter I, this is a social value that is easily ignored within consequentialist, utilitarian driven standards that clearly prefer evidence based technocratic outcomes to 'political jostling and compromise that may lack evidence of a clear rational basis'. ${ }^{69}$

The application of competition law in these types of cases raises the question of the position and role of competition in society. Is competition an instrument or an overarching goal? The fact that the closure of the coal plants was a seemingly inherent part of the achievement of broadly supported societal objectives regarding the environment played no part whatsoever in the analysis of the ACM. This narrow framework of analysis, combined with the way the ACM got involved in the discussion regarding the EASG illustrates how a socially relevant issue can be dis-embedded from its societal function through the narrow lens of an efficiency driven framework. From the perspective of social legitimacy and mutual responsiveness this case mostly demonstrates the institutional lacuna in the way that societal interests and competition objectives can be aligned with each other. Economic operators that are in competition lack a framework within which private initiatives with a social component can be pursued in a way that there is not an inherent tension of a potential infringement of the competition rules. ${ }^{70}$ One could also think of some more contentious issues.

In 2001, different producers of milk in the Netherlands initiated a plan to raise the price of litre milk with 10 cent for a period of two months as a response to the outbreak of the foot-and-mouth disease and the extra income would be reserved for the farmers to partly compensate their damages. ${ }^{71}$ This is an interesting example of a private initiative with a potential genuine societal, redistributive aim, which was cancelled due to its anti-competitive effects. The problem here and also in the other cases discussed is the legitimacy of the pursuit of the social objective to the detriment of competition. At some point the pursuit of these objectives in a private

\footnotetext{
See Monti above (no. 18). Also see Ankersmit above (no. 6) at 244 and further.

See also Gerbrandy above (no. 30).

71 Case 2432 - 17 April 2001. The ACM has a collection of cases on this topic: https://www.acm.nl/nl/onderwerpen/concurrentie-en-marktwerking/duurzaamheid-enmededinging/kennisbank-duurzaamheid (accessed 10-12-2015).
} 
context needs to be fed by some kind of public legitimacy. As AG Jacobs noted in the Albany case, echoing the words of Adam Smith (cited in the introduction):

"The rationale underlying the competition rules' wide scope of applicability ratione materiae is simple. It can be presumed that private economic actors normally act in their own and not in the public interest when they conclude agreements between themselves. Thus, the consequences of their agreements are not necessarily in the public interest." 72

The point is that there are societal contexts where a more dynamic model is called for, within which, on the basis of public-private deliberation, both societal goals and effective competition can be aligned and pursued on constructive terms. I mean dynamic in the sense that some of these societal objectives arise as a response to a certain social reality or in the context of a process that engages different societal actors. This chapter argues that a dynamic model can be distilled from existing case law of the Court of Justice if one takes the perspective of responsiveness.

In a more harmonious setting, the ACM analysis concerning EASG would have taken place within an institutional representative context that could interrelate with the representative public stakeholders that have been part of the process that has led to the Energy Agreement. In stead, the fact that the closing down of the coal plants was part of a wider agreement concerned with bringing together various societal actors with the intention of creating co-responsibility for the objective of a sustainable environment was ignored. The narrow framework of analysis that the ACM applies illustrates how the application of the competition law framework can dis-embed a social agreement from its societal function and reduce it to efficiency benefits; failing to recognise the importance of the societal discursive process as an overarching value in itself. Ideally, there would be an institutional framework that allows the competition interests and a societal discursive process to align towards a common shared interest. This relates back to the social purpose of the internal market that was highlighted in Chapter I; the constructive interplay of different normative orders within the European Union. Such institutional framework is lacking at the moment and it remains difficult for (associations of) undertakings to

72 A-G Jacobs opinion in case Case C-67/96 Albany [1999] ECR I-5751, para. 184. 
develop or be part of a discursive process that pursues social interests, in congruence with competition law. This last point is clearly present in the third case example below.

\section{iii. The Chicken of Tomorrow: the market rules when the state retracts?}

In the beginning of 2013 the main branch organisation on foodstuffs in the Netherlands announced that 'another chicken' would be introduced into the Dutch supermarkets. Most of the organisations from the poultry sector, the chicken meat producing industry and supermarkets came together during a roundtable meeting to discuss a more sustainable production of chicken meat ('the Chicken of Tomorrow'). The aim of these negotiations was to introduce a sector wide sustainability impulse on the basis of the introduction of a minimum standard and has to be perceived within a wider context within which, initially, Dutch livestock holders responded to the increased attention within Dutch society to animal welfare. ${ }^{73}$ These types of supply chain initiatives are stimulated by the Dutch government and institutionalised on the basis of public-private forms of cooperation. ${ }^{74}$ The initiative is an example of the new type of 'hands off' governance that is promoted by the current government in the Netherlands. As was discussed in the introduction to the case studies, previous institutional context based on the 'product boards', which would have normally be involved in the creation of policy on animal welfare, no longer exist. Instead, it is the sector itself that has become responsible to drive these sustainability initiatives in the Netherlands.

73 See in Dutch: Commissie van Doorn, 'Al het vlees Duurzaam: De doorbraak naar een gezonde, veilige en gewaardeerde veehouderij in 2020’ 2-9-2011 http://www.rijksoverheid.nl/bestanden/documenten-enpublicaties/rapporten/2011/11/23/al-het-vlees-duurzaam-de-doorbraak-naar-een-gezonde-veilige-engewaardeerde-veehouderij-in-2020/al-het-vlees-duurzaam.pdf (accessed 10-12-2015). The case has led to some debate in the Netherlands: L. Ankersmit, 'Het einde van de kiloknallers? De grenzen aan zelfregulering van duurzaam vlees onder het kartelverbod' Actualiteiten Mededingingsrecht (2011) 149155; ; J Mulder, 'Een duurzame maatschappij, wat mag dat kosten?', NJB 2015/1400 1912-1920.

74 See (all-in Dutch):www.duurzamereten.nl/nieuws/platform-wordt-alliantie-verduurzaming-voedsel (accessed 10-12-2015). 
The Dutch government had indicated that the policy in this area should be informed and guided on the basis of sector wide and based initiatives on the processing of life stock. ${ }^{75} \mathrm{~A}$ sector-wide statement of intent was signed that committed the livestock sector, the meat producing industry and retailers to move towards a situation where only sustainable produced meat would be sold in 2020 . The Chicken of Tomorrow initiative took place within this context. ${ }^{76}$ As such, these initiatives were to some extent an interaction between government and market, which led to public-privately set goals for sustainability. On the basis of these sector-wide initiatives, which are partly fed publicly, a process of embedding of economic activities may take shape that set the preconditions for trade in poultry products.

The minimum standards that were part of the Chicken of Tomorrow initiative concerned agreements on the keeping of a slower growing breed of chickens, more space for chickens on the basis of a reduction of the number of chicken in a set space with $10 \%$, improved conditions within the stables, stricter controls on animal welfare standards and a more natural day-night rhythm, lowering of the use of antibiotics, the use of $100 \%$ sustainable soya food and a number of other environmental measures. ${ }^{77}$ The initiative met with a lot of criticism, which according to animal welfare organisations, would improve the conditions of chickens only marginally. Indeed, at first sight, the measures do look minimal and the improvements in chicken welfare would not be ground-breaking but the initiative's aims was to introduce a sector wide minimum standard from which to move upwards. That is to say, to introduce a standard of animal welfare under which trade in chicken meat would be unacceptable.

The analysis of the ACM ignored this societal context and assessed the initiative solely from the perspective of the narrow application of the competition law framework. The assessment of the ACM concluded that the sustainability

75 Letter with the position of the Dutch government, 'Toekomst van de intensieve veehouderij' Official parliamentary documents: $28973 \mathrm{nr} .134$ accessible at https://zoek.officielebekendmakingen.nl/kst28973-137.html (accessed 10-12-2015).

76 ACM assessment of the sustainability agreements 'Chicken of Tomorrow' (ACM/DM/2014/206028), January 2015, p. 2.

77 Ibid., page 2-3. 
initiative qualified as a restriction of competition on the retail market for chicken meat because 'regularly' produced chicken meat would no longer be for sale in Dutch supermarkets. The ACM concluded that this limited choice for consumers and removed a competitive benchmark, namely chicken meat produced on the basis of lower standards. The analysis of the ACM aimed to provide guidance to companies that would want to implement such sustainability initiatives. Before an initiative is taken that restricts competition, companies must, according to the ACM, make an appraisal demonstrating clearly whether the restrictions can be justified on the basis of the benefits it brings to consumers. This refers back to the previously discussed obligation for subjects of competition law to self-assess their status on the basis of the position and guidance papers that issued by (national) competition authorities.

For this purpose, the ACM has in this case, by way of 'guidance', conducted a 'willingness to pay' analysis. ${ }^{78}$ The ACM considered that the first condition of Article 101(3) TFEU, i.e. the contribution to the production or distribution of goods or to promoting technical or economic progress, would only be fulfilled if the measure would eventually lead to a higher consumer surplus, which was to be determined on the basis of the willingness of consumers to pay more for the 'added' animal welfare. Consumer panels consisting of 2,000 households were asked to make a choice between different types of chicken meat. Consumers could choose between different types of chicken meat that differed with regard to the level of animal welfare that was taken into account in the production of the meat. In addition, respondents were urged to consider the effects of their choice on their (artificial) monthly grocery budget so that it could be quantified how much importance they would exactly attach to animal welfare. The economic report of the ACM made clear that the purpose of the investigation was not to "to simulate the actual selection process in stores but to find out what consumers really want to pay

Economic assessment ACM, Effects of the Chicken of Tomorrow - Costs and benefits for consumers M. Mulder, S. Zomer (ACM) \& T. Benning, J. Leenheer (CentERdata), October 2014 (accessible on acm.nl). 
for something." ${ }^{79}$ Respondents who had chosen to buy no chicken whatsoever have been identified in the research as consumers for whom there exists no chicken at all, which would meet the respondent's preferences. Within the report, the utility that these consumers derived from not buying chickens was set at 0 . Concomitantly, the "willingness to pay" for these consumers was also set at $0 .{ }^{80}$

Eventually the economic analysis of the ACM concluded that the willingness to pay for the Chicken of Tomorrow was not large enough to justify the increase in the consumer price. On balance, according to the study, there would be a negative effect on consumer surplus of 0.64 euro per kilogram of chicken breast. ${ }^{81}$ Moreover, the ACM considered that it would be preferable if, instead of introducing a minimum standard, consumers would be better informed about animal welfare on the basis of labels. This could then also be a part of a broader commercial strategy of a supermarket to attract consumers who value these sustainable products. According to the ACM it would therefore be more appropriate if sustainability initiatives would focus on measures to improve animal welfare by educating consumers and stimulating consumer confidence in other types of production, as part of a competitive process. ${ }^{82}$

This analysis of the ACM is problematic when framed within the introduced perspective. This is strikingly illustrated on the basis of the example of a consumer who does not buy chicken. All possible considerations that consumers may have not to buy chicken are reduced in the analysis of the ACM to a lack of willingness to pay for sustainable produced chicken. Moreover, the emphasis put on the artificiality of the assessment of consumer behaviour and explicitly not "the actual selection process in stores" undermines the credibility of the whole assessment. The narrow framework of assessments values a multiplicity of intentions and social interests in terms of a monetary interest. Moreover, the actual selection process of consumer in supermarkets should be central in an analysis that looks for the 'reality'

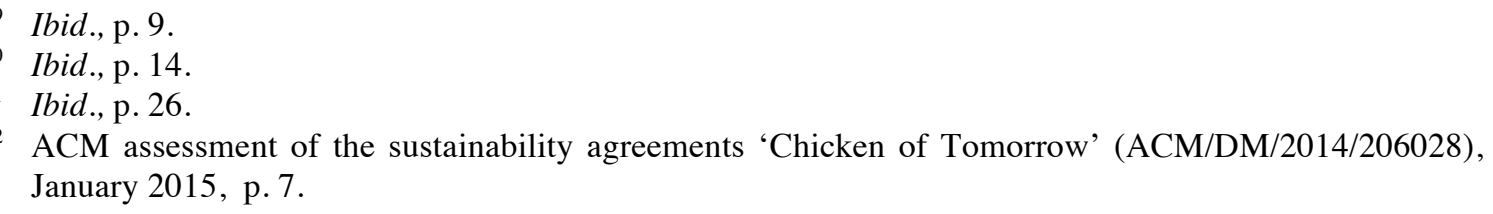


of consumer interests. Importantly, because there has been research suggesting that it is unlikely for the average consumer to consistently and consciously consider animal welfare in the actual purchase decision. ${ }^{83}$ Secondly, there may be no real choice for consumers for whom the more expensive free-range chicken is not affordable but who think that animal welfare is important. Hence, a minimum standard constitutes a different measure and a different social purpose than to unveil the exact 'willingness to pay' of a consumer. More importantly, the introduction of a minimum standard does not inhibit the use of labels and commercial strategies for supermarkets to attract consumers who value sustainable products. As an aside, the position of the ACM regarding "the better way" to achieve sustainability in the production of chicken meat is highly questionable. The use of eco-labels is assigned a very questionable role in securing sustainability goals. ${ }^{84}$ The crucial point is that the analysis of the ACM is, explicitly, published as guidance material for undertakings to pursue these objectives in their selfassessments. On this point there is therefore an explicit and inherently limited valuation with respect to what matters and how things matter in society on the basis of a narrow competition based perspective.

Therefore, from a broader societal perspective several question marks can be placed on the approach to animal welfare that the ACM supports in its analysis. By pursuing animal welfare on the basis of consumer preference and to conceptualise it as a monetary consideration, a choice is made for a particular type of society. That is a society where the consumer or the market largely determines whether and how to achieve certain societal interests. To put social objectives in the hands of the consumer is a profoundly political decision. Is it socially desirable to place a number on the welfare of a chicken or the way we interact with the environment? Perhaps, but the point is that (i) this is not necessarily the case, (ii) it is socially relevant to discuss it exactly on the point that market and non-market interests intersect and (iii) the competition platform constitutes a suitable starting point for

\footnotetext{
83 For example, R.E. Horne 'Limits to labels: The role of eco-labels in the assessment of product sustainability and routes to sustainable consumption', International Journal of Consumer Studies 33(2009) 175-182.

84 Ibid, p.181.
} 
this dialogue even if only to switch to another platform where competition will be but one of the interests at stake. The ACM, however, would argue that this is simply either a competition problem or not. The government can decide on this issue and prioritize animal welfare through legislation should it so desire. ${ }^{85}$ Thus the issue would be taken outside the sphere of competition and it would be solved within a democratically legitimate framework. ${ }^{86}$

Importantly, the position of the ACM, again, points towards the institutional lacuna that has been now repeatedly discussed in the context of the previous case studies. The position of the ACM in these cases has been adverse and eventually crucial in the way that the sustainability initiatives have been pursued. It will be argued in the next section that this institutional lacuna can be addressed on the basis of some approaches and ideas that have been set out in EU case law and, when tied together around the idea of responsiveness, allow for an approach that addresses the problems that have been raised on the basis of the case studies discussed in this section.

\section{Responsiveness in the case law of the Court of Justice}

The normative concern that underlies the discussed case examples is that the valuation that is implicit in the evaluative standards that may be applied to social

85 It is important to note that the Chicken of Tomorrow case is in flux. The case has led to a political debate on the reach of the competition rules and, in particular the interaction between competition and sustainability initiatives. Currently, the Dutch Ministry of economic affairs is in the process, in coordination with the European Commission, of drafting new legislative guidance on how sustainability initiatives and competition law should interact. See further above (no. 69).

${ }^{86}$ As a side note it is important to note that this position may not be tenable in light of European case law. Dutch competition law is not applied in a vacuum but is part of the European legal order and the ACM applies the European competition rules. One of the important objectives for which the TFEU creates a legal basis is to denounce outdated national practices and legislation. For example, in the case Consorzio Industrie Fiammiferi a royal decree of 1923 in Belgium was set aside that protected matchmakers in Italy from competition. The Court decided in that case that the national competition authority is required to set national legislation aside as soon as it is established that such legislation is in conflict with European competition rules. In the European context, the competition rules thus also apply to national legislation and serve as a strong crowbar to force national governments to reconsider restrictive competition practices, also if it is of a legislative nature. Especially now that the ACM has established that this sustainability initiative is in conflict with (European) competition law, a state measure that would incorporate these commitments should, in principle, be put aside by the ACM on the basis of the CIF judgment. Case C-198/01 (CIF). 
realities on the basis of EU competition law are based on a metric that risks doing violence to potentially genuine and worthwhile aspects of those objectives. Moreover, the unitary metric, transforms the balancing of competing values into an issue of calculation and the nature of the problem is thereby transformed into one of quantification. Quantification risks loosing the expressive value that is inherent in a normative conflict and the consequent potential for social learning that arises from it. The following sections group together lines of cases from the Court that demonstrate a certain responsiveness to potential normative conflicts between the valuation that is implicit in the competition rules and the social realities addressed by these rules. These approaches from the Court serve the purpose of building blocks that can be reconstructed into a coherent model of adjudication from the perspective of social legitimacy and address the institutional lacuna that was identified in the case studies above. Approaching the case law of the Court of Justice from the perspective of responsiveness provides a novel view, in particular, on requirements of institutional design within the Member States that are required to pursue EU competition restrictive social interests. As will be discussed in the subsections below, the perspective of responsiveness brings together lines of case law that are not normally considered to be related but, as will be demonstrated, can be grouped together from the perspective of responsive adjudication. ${ }^{87}$

\section{A. Responsiveness to social context in Albany, Poucet Pistre and Wouters}

\section{i. $\quad$ The Albany building block: valuation of different social spheres}

Firstly, it is important to emphasize that the Court at various times and ways has shown clear responsiveness towards the incompatibility between the rationale behind the pursuit of interests of a wider social nature and the normative concerns

87 The discussion of the lines of cases have been discussed similarly in earlier publications: J. Mulder, 'Op het snijvlak van onafhankelijkheid en openheid :wat is de rol van de ACM in een duurzamemaatschappij?', SEW 2014, p. 565-578; J Mulder, 'Een duurzame maatschappij, wat mag dat kosten?', NJB 2015/1400 1912-1920; J. Mulder, 'Finding the public interest and the case of the Friesien horse', 2013 ACLE Conference Paperhttp://acle.uva.nl/events/competition--regulationmeetings/conference-papers-9th-cr-meeting-2013.html (accessed 10-12-2015). 
of the competition law framework. The Court has, for example, ruled in several cases that agreements in the context of collective bargaining between workers and employers may be excluded from the scope of Article 101 TFEU ${ }^{88}$ The Court held in Albany that some restrictions on competition are inherent in the pursuit of collective agreements between organisations representing employers and workers. Specifically, agreements entered into within the framework of collective bargaining between employers and employees that are intended to improve employment and working conditions must, by virtue of their nature and purpose, be regarded as not falling within the scope of Article 101(1) TFEU. ${ }^{89}$ In the cases Drijvende Blokken and Brentjes, which the Court issued on the same day, the same reasoning was used with respect to a supplementary pension fund set up for employees in the transport and dock industry and the building sector..$^{90}$ The reasoning of the Court to allow a genuine societal process some leeway from the competition rules was implicitly confirmed in Pavlov. ${ }^{91}$ In Pavlov the Court refused the Albany reasoning to be applied to self-employed medical specialists because the agreement was not concluded in the in the context of collective bargaining between employers and employees and aimed at improving employment conditions of workers, but it was aimed at working conditions amongst self-employed persons. ${ }^{92}$ In other words there nature of the negotiations was not one of social protection.

It is, therefore, the nature and purpose of an agreement that may warrant its exclusion from the scope of the competition rules, specifically, because of the impediment of the social objectives that are pursued with these agreements, should they be subject to the competition rules. It is clear that certain restrictions of competition are inherent in collective agreements between organisations, representing employers and workers. However, the Court considered that some of

88 Case C-67/96, Albany [1999] ECR I-05751; Joined Cases C-115-117/97 Brentjens [1999] ECR I-6025; Case C-219/97 Drijvende Blokken [1999] ECR I-6121.

89 Case C-67/96, Albany [1999] ECR I-05751, para. 60.

90 Joined Cases C-115-117/97 Brentjens [1999] ECR I-6025, para. 57; Case C-219/97 Drijvende Blokken [1999] ECR I-6121, para. 47.

91 Similarly reasoning also in Ankersmit above (no. 6) at 276.

92 Joined Cases C-180/98 to C-184/98 Pavlov and Others [2000] ECR I-6451, paragraph 67; also Case C-222/98 van der Woude [2000] ECR I-7111, paragraph 22. 
the social policy objectives pursued by such agreements would be undermined if management and labour were subject to the liability of infringing the competition rules when seeking to adopt measures to improve conditions of work and employment. The Court, implicitly, recognises a tension between, in terms of the debate above, the competition and noncompetition interests at stake in this case. The social value of the process of negotiation between employers and employees overruled the application of the competition law framework. ${ }^{93}$

In its decision the Court referred to the Treaty that provided that the EU Commission is to promote close cooperation between Member States in the social field, particularly in matters relating to the right of association and collective bargaining between employers and workers. Even though the Court refers to the social objectives, what is essentially protected with this legal analysis is the process of negotiation between management and labour. In other words, it is mainly the process that makes the exclusion of the negotiations necessary. The organizational structure that brings together these societal actors makes them co-responsible for these objectives, thereby, creating mutual obligations and ensuring that they operate according to the social value attached to these objectives. As such, this allows for a certain responsiveness to the process within which social objectives are pursued to be recognised and valued in the application of the competition law framework.

The Court, in Albany, exempted collective agreements from the application of the competition rules by reference to the objectives and values that are mentioned in the Treaty and thereby created an alternative type of valuation of this societal process within the legal framework of the internal market. It is through an extension of this rationale that the pursuit of other social objectives than the improvement of conditions of work and employment that a rationale of social legitimacy based on the idea that different types of social spheres require different kinds of valuation.

93 See also A. Sangiovanni, 'Solidarity in the European Union', 196(2013) Oxford Journal of Legal Studies, p. 1-29; P. Craig, 'Competence and Member State Autonomy: Causality, Consequence and Legitimacy' in Hans W. Micklitz and Bruno de Witte, (eds.), The European Court of Justice and the autonomy of the Member States, (Oxford Legal Studies Research Paper No. 57/2009); J. Shaw, Social law and policy in an evolving European Union, (Oxford Hart 2000); G. de Búrca, EU law and the welfare state: in search of solidarity (Oxford University Press 2005); M. Dougan and E. Spaventa (eds.), Social welfare and EU law (Oxford Hart 2005). 
The rise of noneconomic objectives was discussed in the Chapter I. In Lisbon there is more emphasis on sustainable development of a Europe based on balanced economic growth and price stability, policies based on a spirit of solidarity, a competitive social market economy aimed at full employment and social progress, the pursuit of social cohesion and a high level of protection and improvement of the quality of the environment combined with requirements of consistency among Union policies and consequent duty to take into account environment, consumer protection employment, social protection, education, health, combating discrimination in defining and implementing Union activities. The reasoning in Albany provides for an argument that the evolution in scope of nonmarket interests within the primary law framework is not without legal consequences and should make space for different kinds of valuation of different social spheres. However, for the puzzle of social legitimacy, Albany provides only a limited answer since the analysis regarding the exact nature and purpose of the agreement is largely absent from the Court's analysis, which merely mentions that the category of agreements, i.e. collective agreements resulting for social dialogue, and the purpose, i.e. the establishment of additional pension funding, does not "by reason of its nature and purpose, fall within the scope of Article [101 (1) TFEU]"94. The reasoning of the Court on this point is therefore circular and incomplete. That is to say that the Court did not provide a rationale for the alternative valuation to be implemented but rather assumed that the process of negotiation between capital and labour served a purpose that was inherently outside the reach of the competition rules. This assumption lacks reasoning so as to distinguish the competition from the noncompetition interest. The next subsections explore whether these gaps in the legal analysis can be addressed by reflecting on other lines of case law of the Court where it has been responsive to social context in different parts of the legal analysis.

94 Case C-67/96 Albany [1999] ECR I-5751, paras 62 to 64. 


\section{ii. Poucet and Pistre building block: a rationale for the alternative valuation of a noneconomic social sphere (part one)}

The Court incorporates responsiveness in its legal qualification of an entity as 'undertaking' for the purpose of the competition rules. The legal definition of an entity as undertaking within the competition rules depends on the economic nature of the activity concerned. It is therefore possible for an entity to be treated as an undertaking with respect to part of its activities and not for others. ${ }^{95}$ For example, universities that are partly operating within a market environment (e.g. with competitive tailored business courses) and partly fulfilling public educational tasks are only subject to the competition rules in so far it concerns activities that are in potential competition with other educational service providers. The definition of an undertaking is functional to the application of the competition rules. ${ }^{96}$ Therefore, what is to be considered as an economic or noneconomic activity cannot be given $a$ priori status and requires a case-by-case analysis. It is not the formal status of an entity (e.g. a public undertaking) or an entire sector (e.g. healthcare), nor the way in which it is funded, which determines whether its activities are deemed to be subject to the competition rules (economic or noneconomic); it is the nature of the activity itself. ${ }^{97}$ For the purpose of this analysis the Court has considered "the nature, the aim and the rules" applicable to a given activity. ${ }^{98}$ Participation in a market has been considered as representing activities of an economic nature, "any activity consisting in offering goods and services on a given market is an economic activity" ${ }^{99}$ Therefore, it is not the mere fact that the activity may, in theory, be carried on by private operators that is decisive, but the fact that the activity is

95 Case C-222/04 Cassa di Risparmio di Firenze [2006] ECR I-00289; Case C-118/85 Commission v Italy [1987] ECR 2619. Compare also Cases C-205/03 P. Fenin [2006] ECR I-06295 and T-155/04- Selex [2006] ECR II-04797 for a situation where different activities could not be analysed separately

96 Case 118/85 Commission v Italy [1987] ECR 2599, paragraph 7: "the State may act either by exercising public powers or by carrying on economic activities of an industrial or commercial nature by offering goods and services on the market".

97 Case C-82/01 Aéroports de Paris [2002] ECR 2002 I-09297.

98 Case C-118/85 Commission v Italy [1987] ECR 2599, paragraph 7:

99 Joined Cases C-180/98 to C-184/98 Pavlov and Others [2000] ECR I-6451, paragraph 75, and Case C475/99 Ambulanz Glöckner [2001] ECR I-08089, paragraph 19. See also Case C-309/99 Wouters and Others [2002] ECR I-1577, paragraph 47, and Case C-82/01 P Aéroports de Paris v Commission [2002] ECR I-9297, paragraph 79. 
carried out under market conditions. On this basis, tasks that are exclusively exercised in the public interest, such as the maintenance of air navigation safety ${ }^{100}$ and the conservation of nature, ${ }^{101}$ have been excluded since those activities, in the concerned cases were to be considered as inherent to "the essential functions of the State". ${ }^{102}$ Cases that involve the "exercise of official authority" for the purpose of regulating the market (as opposed to participating in it) do not fall within the scope of competition law. ${ }^{103}$ The essence of this reasoning originates from the judgment in Höfner and Elser. ${ }^{104}$ The Court there considered that the activity was economic in nature, since "employment procurement has not always been, and is not necessarily, carried out by public entities" (emphasis added). Similarly, in the case Ambulanz Glöckner the Court reasoned that health organisations providing services on the market for emergency and ambulance services were held to be undertakings, because "such activities have not always been, and are not necessarily, carried on by such organisations or by public authorities" (emphasis added). ${ }^{105}$ On this basis the Court assessed Italian customs agents to be undertakings because: "they offer, for payment, services consisting in the carrying out of customs formalities, relating in particular to the importation, exportation and transit of goods, as well as other complementary services such as services in monetary, commercial and fiscal areas" ${ }^{106}$ Hence, there was, due to the infrastructure that governed these activities no "necessity" for the exclusion of the competition sphere.

This reasoning is essentially responsive to social context since it has to be determined when an activity is carried out under market conditions. This responsiveness is demonstrated mainly in cases that involved a conflict between competition and what has been coined as principles of solidarity. The Court has established in these cases that conduct, which is undertaken with the objective of

\footnotetext{
100 Case C-364/92 SAT Fluggesellschaft('Eurocontrol [1994] ECR I-43.

101 Case C-343/95 Diego Calì \& Figli [1997] ECR I-1547.

102 Ibid. paragraph 22.

${ }^{103}$ Case T-313/02 Meca-Medina and Majcen v Commission [2004] ECR II-0000, paragraph 41.

104 Case C-41/90 Höfner and Elser [1991] ECR I-1979

105 See paragraphs 67 and 27, respectively, of the Opinions of Advocate General Jacobs in Ambulanz Glöckner [2001] ECR I-08089 and Joined Cases C-264/01, C-306/01, C-354/01 and C-355/01 AOK-Bundesverband and Others [2004] ECR I-2493.

106 Case C-35/96 Commission v Italy [1998] ECR I-3851, paragraph 37
} 
capitalisation is incompatible with the functioning of a sector on the basis of principles of solidarity. The Court has never truly developed this principle of capitalisation but the implicit reasoning suggests some manifest irreconcilability between, for example, 'capitalisation' and 'solidarity'. In Poucet and Pistre, the question arose as to the compatibility of compulsory membership of a social security scheme with competition law. In this case the Court referred to the nature of the organisations concerned: "the concept of undertaking within the meaning of Articles [101 and 102 TFEU] does not encompass organisations charged with the management of social security schemes of the kind referred to in the judgments of the national court". The Court decided, "those schemes pursue a social objective and embody the principle of solidarity" ${ }^{107}$ The manner in which the principle of solidarity is embodied should form the basis of the classification and the 'exclusively social' function fulfilled by those organisations "is based on the principle of national solidarity and is entirely non-profit-making”. The Court also noted that "the benefits paid are statutory benefits bearing no relation to the amount of the contributions". 108

This line of case law that originated with Poucet and Pistre is interesting because it demonstrates a rationale for the valuation of a different social sphere. A social sphere that is inherently irreconcilable with the sphere of competition because of the underlying rationales. There is responsiveness from the EU competition law framework in the sense that local rationales such as solidarity are recognised as the driving rationales of a particular social context and allowed an autonomous existence within an alternative type of valuation. There is, however, mutual responsiveness because the pursuit of these objectives is made conditional on the presence of certain institutional requirements and safeguards. Therefore, the Member States need to respond to requirements that set out the institutional conditions within which these objectives can be pursued. For example, in Cisal, the Court had to determine whether the compulsory membership of a national

\footnotetext{
107 Joined Cases C-159/91 and C-160/91 Poucet and Pistre [1993] ECR I-637.

108 Ibid.
} 
insurance scheme was subject to the competition rules. ${ }^{109}$ The Court held that the Italian national institute for insurance against accidents at work ('INAIL'), operated in accordance with the principle of solidarity. Importantly, it was also subject to the control of the state, which set the level of contributions and determined that membership was to be compulsory. That INAIL indeed operated in accordance with the principle of solidarity was determined on the basis of an analysis of a number of elements: "that the insurance scheme was financed by contributions the rate of which was not systematically proportionate to the risk insured; the amount of benefits paid was not necessarily proportionate to the insured person's' earnings". ${ }^{110}$ The Court therefore held that the INAIL did not carry on an economic activity, with the result that competition law did not apply. In the case of FFSA and Others the question related to the monopoly of management of an old-age insurance scheme conferred on a mutual fund. ${ }^{111}$ In this case the Court considered that the entities, which managed the retirement scheme qualified as undertakings. The determining factors in this case concerned "the fact that membership of the retirement scheme was optional, that the scheme was managed in accordance with the principle of capitalisation and that benefits were calculated on the basis of contributions made". ${ }^{112}$ In the second relevant part of the Albany judgment, a Dutch sectoral pension fund was held to be an undertaking for the purposes of competition law on the basis of the same reasons. The Court concluded that an element of competition was introduced, which impacted the assessment and opened up the sector to the competition rules. That there were also circumstances present, such as the pursuit of a social objective or the fact that the fund was non-profit-making were "not sufficient to 'deprive' the activity carried on of its economic nature". ${ }^{113}$ Similar reasoning is adopted in other cases of the Court. ${ }^{114}$

109 Case C-218/00 Cisal [2002] ECR I-691. In paragraphs 38 to 40 of Cisal, it is stated that solidarity was evidenced by the fact that contributions were not systematically proportionate to the risk insured against, nor were the benefits paid strictly proportionate to the insured person's earnings.

110 Ibid., paras 38-42.

111 Case T-106/95 FFSA and Others [1997] ECR II-00229.

112 Ibid., para. 21

113 Case C-67/96 Albany [1999] ECR I-5751.

114 Joined Cases C-180/98 to C-184/98 Pavlov and Others [2000] ECR I-6451, C-355/01 
The nature of the activity has thus both a formal and substantive component in the case law of the Court. The formal conditions relate to the existence of a market, state prerogatives or obligations of solidarity. ${ }^{115}$ Most importantly, the formal notion of the non-competition interest determines that some rules or regulations do not enter 'the sphere of economic activity' because the State defines the public-interest criteria and the essential principles with which its rules must comply and retains the power to adopt decisions. In that situation rules adopted by private associations remain within state primacy and are not covered by the Treaty rules applicable to undertakings. Other Treaty articles could of course then be triggered (internal market rules or article 106 TFEU). ${ }^{116}$ In the solidarity cases the formal criteria relate to the institutional safeguards that are in place and implement and necessitate entities to follow principles of solidarity. In substantive terms, solidarity has been identified as operating on the basis of another normative order. In the words of AG Fennelly in Sodemare

“...the existence of systems of social provision established by Member States on the basis of the principle of solidarity does not constitute, as such, an economic activity, so that any inherently consequent restriction on the free movement of goods, services or persons does not attract the application of Treaty provisions. Social solidarity envisages the inherently uncommercial act of involuntary subsidization of one social group by another. Rules closely connected with financing such schemes are more likely to escape the reach of the Treaty provisions on establishment and services. Thus, pursuit of social objectives on the basis of solidarity may lead Member States to withdraw all or part of the operations of social security schemes from access by private economic operators". ${ }^{117}$

AOK-Bundesverband and Others [2004] ECR I-2493.

115 Case C-222/04 Cassa di Risparmio di Firenze [2006] ECR I-00289.

116 For a given service to qualify as an economic activity under the internal market rules (free movement of services and freedom of establishment), the essential characteristic of a service is that it must be provided for remuneration. The service does not, however, necessarily have to be paid by those benefiting from it. The economic nature of a service does not depend on the legal status of the service provider (such as a non-profit making body) or on the nature of service, but rather on the way a given activity is actually provided, organised and financed. In practice, apart from activities in relation to the exercise of public authority, to which internal market rules do not apply, it follows that the vast majority of services can be considered as "economic activities" For article 106 it all depends on a procedural review of the organisation of the public service concerned.

${ }^{117}$ Case C-70/95 - Sodemare and Others v Regione Lombardia [1997] ECR I-03395, para. 29. 
Hence, solidarity constitutes a normative order that cannot be subsumed under a market order that operates on the basis of a principle of capitalisation. That is to say that the Court identifies that sectors that operationalize under a principle of capitalization or under a principle of solidarity are representative of different normative spheres and that the normative sphere that is applicable in a sector that is organised on the basis of a principle of solidarity cannot be captured in a legal framework that is based on a competition rationale. That is not to say that the social and competition spheres are always irreconcilable. The interplay of the two, potentially irreconcilable principles is pointedly indicated by the Court in $A O K$ Bundesverband, where sickness funds operated on the basis of a solidarity system but the German legislator introduced elements of competition for the purpose of attracting members

“... the legislature introduced an element of competition with regard to contributions in order to encourage the sickness funds to operate in accordance with principles of sound management, that is to say in the most effective and least costly manner possible, in the interests of the proper functioning of the German social security system. Pursuit of that objective does not in any way change the nature of the sickness funds' activity". ${ }^{118}$

In this short passage the Court demonstrates the expressive value of the interplay of competition and non-competition interests, which requires a specific and concrete articulation of the limits of both solidarity and competition. The moment of societal learning is reached where the Court establishes the limits of both spheres in a concrete manner. Hence, in these cases the Court is willing and able to implement a different kind of valuation towards a social sphere that is governed by the principle of solidarity.

The 'solidarity cases' have given impetus to a line of literature that considers solidarity as an independent principle within EU competition law ${ }^{119}$ and the

118 Joined Cases C-264/01, C-306/01, C-354/01 and C-355/01 AOK Bunderverband [2004] ECR I-02493, para. 56

119 A. Winterstein, 'Nailing the Jellyfish: Social Security and Competition Law' (1999) 20 European Competition Law Review at 324; M. Ross 'Article 16 EC and Services of General Economic Interest: from Derogation to Obligation' (2000) 25 European Law Review at 22; E. Szyszczak, 'Public Services in Competition Markets' (2001) 21 Yearbook of European Law 35, 64; M. Ross, 'Promoting solidarity: 
principle has been conceived as a potential "buttress" against internal market law and competition law specifically ${ }^{120}$. Solidarity is generally framed as a principle that necessarily opposes the objectives of competition law and as a signalling post for an area where Member States have retained full control over national policy orientation. The discussion of case law, however, indicates that Member States do have to take into account principles of good governance in the organisation of sectors that are based on the principle of solidarity. The Court has limited the solidarity "buttress" to situations where the exercise of solidarity is under strict state supervision and takes place within a legislative framework where objectives are installed by the state. ${ }^{121}$

In other words, these sectors have to be consistently organised in accordance with the solidarity principle in order to merit an existence outside of the scope of the competition rules. Moreover, as the Court noted above in AOK Bunderverband, there is no inherent irreconcilability between competition and solidarity. Instead, the Court assesses, in concreto, whether solidarity and competition are reconcilable. As such, solidarity is not necessarily a completely separate or 'unique' area, which is singularly able to act as a buttress against the evils of the internal market. Potential irreconcilable normative conflicts between societal organisational principles are not limited to these two spheres and it is submitted that the rationale employed by the Court in solidarity cases can be extended beyond the potential irreconcilability of just solidarity and competition. From the perspective of social legitimacy the Court of Justice has, with the Albany and Poucet Pistre lines of case law, established a rationale for context specific valuations of different social spheres and set out the beginning of a more comprehensive approach that, in a

From public services to a European model of competition?' 44(2007) Common Market Law Review at 1057; N. Boeger, 'Solidarity and EC competition law' (2007) European Law Review, at 319; E. Szyszczak, The Regulation of the State in Competitive Markets in the EU (Oxford Hart Publishing, 2007).

${ }^{120}$ T.K. Hervey, 'Social solidarity: a buttress against internal market law' in J. Shaw (ed.), Social Law and Policy in an Evolving European Union (Oxford Hart Publishing 2000) 31-47.

121 Case C-437/09 AG2R Prevoyance, para. 46, also case Case C-222/04 Cassa di Risparmio di Firenze [2006] ECR I-00289. 
dynamic and context-specific way, instructs the constructive interplay between competition and non-competition spheres.

Below I explore a potential further extension of this rationale on the basis of another line of cases.

\section{iii. Wouters: a rationale for the alternative valuation of a noneconomic social sphere (part two)}

The cases discussed above take into account the nature of the activity on the basis of the question whether they take place in market or nonmarket conditions to determine whether or not specific entities operate as undertakings. The rationale set out by the Court in Poucet an Pistre, which dis-applies the competition law framework in case that a sector is organised on the basis of principles of solidarity, is extended in case law where there is a potential conflict between the competition rules and private led initiatives in the development and pursuit of social interests. Here we enter a line of cases, which starts with the Wouters case. ${ }^{122}$ The central question in Wouters is to what extent and under what circumstances (associations of) undertakings can themselves formulate objectives as a public interest that can be pursued to the detriment of effective competition. In Wouters the Court qualified a decision of the Dutch Bar to prohibit multi-disciplinary partnerships between attorneys and accountants as not infringing article 101(1) TFEU. The Bar was charged on the basis of Dutch law to adopt deontological rules that assured the correct exercise of the attorneys' profession. The Court first established that the regulatory powers that were provided to the Bar were not strictly supervised by the Dutch state and there was scope for the Bar to define public-interest criteria and the way to pursue them. ${ }^{123}$ Consequently, the Bar qualified as an association of undertakings. Therefore, even though the Bar functions as the regulatory body of a

\footnotetext{
22 Case C-309/99 Wouters and Others [2002] ECR I-1577. Three key pieces on Wouters J. Vossestein annotation in Common Market Law Review 39(2002), 841-863, Monti above (no. 8) 1057-1099; I. Wendt, EU Competition Law and Liberal Professions: an Uneasy Relationship? (Leiden: Brill Academic Publishers, 2012).

123 Case C-309/99 Wouters and Others [2002] ECR I-1577, para. 68
} 
profession, whenever it adopts its regulations, the competition rules apply. However, the Court of Justice considered that not every restriction of competition that flows forth from this necessarily falls within the prohibition laid down in Article 101(1) TFEU. ${ }^{124}$ The overall context of the restriction matters:

"More particularly, account must be taken of its objectives, which are here connected with the need to make rules relating to organisation, qualifications, professional ethics, supervision and liability, in order to ensure that the ultimate consumers of legal services and the sound administration of justice are provided with the necessary guarantees in relation to integrity and experience (...). It has then to be considered whether the consequential effects restrictive of competition are inherent in the pursuit of those objectives."

The reasoning adopted by the Court calls to mind the reasoning adopted by the Court in Albany where it considered that certain agreements by virtue of their nature and purpose should be regarded as not falling within the scope of Article 101(1) TFEU. However, where in the Albany context it was the societal process that mattered and influenced the nature and purpose of the agreement, in Wouters the reasoning of the Court is specifically related to the rationality of the objectives of an agreement. The Court did not consider possible efficiencies of the restrictive agreements. The decisive question was whether the prohibition was necessary for the proper practice of the legal profession. Whether or not Dutch attorneys could provide more efficient advice to companies if one entity could provide legal and accounting services at the same time was not at stake. In stead, the Court created a possibility to lift a restriction on competition from the strict application of the competition law framework to a domain beyond the efficiency logic of the exemption framework and, consequently, towards another type of valuation. The objective of integrity was considered to be a legitimate objective and all the consequent restrictions on competition were to be evaluated on the basis of another test. This alternative valuation took place on the basis of the question whether the restrictions of competition are inherent to the pursued objective and do not go

124 Ibid., para. 97 
further than necessary. ${ }^{125}$ Although not explicitly stated, the inherent logic at work here appears to be fairly clear. The Court assumes that integrity of a profession is not an objective that can be translated within the efficiency targets of the exemption conditions of article 101(3) TFEU and hence merits an existence outside of this framework. Therefore, it can be said that the Court was explicitly responsive to the non-competition context and the potential negative impact of changing that context to the benefit of efficiency considerations. ${ }^{126}$ Thus, the Court created a rationale to incorporate responsiveness in the legal review of restrictions on competition on the basis of a context-specific assessment of the rationale behind competition restrictive measures; a rationale that goes beyond competition versus solidarity conflicts. As was discussed with regard to Albany, the Court in that case did not provide a rationale for how an alternative valuation of a social sphere that potentially falls outside of the reach of the competition sphere is to be implemented but rather assumed that the process of negotiation between capital and labour served a purpose that was inherently outside the reach of the competition rules. As said, this assumption lacks reasoning so as to distinguish the competition from the non-competition interest. Similarly, in Wouters there is to some extent an assumption from the Court that the integrity of the attorneys' profession is irreconcilable with the exemption criteria of 101(3) TFEU.

An opinion of AG Wahl in the case FNV Arts v. the Netherlands illustrates, how these gaps can be potentially addressed. ${ }^{127}$ In this case, the Dutch ACM protested against provisions in a collective agreement that set the minimum rates of

125 Ibid., paras 98-106.

126 See for another opinion Vossestein above (no. 122) on p. 859: "On the other hand, in my view it may not be excluded that the Court had competitive considerations in mind. The Court refers in paragraph 97 to the need 'to ensure that the ultimate consumers of legal services and the sound administration of justice are provided with the necessary guarantees in relation to integrity and experience'. The Court may be viewing the regulation, looked at in an overall context, as improving quality, enhancing consumer choice and thus pro-competitive". Whish sees Wouters mainly as the application of the inherent restrictions case law in a regulatory context: "This seems to be a different application of the concept of ancillarity from that in earlier case law: the Wouters case is concerned with what could be described as 'regulatory ancillarity', whereas earlier judgments were concerned with 'commercial ancillarity'; perhaps the use of these two terms would be useful in, first, demonstrating a continuity with the earlier case law, through the common use of the idea of ancillarity, while also capturing the difference between the two situations, by distinguishing commercial and regulatory cases" in Whish and Bailey, above (no. 1) p. 132.

127 Opinion AG N. Wahl in case C-413/13 np (FNV Kunsten t. Staat der Nederlanden). 
musicians who were employed on the basis of self-employed contracts for an orchestra in the Netherlands (so-called 'employee replacements'). The ACM has taken the view in this case that such provisions in a collective agreement are problematic and prohibited on the basis of article 101 TFEU because the selfemployed musicians qualified as undertakings for the purposes of the competition rules. ${ }^{128}$ Since self-employed compete on the basis of their fees, the collective agreement was to be considered as a restriction on competition. The collective labour organisation FNV argued against this reasoning and submitted that the collective agreement for the self-employed are a necessary measure against strategies of social dumping. Employers that employ self-employed for lower wages install incentive mechanisms that will eventually damage the regularly employed because it will negatively impact their willingness to pay higher wages to the 'normal' employees. Moreover, the self-employed are not truly independent agents because they are treated on the same basis as the regular employees. Because they therefore qualify as falsely self-employed, the Albany exemption would apply and the rates that are set would not be subject to competition enforcement.

The assessment proposed by the AG to determine whether the collective agreement was subject to the competition rules is relevant for a further development of the Wouters and Albany frameworks in the context of the mutual responsiveness model. In FNV Arts $v$. the Netherlands the AG argues that for the assessment whether a socially legitimate aim is subject to competition enforcement, it is required to determine in concreto whether a real and serious danger of social dumping exists and, if so, whether the designed provisions are necessary to prevent that dumping from taking place. ${ }^{129}$

Therefore, on the basis of this context-specific approach the social goals should manifest themselves concretely and are to be provided with a genuine right to exist before the application of the competition framework can be excluded and,

28 ACM position paper 5 December 2007: https://www.acm.nl/nl/publicaties/publicatie/6544/NMaMededingingswet-staat-geen-tariefafspraken-voor-zelfstandigen-toe-in-caos/

129 Opinion AG N. Wahl in case C-413/13, FNV Kunsten t. Staat der Nederlanden, paras 88 to 95. The Court did not go into this specifically but, instead tuned the judgment towards the conditions of the assessment that would have to determine whether the musicians qualified as employees or undertakings and it referred the case back with guidance on this question (paras 38-42). 
hence, an alternative valuation should take place. This context-specific in concreto approach advocated by AG Wahl is reminiscent of the Court's reasoning in $A O K$ Bunderverband, cited above, where the Court considered to what extent an introduction of competition to part of the activities of a sickness fund was capable of concretely affecting the nature of its activities. The Court established whether the application of competition principles threatened the nature of solidarity in that specific situation. Equally, the approach of the AG puts emphasis on the expressive value of the interplay of competition and non-competition interests, which requires a specific and concrete articulation of the limits of both competition and genuinely irreconcilable non-competition interests. Again, the moment of societal learning is reached where the Court establishes the limits of both spheres in a concrete manner.

This part of the (extended) Wouters framework is concerned with the substantive interplay between the principles of competition and potentially irreconcilable non-competition interests. However, the framework of analysis applied by the Court should also include a formal component that is concerned with the public law infrastructure within which noncompetition interests are pursued. This formal component would have to be concerned with the question whether the (association of) undertaking(s) in question is sufficiently embedded in a public law framework to be considered enabled to define the public interest it pursues and in what way. This boils down to the question if the legitimate interest can be defined independently by a private professional association or whether it has to flow as a compulsory obligation from a public law framework ${ }^{130}$ We can refer back on this point to the words of AG Jacobs that were cited above

"It can be presumed that private economic actors normally act in their own and not in the public interest when they conclude agreements between themselves. Thus, the consequences of their agreements are not necessarily in the public interest." 131

Thus, the formal requirement is concerned with the embedding of private actions within a public law framework. Can all private parties just set aside the competition rules on the basis of self-defined actions in pursuit of a non-

\footnotetext{
130 Similarly Whish and Bailey above (no. 1) on p. 135.

131 A-G Jacobs opinion in case C-67/96, Albany [1999] ECR I-5751.
} 
competition interest? ${ }^{132}$ As was explained before with respect to the case study on the Energy agreement, at some point the pursuit of these objectives in a private context needs to be fed by some form of public legitimacy. The Court's approach to this issue in Wouters is confused. The Dutch Bar association was governed by public law, established by statute, in order to further a public interest. For that purpose it was endowed with regulatory powers, which required it to guarantee, in the public interest, the integrity (in terms of independence and loyalty to the client) of the legal services of its members. However, the Court approached this aspect of the case mainly to determine whether this public law context was sufficient to exclude it from the scope of competition law, such as with regard to public interest tasks that are exclusively exercised in the public interest, such as the maintenance of air navigation safety ${ }^{133}$ and the protection of the environment. ${ }^{134} \mathrm{Next}$, in its analysis of the social context these regulatory powers played a role for the Court to establish the singular position of lawyers vis-à-vis accountants in the Netherlands, which required the former to exclusively act in the interest of their clients. It remained, however, rather unclear what the facets of a public law institutional framework would have to look like, to accommodate the pursuit of private initiatives that pursue a non-competitive interest. This aspect has also not been clarified in later case law of the Court where the Wouters analysis was applied. ${ }^{135}$

See also Gerbrandy above (no. 30), 81-103

133 Case C-364/92 SAT Fluggesellschaft('Eurocontrol') [1994] ECR I-43.

134 Case C-343/95 Diego Calì \& Figli [1997] ECR I-1547.

135 The Wouters framework is explicitly applied in three other cases, which will be shortly discussed specifically as regards this procedural component. In Meca-Medina (Case C-519/04 Meca-Medina [2006] ECR I-06991) the issue at stake concerned the admissibility of potentially disproportionate antidoping rules, which were justified by a legitimate aim, namely to ensure the fairness of the competition and to ensure equal opportunities for athletes, to ensure their health, integrity and the objectivity of the competition as well as the ethical values of sport. As in Wouters, the Court decided in this case that restrictions on competition, which, in light of the overall context in which a decision has been taken, are inherent to the pursuit of a legitimate aim, do not lead to an infringement of the competition rules. The public context in this case was more evident than in Wouters since the rules were drawn up by the IOC, a recognised public international entity. Although the Court reaffirmed a context-specific approach it remained unclear how an institutional framework would have to be designed, specifically, so that private initiatives that pursue a non-competitive interest fall outside the scope of the competition law framework. The case OTOC (Case C-1/12 OTOC [2013] np) provided, at first sight, more room for the Court to go into the specifics of this aspect in the Wouters analysis. OTOC is the professional association of accountants in Portugal, legally responsible for establishing a system of continuing education that ensures the quality of Chartered Accountants. OTOC itself offered the curriculum to the 
Therefore, the Wouters type of assessment by the Court adds another factor to the potential social legitimacy model of the Court. The Albany and Poucet Pistre lines of case law have established the requirement for context specific valuations of different social spheres and set out the beginnings of a more comprehensive rationale to determine, in a dynamic and context-specific way, the constructive interplay between competition and non-competition spheres. Wouters can be seen as an extension of this idea, widening the scope of potential irreconcilable noncompetition interests to be transposed to a type of valuation outside of the strict application of the exemption criteria of 101(3) TFEU. At this point it becomes necessary to look more specifically at the institutional frameworks that would be required to legitimately restrict competition. As said, Wouters leaves a gap on this point, leaving it rather unclear what the facets of a public law institutional framework would have to look like, to accommodate the pursuit of private initiatives that pursue a non-competitive interest.

B. The requirements of mutual responsiveness in Arduino, Cipolla and Mauri

The gap that the Wouters case law leaves can be better understood and partly addressed if a connection is made with yet another but strongly connected line of

exclusion of other providers. The Court ruled that the elimination of competition could not be considered necessary to ensure the quality of the services of sworn auditors and Article 101(1) TFEU applied to them. The Court considered that although OTOC was designated to ensure the quality of the education on the basis of the public framework, the public law framework allowed a wide margin of discretion to OTOC for the development of the actual principles, conditions and modalities that would be part of the system of continuing education. It was therefore not a situation where the competition rules could be excluded based on the fact that the rules qualified as government measures. Following this finding, the Court held that the restrictions on competition, in light of the overall context in which the decision was taken could not qualify as inherent to the pursuit of the objectives. In the case of CNG (Case C-136/12 CNG [2013] np), the issue concerned a code of conduct of the Italian Order of Geologists (CNG) in which a tariff arrangement was made on the basis of a provision in the Civil Code, that held that tariffs should be consistent with the size of the work and "the dignity of the profession." The Italian Competition Authority found that the NCG had infringed Article 101 TFEU by influencing its members to align their members economic behaviour on the basis of the benchmark of the "dignity fee'. According to CNG the tariff regime was necessary to provide some safeguards for the end users of the services concerned. The Court considered that the aims that were pursued could be considered legitimate and it was up to the national court to determine whether "the dignity of the profession" brought forward necessary limitations for the accomplishment of certain safeguards for end users. In $\mathrm{CNG}$, the Court emphasized the legitimacy of the objective, which was in this case specifically enshrined in a law. 
cases, where the Court has established under what circumstances a restrictive state measure violates EU competition law, according to the effet utile principle. ${ }^{136}$ These concern, inter alia, a number of cases that originated from conflicts between the Italian regulatory schemes for attorneys and the internal market rules. As was quoted above in section II, an important policy objective of the Commission in the period 2000-2005 was to test potentially out-dated regulatory schemes within Member States concerning liberal professions. In particular, the Commission had targeted the regulatory systems of the legal profession around Europe. The Commission concluded that some regulations were affected by the "weight of tradition," "fail to see how things can be done differently," and did not or no longer regulate in the public interest. ${ }^{137}$ This liberalisation initiative was partly triggered by two cases. One of these cases was actually Wouters, which, as was discussed above, provided quite some deference to the Dutch Bar on the issue whether a restrictive rule was necessary and proportionate to pursue the public interests involved, stating that "the Bar of the Netherlands is entitled to consider that the objectives pursued by the ... Regulation cannot... be attained by less restrictive means". ${ }^{138}$ The Commission was concerned that this deference would further restrict market access and competition in the sphere of liberal professions. ${ }^{139}$

On the same day of the Wouters judgment, the Court of Justice also issued a judgment in the case Arduino, which further antagonised the Commission and provided impetus for its liberalisation agenda. This judgment concerned Italian legislation on the fixing of lawyers' fees. The Court of Justice reviewed this legislation in light of Article 4(3) TEU in conjunction with Article 101 TFEU. Since 101 TFEU applies to the conduct of undertakings, the Court of Justice had

\footnotetext{
${ }^{136}$ For an extensive and deep analysis of this line of case law see H. Schepel, 'Delegation of regulatory powers to private parties under EC competition law: towards a procedural public interest test', Common Market Law Review 39(2002), 31-51.

${ }^{137}$ Communication from the Commission: Professional Services-Scope for More Reform: Follow-Up to the Report on Competition in Professional Services, at 10, COM (2005) 405 final (Sept. 5, 2005), available at http://eur-lex.europa.eu/LexUriServ/LexUriServ.do?uri=COM:2005:0405:FIN:EN:PDF. See for an extensive overview L.S. Terry, 'The European Commission Project Regarding Competition in Professional Services', 29(2009) Northwestern Journal of International Law \& Business, 1.

138 Case C-309/99 Wouters and Others [2002] ECR I-1577, para. 108.

139 See Terry above (no. 137) at 26.
} 
only by way of exception held that national measures can also be covered by 101 TFEU in situations where Member States can be seen as not cooperating in good faith in the application of Union law. On this basis the Court of Justice has held that such 'faithful cooperation' is infringed where a Member State requires, favours or reinforces an anti- competitive agreement or abandons its own regulatory powers and delegates them to private operators, who then infringe the competition rules. ${ }^{140}$ In Arduino the Court held that although part of the lawyers tariff scheme was delegated to the Italian Bar association, the scheme, nevertheless, never lost its character of a state scheme since in the Italian Bar submitted only a draft tariff scale to the Minister for Justice, who had the power to have the draft amended or defer its application. ${ }^{141}$ It is important to highlight that because of the fact that these cases involve national regulation or some form of governmental validation, there is a connection to free movement law. This dimension was not addressed in Arduino but came to fruition in the Cipolla case, partly as a result of the Commissions' arguments that were presented in the case. ${ }^{142}$ In this case the Court considered with regard to the same Italian tariff scheme for attorneys, that the fixing of minimum tariffs deprived lawyers that were established in another Member State of the possibility of competing effectively with lawyers established inside Italy who would have better opportunities for winning clients than competing lawyers established abroad (who would arguably have higher costs accessing the Italian market). As a consequence the freedom to provide services was restricted. The Court considered that the restriction could be justified, provided that "there is a correlation between the level of fees and the quality of the services provided by lawyers and whether, in particular, the setting of such minimum fees constitutes an appropriate measure for attaining the objectives pursued, namely the protection of consumers and the proper administration of justice" ${ }^{143}$. The Court indicated that this correlation was not unlikely on the basis of the specificities of the Italian market

\footnotetext{
140 Case C-35/99 Arduino [2002] ECR I-01529.

141 Ibid. para. 41.

${ }^{142}$ Case C-94/04 - Cipolla and Others [2006] ECR I-11421.

143 Ibid. para. 66.
} 
and the more general asymmetry of information between 'client-consumers' and lawyers: "Lawyers display a high level of technical knowledge which consumers may not have and the latter therefore find it difficult to judge the quality of the services provided to them" ${ }^{144}$. The Court referred the case back to the national court on the basis of these guidelines. It can be argued that with the Cipolla case the Commission achieved at least partly its objectives of creating a legal framework that is able to test whether historical regulatory schemes are still genuinely concerned with the protection of public interests.

The applicability of the free movement rules in situation where both 101 TFEU and the free movement rules apply has some implications for the model of adjudication that is developed in this Chapter, which will be touched upon in the next section. However, what matters for current purposes is that the Court in this line of cases determines, inter alia, what is required from a public law framework, which involves the private sphere in the development of policy measures, if it is to retain the character of a government measure. ${ }^{145}$ Therefore, this case law provides guidelines for situations in which states instruct private parties to take certain measures but the measures, nevertheless, retain the character of a government scheme. In Arduino, the Court ruled that this is the case, for example, when members of a professional organization can be regarded as experts that can be considered independent from the undertakings that involved in the policy making and when they are legally required to take into account not the interests of the undertakings or their associations but, mainly, to take into account the 'public interest' and the interests of undertakings in other sectors or the interests of those who use the services in question. ${ }^{146}$

In Reiff the "official character" of legislation was retained because the public authorities had to "ensure that the boards fix their tariffs by reference to

\footnotetext{
144 Ibid. para. 68.

145 See also Case C-185/91 Reiff Bundesanstalt für den Güterfernverkehr [1993] ECR I-5801, Case C153/93 Delta [1994] ECR I-2517; Case C-140/94-C-142/94 DIP e.a. [1995] ECR I-3257 and Case C35/96, Commission/Italy [1998] ECR I-3851.

${ }^{146}$ Case C-35/99 Arduino [2002] ECR I-01529 paras. 36-38
} 
considerations of the public interest" ${ }^{147}$ In the Mauri case, the Court held that the emanation of the state in such proceedings can take place in several ways but, in any case, at key moments, should be potentially decisive within a process that shapes the measures. ${ }^{148}$ Certainly, as far as the measures will only be binding after the state has approved, then the measure retains the character of a government measure, provided that such approval is not just a formal stamp but has actually involved substantive engagement in the formation of the measures. ${ }^{149}$

The rationale that lies underneath most of the cases discussed in this section now becomes more apparent. That rationale is concerned with a question of accountability as a source of legitimacy. The competition rules provide accountability by way of the market. Private measures that aspire the achievement of public interest are provided with legitimacy because they can be accounted for in terms of the market. That is to say, if the measures on balance manage to achieve an outcome that leads to an increase in consumer welfare then there is no need for the political sphere to get involved and provide legitimacy to the development of measures that aspire to serve a public interest. If there is no such accountability for measures that aspire to serve the public interest but, in the process, limit another public interest, then they require another source of legitimacy.

The emphasis of the Court in the discussed lines of cases (Albany, Poucet and Pistre and Wouters), on some level, all share a concern for unveiling this additional source of legitimacy and it becomes most apparent in the Arduino and Mauri types of cases. ${ }^{150}$ The willingness of the Court to be responsive to social context, which is substantively irreconcilable with the normative framework of the competition rules, is therefore conditional upon the presence of another source of legitimacy, which

${ }^{147}$ Case C-185/91 Reiff Bundesanstalt für den Güterfernverkehr [1993] ECR I-5801 para. 22.

${ }^{148}$ Case C-250/03 Mauri [2005[ ECR I-01267

${ }^{149}$ Ibid., paras 33-36.

${ }^{150}$ See also Schepel above (no. 66) at 51: “...the Court has fashioned a public interest test that transforms Community competition law into a rudimentary set of procedural norms of good governance for private regulation. It is a set of norms that recognises that the legitimacy of economic self-regulation depends on procedures that ensure the meaningful participation of all concerned parties rather than on hierarchical structures of formal political accountability. In that sense, the "delegation" test contributes to the constitutionalization of private governance". 
can be found in the design of the public law framework surrounding private initiatives that restrict competition. In Wouters the concerned measures were not of a nature that they could be considered, de facto, as measures from the state. However, it mattered, from this perspective, that the public law framework enabled the Dutch Bar to develop rules that would guarantee the integrity of the profession because this provided a degree of public legitimacy to the restriction on competition.

We will return now to the case studies with the insights that the discussed case law has provided.

\section{A dialogue of mutual responsiveness: the interplay of principles of substantive efficiency, margins of discretion and good governance in competition law}

\section{A. A framework of mutual responsiveness}

A model of social legitimacy based on the idea of mutual responsiveness can be constructed on the basis of the case law of the Court. In summary, the Albany and Poucet Pistre lines of case law have established the need for context specific valuations of different social spheres and set out the beginnings of a more comprehensive rationale to determine, in a dynamic and context-specific way, the constructive interplay between competition and non-competition spheres. The Wouters case law can be seen as an extension of this idea, widening the scope of potential irreconcilable non-competition interests to be transposed to a type of valuation outside of the strict application of the exemption criteria of 101(3) TFEU. ${ }^{151}$ However, the mutual responsiveness that is required for wider social objectives to be taken into account in determining whether or not there is a restriction on competition requires a source of legitimacy within a public law framework that feeds privately developed social objectives. Reading the Arduino

\footnotetext{
${ }^{151}$ The advocated approach therefore conceives the Wouters type approach or the application of the 101(3) TFEU exemption criteria as mutually exclusive.
} 
cases by analogy provides insight with regard to the question how such frameworks can be organised.

The principles resulting from this case-law can be reconstructed for the purpose of establishing a framework of assessment for competition authorities and judicial review to be responsive to social context and, concomitantly by extension, as a guide for legislators to set out their public-private frameworks in a way that ensures the public legitimacy of private sphere initiatives that aspire to achieve public interests but limit competition. As such and perceived as a whole, this framework is clearly reflective of a dialogue of mutual responsiveness.

Firstly, the Court has demonstrated an explicit responsiveness towards the potential irreconcilability between objectives and rationales in competition law and social objectives that have been set up in pursuance of a broader public interest. In the submitted model this concretises in the form of a prior analysis of the 'market situation' regarding the nature of the activities, to determine whether the underlying normative framework of the restrictive activity in question is compatible with the underlying normative framework of the competition rules or not. In this way, a prior, in concreto, analysis of the market situation will take into account the nature of the activities and their authenticity with the intention to unveil whether the aspired aims are genuine and inherent to the pursuit of a public interest that is irreconcilable with the aims of the competition law framework. This contextspecific in concreto approach puts emphasis on the expressive value of the interplay of competition and non-competition interests, which requires a specific and concrete articulation of the limits of both competition and genuinely irreconcilable non-competition interests. The moment of societal learning is reached where the limits of both spheres are established in a concrete manner. This does not exclude the competition interest from the process because the test involves an assessment "whether the consequential effects restrictive of competition are inherent in the pursuit of those objectives". In this way competition law can be applied as a tool for societal dialogue, testing old conventions and requiring the renewed articulation of the pursuit of public interests. On the other hand, it avoids the valuation of regulatory systems merely on the basis of their 'efficiency' merits and fulfils the 
normative promise of social legitimacy, which requires that a diversity of social spheres be subject to different means of valuation.

This is the first step in the submitted framework of assessment. In case there is genuine irreconcilability then the second step concerns an evaluation of the design of the public-private framework of deliberation. The design of the publicprivate framework would need to ensure that the aspired goals are, at important points, fed with public legitimacy and provided with affirmative political oversight. This part of the analysis would therefore unveil if the measures that aspire to serve the public, although inherently irreconcilable with the legitimacy of the exemption framework of the competition rules, are sufficiently provided with a source of legitimacy. On the basis of this second step, it would have to be determined to what extent the public-private partnership actually leads to the pursuit of a legitimate interest. Moreover, as was discussed with respect to Arduino there exists on this point a dimension that connects the pursuit of social objective within a publicprivate framework of governance to the scope of the free movement rules. The free movement rules play an additional part in the assessment of the potential restrictions that such frameworks establish in terms of market access. If there exists a market access restriction, an additional test will determine the potential justification of the regulatory framework from the perspective of the free movement rules. Pursuant to the model that was developed in the second Chapter, this assessment would then evaluate the restriction on the basis of questions relating to its coherence, transparency and systemacy in its wider regulatory context. ${ }^{152}$

Therefore, the second step in the submitted model emphasizes the mutual responsiveness that is inherent in the dynamics of the internal market. Social diversity can be guaranteed within the Union, provided that Member States fulfil a standard of good governance in the organisation of their regulatory affairs. Hence, this approach fits the terms of the social purpose of the internal market that was developed in the first Chapter. The social purpose of the internal market is not to condition choices that necessarily require the market to trump the social sphere or

\footnotetext{
152 See section III.C of Chapter II.
} 
necessarily its opposite, to allow the social to always trump the market. The approach suggested in this Chapter advances a more holistic approach that conceives the market and the social sphere as 'communicating vessels'. Competition derived evaluative standards serve as a tool to tease out discriminatory, disingenuous regulatory choices within Member States but allow for genuine social objectives to exist in accordance with good governance principles that focus on the quality and systemacy of a governance process, instead of on the rationality and efficiency of its outcome. In this way there is neither a sacrifice of the market or a sacrifice of the social and, instead, both social diversity and competition can be accommodated within the internal market.

I will now briefly turn to the case studies to explore how this perspective copes with the highlighted issues in those cases.

B. A return to the case studies on the basis of mutual responsiveness

\section{i. Mutual responsiveness in the Friesian Horse case}

We remember that the Friesian horse case concerned the question whether the pedigree could determine rules that would limit the commercial freedom of its members but was aimed at ensuring the health of the Friesian horse. Returning to this case with the perspective of mutual responsiveness leads to the following findings. As regards the normative interests at stake we would have to establish concretely that the nature of the measures were genuine and inherent to the pursuit of an interest that is irreconcilable with the aims of the competition law framework. This is not necessarily as straightforward as it may seem since the health of the Friesian horse could in this case plausibly be conceived as a 'quality' concern and addressed as such within the exemption framework of 101(3) TFEU, much like the environmental objectives within the CECED case, without damaging the objectives that are actually at stake. The proposed model would not object against that. It would have to be established, concretely, if there is anything in the pursuit of the health of the Friesian horse that would be damaged if tested within the exemption criteria. However, it may simply be the case that the 
required data for the fulfilment of the 101(3) TFEU criteria is not available and that the exemption criteria cannot be fulfilled for, mainly, that reason. This is an issue that concerns a wider discussed problem of incorporating long-term, uncertain benefits of restrictive agreements within the efficiency-based rationale of Article 101(3) TFEU. As was touched upon before, in the application of Article 101(3) TFEU, competition authorities, such as the ACM, tend to attach decisive value to the objective qualification and concretization in economic terms of claimed benefits that may be effectuated by restrictive agreements in order to qualify for an exemption. ${ }^{153}$ However, in situations where the main focus is not the immediate but rather the long term prevention of concerns that cannot be completely quantified, such as presumably in case of the studbook, would that be sufficient for the dis-application of the protective rules? Or is the absence of data in itself sufficient reason to move the evaluation to the alternative framework of analysis that was constructed above on the basis of concerns based on social legitimacy? The developed normative framework provides answers to these questions. ${ }^{154}$

First, the alternative valuation based on substantive irreconcilability and good governance requires that the valuation, which is inherent in the exemption criteria of 101(3) TFEU will damage or disregard essential features of the pursued objectives. If so there is an argument for the exclusion of 101(3) TFEU and to evaluate the restrictive non-competitive objective to establish whether the consequential effects, restrictive of competition, were inherent and the objectives

${ }^{153}$ S. Kingston, Integrating Environmental Protection and EU Competition Law: Why Competition Isn't Special, European Law Journal, Vol. 16, No. 6, November 2010, pp. 780-805

${ }^{154}$ For an alternative idea, see Anna Gerbrandy who has recently submitted to include more public stakeholders within the competition law procedure (in stead of the legal assessment) in order to increase the legitimacy of competition law decisions to take account of non-competition objectives. For example, an appealing version is that of a combination between a public stakeholder panel that is representative of various societal objectives combined with a form of political control that decides on the public interest that should take precedence - see Gerbrandy above (no. 30) at 770. The approach that is advanced here, in stead, argues that competition and wider societal rationales should engage with each other within an institutional framework that is not instructed by an overarching competition law framework, which includes the non-market objectives within its institutional form but instead initiates a broader societal dialogue which allows for an identification of normative conflicts and the disapplication of the competition law framework when appropriate. 
sufficiently embedded within an overarching public law or regulatory framework. However, as said, it is unclear if the non-competition interest in this case is concerned with objectives that fall outside of concerns that are related with the efficient functioning of the studbook. Within the submitted model, this would be different if the rules of the studbook were reflective of choices related to concerns that could be traced back to a normative commitment and choice to the embedding of a market within a high standard of animal welfare in the Netherlands.

The studbook was, at the time of the measures, recognized as an official pedigree by the previously discussed product organisation for livestock, meat and eggs, which was a public-private entity, legally responsible for industry wide interests, including animal welfare. Within this context FPS had to adhere to requirements that were set for 'official' pedigrees across the Netherlands and this included the organisation of a pedigree in a way that would ensure that the preservation of the breed would be guaranteed on the basis of concrete breeding improvement programs. Moreover, the measures of inbreeding control that were pursued in the studbook were explicitly recognised by the Food and Agriculture Organization (FAO) of the United Nations as essential for the health and survival of a race.

The public law framework therefore did to some extent embed the choices of the studbook within a wider, arguably societal commitment, for the protection and preservation of the breed, which would qualify it as a non-competition objective. The analysis would in that situation still consider whether all restrictive effects on competition were inherent. It would therefore have to be established to what extent the preventive measures were indeed based on concrete evidence that there did exist a plausible threat to the health of the Friesian horse. However, the evaluation would not require the immediate objective qualification and concretization in economic terms of the claimed benefits because the identification of the need to install protective rules would be connected and inherent to the normative societal, non-competitive, commitment to long-term animal welfare. However, the design of the public-private framework would then 
need to ensure that these aspired goals are, at important points, provided with affirmative forms of political oversight. This part of the analysis would therefore unveil if the measures that aspire to serve a public interest were indeed sufficiently and genuinely provided with a source of legitimacy. ${ }^{155}$

\section{ii. Mutual responsiveness in the Energy Agreement for Sustainable growth}

As described, the Energy agreement involved more than forty organisations in the definition of an energy and climate policy and took place within a public law framework that was set up for the purpose of negotiations between various public stakeholders. ${ }^{156}$ The interest wide agreement was intended to offer long-term sustainable prospects and create trust and involvement on the part of individuals, businesses, and civil society organisations.

The interest at stake in this case, which cannot be quantified within the competition law framework, concerns the process that has led to a specific organisational structure and brought together various societal actors in a way that would make them co-responsible for these objectives on the basis of mutual obligations tuned towards a shared social value. By insisting on quantification, a narrow framework could dis-embed such an agreement from its societal function and reduce it to efficiency benefits; failing to recognise the importance of the discursive process as an overarching societal value in itself. Instead, mutual responsiveness would conceive the competition interest and the societal discursive in a way that they would align towards a common, shared interest.

\footnotetext{
${ }^{155}$ As discussed before, the appellate court in Arnhem decided regarding the question of legitimacy that, unlike the situation in Wouters, this public framework context did not qualify the measure as a 'special and weighty public interests'. Consequently, the pursuit of the health of the Friesian horse could not be considered a 'legitimate' purpose and should therefore be assessed on the basis of the exemption criteria of 101(3) TFEU. In terms of an accountability perspective, it was decided that this was to be provided by the market.

${ }^{156}$ The public stakeholders included central, regional and local government, employers' associations and unions, nature conservation and environmental organisations, other civil society organisations and financial institutions.
} 
A good argument can be made that the closing down of the coal plants was inherent for the existence of the agreement as a whole that in itself, as a process, reflected an Albany type context and served a purpose that was broader and irreconcilable with the efficiency criteria of 101(3) TFEU. The inherent restriction test would then still provide this assessment with the means to assess concretely whether the societal narrative at stake was authentic and not used to disguise protective or merely anticompetitive measures.

Again, as regards the second requirement in the submitted model, it would have to be assessed if the public-private context within which the measures where shaped ensured the public legitimacy of the measures in question. The design of this framework would have to involve state involvement in the substantive formation of the objectives and a confirmation that the interests pursued were in accordance with the public aims and policy of the state, even though they were established in a dynamic public-private context. In this way competition law becomes very much a tool for societal dialogue, testing societal dialogue and requiring the concrete articulation of the pursuit of public interests. However, it avoids the valuation of socially relevant agreement merely on the basis of its 'efficiency' merits and fulfils the normative promise of social legitimacy, which requires that a diversity of social spheres be subject to different means of valuation.

\section{iii. Mutual responsiveness in the Chicken of Tomorrow case}

In the context of the Chicken of Tomorrow case, the in concreto assessment would determine if and how the 'embedding' of the economic activity on the basis of a minimum standard for the production of chicken meat would address an authentic societal interest that is irreconcilable with the exemption criteria of 101(3) TFEU. Again, similar to the Friesian horse, the case would have to be made that the introduction of a minimum standard was an expression of a normative commitment concerning the embedding of economic activity in this sector, which in a sense precedes the market. The exemption criteria, instead, strictly applied would led the market decide. That is to say, to pursue animal welfare on the basis of consumer preference and to conceptualise it as a monetary consideration. This is a profoundly 
political decision. However, in the absence of an institutional framework that provides public legitimacy to the minimum standards of poultry trade, the sector cannot be legitimately left to decide on such matters. Hence, sustainability initiatives such as these are likely to suffer on the basis of a deferential government. The Dutch government had indicated that the policy in this area should be informed and guided on the basis of sector wide and based initiatives on the processing of life stock but this is clearly insufficient from the perspective of mutual responsiveness, which requires an active and aware government that institutionalises, to some extent, the pursuit of sustainability initiatives within the framework of good governance that the competition rules advance. Hence, with regard to the second limb of mutual responsiveness we would have to conclude that, despite the existence of a clear public-private deliberative framework, it was not transparent to what extent and on which points state involvements was present. Implicitly, it definitely was since the Dutch government had expressed its disappointment about the position of the ACM and also confirmed at that point that the policy was very much in line with the Dutch policy objectives. However, as was discussed above, in terms of accountability the public-private framework failed to provide sufficient clarity as to the public legitimacy of the interests that were pursued.

\section{Conclusion}

Mutual responsiveness in the context of EU competition law means, accepting the primacy of a market-based rationale to initiate a dialogue with regard to the regulatory choices of Member States, whilst explicitly allowing space for the development of non-competition based residual and conflicting objectives.

There are two main implication of this debate for the operation of competition law in the presence of non-competition based public objectives. First, that the conventional framing of the conceptual dichotomy between the market on the one side and residual noneconomic aspects of the social on the other is underdeveloped and fails to capture what is at stake when these spheres meet. Second, that clarity in the framing of competition and noncompetition conflicts is needed to instruct 
balancing exercises in adjudication and tells something about how competition authorities should deal with (noneconomic) social interest objectives in their decision making process and, importantly, the institutional requirements for Member States to allow undertaking to pursue social objectives that are restrictive of competition in accordance with the EU competition law framework.

The dichotomy between market and nonmarket or economic and noneconomic is there to allow or even force a deliberative space for broader than monetary or efficiency based considerations of what matters in social relations. Sustainability, the integrity of a profession or the way animals are treated harbour important social values that do not necessarily speak market talk. However, such market talk is provided with a source of legitimacy within the EU competition rules and can be applied to initiate a social dialogue on the validity and systemacy of regulatory choices within the Member States. Competition law should then, however, incorporate means to value different social contexts differently, and in congruence with the underlying normative commitments of those contexts. Such responsiveness depends on institutional design.

The language of sustainability, animal welfare and professional standards, where voiced by private operators, needs a governance structure of legitimacy if they restrict the competition rules. The case law of the Court of Justice demonstrates a definite responsiveness to broader social values and has recognised it specifically with regard to collective negotiations, solidarity and to a lesser extent to other types of non-competition interests that are pursued within quasi public law frameworks by private entities with their own interests. The gap that the latter case law leaves is mostly concerned with the alternative source of legitimacy that is required from the perspective of mutual responsiveness. It was found in Wouters but in a way that would not allow any generalisations as regards its broader implications. By connecting the Arduino, Cipolla and Mauri types of reasoning to Wouters, a more general rationale of mutual responsiveness emerged. A responsiveness that allows on the one hand a finding of inherent irreconcilability between the normative order of the competition rules and the values with a broader social aim but requires a source of legitimacy for the pursuit of those aims. It is 
only if both are present that the requirements, which EU competition law advances, can be met. As such, there is here a clear connection to the argument from transnational effects that installs requirements of good governance on the way that Member States pursue aims that have effects of a cross border nature. In the area of competition law this translates into a double-sided requirement. If such measures can be accounted for on the basis of the efficiency criteria of the competition rules then the market provides legitimacy to cross border effects. Alternatively, there should be another source of legitimacy that pursues genuine and authentic legitimate concerns within a transparent public law framework.

The case studies have demonstrated that there is a need for Member States to actively structure public-private frameworks where private initiatives are crucial in the development of social goals that restrict competition. Although the examples of the Energy agreement and the Chicken of Tomorrow case demonstrate a clear involvement of the government, it was arguably not specific enough to infuse these initiatives with the public legitimacy that they require. Eventually, the identification of noncompetition spaces could be structured as entrance points for forms of explicit democratic deliberation. In this way diversity can be cherished outside of efficiency logic and in accordance with the fundamental aims of the EU. Simply put, competition and public interest conflicts fall either within the scope of a competition rule, after which the method to resolve a conflict should be based on a weighing of efficiency merits, or outside the scope of the competition rule and the outcome should be based on a procedural review of the quality of the process that restricts competition. Competition authorities have in this latter stage a complementary and not an overarching role to play. They should be included in the societal narrative as the stakeholder of the public interest of competition and fulfil that role through providing a voice for competition that stands next to the other represented voices of public interest but not as an overarching and normative conditioner of these processes within society. 


\section{CHAPTER IV}

\section{The social legitimacy of EU state aid law}

II. Problematisation: Valuation, indeterminacy and incommensurability in state aid law

A. Organizational principles in EU state aid law 214

i. Introduction 214

ii. The proceduralisation of the state aid rules 216

iii. Modes of valuation in state aid: market versus regulation 223

B. The expedient nature of market derived standards within state aid law 225

i. Introduction 226

ii. The potential expedient scope of the market economy operator principle (part one): the absence of rationale of genuine regulation versus the clear rationale of a private investor/creditor

iii. The scope of the market economy operator principle (part two): control over economic assets or public infrastructure 232

C. The potential crowding out effects of the market operator principle 234

D. The conditional pursuit of services of general interest on the basis of adversarial relationships

III. Responsiveness in the models of adjudication of the Court in state aid law

B. Mutual responsiveness: between regulation and the market 245

i. The quest for a more comprehensive rationale for public authority 245

ii. The individual aid measure in its wider context 249

iii. The connection to the wider regulatory context: a good governance model 252

C. Mutual responsiveness in the application of the Altmark framework 260

IV. A dialogue of mutual responsiveness: the interplay of principles of substantive efficiency, margins of discretion and good governance in State aid

A. Introduction 267

B. The dialogue of mutual responsiveness in state aid 268

C. The required mutuality of the dialogue 272

V. Conclusion 


\section{Introduction}

We arrive in the field of state aid after having developed and applied a normative framework based on social legitimacy. Internal market adjudication in the areas of free movement and competition law has been critically assessed and reconstructed in accordance with the perspective of social legitimacy. So far the intention has been to unveil the potential normative concerns in these areas and to point towards ways to deal with them. It is submitted that this exercise has allowed for the development of a model of social legitimacy that enables the Court to adjudicate internal market conflicts in tune with a variety of social interests and actors. The idea of a dialogue based on mutual responsiveness was introduced to accommodate the normative claims of social legitimacy (and complete the argument from transnational effects). Mutual responsiveness means, simply, that, on the one hand the supranational market integration rationales have to incorporate responsiveness to Member State context and diversity and, conversely, that the pursuit of social interests on a Member State level have to be in some way responsive to the objectives of market integration within the institutional structures that pursue these social interests. The internal market rules are, from this perspective, to be conceptualised as the starting point of a dialogue, based on the shared values of market integration.

The previous chapters introduced how market access and competition can be used as tools for such a dialogue provided that these rules incorporate responsiveness towards social context, which may be restrictive of market integration objectives but reflective of important and legitimate societal fabric. If this responsiveness is absent, social legitimacy is at risk. This chapter explores these issues in the area of EU state aid law and contributes to the existing literature by discussing the EU state aid rules in the context of social legitimacy and introducing the idea of mutual responsiveness to this area of internal market law. Over recent years some important contributions have been made to the discussion of the EU state aid rules concerning their wider function and constitutional status within the internal market, ${ }^{1}$ in a field

1 F. De Cecco, State Aid and the European Economic Constitution (Hart Publishing 2013) and J.J.P. Lopez, The Concept of State Aid under EU Law - From internal market to competition and beyond (Oxford University Press 2015). See also M. Ross, 'State Aids: Maturing into a Constitutional Problem' (1995) Yearbook of European law 79; M. Ross, 'State Aid and National Courts: Definitions and Other Problems - a 
of internal market law that is otherwise primarily dominated by insulated and practitioners led, specialised, debates. ${ }^{2}$ The issue of the potential impact of the EU state aid rules on the pursuit of social objectives by Member States has also featured amongst these contributions. ${ }^{3}$ As such, some of the approaches and adjudicative techniques of the Court and the General Court ('GC') that will be discussed in this Chapter have been touched on before. The salience of this chapter, in light of the existing contributions, is claimed to be particularly present in two ways. Firstly, in the discussion of the structural social legitimacy concerns with regard to the potentially expedient nature of market based evaluations in state aid cases. With "expedient use" I mean, rather idiosyncratically, the quick adoption of market-based techniques when these may not be justified in light of the social context that is involved. Secondly, with the introduction of the idea of mutual responsiveness to state aid law. This allows a connection between state aid law and the wider debate on the social legitimacy of the internal market. By adopting the perspective of mutual responsiveness in reconstructing some lines of case law from the Court, it will become clear that regulatory space of Member States can certainly deviate and be excluded from the normative state aid objective of undistorted competition but needs to be infused with a variety of good governance requirements (in so far as selective advantages are granted to undertakings as part of broader social regulatory objectives). This is a largely novel view, which allows a conceptualisation of the state aid rules as being an integral part of the wider dialogue of mutual responsiveness in internal

Case of Premature Emancipation?' (2000) Common Market Law Review 401; M. Ross, 'Decentralization, Effectiveness, and Modernization: Contradiction in terms?' (2004) in A. Biondi, P. Eeckhout and J. Flynn (eds), The Law of State Aid in the European Union (Oxford University Press, 2004).

2 Mostly with respect to tax issues: e.g. C. Quigley, 'General Taxation and State Aid', in A. Biondi, P. Eeckhout and J. Flynn (eds), The Law of State Aid in the European Union (Oxford University Press, 2004) 207; K. Bacon, 'Differential Taxes, State Aids and the Lunn Poly Case' (1999) European Competition Law Review 384; P. Nicolaides, 'Fiscal State Aid in the EU: the limits of Tax autonomy' (2004) World Competition 319. Also with respect to 'economic' issues: e.g. P. Crocioni, 'Can State Aid Policy Become more Economic-Friendly?' (2006) World Competition 89; D. Neven and V, Verouden, 'Towards a more refined Economic approach in State Aid Control' in W. Mederer, N. Pesaresi and M. van Hoof (eds) EU Competition Law (Claeys\&Casteels 2008), 99.

3 See particularly A. Biondi, and L. Rubini, 'Aims, Effects and Justifications: EC State Aid Law and Its Impact on National Social Policies', in Dougan, M. and Spaventa, E. (eds), Social Welfare and EU Law (Hart Publishing, 2005), 79. 
market law on the basis of an interplay of substantive efficiency, margins of discretion and procedural good governance principles.

The chapter develops further as follows. First, a description of the objectives of EU state aid law and an identification of the areas of potential normative concern from the perspective of social legitimacy (section II). Second, I will explore the case law of the Court and GC to trace fragments of mutual responsiveness in its case law (section III). Third, these fragments will be reconstructed into a coherent model of adjudication based on a dialogue of mutual responsiveness (section IV). Section V concludes.

\section{Problematisation: Valuation, indeterminacy and incommensurability in state aid law}

\section{A. Organizational principles in EU state aid law}

\section{i. Introduction}

In this section I will discuss the state aid rules as a whole, describe important developments in the policy making efforts of the European Commission and then move to the area within state aid law that is most relevant from the perspective of social legitimacy.

In state aid law, similar to free movement and competition, the potential conflict between the objectives of market integration and Member State objectives is reflected in the primary Treaty rules. EU state aid law is contained in articles 107 to 109 TFEU. Article 107(1) TFEU is based on the assumption that selective economic advantages granted to undertakings by the state should be deemed 'incompatible with the common market'. However, under articles 107(2) and (3) TFEU, potential socio-economic objectives of the measure may be considered with the result that an otherwise incompatible aid becomes compatible with the common market. Article 107(1) provides that:

[s]ave as otherwise provided in the Treaties, any aid granted by a Member State or through State resources in any form whatsoever which distorts or threatens to distort competition by favouring certain undertakings or the production of certain goods shall, in so far as it affects trade between Member States, be incompatible with the internal market. 
Preventing 'competition distortions' is the touchstone of the prohibition contained in Article 107(1) and it has five constituent elements: (1) there must be an intervention by the State or through State resources; (2) this intervention must create an advantage for undertakings within the meaning of competition rules of the Treaty; (3) the advantage must be granted to certain undertakings or to the production of certain goods selectively; (4) the intervention must be likely to distort or to threaten to distort competition; (5) the intervention must be likely to affect trade between the Member States. If a measure cumulatively fulfils these criteria, it triggers a notification duty and a standstill obligation. Article 107(2) goes on to list categories of aid, which are compatible with the common market, and in Article 107(3) those categories of aid that may be considered by the Commission to be compatible. Examples of the former are aids with a social character granted directly to consumers (not undertakings) and aid to make good for any damage caused by natural disasters or 'exceptional occurrences'; examples of the latter are aid to promote the economic development of areas where the standard of living is abnormally low or to 'remedy a serious disturbance in the economy of a Member State'. Hence, measures which are found to qualify as State aid within the meaning of Article 107(1) TFEU are subject to EU State aid control and that means that they are in principle prohibited. The Commission is then empowered to 'declare' them compatible under Article 107(3) TFEU, when it is deemed to be in the common interest. The general principle behind the Commission's compatibility assessment is to balance the positive impact of the aid measure (pursuing an objective of common interest) against its potential negative effects (the distortion of competition). For this assessment the Commission largely defers to predetermined criteria or proxies. The conventional method taken in the block exemption regulations and in most enforcement guidelines is to predefine a set of objectives (e.g. aid for environmental projects) and the eligible costs (the costs of an environmental project) on the basis of which undertakings can then receive the State aid.

The central normative assumption behind the state aid rules is that the role of the state in the market should not lead to competition distortions between undertakings. As such it is reflective of a joint commitment of the Member States to ensure competitive markets. Traditionally the main concern of EU state aid law was to address specifically protectionist aims of Member States that were intent on financing sectors of the national economy or 
boosting national champions. ${ }^{4}$ Still today, state aid is often applied to uncover protectionist aims of Member States. Thus, recently, the Commission decided that Luxembourg and the Netherlands had on the basis of a web of complex tax laws granted selective tax advantages to Fiat and Starbucks, respectively. DG Competition Commissioner Margrethe Vestager stated: "Tax rulings that artificially reduce a company's tax burden are not in line with EU state aid rules. They are illegal. I hope that, with today's decisions, this message will be heard by Member State governments and companies alike."

Although these goals of state aid law are still part of the day-to-day state aid regime, the regime has significantly evolved, normatively, towards an area of law that is also concerned with ensuring that interactions between the state or emanations of the state and the market are efficient and take place with the least of costs to the Union. ${ }^{5}$ This is quite a normative shift, which, as will be discussed further below, has taken place largely on the basis of a normative reading of existing legal categories of state aid law, on the basis of market derived standards. The implementation of this idea has been achieved primarily on the basis of work from the European Commission ${ }^{6}$ who has been able to almost entirely proceduralise this area of internal market law.

\section{ii. The proceduralisation of the state aid rules}

Article 108 TFEU, crucially, provides for the supervision of state aid by the Commission, and imposes the duty on Member States to notify the Commission in advance of any plans to grant or to alter aid. The Commission has issued an extensive collection of guidance papers, forms for notifications and reporting, block exemption regulations, temporary rules, horizontal rules and sector-specific rules that Member States can rely on in their design of aid schemes or ad hoc individual aid actions. ${ }^{7}$ These legislative documents all

4 J.J.P. Lopez, The Concept of State Aid under EU Law - From internal market to competition and beyond (Oxford University Press 2015) at 45 and further; C. Quigley, European State Aid Law and Policy (Oxford Hart Pub., 2015) at 270.

5 The recent published monograph of Lopez above (no. 4) describes the evolution of the concept of State Aid, from p. 12.

6 Ibid.

7 Including rules on Procedure; forms for notifications and reporting; Block Exemption Regulations; 
serve the purpose of minimising conflict and streamlining, in procedural terms, the allocation of governmental aid mechanisms.

In this respect it is important to note that over the past decade the state aid regime has been subject to what the Commission calls 'simplification and streamlining', first, under the Commission's 2005 State Aid Action Plan. ${ }^{8}$ Second, and more importantly, the State aid modernisation (SAM) initiative, carried out by the Commission since May 2012. This has brought forward major changes with structural effects for the application of EU state aid law. ${ }^{9}$ As a whole the SAM initiative is targeted at "enhancing the effectiveness of aid in supporting growth, in view of the Europe 2020 strategy's objectives". For this purpose the Commission is implementing a priority based policy where enforcement of state aid is limited to cases with "the biggest impact on the internal market". ${ }^{10}$ A big part of the SAM project involves a decentralisation of the state aid rules, which in some ways resembles the modernisation package that the Commission implemented with regard to the EU competition rules. ${ }^{11}$ The SAM package focuses on 'common principles'. Aid measures should satisfy a certain number of criteria in order to be considered compatible with the Treaty. They need to contribute to a 'well-defined objective of common interest' and have to be necessary and appropriate. Moreover, the beneficiary will need to undertake a project or activity, which he would not have done without the aid (the incentive effect) and the amount of aid has to be proportionate. Lastly, aid should avoid undue negative effects on competition and trade. ${ }^{12}$ Key to the

temporary rules in response to the crisis; horizontal rules; sector-specific rules; specific aid instruments; on the transparency of public undertakings; on Services of General Economic Interest (SGEI); on rules applicable to State aid in transport sector; on rules applicable to State aid in coal sector. See http://ec.europa.eu/competition/state_aid/legislation/legislation.html for an overview (accessed 10-12-2015).

8 Notable measures have included the General Block Exemption Regulation of 2008. Commission Regulation (EU) $\mathrm{N}^{\circ} 651 / 2014$ of 17 June 2014 declaring certain categories of aid compatible with the internal market in application of Articles 107 and 108 of the Treaty.

9 http://ec.europa.eu/competition/state_aid/modernisation/index_en.html (accessed 10-12-2015).

10 Communication from the Commission to the European Parliament, the Council, the European economic and social Committee and the Committee of the regions - EU State aid modernisation (SAM) (COM/2012/0209 final).

11 See also X. Boutin and R. Peduzzi, "Searching for 'Good Aid': The Role of Evaluation,” European State Aid Law Quarterly 14(2015) p 250-59.

12 These principles have been implemented in all the main horizontal guidelines and frameworks: see Guidelines on regional State aid for 2014-2020 (OJ C 209 of 23.7.2013, p. 1); Guidelines on State aid to promote risk finance investments (OJ C 19, 22.1.2014, p. 4); Framework for State aid for research and 
modernisation package is that the new State aid architecture requires, from the Member States, a higher level of transparency and, in some cases, a periodic evaluation. A central element of the modernisation package is the new General Block Exemption Regulation (GBER), which has been extended horizontally by adding several new categories of aid exempted from prior notification and vertically, with higher notification thresholds and numerous simplifications in the applicable conditions. ${ }^{13}$ Estimates of the Commission claim that about three quarters of State aid measures and some two thirds of aid amounts can be exempted under the new GBER and up to $90 \%$, if Member States fully use the possibilities offered by the Regulation and design their aid schemes accordingly. ${ }^{14}$ The Commission envisages a stronger role for Member States in correctly applying State aid rules and selfassessing their State aid measures. For this purpose the Commission has introduced a simplification for Member States regarding the ex-ante assessment of aid compatibility with some new or reinforced ex-post safeguard mechanisms. These safeguards include monitoring (a periodic review of legality of a sample of State aid measures implemented by Member States), transparency (Member States will have to put in place national or regional public websites listing all the beneficiaries of individual aid) and, crucially, evaluation (an assessment of whether the aid actually achieved what they were meant to achieve and a verification of the balance between the aid's public objective and its impact on competition and trade between Member States). ${ }^{15}$

development and innovation (OJ C 198, 27.6.2014, p. 1); Guidelines on State aid for environmental protection and energy 2014-2020 (OJ C 200, 28.6.2014, p. 1); draft Guidelines on State aid for rescuing and restructuring non-financial undertakings in difficulty (OJ C 249, 31.07.2014, p. 1); and a new Communication - Criteria for the analysis of the compatibility with the internal market of State aid to promote the execution of important projects of common European interest (OJ C 88 of 20.6.2014, p. 4). In addition, some important guidelines concerning specific sectors have been adopted in the context of modernisation and in line with the same common principles: EU Guidelines for the application of State aid rules in relation to the rapid deployment of broadband networks (OJ C 25 of 26.1.2013, p. 1); Communication from the Commission on State aid for films and other audiovisual works (C 332, 15.11.2013, p. 1); Guidelines on State aid to airports and airlines (OJ C 99, 4.4.2014, p. 3); EU Guidelines for State aid in the agriculture and forestry sector and in rural areas 2014 to 2020 (OJ C 204, 1.7.2014, p. 1).

13 Commission Regulation (EU) No 651/2014 of 17 June 2014 declaring certain categories of aid compatible with the internal market in application of Articles 107 and 108 of the Treaty Text with EEA relevance

14 Boutin and Peduzzi above (no. 11).

15 Commission Regulation (EU) No 651/2014 of 17 June 2014 declaring certain categories of aid compatible with the internal market in application of Articles 107 and 108 of the Treaty Text with EEA relevance 
The set up of the state aid regime and the consequent highly policy driven nature of it has made it difficult to point out genuine normative conflicts between legitimate policy choices of Member States and the objectives that are pursued in the state aid framework. In this sense a lot of the potential conflicts that are of concern from the perspective of state aid have been 'negotiated' and Member States have agreed to follow certain procedures on when they grant state aid in specific sectors. ${ }^{16}$ Clearly, protectionist aims of Member States conflict in normative terms with those of the state aid regime but such aims are, a priori, excluded as legitimate. Moving beyond such prima facie protectionist aims of Member States, it is difficult to identify genuine (and legitimate) normative conflicts within the EU state aid regime. This can, in part, be attributed to the Commission's effort to implement an expansive idea about the aims and objectives that can be addressed with State Aid and combined with its proceduralisation efforts it has been able to largely streamline the way Member States finance public service missions and develop aid schemes. As said, a lot of the potential conflicts have therefore been resolved on the basis of the procedures that set out how Member States have to proceed if they want to provide state aid for certain social objectives. Moreover, the Commission has adopted a wide definition of (social) market failure to structure its policy around. Simply said, the Commission's policy is essentially concerned with a normative procedural assessment of the optimum allocation of state resources, whilst allowing a broad range of policy goals, provided they serve a common/community interest. In the process the Commission perceives market failure to be very wide in scope, as a situation where the market does not achieve social welfare optimal outcomes. The approach in today's competition economics theory and the policy of the European Commission ${ }^{17}$ is, for example, to include redistributive equity concerns within the market efficiency rationale of market failures. The idea behind it is that if market failure can be defined as a situation where the market does not achieve welfare optimal outcomes, it could perfectly encompass equity (redistributive) concerns. Consequently, social concerns are then internalised within the concept of a market failure. This is basically also reflected in the previously mentioned

\footnotetext{
16 See V. Verouden, 'EU State Aid Control: The Quest for Effectiveness' European State Aid Law Quarterly Volume 14, Issue 4 (2015) pp. 459 - 464.

17 Restricting State aid to market failure situations is one of the main aims introduced by the 2005 State Aid Action Plan.
} 
'incentive effect' test, which is to say that the aid must be provided as an incentive to further develop activities or projects that serve a common interest and in which the beneficiary would not engage without the aid.

A more narrow understanding of market failure would be concerned with fixing information asymmetries (so that consumers and producers take decisions taking into account all information), externalities (so that prices reflects all costs, including costs to third parties) and market power (so that firms cannot profitably charge prices in excess of marginal costs). However, the concept of a market failure as applied by the Commission is expanded to include situations where the market does not achieve social welfare optimal outcomes that can be defined along the lines of the common interests for the Union. As was identified in the first chapters, these common interests have evolved significantly and since Lisbon include a vast range of social objectives. However, the point in the first chapter was also that, in so far as these objectives were pursued on a EU level, in particular by the European Commission, they could best be perceived as 'commoditized' versions of the social. This emanation of the social, on the EU level, has a very specific meaning and context. Simply said, and as was argued in Chapter $\mathrm{I}^{18}$ it is an understanding of the social that is often ancillary to or supportive of economic objectives. ${ }^{19}$ It can be argued that this conception of the social has come to fruition within the area of the state aid rules. The modernisation package of the Commission is ultimately targeted to embed an idea of what constitutes 'good' aid, i.e. compatible aid. ${ }^{20}$ The package will, according to the Commission, "help designing smarter schemes with a better incentive effect and less competition distortions. Seen more broadly, it should be considered as part of a general move towards sound evidence-based policy making". ${ }^{21}$ In this context the Commission speaks about 'evaluation communities', which "have a genuine interest in improving the effectiveness and efficiency of spending measures".22

18 See Chapter I section III.B.

19 See further e.g. A.Somek, Engineering Equality : An Essay on European Anti-Discrimination Law (Oxford; New York: Oxford University Press, 2011) and M.Saveska, "Polanyian Reading of the Socio-Economic Transformations of the European Union," Journal of Contemporary European Studies 22, no. 4 (2014).

20 See Boutin and Peduzzi above (no. 11).

21 Ibid.

22 European Commission, Issues Paper 12/04/2013, 'Evaluation in the field of state aid', 
It is likely that the efforts of the Commission to nudge Member States towards the implementation of 'evaluation communities' that structure and implement a very specific idea of governance has systemic effects. That is to say that there are likely to be policies or objectives that are not developed because Member States are already thinking only in terms of the smart regulation rationale of the Commission. ${ }^{23}$ In this way genuine norm conflicts are neutralised or depoliticized in the early stages of policy formulation by the Commission in a slightly covert way and it would require a challenging empirical research effort to quantify the actual effects of the Commission's state aid policy in terms of the limits it imposes on social diversity within the Union. As such, in purely conceptual terms, the wide approach to market failure leads to a partial politicization of the economic concept and a de-politicization of the social objectives involved.

This process in the state aid rules closely resembles the 'modernisation' and decentralisation efforts in competition law. As was argued in the previous chapter, the development and 'modernisation' of the EU competition rules went through two important developments that influence the ability of EU competition law to accommodate regulatory diversity. First, the so-called more 'economic approach' on which basis the Commission is now of the opinion that only 'economic efficiencies' or 'pro-competitive effects' of restrictive agreements are accepted in order to fulfil the first condition of the exemption criteria and decisive value is attached to the objective qualification and concretization, in purely economic terms, of the claimed benefits that may be effectuated by restrictive agreements in order to qualify for an exemption. Second, the 'modernisation' of EU competition law has also involved a decentralisation of the application of the competition rules. This implies, firstly, that national competition authorities are now, theoretically, the main enforcers of EU competition law and, secondly, that undertakings themselves are to 'self-assess' their status under the competition rules, whereas formerly they were able to request for official 'exemption decisions' from competition authorities. As such, the enforcement of the

http://ec.europa.eu/competition/state_aid/modernisation/evaluation_issues_paper_en.pdf (accessed on 10-122015).

23 See the better regulation initiative of the European Commission http://ec.europa.eu/smartregulation/index_en.htm (accessed on 10-12-2015). 
competition rules should be internalised all the way down into the minds and calculus of the undertakings themselves. As such, the previous chapter painted the following picture: A retracting state that increasingly defers socio-economic policy making to undertakings; a European Commission that pushes for a one-dimensional idea of what matters in terms of socio-economic policy - at least whenever it infringes the competition rules - and undertakings that feel increasingly compelled to structure their potentially green and social objectives in accordance with what is efficient and for the sole benefit of a consumer.

The process and policy initiatives of the Commission in state aid policy are largely the same. Consequently, one would indeed expect to see less conflict as the social becomes part of a technocratic process of resolving market failures. This is confirmed with even a cursory glance at the overviews of EU state aid cases that lists the decisions of the Commission by type of decision from 2000 to 2013. Over 90\% of the Commissions' decisions approve notified aid measures. ${ }^{24}$ This excludes the aid schemes that are, additionally, exempted under the block exemption regulations. I think it is likely that the proceduralisation of a lot of state aid decision contributes to the fact that it is rare to see a negative decision from the Commission. It is therefore understandable why the Commission feels confident that the idea of evaluative communities on a Member State level, i.e. outsourcing state aid control, is now worth pursuing in full.

Within this context, normative claims over the functioning of the state aid regime as a covert technocratic process that depoliticizes the formulation and pursuit of social objectives can be formulated on the basis of concerns about its democratic legitimacy and as an encroachment on the constitutional space for Member States to develop aid schemes. ${ }^{25}$ It matters whether policy objectives developed by Member States are to be defined within the technocratic domain of the proceduralised world of the state aid rules or whether they are allowed to take shape within 'normal politics' and the democratic arenas of the Member States. Arguably, the political process of the pursuit of some regulatory objectives is what matters most. This is reminiscent of the normative concerns that were developed in the first

24 http://ec.europa.eu/competition/state_aid/scoreboard/non_crisis_en.html (accessed on 10-12-2015).

25 This is one of the main starting points of the study of De Cecco above (no. 1). See also M. Bovens, "New Forms of Accountability and EU-Governance," Comparative European Politics 5(2007), 104-20. 
chapter: some non-economic objectives tend to share or require a social and political pact that underlies the objectives that are pursued. As such, even if, theoretically speaking, a market or technocratic approach towards regulating access to public infrastructure would accommodate the functional features of an objective, there may be something lost in the process of pursuing the objective as part of a genuine political or regulatory process. ${ }^{26}$

The central issue pursued here is the potential incommensurability between the evaluative standards applied on the basis of the state aid regime with social objectives that are formulated on a Member State level. More specifically, incommensurability as discussed in the first chapter occurs in the application of state aid law when objectives pursued by Member States cannot be aligned along the metric that is pursued within those rules without doing violence to the potentially genuine and worthwhile aspects of those objectives. It was discussed that the social purpose of EU law in the internal market as applied by the Court is to express instances of such irreconcilability before adopting evaluative principles that are congruent to the conflict that is being adjudicated. Social legitimacy, in turn, depends on the extent that the Court is able to accommodate and identify genuine social objectives within its evaluative rationales. Hence, the moment of defining what can be defined as a state aid counts. It is at this juncture, where a decision is made whether a policy or regulatory framework can be developed outside of the state aid rationale or within the standards and justifications that are already prescribed in state aid control - that genuine norm conflicts come to the front and need to be adjudicated by the Court. ${ }^{27}$

\section{iii. Modes of valuation in state aid: market versus regulation}

In a case that may have very well inspired the Dassonville formula, thirteen years later, the Court determined already in 1961 that

"the concept of aid is ... wider than that of a subsidy because it embraces not only positive benefits, such as subsidies themselves, but also interventions which, in various forms, mitigate the charges which are normally included in the budget of an undertaking and which, without,

\footnotetext{
26 See similarly, R. Bellamy, 'The liberty of the moderns: Market freedom and democracy within the EU' (2012) 1 Global Constitutionalism, pp. 141-172, 168.

27 Similarly De Cecco above (no. 1) 1-3.
} 
therefore, being subsidies in the strict meaning of the word, are similar in character and have the same effect". ${ }^{28}$

As will be further discussed below, the Court has since then consistently held that 'aid' is to be defined in relation to its effects, thus allowing the Court and the Commission to subject many forms of governmental 'interventions' to the Treaty provisions. ${ }^{29}$ The wording of the Court is indeed similar to the Dassonville formulation, which subjects measures "with equivalent effect" to quantitative restrictions to the scope of the free movement rules. ${ }^{30}$ The scope of the state aid rules is therefore wide, potentially covering all sorts of governmental interventions that lead to selective advantages for undertakings, and as will be argued further below requires responsiveness to avoid problems of social legitimacy. It will be demonstrated that also in terms of responsiveness the Court has shown some overlap with the free movement rules in the development of evaluative principles to determine whether there is state aid or not. As will be discussed further below, different evaluative standards have been acknowledged by the Court for the purpose to evaluate governmental interventions of different kinds.

For example, as will be discussed further below, the Court has established that the application of a market-based evaluation of a governmental intervention should be preceded by an assessment of the 'nature of the measure'. In principle, only if the state is acting to participate on the market - e.g. as a shareholder - should market based standards be used to evaluate whether any advantages have been granted. If, instead, the state is acting as a regulator, the 'market rationality' principle is replaced with evaluative standards based on questions whether regulation benefits a specific (group of) undertaking(s) or whether a measure involves a state resource. Social legitimacy then depends on whether the evaluative standard is congruent with the underlying social context. It shall be discussed below that the Court and the GC sometimes struggle in finding a coherent rationale for this distinction and

28 Case 30/59 Steenkolenmijnen v High Authority [1961] ECR 1, 19.

29 Such as direct subsidies, loans, guarantees, exemption from the ordinary rules concerning taxes and social contributions, under-price sales, capital injections, provision of market research and advertising activities or logistical and commercial assistance, payment of outstanding wages or redundancy costs, or exemption from the normal application of insolvency rules.

30 As argued by Biondi and Rubini above (no. 3) at 89. 
that, as a result, market based evaluations may become dominant and applied to social contexts that are unsuitable to be approached on that basis. ${ }^{31}$ It was mentioned before that, for the definition of state aid, five constituent elements need to be fulfilled. The adjudicative technique of the Court in the definition of state aid is based on a rationale of categorization. With this I mean that the Court has to establish if a certain context qualifies as a state resource; a selective advantage; a distortion of trade; an impact on trade between Member States. Such processes of categorisation harbour rationales that may result in qualifying a social reality in terms that it is manifestly unsuited for. Importantly, in order to determine what is the most efficient relationship between state and market, the state aid rules have to correctly distinguish the state from its role as a public authority and regulator from the state as a market participant.

For example, genuinely regulatory objectives concerning the regulation of public infrastructure may be qualified as foregoing state resources on the basis of a market based valuation of the social context involved. It is on this point that market efficiency standards may be imposed as a yardstick of valuation for social contexts that do not fit (completely) within those evaluative standards. ${ }^{32}$ From the perspective of social legitimacy the problematic areas of state aid law therefore concern those areas where genuine and legitimate policy choices are plainly rejected or simply not recognised within the evaluative rationales. That is to say, tensions between normative choices of Member States towards the functioning of their economy and the restrictions imposed by the state aid regime on political mechanisms such as subsidies and other forms of regulatory intervention to implement political choices. Such errors of wrong valuation may occur because in some crucial parts of its analysis the Court uses market-derived standards. These will be further discussed below.

\section{B. The expedient nature of market derived standards within state aid law}

\footnotetext{
See also De Cecco above (no.1) at 88 .

32 Interestingly, in the area of state aid law, the market standards are occasionally also 'used' by Member States to justify behaviour with seemingly protectionist aims Case C-124/10 P European Commission v Électricité de France (EDF), nyp. Something I will return to further below.
} 


\section{i. Introduction}

One of the most important and contentious criteria to establish state aid is the 'advantage' given to one or more undertakings. In simple terms, advantage means a benefit that could not have been obtained "under normal market conditions; or in the absence of the intervention by the aid granting authority". ${ }^{33}$ As a consequence such advantages "lighten the burdens normally assumed in an undertaking's budget". ${ }^{34}$ As was briefly discussed before, on the basis of the Steenkolenmijn judgment, the concept advantage can be understood very wide and encompasses grants, subsidies, loans or guarantees by the State, ${ }^{35}$ anything owed to the State (which the State would fail to collect), ${ }^{36}$ anything the State gives up without objective reason, ${ }^{37}$ services it purchases at excessively high prices ${ }^{38}$ or any other types of advantages flowing from governance frameworks (provided they provide a selective benefit). ${ }^{39}$

To assess when the actions of a public authority qualify as conferring an advantage, the Court has, on instigation of the Commission, accepted to adopt a test that is described as the market economy operator principle (MEOP - encompassing both the market economy investor and creditor principles) ${ }^{40}$ On the basis of this principle the decision of a public authority to grant a subsidy, loan or guarantee, to forego anything or purchase services is compared with the decision that a private market-operator would make under similar circumstances. According to some recent readings of the case law, the Court introduced the MEOP in order to become the main guiding principle upon which to assess whether an

33 E.g. Case C-357/14 P - Electrabel and Dunamenti Erömü v Commission, nyp, paragraph 144

34 E.g. Case 173/73 Italy v Commission [1974] ECR 709, paragraph 26; Case C-387/92 Banco Exterior de España [1994] ECR I-877, paras. 12 and 13; and Case C-280/00 Altmark Trans and Regierungspräsidium Magdeburg [2003] ECR I-0000, para. 84

35 E.g. case C-559/12 France v Commission (La Poste) [2014] nyp and C-275/10 Residex Capital IV [2011] ECR I-13043, para. 39.

36 E.g. C-271/13 P - Rousse Industry v Commission [2015] nyp

37 E.g. C-279/08 P - Commission v Netherlands [2011] ECR I-07671; C-39/14, BVVG Bodenverwertungs- und verwaltungs GmbH [BVVG] v Landkreis Jerichower Land [2015] nyp; C-214/12 P, Land Burgenland v Commission [2013] np.

38 E.g Case T-98/00 Linde v Commission [2002] ECR II-03961

39 E.g. Case C-518/13 - Eventech [2015] nyp, Case C-357/14 P - Electrabel and Dunamenti Erömü v Commission [2015] nyp

40 First in case C-234/84 Kingdom of Belgium v Commission of the European Communities (Meura) [1986] ECR 02263. See Lopez above (no. 4) at 75. 
advantage has been granted. ${ }^{41}$ This is contrary to subsequent case law where the Court has clearly stated the application of the principle should be preceded by an assessment of the 'nature of the measure'. ${ }^{42}$ If, instead, the state is acting as a regulator, the 'market rationality' principle would have to be replaced with evaluative standards based on questions whether regulation benefits a specific (group of) undertaking(s) or whether a measure involves a state resource ${ }^{43}$ However, it shall be discussed below that the Court and the GC sometimes struggle in finding a coherent rationale for this distinction and that, as a result, market based evaluations may become dominant and applied to social contexts that are unsuitable to be approached on that basis

Fransesco de Cecco describes that the market operator principle pursues, in effect, substantive equality. ${ }^{44}$ That is to say, to achieve a situation in which undertakings, regardless of their relationship with the state compete on an equal footing. In this sense, an important objective of state aid law is to neutralise the effects of state intervention by "subjecting it to scrutiny based on market drawn criteria" ${ }^{45}$ As such, one of the main objectives of the MEOP is to bring transparency and clarity into the Member States activity on the market. It is clear that this is, more generally, one of the main objectives of the state aid rules, which was clearly established by the Court in Altmark where it held that in order for compensation for public service obligations not to constitute State aid, "the recipient undertaking must have public service obligations to discharge and these must be clearly defined". ${ }^{46}$ Moreover, "the parameters on the basis of which the compensation is calculated must be established in advance in an objective and transparent manner" ${ }^{47}$ It can be said that in Altmark, the Court sought to eliminate any possibility of manipulation of state resources to the benefit of selective undertakings. ${ }^{48}$

\footnotetext{
41 E.g. Lopez above (no. 4) at 101.

42 In Case C-124/10 P European Commission v EDF and others [2012] ECR nyp.

43 As argued by De Cecco above (no. 1)

44 Ibid.

45 Ibid., at 74.

46 Case C-280/00 Altmark Trans and Regierungspräsidium Magdeburg [2003] ECR I-0000, paragraph 89

47 Ibid., paragraph 90

48 Opinion of AG Mazak in Case C-124/10 P European Commission v Électricité de France (EDF) and Others, paragraph 95 .
} 
Crucially, in this respect, the Court has rejected the idea that certain aims of fiscal or social policies would fall outside of the ambit Article 107 TFEU. The Court has always insisted that the question of aid does not distinguish between the measures of state intervention concerned by reference to their causes or aims but defines them in relation to their effects. ${ }^{49}$ It is therefore not possible for a Member State to only invoke the legitimacy of the aim pursued in order to avoid the application of the state aid regime. ${ }^{50}$ Instead, by requiring that market 'rationality' is to inform the decision of public authorities, MEOP indeed turns market standards into regulatory standards, which scope, depth and intensity can be illustrated by way of discussing some recent case law. Hence, the following discussion of some recent approaches of the Court of Justice and the General Court will serve as a problematisation of the application of the MEOP from the perspective of the social legitimacy of the EU state aid regime. The MEOP can become expedient and pervasive at the moment that there is not a clear rationale to separate the role of the state in its action that pursue regulatory interests from the role of the state in its actions that pursue participation in the market. The following sections set out how and why this might be problematic.

\section{ii. The potential expedient scope of the market economy operator principle (part one): the absence of rationale of genuine regulation versus the clear rationale of a private investor/creditor}

As was briefly touched on above, the Court has established that the MEOP should be applied after an assessment of the 'nature' of an aid giving measure. Arguably, in clear regulatory contexts concerning the exercise of public authority, it would not be applied. That this can be a topic of discussion is illustrated in, for example, the case The Netherlands and ING against the Commission, which concerned a measure by virtue of which a Dutch bank

49 Eg Case C-39/14 BVVG [2015] nyp, C-417/10 3M Italia [2012] nyp, para. 36; Case C-487/06 P British Aggregates v Commission [2008] ECR I-10515, paras. 84 and 85; Case C-56/93 Belgium v Commission [1996] ECR I-723, para. 79; Case C-241/94 France v Commission [1996] ECR I-04551, para. 20; Case C75/97 Belgium v Commission [1999] ECR I-03671, para. 25; and Case C-409/00 Spain v Commission [2003] ECR I-01487, para. 46.

50 Case C-487/06 P British Aggregates v Commission [2008] ECR I-10515, para. 84, Case C-241/94 France v Commission [1996] ECR I-4551, para. 21; Case C-342/96 Spain v Commission [1999] ECR I-2459, para. 23; and Case C-75/97 Belgium v Commission ECR I-03671, para. 25 
was granted favourable conditions for the repayment of state aid that it had received in the wake of the financial crisis. ${ }^{51}$ It was favourable because the rate of remuneration was lower than what had been originally agreed between the Dutch government and ING. The argument was made that this could not be considered state aid because a private investor would never find itself in the same situation as the Dutch government in relation to ING. The GC rejected this argument. Instead the GC decided that a hypothetical private investor could very well accept to accept repayment on different terms than initially agreed, for example, "if it could benefit from avoiding the risk of holding shares whose future value was unknown". The Commission failed to assess such potential benefits. The Court agreed with this and held that

"an economic advantage must, even where it has been granted through fiscal means, be assessed in the light of the private investor test if, on conclusion of an overall assessment, it appears that, notwithstanding the fact that the means used were instruments of State power, the Member State concerned has conferred that advantage in its capacity as shareholder of the undertaking belonging to it ... It follows that the applicability of the private investor test to a public intervention depends, not on the way in which the advantage was conferred, but on the classification of the intervention as a decision adopted by a shareholder of the undertaking in question". ${ }^{52}$ (emphases added)

The Court went on to observe that any holder of securities, in whatever amount and of whatever nature, may wish or agree to renegotiate the conditions of their redemption

"What is decisive ... is whether the amendment to the repayment terms of the capital injection has satisfied an economic rationality test, so that a private investor might also be in a position to accept such an amendment, in particular by increasing the prospects of obtaining the repayment of that injection". ${ }^{3}$

In view of what was discussed before, the Court raises here, implicitly, the question of the rationale of a public authority versus the rationale of a private investor. In the absence of a rationale that can bring such measures within a general regulatory framework, the authority in effect concedes that it grants State aid unless it can claim that it acts as a private investor and positively provide evidence to establish that its transactions with undertakings can generate a return that would be acceptable in market terms. I will discuss in section III to what extent the reasoning of the Court harbours a potential for responsiveness to social context. What matters

\footnotetext{
Case C-224/12 P, Commission v The Netherlands [2014] nyp.

Ibid., paragraphs 30-31.

53 Ibid., paragraph 36.
} 
here is that the potential scope of the MEOP is, as interpreted by the Court, wide, especially if one takes into account how regulatory intervention takes place in post-Thatcher Europe. ${ }^{54}$ Essentially those processes have obscured the difference between market and non-market approaches in regulatory intervention.

As was discussed in the first chapter, processes of privatisation and liberalisation have spread over Europe and led to new forms of regulatory intervention and the gradual process by which the role of the state as a direct provider of public services disappeared has led to the creation of 'new regulatory tools' that are aimed at safeguarding the public interest on the basis of terms set by new public management reforms ${ }^{55}$ Outside of general schemes, state support to undertakings charged with public service obligations, providing services of general economic interest, as regulators or as a shareholder in undertakings with public responsibilities are amongst those new regulatory tools. The goals of the new public management wave has been to "improve the effectiveness and efficiency of the public sector; to enhance the responsiveness of public agencies to their clients and customers; to reduce public expenditure; and to improve managerial accountability" ${ }^{96}$. This was undertaken by “doing away with hierarchy, monolithic systems, politically neutral administrative bodies, standardized personnel system and standardized regulation of citizens and companies for the benefit of a market-like, deregulated system of pseudo-corporate, autonomous service providers and enthusiastic public managers". ${ }^{57}$ Therefore, one of the key features of these reforms has been to not make any distinctions between the public and the private sector when it comes to how the public sector is managed; separating commercial activity from noncommercial activity and emphasizing financial reporting and accountability. ${ }^{58}$

54 See also B. Lange, F. Haines, and D. Thomas (eds), Regulatory Transformations : Rethinking EconomySociety Interactions, (Oxford Hart Publishing, 2015).

55 See further E. Szyszczak, The Regulation of the State in Competitive Markets in the EU (Oxford, 2007), 3-4; S. Picciotto, "Liberalization and Democratization: The Forum and the Hearth in the Era of Cosmopolitan Post-Industrial Capitalism," Law and Contemporary Problems 63, no. 4 (2000): 157-78.

56 T. Christensen and P. Laegreid (eds.), The Ashgate Research Compnion to New Public Management (Ashgate Surrey 2011) p. 1.

57 T. Beck Jorgensen and L. Bogh Andersen: An Afternath of NPM: Regained Relevance of Public Values and Public Service Motivation in T. Christensen and P. Laegreid (eds.) The Ashgate Research Compnion to New Public Management, (Ashgate Surrey 2011), at 335.

58 Z. Hoque and J. Moll, 'Public Sector Reform: Implications for Accounting, Accountability and Performance of State- Owned Entities - An Australian Perspective', International Journal of Public Sector Management, 14(2001) at 305. See also P. Dibben and P. Higgins, 'New Public Management: Marketization, 
Moreover, on the basis of the state aid rules the relationship between the state and the provider of public services in many of these regulatory bonds has to be based on the behavioural standard of the prudent investor in every action that brings forth an advantage or, alternatively, to notify the state aid. This has led to a new reality for authorities pursuing regulatory intervention in the market. ${ }^{59}$ Although the Court recognises explicitly that the private investor principle has to be excluded in the event that the state acts as a public authority, since such situations can never compare to those of a private investor in a market economy, the new regulatory tools and implementation of principles of new public management make it increasingly obscure to understand what public authority actually entails outside of the traditional functions that have always been strongly associated with state authority (police, public health, public security). ${ }^{60}$

Take Ryanair $v$ Commission, which concerned the setting of airport charges by regulation of the Walloon Region. The GC held that the setting of airport charges was closely connected with the use and operation of Charleroi airport, which was an economic activity and that it was necessary to differentiate between that specific economic activity and activities that fell strictly under public authority powers. ${ }^{61}$ The GC held that the regulatory powers of the Walloon Region to fix airport charges did not mean that its regulatory decision to lower those charges would not fall in the sphere of the private investor principle, "since such a scheme could have been put in place by a private operator" ${ }^{2}$. Just to have the regulatory power is therefore not enough to exclude the validity of the MEOP as a evaluative principle unless the activities in question can somehow be connected "by their nature, their aim and the

Managerialism and Consumerism' in P. Dibben, G. Wood and I. Roper (eds.) Contesting Public Sector Reforms, (London, Palgrave Macmillan 2004); W. Dunn and D. Miller, 'A Critique of New Public Management and the Neo-Weberian State Advancing a Critical theory of Administrative Reform', Public Organization Review, 7(2007) 345-358.

59 Also E. Szyszczak, 'Public Services in Competition Markets' (2001) 21 Yearbook of European Law 35, at 64.

60 Such as for example in C-364/92 SAT Fluggesellschaft [1994] ECR I-00043. See also L. Hancher, "Towards a new definition of a State aid under European Law- Is there a new concept of State aid emerging", (2003) EStAL, 365-373, at 366-368

${ }_{61}$ Case T-196/04 - Ryanair v Commission [2008] ECR II-03643

62 Ibid., para. 101. 
rules to which they are subject, are connected with the exercise of powers...which are typically those of a public authority" ${ }^{\prime 3}$.

These examples point out that in view of the development in public management it is likely that the MEOP is of increasing importance in regulatory contexts. However, the reasoning based on the connection to the 'traditional' exercise of public power is out-dated and as will be discussed further below should be exchanged for a more dynamic approach, one that is responsive to potential genuine regulatory intentions of Member States.

\section{iii. The scope of the market economy operator principle (part two): control over economic assets or public infrastructure}

Moreover, and increasingly challenging, where the state acing as a regulator creates or has control over an asset, it may be necessary to determine whether that asset has an economic value and whether that value may constitute a transfer of state resources. ${ }^{64}$ This was at stake in Bouygues Sa v Commission where the GC held that the exercise of state functions does not preclude the taking into account of economic facts in connection with the management of a scarce public resource such as radio frequencies constituting the public airwaves, to which a right of access or a right of usage may be granted. ${ }^{65}$ Again, the argument that the assets in question had no equivalent in the hands of private managers was not sufficient for excluding them as a state resource. Some economic value could be assigned to it and it therefore was an asset, which the state should approach on the basis of prudent market operator principles, if it would want to avoid the applicability of a state aid notification obligation. ${ }^{66} \mathrm{~A}$ similar rationale applied with regard to the Netherlands that allowed the

C-364/92 [SAT Fluggesellschaft 1994] ECR I-00043 para. 30.

64 Also A. Biondi, "Some reflections on the notion of "State Resources" in European Community State Aid Law' (2007) 30 Fordham International Law Journal at 1426.

65 Case C-431/07 P - Bouygues and Bouygues Télécom v Commission [2009] ECR I-02665.

${ }^{66}$ Although the Court decided in para. 110 that "the amount payable as a fee can constitute State aid only if, all other things being equal, there is a difference between the price paid by each of the operators concerned, it being recalled that, according to the Court of Justice, it is the time when each of the operators concerned entered the market that must be taken into account [...]. On the other hand, if the national authorities decide as a general principle that licences will be awarded free of charge, or awarded by means of public auctions or awarded at a standard price, there is no aid element, provided these terms are applied to all the operators concerned without distinction". 
transfer by undertakings of trading emission allowances, free of charge ${ }^{67}$ The GC held that "those assets are put at the disposal of the undertakings concerned free of charge, whereas they could have been sold or put up for auction; The Kingdom of the Netherlands has thus forgone State resources" ${ }^{68}$ In appeal, this was confirmed by the grand chamber of the Court of Justice, which added that

"the tradability of the NOx emission allowances depends above all on the fact that the State, first, authorises the sale of those allowances and, second, allows those undertakings which have emitted a surplus of NOx to acquire from other undertakings the missing emission allowances, thereby agreeing to the creation of a market for those allowances...by making those allowances tradable the Kingdom of the Netherlands confers on them a market value". ${ }^{9}$

An analogy can be drawn on this point with the distinction between economic and non-economic activities and the application of the competition rules in article 101 TFEU. As was discussed there, the Court has consistently held that any activity consisting in offering goods and services on a market is an economic activity. ${ }^{70}$ However, the question whether a market exists for certain services may depend on the institutional means through which those services are organised in the Member State concerned..$^{71}$ Similar as with the competition rules, the State aid rules only apply where an activity is provided 'in a market environment'. Therefore, the economic nature of certain services may differ between the Member States since this remains subject to political choices or Member State specific economic developments, which may also change over time. At the same time, however, simply the decision of an authority not to allow third parties to provide a certain service (such as with inhouse services) does not rule out the existence of an economic activity. In spite of such market closure, an economic activity can exist, simply, "where other operators would be willing and able to provide the service in the market concerned". ${ }^{72}$ This rationale is

67 Case T-233/04 Netherlands v Commission [2008] ECR II-00591.

68 Ibid., para. 70.

69 Case C-279/08P Commission v Netherlands [2011] ECR I-07671 paras. 88 and 107.

70 Case 118/85 Commission v Italy [1987] ECR 2599, para. 7; Case C-35/96 Commission v Italy [1998] ECR I3851, para. 36; Joined Cases C-180/98 to C-184/98 Pavlov and Others [2000] ECR I-06451 para. 75.

71 Joined Cases C-159/91 and C-160/91 Poucet and Pistre [1993] ECR I-637.

72 See also the Opinion of Advocate General Geelhoed in Case C-295/05 Asociación Nacional de Empresas Forestales (Asemfo) v Transformación Agraria SA (Tragsa) and Administración del Estado [2007] ECR I2999, paragraphs 110 to 116 . 
potentially expedient in the sense that the potentiality of private operators providing the service in question can be increasingly wide, especially in a context of increasing liberalisation and privatisation. Similarly, the reasoning of the Court in the Dutch NoX case and other cases is potentially expedient since, if read in a certain way, there is, with regard to public infrastructure, always the potential of a resource and the actions of states may therefore quickly be qualified as forgoing that state resource.

\section{The potential crowding out effects of the market operator principle}

After having established that the MEOP harbours a risk of being adopted too easily and without sufficient context-sensitivity, we can say something about the potential effects of applying that principle to social contexts, which may pursue objectives that are potentially damaged or ignored within the evaluative standard of the market economy rationale. By way of introduction, the case Rousse Industry provides some insights into what MEOP actually entails. Rousse is a Bulgarian manufacturing company specialising in metal constructions. It received State aid that the Commission found to be incompatible with the internal market in the form of loans it could not repay to the Bulgarian state. ${ }^{73}$ The GC stated that a "prudent and diligent private creditor", which is faced with a situation where a debtor's financial situation is worsening and is not making payments on its loan, would make a choice between launching proceedings against the debtor or reaching an amicable arrangement if that would recover more or at least part of the debt. ${ }^{74}$ The Court agreed that the Bulgarian authorities had not acted as a private creditor because they limited themselves exclusively to the amicable route. Only 'reminders' for the payment were sent. There was, however, no specific evidence that Rousse Industry would eventually return to a viable status. ${ }^{75}$ At this point the Bulgarian authorities would have to provide evidence of the profitability of the scenario it was following at that time. The Court decided that a public authority, which is owed money must exhaust all the options available to recover the loan and if necessary force the debtor into liquidation

\footnotetext{
C-271/13 P - Rousse Industry v Commission [2014] ECR nyp. Case T-489/11 Rousse Industry v Commission [2013] ECR np.

Ibid., paras 60-61
} 
"whenever a forced sale of assets would result in a higher yield in terms of recovered money". 76

In terms of behavioural standards, the prudent private investor represents a fundamental benchmark and has been defined as an "an investor who wishes to maximise his profits but without running excessive risks" as well as being "guided by prospects of profitability". In a similar tone, Advocate General Jacobs underlined in Spain v Commission that State aid is granted whenever a Member State makes available to an undertaking funds which in the normal course of events would not be provided by a private investor applying ordinary commercial criteria and "disregarding considerations of a social, political or philanthropic nature". ${ }^{77}$ In cases where a company in financial distress proposes its creditors to rearrange its debt, each creditor acting as a private investor is expected to "make a decision having regard to the amount offered to it under the proposed agreement, on the one hand, and the amount it expects to be able to recover following possible liquidation of the firm, on the other" ${ }^{78}$. Therefore, in the absence of specific and credible evidence of return to profitability, it is unrealistic to imagine that a private creditor placed in a similar situation could be persuaded that chances of successful recovery are maximized with deferring repayment. The burden of proof supporting that the Member State authorities in fact acted in accordance with the private creditor test lies with the Member State. ${ }^{79}$

Therefore, relationships based on 'trust' or 'informal relations' are provided, on first sight, a very limited recognition within the world of the prudent private investor, unless they can be specifically quantified in terms of profitability. A private investor should be motivated solely by the possibility of making profits or return on investment and ignore all other policy objectives of a public nature at that stage. ${ }^{80}$ Should any social ambitions be present then the Member State is to notify this as a State aid to the Commission, where these ambitions shall be reviewed. Simply said, the hypothetical private investor may not wilfully forgo any

\footnotetext{
Ibid., para. 65.

77 AG Jacobs in Joined Cases C-278/92, C-279/92 and C-280/92 Spain v Commission [1994] ECR I-4103, para 28.

78 Case T-152/99, Hamsa v Commission [2002] ECR II-3049, para. 166.

79 Case T-318/00 Freistaat Thüringen v Commission [2005] ECR II-4179, para. 180.

80 Case C-278/92 Spain v Commission [1994] ECR I-4103; Case T-358/94 Air France v Commission [1996] ECR II-02109.
} 
obvious opportunity for profit. ${ }^{81} \mathrm{He}$ may be guided by the same objective as a group of companies that tolerate short-term losses by one of the subsidiaries in order to achieve longterm profits for the group as a whole, possibly because this protects the image of the group. ${ }^{82}$ However, when a public authority invests at the same time similar amounts on equal terms with a private investor, there is the presumption that the authority is acting rationally to earn a reasonable return on its investment. This is the case even when the firm in which the authority invests has suffered losses. In this eventuality the public authority and the private co-investor should be investing on the basis of a plan that can turn the firm around and return it to longterm profitability. ${ }^{83}$

Since the test of the private investor is a comparison of the behaviour of a public authority and a hypothetical investor, the corroborative evidence that is accepted by the Commission consists of analyses, reports or declarations from independent banks, venture capital companies, consultants or other economic experts. ${ }^{84}$ It should be noted that the private investor concept as applied in state aid law is narrower than the likely actual behaviour of real investors. We know, for example, that market participants often act on far more than mere efficiency considerations. Often, as e.g. Macaulay has demonstrated, the non-contractual relations and factors influence business relationships to a great extent, regardless of the formal contracts and relationships that are in place. ${ }^{85}$ To what extent the market operator principle therefore actually reflects behavioural market rationality is questionable. This adds to the argument that the MEOP should not carelessly be applied but preceded by an analysis of the societal context that it is being applied to.

Moreover, there is no room for the more subtle elements of the relationship between the state and undertakings that receive advantages in judicial review and the application of the state aid rules. There are of course good reasons for a purely functional evaluation of such

81 Case T-228/99 WestLB v Commission [2003] ECR II-435.

82 E.g. Case C-303/88 Italian Republic v Commission [1991] ECR I-01433. A private investor that already owns shares in a company may tolerate short-term losses and behave differently than a new investor in order to protect his existing investment or in order to avoid paying any extra costs or incurring penalties from liquidating his shareholding in Case C-42/93 Spain v Commission [1994] ECR I-4175, paragraphs 13 and 14; Case C-323/00 P DSG Dradenauer Stahlgesellschaft v Commission [2002] ECR I-03919 para. 42.

83 Ibid.

84 Case T-228/99 WestLB v Commission [2003] ECR II-00435.

85 S. Macaulay, 'Non-Contractual Relations in Business: A Preliminary Study', 28(1963) American Sociological Review at 55. 
relationships since recognising or allowing trust and informal considerations to rule the relationship between the state and its debtors would simply be too amorphous for judicial review and raise problems for the application of the state aid rules. ${ }^{86}$ That is to say, trust and informality are just a step away from the granting of advantages for protectionist aims. On the other hand, a completely functional and under-socialised model of adjudication could threaten the social cohesions, solidarity or identity that a state perhaps pursues and applies in social situations. Hence, there is a potential loss to be considered there. It is generally understood that a social fabric where economic actors are repeatedly in contact with each other allows for the development and dissemination of trust to develop. ${ }^{87}$ This form of embeddedness, highlighted in the first chapter, concerns the role of concrete personal relations based on reciprocity in generating trust and discouraging opportunistic behavior. It has been shown that the quality and intensity of social relations may facilitate the strengthening of trust and discourage opportunistic behaviour. ${ }^{88}$ This responds to the functional idea that society can be identified on the basis of its individual interests and, merely seeing those individuals as freely contracting economic and social agents. A simple convergence of individual interests creates bonds that are too weak and superficial to give stability to social relations. ${ }^{89}$

The social relationships that the state can maintain on the basis of the MEOP are, however, individualistic, mechanistic and based, exclusively, on self-interest. The concept harbours a reductionist view of the variety of organisational principles that may govern certain social contexts. ${ }^{90}$ Social legitimacy is concerned with the social value that can be lost in the perception of state market relationships within purely functional terms. However, it

86 G. Davies, "Democracy and Legitimacy in the Shadow of Purposive Competence," European Law Journal $21(2015)$ at 2.

87 M. Granovetter, 'Economic Action and Social Structure: The Problem of Embeddedness', American Journal of Sociology (1985) at 481.

${ }^{88}$ M. Tulio F. Zanin and C. P. Migueles, 'Trust as an element of informal coordination and its relationship with organizational performance', EconomiA 14(2013) at 77.

89 See also E. Durkheim, The Division of Labor in Society. (New York: Free Press of Glencoe, 1964), at 152.: : "for where interest alone reigns, as nothing arises to check the egoism confronting one other, each self finds itself in relation to the other on a war footing".

90 It is in this sense a rationale very close to Adam Smiths dictum: "It is not from the benevolence of the butcher, the brewer, or the baker, that we expect our dinner, but from their regard to their own interest. We address ourselves, not to their humanity but to their self-love, and never talk to them of our own necessities but of their advantages" A. Smith, The Wealth of Nations (edited by R. H. Campbell and A. S. Skinner, The Glasgow edition of the Works and Correspondence of Adam Smith 1976), vol. 2b at 26. 
must also be clearly recognised that this is to some and perhaps a large extent a necessity since judicial or administrative review cannot be expected to integrate all social subtleties of these relationships. The tools available to adjudicate in state aid matters may simply lack sufficient refinement to take account fully of diverse kinds of valuation. ${ }^{91}$ It may follow that state aid in some cases ought to operate on the reductionist and functional assumptions of the prudent investor when it approaches certain contexts. Section IV shall further explore the possibilities and limits in this regard.

This discussion of the case law in the previous sections was not to suggest that the setting of airport charges, granting of radio licenses to operate or regulating the tradability of emission allowances is, necessarily, a typical public authority activity that should be allowed to exist outside of the scope of application of the MEOP but merely to point to the potentially expansive scope of the private investor rationale, which when combined with the idea that the State is under an obligation to actively pursue profit where it has control over an asset, becomes profoundly pervasive in some regulatory contexts. Mainly within many new regulatory and governance contexts, it becomes increasingly difficult to envisage an alternative rationale besides that of the prudent private market operator. As was discussed in this section, there is not a lot of margin of appreciation for the wider societal context once within the MEOP. One such alternative would, for example, be 'public spiritedness,' based on the desire to provide certain goods communally as part of the state. ${ }^{92}$ This is, obviously, an amorphous, fragile, difficult to quantify, form of social value. However, once organised on the basis of individualistic market incentives, it might be difficult to maintain such organisational forms. ${ }^{93}$

Therefore, if the limits between the market and legitimate regulation are not coherently drawn there is a risk of genuine norm conflict failure, which is to say that the market economy operator principle could be applied to govern or foreclose legitimate aims of a regulatory nature that are insufficiently captured or addressed in terms of a market economy operator test. This has some foreshadowing effects. For example, AG Wahl, in the Eventech

\footnotetext{
91 See more generally on this point C.R. Sunstein, "Incommensurability and Valuation in Law". Michigan Law Review 92(1994) at 779.

92 N. Boeger, "Solidarity and EC Competition Law," European Law Review 32(2007) p. 319-40.

93 Ibid.
} 
case (to be discussed further below in section III), pointed to the danger, that if the State aid rules were to be interpreted as generally requiring Member States to charge for access to public infrastructure or State-controlled resources, this might deter States from creating or opening up areas to which there has previously been no, or only limited access. ${ }^{94}$ Equally, it might deter undertakings from participating in that process since paying for the use public infrastructure might deter requesting access, which might result in access being given only to the economically most resourceful, and possibly defeating the legitimate purposes of a certain redistributive policy objective. ${ }^{95}$ In this way there is a clear risk that the rationale associated with the market operator principle crowds out other potentially legitimate objectives that are simply not considered relevant.

\section{The conditional pursuit of services of general interest on the basis of adversarial relationships}

Similar concerns can be voiced with respect to the efficiency rationale that governs the financing of services of general economic interest (SGEI). The Treaties, secondary legislation and the institutions attribute to the SGEI a central role in promoting social and territorial cohesion and as being part of the shared values of the Union. The Court of Justice approach to the idea of SGEIs is that they 'exhibit special characteristics as compared with those of other economic activities' ${ }^{96}$ Member States have a wide margin of discretion in defining a given service as an SGEI. The Commission's competence in this respect is therefore traditionally limited to checking whether the Member State has made a manifest error when defining the service as an SGEI and to assessing any State aid involved in the compensation. On what basis the Commission can question Member States definition of an SGEI has not yet been tested before the Court of Justice..$^{97}$ The Commission is of the opinion, and indicates as such

94 AG opinion Wahl in Case C-518/13 - Eventech [2014] nyp, paras. 30-33.

95 Ibid., para 30.

96 Cases C-179/90 Merci convenzionali porto di Genova [1991] ECR I-5889, para. 27; Case C-242/95 GT-Link A/S [1997] ECR I-4449, para. 53; and Case C-266/96, Corsica Ferries France SA [1998] ECR I-3949, para. 45.

97 The issue has been before the GC recently in case T-309/12 - Zweckverband Tierkörperbeseitigung $v$ Commission nyp and will be further discussed in section 4. 
in its Communication on the topic, that it is in any case 'not appropriate' "to attach specific public service obligations to an activity which is already provided or can be provided satisfactorily and under conditions, as defined by the State, by undertakings operating under normal market conditions". ${ }^{98}$ Again, as for the question of whether a service can be provided by the market, the Commission acknowledges that it is "limited to checking whether the Member State has made a manifest error". As such, with regard to the definition of SGEI, there is a similar dynamic, or operational rationale in place as has been identified in the previous chapters on competition and free movement. Meaning that there is a soft market primacy approach as towards State involvement in the market through the setting of policy objectives, which should first consider whether the objectives in question are pursued by the market and subsequently whether regulatory action should be pursued for the instances where the market does not achieve social welfare optimal outcomes. Regulatory action that deviates from this principle then has to fulfil procedural safeguards, for which the well-known Altmark case provides the central framework. ${ }^{99}$

The facts behind Altmark are widely known. In 1990 Altmark Trans (Altmark) obtained licences and subsidies for passenger transport by bus in the Landkreis (district) of Stendal. A competitor complained that Altmark Trans would not be economically viable but for the subsidies. The handling Court in Germany had concerns about the compatibility of the subsidies and accordingly referred the issue to the Court of Justice. The Court then used this case to set out the conditions under which the financing of public services would be immune from a state aid challenge. It formulated four conditions for state aid to be excluded. ${ }^{100}$

98 In the 2011 SGEI Communication the Commission considers it would not be appropriate to attach specific PSO to activities provided by undertakings operating under normal market conditions, cf. Communication on the application of the European Union State aid rules to compensation granted for the provision of services of general economic interest, OJ 2012 C 8/4, para 48. See T. Muller, "Efficiency control in State aid and the Power of Member States to define SGEIs", European State Aid Law Quarterly, 1(2009) at 8.

99 Case C-280/00 Altmark Trans GmbH and Regierungspräsidium Magdeburg v Nahverkehrsgesellschaft Altmark GmbH [2003] ECR I-7747.

100 Paras. 89 to 93: "the recipient undertaking must have public service obligations and the obligations must be clearly defined; the parameters for calculating the compensation must be objective, transparent and established in advance; the compensation cannot exceed what is necessary to cover all or part of the costs incurred in the discharge of the public service obligations, taking into account the relevant receipts and a reasonable profit; where the undertaking which is to discharge public service obligations is not chosen pursuant to a public procurement procedure which would allow for the selection of the tenderer capable of providing those services at the least cost to the community, the level of compensation needed must be 
The idea behind Altmark and the way that it has been mostly interpreted afterwards is that Member States retain their autonomy in designating certain activities as SGEIs, but are significantly constrained in the way that they structure them. Therefore, the assumption is that "it is possible to question the efficiency of SGEI providers without questioning SGEIs" "101. It has been argued that Altmark follows the Glöckner case law of the Court by holding that SGEIs should be delivered efficiently. ${ }^{102}$ The reasoning in this case was that a limitation of the competition law framework would not be accepted if it could be shown that the undertakings charged with the delivery of public service mission were in practice unable to satisfy the existing demand in relation to those services. The emphasis that the Court put in Altmark on the condition that SGEIs will have to be delivered 'at the least cost to the Community' and the role of efficiency in the selection of the SGEI provider is reminiscent of this rationale. ${ }^{103}$

It has been argued that the use of public procurement would threaten to "undermine some of the central values associated with the provision of public services, notably trust and the use of co-operative rather than conflictual, or adversary, relations". ${ }^{104}$ These concerns are related to the way that Member State's are now obliged to structure the provision of SGEIS and the concern would be that the possibilities for Member States within the given scheme are inherently limited to the detriment of genuine and legitimate policy structures. Moreover, the efficiency requirement for when an undertaking is not chosen pursuant to a public procurement procedure can be considered as strict and its evidentiary burden is usually not met, therefore conditioning Member States to use public procurement procedures. As said, the key characteristic of public procurement procedures is that they are based on adversarial relationships, which create a principal and agent relationship based on a competition for capital. ${ }^{105}$ That is to say, the parties to the contract are balancing between self-interest and

determined on the basis of an analysis of the costs of a typical well-run company".

101 See De Cecco above (no. 1) at 159.

102 Case C-475/99 - Ambulanz Glöckner [2001] ECR I-08089

103 See De Cecco above (no. 1) at 165.

104 T Prosser, 'Competition Law and Public Services: From single market to citizenship rights', 11(2005) European Public Law 543, at 562.

105 M. Regan, "Public infrastructure procurement: A comparative analysis of adversarial and non-adversarial contracting arrangements", (2012) Public infrastructure bulletin, at 3-4; J. Boston, "Basic NPM Ideas and their Development" in T. Christensen and P. Laegreid (eds.), The Ashgate Research Companion to New 
their obligations under the contract. Moreover, where the contractor unbundles services into separate contracts and subcontracts, the same adversial relations are recreated, compounding the self-interests involved and limiting opportunities for collaboration and trust to develop. ${ }^{106}$ Again, the policy framework of the Commission in this area is both impressive and pervasive. ${ }^{107}$ The Commission has taken the conditions that were set out by the Court literally and has tried to use that framework to push Member States in the structuring and financing of public missions. ${ }^{108}$ However, there are only very few Commission decisions, in which contracts have been established without the use of a public procurement procedure, in which the Commission came to the conclusion that the Altmark test was satisfied and it is obvious that the Commission conditions Member States to the use of the procurement procedure in the structuring of their SGEIs. ${ }^{109}$ The concerns in this area of the state aid regime are therefore similar to the concerns that were voiced with regard to the expedient nature of market based evaluative principles for the actions of Member States. That is to say, the state aid regime may implement a reductionist view of the variety of organisational principles that may govern certain social contexts. Social legitimacy is concerned with the social value that can be lost in the perception of state market relationships within purely functional terms. The next section shall explore to what extent the European courts have incorporated mechanisms of responsiveness in its case law.

Public Management, (Surrey Ashgate 2011); D. Osborne and T. Gaebler, "Reinventing government: how the entrepreneurial spirit is transforming the public sector", (New York Addison Wesley Publishing Company 1992).

106 Ibid.

107 J.L Buendía Sierra and P. Rivas, J. Manuel, "The Almunia Package: State Aid and Services of General Economic Interest" in E. Szyszcak and J.W. van de Gronden (eds.) Financing Services of General Economic Interest, (The Hague T.M.C. Asser Press 2013) at 125; T.M. Rusche, "The Almunia Package" in E. Szyszcak and J.W. van de Gronden (eds.) Financing Services of General Economic Interest, (The Hague T.M.C. Asser Press 2013) at 108.

108 M. Klasse, "The Impact of Altmark: The European Commission Case Law Responses" in E. Szyszcak and J.W. (eds.) in Financing Services of General Economic Interest, (The Hague T.M.C. Asser Press 2013) at 35.

109 Notable exceptions include "Commission, 16 December 2003, State aid N 475/2003 Security of Supply Ireland (CADA); Commission, 16 November 2004, State aid N 381/2004 Broadband Infrastructure Project Pyrénées-Atlantiques; Commission, 3 May 2005, State aid N 382/2004 Broadband infrastructure project Limousin (Dorsal); Commission, 30 September 2009, State aid N 331/2008 Broadband Hauts de Seine; Commission, 24 May 2007 Energy supply Slovenia OJ 2007 L 219/9; Commission, 15 September 2009, State aid N 206/2009 Financing of the public transport services in district of Anhalt-Bitterfeld; Commission, 15 September 2009, State aid N 207/2009, Financing of the transport services in district of Wittenberg”. 


\section{Responsiveness in the models of adjudication of the Court in state aid law}

\section{A. Introduction}

The first chapter developed the idea that the social purpose of the multilateral EU internal market is to develop institutional rationales with sufficient sophistication to allow for communal diversity and promote the objectives of market integration. It is clear that the scope for communal diversity/social context, within the terms of most of the market-derived standards as were discussed in the previous sections are limited. The valuation of societal context is mostly functional and the scope for unprofitable courses of action seems limited. The point here, from the view of the normative expectations that were developed in the first chapter, is the recognition of embedded social context within overarching governance rationales. Some communal contexts lend themselves easily to economic regulation. The 'instrumental community' context fits within a form of regulation based on an evaluative principle of efficiency. Problems may arise, however, when such economic substantive efficiency oriented governance mechanisms would be installed to regulate social context based on trust, informal values, public spiritedness and so forth. The balance from the perspective of state aid is therefore a difficult one since trust and informal relations are, perceived from a state aid perspective, important factors contributing to in-transparency and constitutive to relationships, which are likely to end up in granting covert advantages to some undertakings and not to others. ${ }^{110}$ The rigidity of the prudent private investor standard leaving aside all social, regional-policy and sectoral considerations ${ }^{111}$ is, at least partly, based on this idea of the need for administrability and transparency in state aid matters. On the other hand, there is an inherent reductionist view of the legitimate relationship between the state and the market at play. One that in its valuation of state action may exclude valuable social practices

\footnotetext{
110 This concern is reflected in the case law of the Court that identifies policy discretion for Member States in granting advantages or derogations from general applicable legislation as evidence for selectivity in cases: C-241/94 France v Commission [1996] I-04551, paras. 23 and 24; C-200/97 Ecotrade, [1998] ECR I-07907, para. 40; C-295/97 Piaggio [1999] ECR I-03735, para. 39; C-256/97 DM Transport [1999] I-03913, para. 27; and C-6/12 P,, np, para. 27.

111 Case C-234/84 Belgium v Commission (Meura) [1986] ECR 2263, para. 14 (emphasis added).
} 
that in all likelihood contributes to social cohesion and capital within member States. This is a potential effect of turning the market into the platform for accountability in state aid matters. ${ }^{112}$ The market based regulatory standards that state aid law introduces may condition public bodies towards actions that are justified exclusively on the grounds of their commercial self-interest and thereby crowd out potential alternative visions towards the appropriate role of public authorities and the direction that policy objectives take.

Consequently, it is likely that the state aid rules may further condition Member States towards the installation of a spectrum of a cost-benefit analysis, which may soon become the primary frame of reference for public authorities. Therefore, as was noted in the previous section, if the limits between the market and legitimate regulation are not coherently drawn there is a risk of genuine norm conflict failure, which is to say that the market economy operator principle is applied to govern or foreclose legitimate aims of a regulatory nature that are insufficiently captured or addressed in terms of that test. Moreover, there are clear instances where the EU state aid rules, as they are interpreted by the Commission, the GC and the Court neutralise potentially salient issues within a technocratic syntax that largely proceduralises the way Member State structure regulatory interventions in the market. There is a risk that thereby state aid rules systematically devalue or exclude possible alternative routes, which forego the development of social capital on a Member State level. ${ }^{113}$

The previous section has identified instances where the state aid rules impose norms on Member States which may exclude relevant social context from the state aid evaluation and force member State's to behave according to narrow market derived criteria that are one dimensional and under socialised. This section discusses the state aid case law of the Court with a view to trace instances where it has shown an explicit responsiveness to such context and allow for the potential of social norm diversity. The next section IV shall reconstruct that case law into a coherent model of social legitimacy that allows the Court to implement an 'operational rationale' whenever it has to adjudicate a conflict between the objectives of state

\footnotetext{
112 See on this also De Cecco above (no. 1) at 76.

113 Similar concerns voiced by M. Dani, "Rehabilitating Social Conflicts in European Public Law," European Law Journal 18, 5(2012).
} 
aid and restrictive domestic (social) interests that is in accordance with the dialogue of mutual responsiveness.

\section{B. Mutual responsiveness: between regulation and the market}

\section{i. The quest for a more comprehensive rationale for public authority}

It was highlighted before that that the Court has been quite explicit about the need to juxtapose cases involving Member States acting in their role as public regulators and cases where they act as market participants. Arguably, when the state acts as a regulator its actions cannot be held accountable on the basis of the behavioural standards as derived from the MEOP. For example, the Court held in Spain v Commission that "a distinction must be drawn between the obligations which the State must assume as owner of the share capital of a company and its obligations as a public authority". ${ }^{114}$ In Altmark, AG Léger noted that the Court applies the MEOP only in situations where the intervention of the State is of an economic nature. Where "the conduct of the State is capable of being adopted, at least in principle, by a private operator acting with a view to profit", it should apply. ${ }^{115}$

In these situations the conduct of the state should be evaluated on the basis of market derived standards for the reason that a private operator that is operating on the basis of selfinterest profit motives may have made similar decisions. However, the principle would not apply where the activity concerned falls within the exercise of public powers of the State, such as "tax policy or social policy". ${ }^{116}$ Similarly in Westdeutsche Landesbank Girozentrale and Land Nordrhein-Westfalen $v$ Commission, the GC noted that

"as regards the Land's argument based on increased tax revenue, the Court observes that the Land's position as a public body and its position as the owner of a business must not be

\footnotetext{
114 Joined Cases C-278/92 to C-280/92 Spain v Commission [1994] ECR I-4103, paragraph 22. See also Joined Cases T-129/95, T-2/96 and T-97/96 Neue Maxhütte Stahlwerke and Lech-Stahlwerke v Commission [1999] ECR II-17, para.119.

115 Opinion of AG Leger in Case C-280/00 Altmark Trans and Regierungspräsidium Magdeburg [2003] ECR I-7747

116 Case T-228/99 DEP - Westdeutsche Landesbank Girozentrale v Commission [2003] ECR II-00435
} 
confused. The line of argument based on an increase in tax revenue would be wholly irrelevant for a private investor". ${ }^{117}$ (emphases added)

In the previously discussed Ryannair case the GC annulled a Commission decision concerning aid granted by the Walloon regional government to Ryanair on the basis of an error of law resulting from the Commission's misinterpretation of the scope of the market operator principle, which consisted in holding that the setting of landing charges was not congruent to that principle. The GC focussed on the question whether or not the activity consisted in offering goods and services on a given market. The GC reasoned in line with the previously discussed case law that if the state acted as a private investor, the market operator principle should apply. The GC sanctioned the Commission for not clearly distinguishing between the state acting as a "public authority and the activities of a market participant". ${ }^{118}$ In a similar vein the GC annulled a Commission decision that had found certain measures implemented by France in favour of the state owned energy company EDF amounted to state aid. ${ }^{119}$ At the time, EDF was a public undertaking, wholly owned by the French State. In 1997, within the framework of the opening up of the internal market for electricity the French State amended its legislation. As part of this process, EDF's balance sheets were 'restructured' so as to increase its capital. After the restructuring operation the Commission adopted a decision finding that by virtue of this restructuring the French State had in effect waived a tax claim. The GC annulled the decision, holding that the Commission was not entitled, only because the measure taken was fiscal in nature, to refuse to examine whether the French State had acted as a "private investor in a market economy". ${ }^{120}$ In its reasoning, the GC maintained the distinction that it had traced in previous cases, between economic activities and activities connected with the exercise of public power. However, it added, the distinction could not be traced on the basis of just the legal form used by the state but should instead be based on the nature, aim and the rules to which the states activities were subject, and, crucially, of the

\footnotetext{
117 Case T-196/04 - Ryanair v Commission [2008] ECR II-03643

118 Ibid.

119 Case T-156/04 - EDF v Commission [2009] ECR II-04503; Case C-124/10 P European Commission v Électricité de France (EDF), nyr

${ }^{120}$ Case T-156/04 - EDF v Commission [2009] ECR II-04503 para. 233
} 
objectives that they pursued. ${ }^{121}$ The GC again underlined the need to determine whether the State pursued an 'economic objective' which might also be pursued by a private investor, in order to establish whether or not the MEOP would be applicable

"the measure must be examined not solely according to its form, but on the basis of its nature, its object and its objectives, which presupposes that all aspects of it are examined and that its context is taken into consideration". ${ }^{122}$ (emphases added)

The GC noted that, as the law in question sought to restructure EDFs accounts and to increase its capital, it did not have a fiscal nature, but was an accounting measure with fiscal consequences. In light of these considerations, the GC concluded that the measure at issue could not be regarded as the exercise of public powers, but had to be examined through the lens of the private investor test. However, this formal approach was in turn rejected by the Court. The Court held, instead, that, in a situation where a Member State is both a fiscal creditor of a public undertaking and its only shareholder

"The roles of the State as shareholder of an undertaking, on the one hand, and of the State acting as a public authority, on the other, must be distinguished. Consequently, for the private investor test to be applicable, it must be in its capacity as shareholder and not in its capacity as public authority, that the Member State concerned confers an economic advantage on an undertaking belonging to it". ${ }^{123}$ (emphases added)

In other words, the Court insists on an assessment that is dynamic and specifically concerned with the context in question. The Court specified that, if a Member State relies on the applicability of the private investor test, it must establish, unequivocally and on the basis of objective and verifiable evidence, that the measure implemented falls to be ascribed to the State acting as shareholder. ${ }^{124}$ The Commission argued that when the State imposes taxes in

121 Ibid., para. 234.

122 Ibid., para. 236.

123 Case C-124/10 P European Commission v Électricité de France (EDF), nyr, paras. 80-81.

124 Ibid., para. 82. EDF had an interest that the MEOP would be applied because it considered that the French state had good economic arguments for the forgoing of a tax claim it had on EDF and that a shareholder would have done the same thing in a similar situation. It therefore argued that the fact that the instrument used by the State (the waiving of a tax claim) is inaccessible to the private investor cannot mean that the MEOP must be rejected because it was still, in theory, possible to imagine a situation where a private operator would have the possibility to forego a tax claim, whilst being a shareholder. In that situation it would then be possible to determine how a private operator would act. Indeed, perhaps if acting in its own self-interest only, it could be argued that the French state would then forgo that claim since it would be of a direct benefit to the shareholder of EDF. In other words, EDF reasoned that instruments, which in themselves are not available to private investors, can still be compared to the behavioural principles of private operators. 
the exercise of its public authority it cannot be claimed that it does this in its capacity as a private investor and the same would apply to its corollary - the waiving of tax debts. This was also the argument of AG Mazak in this case

"Consequently, fiscal activities of the State - the imposition, collection, refund or remitting of taxes - are undoubtedly undertaken in the exercise of its public authority and cannot by definition be undertaken as a private investor." (emphases added) ${ }^{125}$

However, the Court decided that if the Member State concerned produces such evidence, it is for the Commission to carry out a global assessment, taking into account all evidence enabling it to determine whether the Member State took the measure in question in its capacity as shareholder or as a public authority. ${ }^{126}$ It is interesting that the Court mentions this global assessment. The Court also referred to this type of assessment in the context of free movement cases, where it established whether or not the pursuit of a regulatory objective was genuine, systematic and coherent with the overall regulatory context. ${ }^{127}$

Accordingly, the Court agreed with the GC in holding that the objective pursued by the French State could be taken into account for the purposes of determining whether the State had acted in its capacity as shareholder. It is important to note that the Court did not provide an explicit answer to the question whether in this specific case the Commission was wrong to decide that the actions of the French State could not be qualified as the prudent behaviour of a private shareholder. The Court only established the principle that the decision to apply or not to apply the MEOP should be subject to a preceding assessment that establishes whether the context and objectives of the measure in question were specific to those of a shareholder or public authority.

However, the Court did not provide guidance with regard to the question how to decide between the domains of the market and the regulator. The rationale that is confirmed by the Court indicates that economic activities that are inherent for the pursuit of "public

This case shows that the MEOP can in some instances be manipulated by Member States to escape from the application of the state aid rules for disingenuous reasons.

125 Opinion of AG Mazak in Case C-124/10 P European Commission v Électricité de France (EDF), nyp, para. 79.

126 Case C-124/10 P European Commission v Électricité de France (EDF), nyr, paras. 86.

127 See section III.C Chapter II. 
authority' objectives are not captured within the State aid rules. However, as said, this is a quite formalistic and limited approach towards the role of the state. The state is either exercising its 'public authority' or it is engaged in market activities. The Court of Justice has been hesitant to further the scope of this reasoning towards a more dynamic approach. In fact, the reasoning on distinguishing the roles of the State as shareholder of an undertaking and as a public authority has never been subjected to an explicit rationale. The highlighted case-bycase approach of the GC and the Court has identified activities that can be associated with the exercise of public authority such as issues of tax or social policy. At the same time, in the absence of an explicit rationale to distinguish the market from the non-market, the MEOP becomes potentially expedient, as was discussed in section II.

\section{ii. The individual aid measure in its wider context}

Although there is, clearly, a call for responsiveness in the case law discussed above, the fact that the actual test is often concerned with a single carved out activity makes it slightly problematic since the individual aid conferring action may very well on its own accord be perceived as market specific. For example, in Chronopost I, it concerned the transfer of a client base; in $P \& O$ European Ferries, the sale of ferry tickets; in Bundesverband deutscher Banken v Commission, the making available of assets; and, in Ryanair, the fixing of airport charges. ${ }^{128}$ Perceived as single activities these are all clearly economic, market specific actions. In particular, the GC made it clear in Ryanair that the airport charges were to be qualified as 'fees' and not as 'taxes' ${ }^{129}$ It is questionable whether this carving out is the right approach since the dissociation of a single activity from a perhaps broader socially relevant context may be unjustified and forego the true purpose of a single measure. The Court acknowledged this, for example, in FENIN, a competition law case concerning 102 and 106 TFEU, where it confirmed that state bodies running publicly

\footnotetext{
128 Joined cases C-83/01P C - 93/01P and C - 94/01P Chronopost and Others $v$ Ufex and Others [2003] I04777; C-442/03 P - P\&O European Ferries (Vizcaya) v Commission [2006] ECR I-04845; T-163/05 DEP Bundesverband deutscher Banken v Commission [2010] ECR II-00387; Case T-196/04 - Ryanair v Commission [2008] ECR II-03643

129 Case T-196/04 - Ryanair v Commission [2008] ECR II-03643
} 
financed hospitals in Spain did not act as undertakings for the specific moment they contracted with the commercial sector to buy medical equipment for use in the hospitals under their management. The GC held that the purchases in question could not be considered separately from the equipment's subsequent use in their hospitals

"the nature of the purchasing activity must therefore be determined according to whether or not the subsequent use of the purchased goods amounts to an economic activity". ${ }^{130}$

The Court concurred with the CFI and concluded that that there was

"no need to dissociate the activity of purchasing goods from the subsequent use to which they are put in order to determine the nature of that purchasing activity". ${ }^{131}$

This line of reasoning has been used by analogy in a specific state aid context. In the Leipzig Halle case the Court rejected the appeals brought by Mitteldeutsch and Flughafen Leipzig-Halle seeking the partial annulment of the GC's judgment concerning the financing of airport infrastructure. ${ }^{132}$ Leipzig had managed to broker a deal with DHL, which would transfer its main hub from Brussels to Leipzig in exchange for the exclusive use of a newly build runway. Moreover, the airport promised to complete the runway, ensure 24/7 operations of the hub and provide sufficient capacity to ensure DHL's operation for an undisclosed period of time. In addition, the airport had an obligation to compensate DHL for resulting losses and damages resulting from the move. After the start of operations this liability would become unlimited.

The court procedure focussed on the financing of the expansion of the airport infrastructure that was necessary to accommodate DHL. The Court considered whether the construction of the airport infrastructure should be qualified as an economic activity within the meaning of Article 107(1) TFEU. The appellants argued that the construction or extension of airport infrastructure should not have been considered as an economic activity in and of itself and its financing by means of public funds could not constitute State aid. The construction of such infrastructure would have to be placed within a broader political context

${ }^{130}$ Case T-319/99 - Fenin v Commission [2003] ECR II-00357

${ }^{131}$ Case C-205/03 P - FENIN v Commission [2006] ECR I-06295

${ }_{132}$ Case C-288/11 P - Mitteldeutsche Flughafen and Flughafen Leipzig-Halle v Commission, [2012] nyr; T443/08 - Freistaat Sachsen and Others v Commission [2011] II-01311 
of transport, economic and regional policy. Moreover, a private investor would never engage in the activity because there is no possibility of profitability (airport charges require authorisation from the airport authority and private investors have no influence over their amount and bear no relationship to investment costs). The Court, however, agreed with the Commission and the GC

"there is no cause to dissociate the activity of building or enlarging infrastructure, in the event, the southern runway from the subsequent use (...)". ${ }^{133}$ (emphases added)

The logical effect of this case is, a contrario, that infrastructure that is separable from the subsequent operation would according to the Court not fall within the scope of State aid rules. Moreover, infrastructure, which is inseparable and which subsequent use is not used commercially would be exempt as state aid since it would be subsumed under the noncommercial nature of the main activities. ${ }^{134}$ However, demonstrating the poverty of a rationale for what distinguishes economic from non-economic spheres, the Court in this regard, quite statically and formalistically, went back to pointing to the exercise of 'state authority' as the main non-commercial sphere and referred to security and police functions, fire-protection measures and public security measures, operating security measures, the German meteorological service and the air-traffic control service. ${ }^{135}$ Although the Court demonstrates in its case law that context is important and also requires distinctions between acts from state authorities made in the capacity as a market participant and public authority it has not developed a principle whereby to distinguish one from the other. The Court refers to the MEOP as a flexible concept that can be adopted as a fluid mentality within contexts where states have exclusive regulatory power but, conversely, state authority is not accompanied by the Court with any distinguishing criteria, based on for example motivations based on nonprofit or 'public spiritedness'. Instead, here the Court refers back to the traditionally perceived minimal state functions such as those that are mentioned above. However, one can further

\footnotetext{
133 T-443/08 - Freistaat Sachsen and Others v Commission [2011] II-01311 para 95.

134 Inter alia T. Wilson, "Infrastructure Financing and State Aid Post Leipzig-Halle", European State Aid Law Quarterly, 1/2014, pp. 24-27. For an application of the Leipzig-Halle principles in the case of sport infrastructure see R. Craven, "State Aid and Sports Stadiums: EU Sports Policy or Deference to Professional Football”, European Competition Law Review, (9)2014, 453-460.

135 T-443/08 - Freistaat Sachsen and Others v Commission [2011] II-01311, para 42.
} 
enrich this rationale by linking it to a line of case, which I submit can be coined as the Court's good governance model in state aid.

\section{iii. The connection to the wider regulatory context: a good governance model}

As was discussed before (section B.i above), the judgements of the Court have shown some overlap with the free movement rules in the development of evaluative principles to determine whether there is state aid or not. In its essence, the MEOP can be compared with the substantive efficiency model of the Court in free movement cases. The Court has also developed valuations based on a margin of discretion, with respect to the chosen policy objectives of a Member State, provided that the regulatory context follows requirements of good governance. As was highlighted before, in principle, if the state is acting as a 'legislator', the 'market rationality' principle is not followed but instead the Court adopts an evaluative standard that is based on an assessment whether regulation benefits a specific (group of) undertaking(s) or whether a measure involves a state resource. For example, the Court reasoned in the case Sloman Neptun that a partial non-application of German employment legislation to foreign crews of vessels flying the German flag did not constitute a grant of aid to the ship owners since

"the system at issue does not seek, through its object and general structure, to create an advantage which would constitute an additional burden for the State or the abovementioned bodies, but only to alter in favour of shipping undertakings the framework within which contractual relations are formed between those undertakings and their employees". ${ }^{136}$

Similarly, in the case Kirshammer-Hack, the Court concluded that the exclusion of small businesses from a legal regime requiring payment of compensation in the event of unfair dismissals did not amount to the grant of an aid to the businesses concerned, reasoning that it

"does not entail any direct or indirect transfer of State resources to those businesses but derives solely from the legislature's intention to provide a specific legislative framework for working relationships between employers and employees and to avoid

\footnotetext{
${ }^{136}$ Joined Cases C-72/91 and C-73/91 Sloman Neptun [1993] ECR I-887 para 21.
} 
imposing on those businesses financial constraints which might hinder their development". ${ }^{137}$

Regardless of the merits of these cases, ${ }^{138}$ these evaluations allow for normative choices of Member States with regard to their economy to exist outside of the technocratic evaluation of the State aid rules and be developed on the basis of internal political choices that embed economic activities. This reasoning is part of a line state aid cases where the Court has considered selective advantages as inherent features of general regulatory schemes. This reasoning was present, for example, in the PreussenElektra case ${ }^{139}$. In short the Court decided in that judgement that Member States may, without it constituting state aid, require private electricity suppliers to purchase electricity from renewable energy sources at minimum prices that are higher than the real economic value and, subsequently, "allocate the financial burden arising from that obligation amongst electricity supply undertakings and upstream private electricity network operators". ${ }^{140}$ The Court considered, in that judgment, "that even if the financial burden arising from the obligation to purchase at minimum prices was likely to have negative repercussions on the economic results of the undertakings subject to that obligation and entail a diminution in tax receipts for the state, that consequence was an inherent feature of such a legislative provision" (emphases added). ${ }^{141}$ This rationale of the Court can be interpreted as providing an area, which is reserved for the Member States, in their legislative roles, where they are not automatically subject to the behavioural standards of a prudent investor nor do they fall within the scope if the technocratic apolitical realm of state aid control.

The objection against applying such a rationale for state aid, in a context where a social objective, such as environmental protection, is pursued would be that this entails taking into account the aims and objectives of the policy of a Member State and as such inhibit the

\footnotetext{
137 Case C-189/91 Petra Kirsammer Hack [1993] ECR I-6185, para 17.

${ }^{138}$ Arguably in Sloman Neptun the Court overlooked the fact that Germany had made these changes in order to improve the competitiveness of their shipping industry. Such aims should fall within the state aid regime.

139 Case C-379/98 - PreussenElektra [2001] ECR I-02099

140 Ibid., para. 59.

141 Ibid., para. 62.
} 
effects based approach of the state aid rules. ${ }^{142}$ Indeed, as was discussed briefly before, consistent case law of the Court has clarified that aid is to be defined in relation to its effects. ${ }^{143}$ In theory this implies that the case law of the Court could never be truly responsive to regulatory intent. As such there are cases such as the Maribel bis/ter case, for instance, where the Court found that the increased reduction in social contributions for manual workers in certain industrial sectors, which were allegedly most affected by redundancies and restructuring, did constitute State aid. ${ }^{144}$ The arguments of the Belgian government, which maintained that the scheme was a general measure reflecting a choice of economic policy consisting in the decision to promote the creation of jobs in industrial sectors because they employ mostly manual workers who earn low wages owing to their minimal qualifications, was rejected.

"The social character of such State measures is not sufficient to exclude them outright from classification as aid for the purposes of Article [107] of the Treaty... Article [107](1) of the Treaty does not distinguish between measures of State intervention by reference to their causes or their aims but defines them in relation to their effects". ${ }^{45}$

It is settled case law that a measure, which has the effect of conferring a selective advantage on an undertaking or a sector, is not relieved of its quality as an aid merely because it was adopted for social purposes. This reasoning stands in a slight contract to the other approach, which allows selective outcomes provided that it is an inherent part of a more general and legitimate aim. However, the cases can be reconciled if viewed from a perspective of governance. For example, in the Maribel bis/ter case the increased reductions in the social contributions could not be justified in terms of the logic of the Belgian general

${ }^{142}$ As argued by for example Biondi, A. and Rubini, L., 'Aims, Effects and Justifications: EC State Aid Law and Its Impact on National Social Policies', in Dougan, M. and Spaventa, E. (eds), Social Welfare and EU Law (Hart Publishing, 2005), p. 89.

143 See the following cases: Case C-387/92 Banco Exterior de España [1994] ECR I-877, para 13; Case C241/94 France v Commission (Kimberly Clark) [1996] ECR I-4551, para 34; Case C-256/97 DMT [1999] ECR I-3913, para 19; Case C-251/97 France v Commission [1999] ECR I-6639, para 35; Case 56/93 Belgium v Commission (Gasunie) [1996] ECR I-723, para 79; Case C-75/97 Belgium v Commission (Maribel bis/ter) [1999] ECR I-3671, para 25; Case C-480/98 Spain v Commission (Magefesa) [2000] ECR I-8717, para 16; Case T-46/97 SIC v Commission [2000] ECR II-2125, para 83; Case C-5/01 Belgium v Commission (Cockerill) [2002] ECR I-11991, para 45; Case C-409/00 Spain v Commission [2003] ECR I1487, para 46; Case T-109/01 Fleuren Compost v Commission (Judgment of 14 January 2004), para 54. 16; Case 342/96 Spain v Commission [1999] ECR I-2459, para 23.

144 Case C-75/97 Belgium v Commission (Maribel bis/ter) [1999] ECR I-3671.

145 Ibid., para. 25 
system of social protection, and its underlying objectives of employment policy, but had rather the "sole direct effect of according an economic advantage to the recipient undertakings alone, relieving them from part of the social costs which they would normally have to bear". ${ }^{146}$ Therefore, the Court looked at the objectives of the Belgium scheme but concluded that the measure in question was not coherent since it derogated from, the general system of social protection. If a differential impact can be connected inherently and genuinely to the nature or general scheme of a reference system, a measure can be excluded as state aid. Within this rule of reason type approach, some consideration of the objectives is necessary since only by doing so is it possible to decide whether it is in line with the logic of the system.

Well known is the approach of the Court in the Aria-Wien Pipeline case. Here, the Court further developed this idea of responsiveness towards the general logic of regulatory schemes. At stake in this case was a law in Austria that granted a rebate on energy taxes to undertakings that were primarily active in the manufacturing of goods rather than in the provision of services. The Austrian government had argued that the energy tax and the rebate was not adopted as an isolated measure but was inherent to the overall "package of measures intended to consolidate the budget. That package, composed of general socially balanced measures affecting all socio-professional groups, [and therefore] should be considered as a whole ${ } 147$. The Court was willing to entertain this argument

"the only question to be determined is whether, under a particular statutory scheme, a State measure is such as to favour 'certain undertakings or the production of certain goods' within the meaning of Article [107](1) of the Treaty in comparison with other undertakings which are in a legal and factual situation that is comparable in the light of the objective pursued by the measure in question". ${ }^{148}$ (emphasis added)

However, the energy tax rebate for goods could not be justified on the basis of the nature or general scheme of the taxation system established under the legislative package that the Austrian authorities considered it an integral part of. It could not be established that such undertakings were more energy-intensive than those active in the provision of services, nor that the environmental objectives underlying the measure under review justified any

\footnotetext{
146 Ibid.

147 Case C-143/99, Aria-Wien Pipeline, [2001] ECR I-8365, para. 43.

148 Ibid., para. 41.
} 
differential treatment of undertakings producing goods. ${ }^{149}$ Moreover, the statement of reasons, which led to the enactment of the national legislation referred to the circumstance that the advantageous terms granted to undertakings manufacturing goods were intended "to preserve the competitiveness of the manufacturing sector". Therefore, the genuine intentions of the Austrian authorities to act in pursuit of environmental objectives were undermined. ${ }^{150}$

The Court did, however, confirm that objectives play a potentially crucial role and demonstrated responsiveness to potentially legitimate objectives pursued on a Member State level in its adjudicative reasoning. The gist of the evaluative test it applied is that the contested measures can be excluded as state aid, provided that they are pursued coherently and systematically and in alignment with regard to the general measures that are under review. The specific measures have to conform to the internal logic of the general system that it forms a part of. That means that a difference in tax rates would have to be justified in the light of the environmental purpose of the legislative package in question. As such, the fundamental criterion for establishing the selective character of a measure lies in the nature of a derogation from the system in which it is set and a measure constitutes a derogation where it does not apply to all the undertakings which, in view of the nature and the scheme of the system, are capable of benefiting from it.

On the basis of this reasoning, selectivity is determined through an 'objective-based analysis' of a regulatory context that needs to fulfil some requirements of good governance. That is to say, it needs to be internally and externally coherent and genuine. Meaning that the objective of a measure is essential to understanding the relevant system, or so called reference framework, on which the answer to the selectivity question is to be based. However, the Court has established that also the reference framework itself has to be set up in a way that it genuinely and systematically pursues legitimate objectives. This was at stake in the British Aggregates case. ${ }^{151}$

In British Aggregates, the United Kingdom had imposed a levy on so- called "virgin aggregates" extracted from nature, the so-called Aggregates Levy (“AGL”), whereas recycled

\footnotetext{
149 See also A. Bartosch, 'Is there a need for a rule of reason in European state aid law? Or how to arrive at a coherent concept of material selectivity', Common Market Law Review 47(2010) 729-752.

150 Case C-143/99, Aria-Wien Pipeline, [2001] ECR I-8365, para. 54.

151 C-487/06 P - British Aggregates v Commission [2008] ECR I-10515
} 
aggregates were exempted from this. The AGL had sustainable intentions. The U.K claimed that its background was concerned with the reduction and rationalisation of the extraction of minerals commonly used as aggregates. The tax exemption was meant to incentivise their replacement with recycled products or exempted virgin materials. The Commission held that the exemption of certain minerals did not constitute State aid, since the scope of the levy was justified by the logic and nature of the tax, i.e. the reference system. British Aggregates, an association of small independent quarrying companies in the United Kingdom that could not benefit from the exemption, brought an action seeking the annulment of the Commission decision. The GC roughly agreed with the reasoning of the Commission and added

\begin{abstract}
"An environmental levy is an autonomous fiscal measure which is characterised by its environmental objective and its specific tax base. It seeks to tax certain goods or services so that the environmental costs may be included in their price and/or so that recycled products are rendered more competitive and producers and consumers are oriented towards activities which better respect the environment. It is open to the Member States, which, in the current state of Community law, retain, in the absence of coordination in that field, their powers in relation to environmental policy, to introduce sectoral environmental levies in order to attain certain environmental objectives. In particular, the Member States are free, in balancing the various interests involved, to set their priorities as regards the protection of the environment and, as a result, to determine which goods or services they decide to subject to an environmental levy". ${ }^{152}$
\end{abstract}

The GC found that, in the absence of Community measures for harmonisation, the decision to introduce an environmental levy such as the AGL falls "within the power of the Member States to set their priorities in the environmental fields" (based on article 11 TFEU). The crucial point in this analysis was that the GC considered the AGL to constitute its own reference system. It was on this point that the Court, in appeal, disagreed and, in effect, determined that the selectivity analysis also involves an assessment as to how the Member State has drawn up the scope of a reference system. ${ }^{153}$ The Court found that the fact that the levy did not apply to all similar activities which have a comparable impact on the environment meant that the activities which are not subject to the levy necessarily benefitted from a selective advantage. ${ }^{154}$ As a whole it made the scope of the regulatory measures

152 T-210/02 RENV-DEP - British Aggregates v Commission [2006] ECR II-02789, para. 114

153 Also De Cecco above (no. 1) at 103.

154 Case T-210/02, British Aggregates v. Commission [2006] ECR II-2789 and Case T-233/04, Netherlands $v$. Commission, [2008] ECR II-591; Case C-487/06 P, British Aggregates v. Commission, [2008] ECR I-10505, 
inconsistent with the broader environmental objectives of the measure. This inconsistency was further established on the basis of the fact that the scope of the measures appeared, as in Austria Wien, to have been established on the basis of a desire to maintain the international competitiveness of certain sectors. ${ }^{155}$ Therefore, the Court did not reject the proposition of the GC that Member States are free to draw the scope of their fiscal measures in accordance with environmental objectives but it established that such regulatory measures would have to be consistent with the objectives that they pursue. ${ }^{156}$ The objectives of environmental protection could not be reconciled with the effects of the regulatory measures that excluded or included aggregates that were not considered on the basis of their environmental effects.

These inconsistencies in the logic and nature of the tax system strengthened the idea that the AGL in fact reflected a desire to exclude some sectors from the levy in order to protect their competitiveness. The faith of the AGL was then basically sealed on the basis of a UK regulatory impact assessment on the taxation of aggregates which stated that "some of the [exempted] materials form significant constituents of products that are traded internationally, whose [United Kingdom] producers would be put at a competitive disadvantage against importers and in export markets". ${ }^{157}$

Therefore, the Court appeared to set out some principles of good governance in its assessment of the reference system to the effect that Member States are required to minutely and transparently pursue objectives and they have to analyse those objectives according to their effects. The discussion of this case law illustrates that if a policy measure is consistent with, for example, general environmental objectives, based on a global approach that considers the regulatory system as a whole and scrutinises the treatment of comparable situations on the basis of the guiding principles that the regulatory systems itself sets out, the generality of the system is ensured and will fall outside of the realm of the State aid rules. ${ }^{158}$ It

para 186

155 Ibid., paragraph 88 .

156 Also De Cecco above (no. 1) at 89.

${ }^{157}$ Case T-210/02, British Aggregates v. Commission, [2006] ECR II-2789 and Case T-233/04, Netherlands $v$. Commission, [2008] ECR II-591; Case C-487/06 P, British Aggregates v. Commission, [2008] ECR I-10505, para. 186

158 See also B. Kurcz, D. Vallindas, 'Can general measures be...selective? Some thoughts on the interpretation of 
requires, however, the fulfilment of good governance principles in the exercise of those roles and a minute understanding from the Member States of their own regulatory systems as a whole.

The question then becomes which objectives the Member States can attach to their reference frameworks. Clearly, they must be contemporaneous and cannot be added with the benefit of hindsight. As such the Court held that

"a distinction must be made between, on the one hand, the objectives attributed to a particular tax regime, which are extrinsic to it, and, on the other hand, the mechanisms inherent in the tax system itself, which are necessary for the achievement of such objectives". ${ }^{159}$

Although the Court has consistently adjudicated on the basis of an effects based approach, it has also provided for a consideration of objectives, already at the stage of defining a measure as state aid. Some impermissible goals can of course be derived from the primary objectives of the State aid regime, such as, considerations related to improving the competitiveness of certain undertakings, industries, sectors or regions are from the very outset impermissible and will have to be notified and justified within one of the existing state aid programmes. In addition, objectives that are harmonised in a state aid context, and hence for which specific state aid programmes have been developed, should be part of the notification process as well.

Taking all of this into account, there is a structural area carved out for the Member States, in their legislative or regulatory roles, where there is responsiveness towards objectives pursued by Member States. In this way the 'call' for responsiveness of the Court with respect to the decision to apply or not to apply the MEOP can be subjected to a more dynamic rationale that evaluates a measure within its wider regulatory context and excludes it from the state aid rules if it forms a coherent and consistent part of a general and legitimate regulatory framework. Although it is not explicitly stated by the Court all the examples discussed in this section, where the Court has considered a measure to be an inherent part of a more general legislative framework regarded instances where the Member State concerned, in

a state aid definition' 45(2008) Common Market Law Review, p. 159-182

${ }^{159}$ Case C-487/06 P, British Aggregates v. Commission, [2008] ECR I-10505, para. 43. 
one way or another aims to "carr[y] out its task towards its population in the social, cultural and educational areas". ${ }^{160}$ It is for such measures and context that there exists a genuine irreconcilability between subjecting such legislation to a technocratic rationale of state aid control or allowing it to take shape as part of domestic political processes. Hence, cases such as RyanAir would be partly concerned with the question whether the taxing of the airport runway was connected to a wider regulatory framework or legislative context, which implemented, for example, some normative choices with regard to the protection of the environment and whether the measure in question could be perceived as genuine and coherent in light of those wider objectives.

\section{Mutual responsiveness in the application of the Altmark framework}

The problems that a strict application of Altmark can bring forth were illustrated in the BUPA case concerning health insurance in Ireland. ${ }^{161}$ Health insurance in Ireland was closed to competition between 1957 and 1996 and the Voluntary Health Insurance Board (VHI) was the only operator until a liberalisation process commenced between 1994 and 1996. The first competitor to VHI was London based BUPA, which entered the market on 1 January 1997 as VHI's main competitor. BUPA was significantly hampered in its competitive actions by the provisions that liberalised the sector, which provided for the establishment of a so-called risk equalisation system (RES). The RES is a mechanism that required a contribution to a general fund from insurers that had a risk profile below the average market risk profile. The general fund would then make a corresponding payment to insurers with a risk profile higher than the average. In practice the application of the RES would lead to funds being transferred from BUPA to the VHI. As incumbent the risk profile of VHI was significantly higher than any other provider. This system was notified as State aid to the Commission. The Commission made a decision not to raise objections to the establishment of the RES.

Rather creatively, the RES was considered as compensation for the obligations associated with a SGEI, namely obligations aimed at ensuring that all persons living in

\footnotetext{
${ }^{160}$ See, among others, Case C-318/05 Commission v Germany [2007] ECR I-6957, para. 68.

${ }^{161}$ Case T-289/03 - BUPA and Others $v$ Commission [2008] ECR II-00081
} 
Ireland would receive a minimum level of healthcare services at the same price, independently of their state of health, age or sex. BUPA appealed the decision of the Commission and based its appeal mainly on the non-fulfilment of the Altmark criteria. On first sight this seemed a strong case for the applicants. The PMI obligations were not assigned to the recipient undertaking; the parameters on the basis of which the compensation was to be calculated were not established in advance in an objective and transparent manner since the HIA had some latitude in determining the risk differential; the compensation was not based on the costs incurred in the discharge of the public service obligations; and the costs incurred by the VHI in complying with the PMI obligations were never compared to those which would have been incurred by the 'efficient operator'. ${ }^{162}$

However, the GC decided to apply the Altmark criteria in a flexible manner. It held, first, that the attribution of an SGEI mission may also consist in an obligation imposed on a large number of, or indeed on all, the operators active on the same market ${ }^{163}$ and that the discretion in calculating the RES payments would not in itself be incompatible with the existence of objective and transparent parameters within the meaning of the second Altmark condition.

"the Member State has a wide discretion not only when defining an SGEI mission but also when determining the compensation for the costs, which calls for an assessment of complex economic facts". ${ }^{164}$ (emphasis added)

With regard to the third Altmark condition, which requires that it be possible to determine the costs occasioned by the performance of an SGEI obligation, the Court considered

"that the quantification of the additional costs by means of a comparison between the actual risk profile of a PMI insurer and an average market risk profile in light of the amounts paid by all PMI insurers subject to the RES is consistent with the purpose and the spirit of the third Altmark condition in so far as the compensation is calculated on the basis of elements which are specific, clearly identifiable and capable of being controlled". ${ }^{165}$ (emphasis added)

\footnotetext{
162 Ibid., para. 123.

163 Ibid., para. 179.

164 Ibid., para. 214.

165 Ibid., para. 237.
} 
The judgment of the GC suggested that the Altmark criteria are to be applied more as guidelines than as strict criteria to be applied to the letter in each individual case. ${ }^{166}$ Consequently, the Altmark test could be modified and respond to accommodate regulatory idiosyncrasies such as the RES. Importantly, the efficiency requirement as laid down by the fourth Altmark condition would not apply if there was no danger that costs resulting from inefficiency would have to be paid for by those liable to finance the scheme in question. ${ }^{167}$ The BUPA judgment was welcomed as a demonstration that state aid law was capable of recognising social concerns mediated through national measures and as "a potentially significant step towards reworking the European model of competition to include elements of solidarity". ${ }^{168}$ This reading of the BUPA case was later explicitly confirmed by the GC in the Belgium hospitals case (CBI)

"It should be pointed out that, although the conditions stated in the Altmark judgment and in the SGEI package concern all sectors of the economy without distinction, their application must take into account the specific nature of the sector in question. [...] The General Court has held, inter alia, that, in the light of the particular nature of the SGEI mission in certain sectors, it was appropriate to show flexibility with regard to the application of the Altmark judgment, by referring to the spirit and the purpose of the conditions stated therein which prevailed when they were laid down, in a manner adapted to the particular facts of the present case". (emphases added) ${ }^{169}$

Similar to BUPA, the Court in Chronopost confirmed the implicit rationale at work in the former case.$^{170}$ Implicit in $B U P A$ is that it is not always possible, in light of regulatory particularities, to, for example, apply an efficient comparator test. This was confirmed in the Chronopost case which concerned the provision of logistical and commercial assistance by the French monopoly postal service La Poste to its subsidiary (Chronopost), which was operating on a competitive market for express delivery services. A competitor complained that these services provided the Chronopost subsidiary with an advantage. The Commission

\footnotetext{
166 A. Bartosch, 'The ruling in BUPA - clarification or modification of Altmark?, EStAL 2(2008) at 211. Also A. Biondi, 'BUPA v Commission' EStAL (2008) at 408.

167 Ibid.

168 M. Ross, "A healthy approach to Services of General Economic Interest? The BUPA Judgment in the CJEU of First instance", European Law Review, 34 (2009) at 127.

169 Case T-137/10 Belgium hospitals case (CBI) [2012] np, paras 85,86.

${ }^{170}$ Case C-341-342/06p La Poste v UFEX and Others [2008] ECR I-04777
} 
denied this and found that the services from La Poste were provided under normal business conditions. The GC partially annulled that decision because it found that the Commission should have verified whether the payments that were received by La Poste would be comparable to those demanded by a private undertaking that was not operating in a reserved sector. ${ }^{171}$ The Court disagreed with this finding and considered that since La Poste was entrusted with the provision of a universal postal service, it required substantial infrastructure and resources enabling it to provide that service to all users, including sparsely populated areas.

\begin{abstract}
"Because of the characteristics of the service which the La Poste network must be able to ensure, the creation and maintenance of that network are not in line with a purely commercial approach. [...] a network such as that available to SFMI-Chronopost is clearly not a market network. Therefore that network would never have been created by a private undertaking". (emphases added) ${ }^{172}$
\end{abstract}

The situation of La Poste was therefore not comparable with that of a private undertaking. Since the provision of logistical and commercial assistance was inseparably linked to the La Poste network it was necessary to determine the normal market price on the basis of available 'objective and verifiable' data without making a comparison with private operators. ${ }^{173}$ It is arguably this particular difficulty that has led the GC in BUPA to apply a more flexible approach and determine that the efficiency comparator requirement as laid down by the fourth Altmark condition would not apply if there was no danger that costs resulting from inefficiency would have to be paid for by those liable to finance the scheme in question. ${ }^{174}$ As in the $B U P A$ case the Court here acknowledged that the rationale behind the organisation of public services was incomparable with a private operator on the market.

However, no clear rationale has been developed to what extent and when 'the specific nature of the sector' would be able to force a more flexible response in the application of the Altmark criteria. On first sight, the effect of the BUPA judgement seems, therefore, to be

\footnotetext{
${ }^{171}$ Ibid., para. 116.

172 Ibid., para. 36

173 Ibid., paras 31-8

174 Also A. Bartosh, 'Clarification or Confusion - How to reconcile the ECJ's rulings in Altmark and Chronopost', European State Aid Law Quarterly 3(2003) at 12.
} 
limited to the regulatory idiosyncrasy of the regulatory conditions around the Irish health insurance system. Moreover, the Commission has continued to apply the Altmark criteria in increasingly strict fashion. ${ }^{175}$ On the basis of the 'Almunia-package' it has been able to steer Member States away from relying on the flexible approach that was discussed above. Importantly, recently, the GC seems to have validated a strict approach based on the Commission's market failure approach in the case Zweckverband, ${ }^{176}$ which concerned the financing of the disposal of dead animal carcasses and slaughterhouse waste, which is partly finance by Germany on the basis of annual contributions to the Zweckverband Tierkörperbeseititgung (ZT). The ZT is a public-law entity that was founded in 1979. All rural districts and larger urban districts in Rhineland-Palatinate and Saarland and two rural districts in Hessen had become members of the ZT. The ZT was authorised by its members to assume all the rights and obligations incumbent on rural districts and urban districts in their capacity as bodies responsible for the disposal of dead animal carcasses and slaughterhouse waste. The Commission considered that these services could not legitimately be considered as forming part to an SGEI mission. The question arose specifically in relation to the compensation that was provided for the obligation to retain spare operational capacity in case of an epidemic. The Commission considered that this was not fundamentally different from other economic activities. The GC agreed

\begin{abstract}
"Pour autant, le pouvoir de définition des SIEG par l'État membre n'est pas illimité et ne peut être exercé de manière arbitraire aux seules fins de faire échapper un secteur particulier à l'application des règles de concurrence [...]. Pour pouvoir être qualifié de SIEG, le service en cause doit revêtir un intérêt économique général qui présente des caractères spécifiques par rapport à celui que revêtent d'autres activités de la vie économique $[\ldots]]^{177}$
\end{abstract}

The GC held that the power of Member States to define SGEI is not unlimited and cannot be used arbitrarily in order to evade the application of competition rules. An SGEI exhibits 'special characteristics' in comparison to other economic activities. These special characteristics had to be demonstrated. Interestingly, the GC reasoned, agreeing with the

\footnotetext{
175 See Klasse above (no. 108).

${ }^{176}$ Case T-309/12 - Zweckverband [2014] ECR nyp, paras. 45 and 62.

177 Ibid., para. 106.
} 
Commission, that the polluter pays principle as developed under Article 19(2) TFEU applies in general to the disposal of animal by-products and, therefore, that it was primarily the responsibility of producers to see to the disposal of fallen stock and slaughterhouse waste and to bear the costs involved. That is to say that the disposal of dead animals and slaughterhouse waste was to be considered as an intrinsic part of the economic activities of farmers and slaughterhouses. Consequently, the financial burden of that disposal had to be borne by farmers and slaughterhouses as part of the normal economic activities and, hence, inhibited a qualification of these services as an SGEI.

"Il est évident que le risque de survenance d'une épizootie est inhérent à l'élevage d'animaux. En application du principe du pollueur-payeur, il est donc également manifeste que les coûts résultant du maintien d'une réserve de capacités en cas d'épizootie doivent être supportés par les éleveurs et les abattoirs". ${ }^{178}$

There are several interesting aspects to this decision of the GC. First, it allowed the approach of the Commission to test whether the aid addresses a market failure, i.e. whether the services offered by existing market operators are insufficient to meet the public general interest. This is clearly the way that the Commission would prefer to assess whether a Member State has committed a 'manifest error' to assess the qualification of an SGEI and the GC has endorsed it in this case. Second, the GC established that the formative potential of the internal market in the process of embedding economic activities. By insisting that the EU based polluter-pays principle is part of the 'normal operations of economic life' the GC held that this infrastructure of economic activity could no longer be regulated by a Member State on the basis of another organisational principle (such as that the state pays for the risks of an epidemic). Next, the GC confirmed its finding in BUPA that Member States have a wide discretion not only with respect to the definition of a public service mandate, but also in determining the compensation cost that was depending on an assessment of complex economic facts. However, this should then always be accompanied with procedural guarantees enabling the Commission to verify the existence of objective and transparent parameters and for this reason these parameters must be defined in a way that Member States do not misuse the concept of SGEI.

\footnotetext{
178 Ibid., para. 121
} 
“C'est d'ailleurs précisément parce que cette détermination n'est soumise qu'à un contrôle restreint des institutions que le deuxième critère de l'arrêt Altmark, point 21 supra, exige que les institutions soient en mesure de vérifier l'existence de paramètres objectifs et transparents, ces paramètres devant être précisés de façon à exclure tout recours abusif de l'État membre à la notion de SIEG". ${ }^{179}$

The GC also acknowledged the interpretation of the fourth Altmark condition in BUPA. The GC emphasized that the application of the Altmark criteria must be flexible and take into account sectoral specificities, in particular, the specificities of discharging public service obligations in individual sectors. The GC specified that this assessment involved establishing that the compensation for keeping the extra storage did not entail the possibility of offsetting any costs that might result from inefficient operations of ZT. Since the compensation payments were not sufficiently distinguishable from the normal operations of ZT, this could not be guaranteed. ${ }^{180}$

The judgment of the GC was appealed but has been withdrawn. It would have been interesting to see whether the Court would validate the few, quite fundamental, choices of the GC. It would certainly not be the first time that the Court overrules the GC in this area. ${ }^{181}$ In particular, accepting the rationale of market failure to define SGEI's, if validated, will definitely be received as a step towards tightening the grip on national choices concerning the organisation, regulation and financing of local public services. If that would become the rule it will have to be established that the given activity could not have been performed under 'normal market conditions' and Member States will have to scrutinize their compensatory mechanisms for public services in legal and economic detail. The important question is to what extent this is only a 'nuisance' or to what extent this leads to an actual impediment of legitimate and genuine public services. The Court appears to have built in fragments of responsiveness in its case law that aims to guarantee that this will not happen. However, as indicated before, the Commission pursues a very specific and pervasive agenda, which is

\footnotetext{
${ }^{179}$ Ibid., para. 148

${ }^{180}$ Ibid., para. 115.

181 As in the Chronopost and Brittish Aggregates cases.
} 
based on a strict application of the Altmark criteria and there is therefore a risk that the more subtle parts of the case law will be ignored in the agenda of the Commission. ${ }^{182}$

\section{A dialogue of mutual responsiveness: the interplay of principles of substantive efficiency, margins of discretion and good governance in State aid}

\section{A. Introduction}

The expedient nature of the MEOP and overly strict efficiency based proceduralisation threaten social diversity and the development of social objectives through 'normal politics' in various ways. If social objectives pursued by Member States would only be taken into consideration at a stage where justifications are assessed by the Commission, ${ }^{183}$ this could lead to instances of incommensurability based on the different contexts within which regulatory objectives on a Member State level are pursued. That is to say, regulatory objectives may pursue objectives or are by nature to be attributed to a particular sphere of accountability. On this basis it can be normatively inappropriate to have them evaluated within the procedural, technocratic State aid framework of the Commission or to enforce a market rationale on the way regulatory objectives are to be pursued. Similarly, an overly strict application of the Altmark framework will exclude legitimate regulatory objectives, which are unable or unsuitable to be 'procured' on the basis of adversial relationships. This is reflected in case law of the Court that concerns instances where the State does not intend to become involved in activities for remuneration "but carries out its task towards its population in the social, cultural and educational areas". ${ }^{184}$

\footnotetext{
${ }^{182}$ S. Rodrigues, 'The European Commission's Reform Strategy' in E. Szyszcak and J.W. van de Gronden (eds.) in Financing Services of General Economic Interest, (The Hague 2013, T.M.C. Asser Press); M. Krajewski, 'Providing Legal Clarity and Securing Policy Space for Public services through a legal framework for services of general economic interest: squaring the circle?', (2008) 14 European Public Law at 377.

183 As argued by Biondi and Rubini above (no. 3) at 89.

184 See, among others, Case C-318/05 Commission v Germany [2007] ECR I-6957, paragraph 68.
} 
The Court has demonstrated responsiveness in the application of the State aid rules by seeking to "disentangle commercial transactions entered into by Member States from the noncommercial and regulatory objectives that accompany them". ${ }^{185}$ The case law allows for what may be seen as the inherent justifications of measures that grant selective economic advantages but are part of general regulatory or legislative schemes, which are themselves incorporating legitimate objectives. This can be seen as an application of a rule of reason approach in the state aid rules. ${ }^{186}$ Legitimate and genuinely pursued 'reference frameworks' are able to pull individual measures that form an inherent part of such framework out of the realm of the state aid regime.

Taking a step back from the case law we can see that the framework of analysis that can be derived from the case law of the Court is from the perspective of a dialogue of mutual responsiveness, similar to the free movement rules. The Dassonville like reasoning of the Court in Steenkolenmijn captures a wide range of regulatory contexts. This is the staring point of a dialogue in which the regulatory choices of Member States have to be evaluated. The principle of substantive efficiency based on the MEOP should not be applied expediently but incorporate responsiveness to allow inefficient outcomes where genuine regulatory objectives are at stake. At the same time, allowing too much flexibility and granting wide margins of discretion in the definition of regulatory objectives may undermine the fundamental role of the state aid rules within the internal market to prevent protectionist measures and discriminatory regulatory choices. Hence, the dialogue of mutual responsiveness within the State aid rules should allow for genuine regulatory (as opposed to commercial or protectionist) objectives to be pursued transparently, in accordance with good governance principles. In this way a dialogue of mutual responsiveness can be established in accordance with the normative requirements of social legitimacy.

\section{B. The dialogue of mutual responsiveness in state aid}

\footnotetext{
185 De Cecco above (no. 1) at 88.

186 See also Bartosch above (no. 149) at 729.
} 
The issue at stake in the Eventech case, and especially the opinion of AG Wahl in that case, provides opportunity to further highlight the dialogue of mutual responsiveness in state aid. In the Eventech case the Court had to decide whether providing free access to public infrastructure to the exclusive benefit of taxi's constituted State aid. ${ }^{187}$ In London, both London taxis (the so called Black Cabs) and private hire vehicles (minicabs) are involved in carrying passengers for payment. However, only the Black Cabs are, on the basis of the regulatory framework, permitted to 'ply for hire' (that is, solicit or wait for passengers without any pre-booking). In contrast, minicabs can only pick up people who have prebooked their services. Moreover, and central to the case, Black Cabs are allowed to use the bus lanes, but the minicabs are prohibited from doing so, during the hours when bus lane restrictions are operational. Conversely, drivers of Black Cabs are subject to strict standards in relation to their vehicles, their fares and their knowledge of London, whereas those standards do not apply to minicabs. The State aid argument that was pursued in this case claimed to see a selective advantage that was granted for the exclusive use of bus lanes by the Black Cabs to the exclusion of others, whereas the non-payment of charges for access to that infrastructure would be considered as a revenue that is foregone. There is a clear analogy available on this point with respect to the legal assessment of the state aid situation in the previously discussed Dutch Nox case, where the Court established that when assets are put at the disposal of undertakings free of charge, whereas they could have been sold or put up for auction, State resources are indeed forgone. In his opinion on the matter AG Wahl was of a different opinion and considered that there are limits to the application of such market rationality in the presence of genuine regulatory objectives

\footnotetext{
"the State aid rules do not specifically require that Member States demand payment for access to such infrastructure, but leave it to their discretion whether or not to grant access free of charge. As an asset in the public domain intended to facilitate transport and mobility for endusers, such infrastructure by its very nature requires that rules be set for its use, including access to it - most evidently in relation to traffic control and maintaining order. That is a regulatory, rather than a commercial matter of the kind that does not justify the application of the rules on competition ... including those on State aid". ${ }^{188}$ (emphases added)
}

\footnotetext{
187 Case C-518/13 Eventech [2015] nyr.

188 Opinion of AG Wahl in Case C-518/13 - Eventech [2015] nyr, para. 29.
} 
The AG went on to specify how this distinction between regulation and commercial matters could be evaluated by the Court

"[...] when regulating access to infrastructure, the State must evidently act in a genuinely regulatory capacity. That includes regulating comparable situations in the same way so that competition is not distorted. Indeed, where infrastructure is made available to all users on an equal and non-discriminatory basis, that is an indication that no aid has been given to those users. By contrast, if, for example, the State generally requests payment for access to public infrastructure (such as a toll fee for using a public motorway) or other resources in the public domain, but grants various undertakings access free of charge on a discretionary basis, revenue may well be forgone in respect of those undertakings". ${ }^{189}$ (emphases added)

The reasoning of the AG shows some interesting analogies with the case law that was discussed in the free movement chapter, in the context of the good governance model. It was discussed there, for example, that a choice for a monopoly-based policy has to be embedded in a general policy that is aimed at a high level of consumer protection. Moreover, the choice for a monopoly-based system can only be genuine if the legislative framework that establishes a monopolist suitably (qualitatively) equips and limits the activities (quantitatively) of the monopolist in a way that genuinely reflects the chosen policy of a high level of consumer protection. ${ }^{190}$ This strand of case law of the Court makes clear that the fundamental choice for a system of protection affects the assessment of Member State policy along the consistency yardstick of the Court. The AG in Eventech suggests a similar rationale for State aid cases, which can be clearly placed in the context of a dialogue of mutual responsiveness.

Firstly, the AG established the limits of a market rationale by establishing that the requirement to pay for public infrastructure was not required in the context of the exercise of a genuinely regulatory objective, which was fundamentally not a commercial matter. The rules that determine access to public infrastructure were endowed with a certain margin of discretion. Secondly, the AG established an evaluation of that regulatory choice within a good governance evaluation, which would evaluate the broader coherence of the regulatory choice made by the Member State concerned.

The Court largely followed the AG's opinion. The Court first established that the bus lanes were not constructed for the benefit of any specific undertaking or any particular

\footnotetext{
189 Ibid., para. 32.

190 See further Chapter II section III.C.
} 
category of undertakings, such as Black cabs, or the supplier of bus services, and were not allocated to them but constructed as part of the London road network and primarily with a view to facilitating public transportation by bus. The Court held that where the state pursues the realisation of an objective laid down by legislation and grants a right of privileged access to public infrastructure, which is not operated commercially by the public authorities to users of that infrastructure, the State does not necessarily confer an economic advantage for the purposes of Article 107(1) TFEU. ${ }^{191}$ Moreover, and importantly the Court held with regard to the identification of the objective that it is

"in principle, a matter within the prerogative of the competent national public authorities alone and they must have a degree of discretion both as regards whether it is necessary, in order to achieve the regulatory objective pursued, to forgo possible revenue and also as regards how the appropriate criteria for the granting of the right, which must be determined in advance in a transparent and non-discriminatory manner, are to be identified". ${ }^{192}$ (emphases added)

The decisive consideration that seems to have inspired the Court towards taking this route was that the access to the public infrastructure is not operated 'commercially' by the public authorities but reflected, in the words of the AG, a genuine regulatory activity. In that circumstance the relevant question from a state aid perspective is not whether the state behaviour conforms to the rationality of an investor or a creditor but whether the regulatory action is asymmetric in its effects and thereby provides a selective economic advantage. To be clear, in that situation there is still the potential of a finding of state aid but the evaluative standard is congruent with a social context that is of a genuinely regulatory nature and focuses on the quality of the process that has led to the restriction. ${ }^{193}$

191 Case C-518/13 - Eventech nyp, para. 48

192 Ibid., para 49.

193 As a side note: One of the implications of these findings is that there is in fact, as Davies has argued before, a very limited role for Article 106(2) TFEU. Article 106(2) TFEU states that SGEIs are only subject to the internal market rules in so far as this does not obstruct the performance, of the SGEI objectives. However, as was established before, a similar rationale basically applies to all genuine regulatory objectives on the basis of the case law of the Court. It is therefore, indeed, questionable if 106(2) TFEU reflects more than a pure value statement. See G. Davies, "What does Article 86 actually do?” in M. Krajewski, U. Neergaard \& J. van de Gronden (eds.), The Changing Legal Framework for Services of General Interest in Europe (The Hague Asser Press 2009) at 51-69). 


\section{The required mutuality of the dialogue}

The mutuality of the dialogue started in state aid law is perhaps most clearly illustrated in the evaluation of the regulatory context of SGEIs. There the GC has demonstrated a willingness to be responsive and established that Member States have a wide discretion not only with respect to the definition of a public service mandate, but also in determining the compensation cost that was depending on an assessment of complex economic facts. However, this freedom is to be accompanied with procedural guarantees enabling the Commission to verify the existence of objective and transparent parameters that allow a review by the European Commission. Therefore, in the area of defining and the financing of SGEIs the model of the Court seems to be based on techniques to assess the coherence and transparency of the regulatory frameworks and measures for the purpose to determine whether they genuinely reflect the intentions of the state. ${ }^{194}$ In the previously discussed Zweckverband case the GC held that the power of Member States to define SGEI is not unlimited and cannot be used arbitrarily in order to evade the application of competition rules. An SGEI exhibits 'special characteristics' that are not addressed by the market alone. These special characteristics have to be demonstrated and the regulatory framework has to be responsive and be specifically tuned to such objectives in order to benefit from the safe harbour created in Altmark. As such and as discussed before, it is clear that this is, more generally, one of the main objectives of the state aid rules; the elimination of any possibility of manipulation of state resources to the benefit of selective undertakings. As noted by Damjanovic, this "quasilegislative approach" establishes concrete criteria as to how the Member States' financing system must be organized but they do not oblige Member States to abolish specific State interventions. ${ }^{195}$ The criteria that require the welfare services to be provided efficiently require them to be financed in a fair and transparent manner but do not interfere in a substantive way with the Member States' competences. ${ }^{196}$

\footnotetext{
194 Also J. Baquero Cruz, 'Services of General Interest and EC Law' in G. de Búrca (ed.), EU Law and the Welfare State - In Search of Solidarity, (Oxford University Press 2005) at 16.

195 D. Damjanovic, "The EU Market Rules as Social Market Rules: Why the EU Can Be a Social Market Economy," Common Market Law Review 50, no. 6 (2013) at 1708.

196 Ibid.
} 
Although some of the evaluative principles of the Court carry the risk of reducing the role of the state to a prudent private investor and demonstrate a tendency to be applied expediently, the case law of the Court can be clearly interpreted as adopting mechanisms to be responsive to specific Member State context and diversity. The expedient nature of the reasoning of the Court in cases like Ryanair, discussed above, where the Court reasons that the fixing of airport fares could also be done by a private operator and, therefore, should be done in accordance with MEOP is only expedient within a regulatory context that does not pursue regulatory objectives other than financial gain. A margin of discretion is provided to Member States for allowing them to define tasks towards its population in the social, cultural and educational areas, in terms of genuine regulatory activities, provided that these can be considered legitimate in light of the broader EU value system. Advantages that flow forth from such regulatory interventions must either be in accordance with the MEOP or form an integral and inherent part with the general objectives of the regulatory intervention in order not to be qualified as state aid. Regulatory idiosyncrasies and genuine regulatory objectives are not disregarded, provided Member State understand their own regulatory intentions clearly and take an overarching coherent approach in similar regulatory affairs.

Confusion about the application of evaluative principles on social context arises mostly on the basis of ill designed regulatory frameworks or opaque state actions such as in $E D F$. So, for example, in Kimberly Clark the Court held that the contributions of the Fonds national de l'emploi (National Employment Fund) (FNE) in the implementation of social plans was liable to place certain undertakings in a more favourable situation than others, since the FNE enjoyed a degree of latitude which enabled it to adjust its intervention in accordance with a number of in-transparent considerations. As Advocate General Jacobs pointed out in that case, the discretion and degree of discretion enjoyed by the FNE in the administration of the aid scheme meant that the FNE contributions were not necessarily available to all undertakings on an equal footing. ${ }^{197}$ Therefore, as was discussed in the previous chapters visà-vis the competition and free movement rules, problems with the state aid regime often arise due to ill designed regulatory frameworks within the Member States. As the previous discussion shows, the Court has established some clear principles with respect to how state

197 Opinion of AG Jacobs in C-241/94 Kimberly Clark [1996 ] ECR I-4551 
aid law perceives the relationship between market and nonmarket concerns on the basis of an idea of mutual responsiveness.

The idea of social legitimacy is therefore clearly present within the adjudicative rationales developed by the Court. The substantive reach of the internal market is reflected in the market derived standards such as the MEOP, which requires the adoption of an evaluative framework that allows for a diversity (a margin of discretion) and plurality of legitimate possibly inefficient substantive outcomes, provided that they are pursued in a transparent, coherent and systematic fashion. Underlying this 'switch' between evaluative frameworks within the state aid rules is the idea of a 'genuine regulatory activity', which is not based on a formalistic idea of traditional state powers but can be shaped in a dynamic fashion by Member States in their fulfilment of tasks towards its population in the social, cultural and educational areas along the yardstick of good governance.

\section{Conclusion}

Similar to the other areas of internal market law, the previous sections demonstrate that the state aid rules are governed by an intermixed application of the principles of substantive efficiency, margins of discretion and procedural unity on the basis of good governance principles. A principle of substantive efficiency is applied on the basis of the MEOP, as a market derived principle that determines in substantive terms how a Member State should act in certain contexts at the least costs to the Community. A similar idea stands behind the proceduralisation based on efficiency of the financing of SGEIs in the Union. ${ }^{198}$ In the application of this principle the Court has articulated clearly that the context has to be established prior to the application of an evaluative principle. Is it a context where the state acts in its capacity as market participant or in its capacity as provider of public tasks towards its population? On this basis the dialogue with the Member States is started.

However, to determine this question the Court has not provided a very clear rationale. The case law suggests that selective advantages that are considered as an inherent part of

198 E. Gromnicka, 'Services of General Economic Interest in the State Aid Regime: Proceduralisation of Political Choices?', European Public Law, 11 (2005) at 429. 
broader legitimate and genuine regulatory objectives will be excused from the application of the state aid rules. Therefore, margins of discretion are provided to Member States in the definition of regulatory objectives, provided that they are not of a protectionist/discriminatory nature or harmonised at the EU level. Such margins of discretion are combined with requirements of good governance. Selective advantages can only be excused if they are an inherent part of broader regulatory objectives. They have to conform to the broader inherent logic of the reference system, which in itself has to be consistent and coherent in terms of its effects and broader regulatory framework. Moreover, procedural unity on the basis of principles of good governance is clearly advanced in the way Member States are required to set up systems of financing of SGEIs.

The discussion of the state aid regime in this chapter has demonstrated that the area for genuine normative conflicts between the objective of undistorted competition and selective aid measures is limited. In comparison with competition and free movement, the state aid rules clearly have more structural positive integration effects. ${ }^{199}$ Especially with respect to the way national regulatory affairs have to be structured or financed in order to remain within national spheres of accountability and the subjecting of previously unregulated areas of national concern to a common regulatory process. ${ }^{200}$ Furthermore, the high degree of proceduralisation of state aid matters have made it a domain of technocracy, highly tuned towards installing common principles and means of evaluation that Member States themselves have to incorporate in the way regulatory and tax schemes are developed. In terms of the internal market's social purpose, the method that is adopted by the Commission is to, as far as possible, install principles within Member States that unify the means of how regulatory objectives take shape. This implies a reduction of potential conflicts between social norms by unifying the means by which such norms take shape. It is therefore important, in view of retaining social diversity that Member States realise where there exists regulatory space for the formation of genuine regulatory objectives.

\footnotetext{
199 Biondi, A. and M. Farley, 'The relationship between state aid and the single market', in Szyszcak, E. (ed), Research Handbook on State Aid (Cheltenham, Edward Elgar, 2011) 277-92

200 See also De Cecco above (no.1) at 80.
} 
The chapter discussed how market derived standards may be potentially expedient and used to evaluate regulatory choices within a metric that risks doing violence to potentially genuine and worthwhile aspects of those objectives. At the same time, the wave of new public management, which installed efficiency principles within Member States' regulatory affairs has made it more difficult to conceptualise alternative forms of governance outside of the spectrum of cost-benefit analysis. Nevertheless, EU internal market law is not committed to these principles and should allow for the possibility of social diversity. Thus, the social legitimacy of the state aid rules depends on the extent and level of sophistication adopted in legal reasoning that identifies instances of irreconcilability before adopting evaluative principles that are congruent to the conflict that is being adjudicated.

There is a line of case law from the Court that insists that the definition of state aid is an objective exercise and has determined that a measure may not escape the prohibition of state aid on the basis of policy considerations since these come into play once the question as to the existence of a state aid is answered. It would then be for the Commission to evaluate a state measure in light of the policy that it pursues as part of the justifications for state aid. Within this view there is no room for a rule of reason and it would potentially involve questioning as AG Jacobs put it "the entire social and economic life of a member state". ${ }^{201}$ It is against this background that the inherent justification test, in light of the general objectives of a regulatory scheme or tax can be understood. These are spaces where the Court has attempted to allow for social diversity based on national regulatory autonomy, which is highlighted in the emphasis the Court has placed on distinguishing cases involving state participation in the market and those concerning regulation. In the process of defining a regulatory measure as state aid the Court has shown a responsiveness to explore the limits of the internal market and developed guiding principles for member States to pursue regulatory objectives which provide selective aid, outside of the realm of the state aid regime. The Court has provided the means for Member States to develop a sort of 'acoustic separation' between the domains of the market and other spheres, thereby allowing the development of different kinds of valuation.

201 AG Jacobs in case C-52-54/97 [1998] ECR I-02629 para. 16. 
Chapter IV - The social legitimacy of EU state aid law

The chapter has developed the argument that if the limits between the market and legitimate regulation are not coherently drawn there is a risk of genuine norm conflict failure, which is to say that the market economy operator principle is applied to govern or foreclose legitimate aims of a regulatory nature that are insufficiently captured or addressed in terms of a market economy operator test. However, it is up to the Member States to create this space themselves. The pursuit of national policy objectives does not necessarily result in a negative outcome from the point of view of state aid, even where the public authority is unable to satisfy the market operator test. Indeed, there is a distinct regulatory space for the genuine pursuit of objectives, provided Member States incorporate clear and transparent objectives that can justify any selective advantages that flow from them.

$* * * * *$ 
Chapter IV - The social legitimacy of EU state aid law 


\section{CHAPTER V}

\section{Conclusion: social legitimacy in the internal market on the basis of the dialogue of mutual responsiveness}

\section{The argument as a whole: normative claims and results}

Social legitimacy encapsulates the normative concerns based on the work of Karl Polanyi. Most importantly, from this perspective, a project that promotes market integration amongst a diversity of social systems and more specifically diversity in "social acquis" can only endure, with political support, in the presence of a constructive interplay between market and non-market objectives. In order to be sustained in the long run, a trade regime such as the internal market within the European Union depends on the structural institutional design and rationales that embed the normative orientations of societies within those regimes and vice versa. What is required, and provided in this thesis, is a language that accommodates social conflicts within internal market law. Thus understood, social legitimacy can be traced back to the original compromise of embedded liberalism, which stands at the basis of the internal market infrastructure of the European Union. This outlook has been adopted to approach adjudication in the main pillars of the internal market.

The first chapter developed this normative outlook by studying the work of Karl Polanyi and it was argued that his historical analysis of the societal effects of market dominance is relevant today, primarily due to his conclusions on the social necessity of a constructive and reciprocal relationship between global market integration and the remaining locality of the social. The risk of market-dominated integration is that marketbased rationales will forcefully reconstruct embedded forms of market-society-state relationships and thus crowd out existing and alternative legitimate social orientations within Member States. Based on the historical insights of Polanyi, the idea of social legitimacy becomes imperative for a political sustainable project that seeks supranational 
market integration. This has been translated into a normative claim concerning how transnational regimes respond to conflicts between interests of a social nature and trade objectives.

The substantive chapters have adopted this Polanyian perspective and looked critically at the adjudicative rationales that govern the internal market. The normative outlook based on social legitimacy is shared in the basic set up of all of the internal market laws. That is to say, the basic embedded liberalism compromise resonates in all areas of internal market law, which primary law set up share the idea that the benefits of a joint commitment to free trade objectives can only be achieved in a sustainable way if combined with a recognition of national public values and societal objectives within those frameworks. However, the studies in the foregoing chapters have all illustrated how, despite this balance, the Court often struggles to adjudicate on the basis of a rationale that can be coherently applied to the question: 'how can the objectives of internal market integration and a commitment to social diversity both be pursued without one necessarily trumping the other?' Indeed, the balance between the requirements from the EU internal market for Member States regulatory choices, whilst at the same time respecting the 'fundamental structures' that exist in the Member States, through a recognition of a diversity of regulatory orientations, is one of the structural challenges faced by the internal market project.

I have submitted that within the context of the internal market this question is best addressed with the idea of mutual responsiveness, which I consider and discuss in Chapter I to be a necessary but underdeveloped element of the constitutional form and the social purpose of the internal market, as envisaged within the EU legitimising theory of transnational effects. In this view, the social purpose of the internal market is not to condition choices that necessarily require the market to trump the social sphere or its opposite, to allow the social to trump the market. The approach suggested on the basis of mutual responsiveness pursues a more holistic approach that conceives the market and the social sphere, quite literally, as 'communicating vessels'. Hence, this 'dialogue of mutual responsiveness' is based on the idea that internal market law is foremost a means to start a conversation with Member States on the normative choices of restrictive laws and regulatory schemes, which requires on one side a responsiveness within the 
application of internal market law to the social context within Member States and, on the other side, a clear understanding and articulation of restrictive objectives that are pursued on a Member State level. The expressive function of internal market law is to unveil these normative conflicts in order to illuminate what is at stake. Questioning and demanding articulation of restrictive regulatory choices within legal frameworks may be an excellent starting point for a dialogue that aims to increase the distinct articulation of regulatory objectives and thereby assists in the identification of embedding organizational principles on the Member State level. The 'dialogue of mutual responsiveness' is therefore based on the idea that internal market law is a means to start an illuminating conversation with Member States on the normative choices of restrictive laws and regulatory choices, which requires on one side a responsiveness within the application of internal market law and, on the other side, a clear understanding and articulation of restrictive objectives that are pursued on a Member State level. That is to say, how responsiveness can be integrated within the legal framework of the internal market and what the proxies and requirements are for the articulation of restrictive regulatory choices.

Thus, it has been argued that market derived evaluative standards may serve as a tool to tease out discriminatory, disingenuous (protectionist) regulatory choices within Member States but always allow for genuine social objectives to exist in accordance with good governance principles. The rationale adopted to evaluate and resolve conflicts should be instructed by a preliminary stage, which frames the conflict at issue in a way that allows the identification of a clash of normative principles, such as between solidarity and the market. First and foremost, this requires clarity in the framing of potential incommensurable conflicts between principles of organization in order to instruct the selection of the appropriate adjudicative standard of evaluation. In this way the normative claims of social legitimacy can be accommodated within the internal market, without dismissing the objective of market integration. In this process, a dialogue of mutual responsiveness will establish the substantive scope and reach of the internal market; to what extent the internal market can substantively accommodate social interests, and when objectives become inherently irreconcilable and the dialogue should adapt towards one of procedural unity. Therefore, the struggle that the Court faces in determining this balance should be cherished as a potential source of deliberative and 
formative potential for both the EU internal market and the Member States. Hence, the term 'dialogue' is purposefully chosen because on the basis of mutual responsiveness, the European adjudicators are able to speak to a range of social interests and actors with the help of a coherent model of adjudication. In this way the social legitimacy of judgements of the Court may be improved because the Court will be able to be quite explicit with regard to the normative demands of the internal market.

I have submitted that in the context of adjudication the normative claims of social legitimacy boil down to the issue of valuation in law and the related problems of indeterminacy and incommensurability. Evaluative standards, adopted in adjudicative contexts, may value social realities within a metric that risks doing violence to potentially genuine and worthwhile aspects of objectives that are pursued on a Member State level and, foremost, determinacy in the framing of the economic and social purpose and potential incommensurable conflicts between potentially conflicting aims is needed in order to instruct adjudication. The substantive chapters illustrate that it is specifically the lack of this clarity - indeterminacy - that may undermine social legitimacy within the EU internal market. The Member States have an important role in improving this clarity by regulation and organising their affairs in accordance with principles of good governance.

From a comparative perspective the social legitimacy issues across the free movement, competition and state aid rules share some striking commonalities. Firstly, the means of valuation that are implicit within the adjudicative rationales applied by the Court (and GC) are similar even though they take place with regard to different techniques of adjudication (e.g. proportionality versus categorisation) or with regard to different legal categories (e.g. undertaking versus public authority). A shared principle of substantive efficiency is pursued on the basis of evaluations that consider the least restrictive (free movement), most efficient (competition) or most profitable (state aid) course of action. The focus in this stage is on substance since the evaluative principle is prescriptive with regard to the chosen course of action on the basis of substantive outcomes. The studies have found shared problems in the way that evaluative standards based on substantive efficiency can value societal realities within a metric that risks doing violence to potentially genuine and worthwhile aspects of social objectives that are pursued on a Member State level. For example, it was found that an evaluative 
adjudicative method such as strict proportionality applied in free movement adjudication seeks the more efficient or less restrictive state measure, thus potentially excluding a relevant and genuine political compromise. The efficiency based exemption criteria in competition law may value competition restrictive sustainability initiatives in terms of the willingness of consumers to pay for a price increase, thus potentially excluding the inherent value of a sustainable environment. The market based evaluative standards in state aid law may nudge public bodies towards actions that are justified exclusively on the grounds of their commercial self-interest, thus potentially crowding out potential alternative visions regarding the appropriate role of public authorities and the direction that certain policy objectives take. As such, problems of social legitimacy across the different fields of internal market law arise with respect to the unchecked application of the principle of substantive efficiency. It was argued that this is not in alignment with the current values and objectives structure of the EU that points towards the importance of institutionalising diversity.

We should recall at this point that the argument from transnational effects conceptualises the intentions of the EU internal market not necessarily as 'pro trade' but as a means to engage in a dialogue with Member States on how their national systems can and need to be adjusted in order to accommodate the out of nation interests that are to be made part of national processes of governing or governance structures. Somek identified a risk in the terms of the dialogue from transnational effects by highlighting that "[a]nchoring the mitigation of transnational effects in the facilitation of market access modifies the focus of the argument". ${ }^{1}$ Indeed, the focussing on the unchecked and expedient use of the principle of substantive efficiency validates Somek's pressing question: "what might be done to prevent the argument from transnational effects from slipping into a freewheeling rampage of economic due process"? ${ }^{2}$

The analyses of case law amongst al the internal market law fields has unveiled a fragmented answer to this question. The Court has in different ways found means to value divergent social context by developing different rationales of valuation, going

\footnotetext{
${ }^{1}$ A. Somek, "The argument from transnational effects I: Representing outsiders through freedom of movement", 16 European Law Jorunal (2010), at 344.

${ }^{2}$ Ibid., at 332.
} 
beyond a mere purposeful utilitarian standard. On the basis of a principle of margins of discretion, areas that are considered sensitive or important for Member States are, within all areas of the internal market, provided with a certain space where Member States can determine regulatory objectives and ways to get there without infringing the internal market rules. This is completed with the principle of procedural good governance through which the Court has provided yardsticks that require integration restrictive interests to be pursued on the basis of transparency, consistency and coherence. Good governance' focus is on procedure and the coherence of the broader regulatory context, rather than on the rationality, efficiency or profitability of the outcome. As such, regulatory choices for a monopoly system in the gambling market, which completely forecloses access to the market, is allowed provided that the wider public law infrastructure is coherently tuned towards a high level of consumer protection. Private initiatives that restrict competition in the pursuit of a social objective are allowed, provided that the regulatory context sufficiently enables private actors and ensures affirmative political oversight. Selective advantages for undertakings that flow from a broader more general regulatory framework are allowed, provided that they are inherent, in accordance with the logic of a reference system, and, again, genuinely pursued by Member States. Looking through the normative-prescriptive lens of social legitimacy at internal market adjudication in free movement, competition and state aid thus reveals that the Court has constructed and applied, albeit incoherently, a mixture of these three evaluative principles to adjudicate internal market conflicts. Therefore, although the chapters have highlighted that there are differences and nuances in the way that social legitimacy problems and solutions arise within the different areas of the internal market, it has also been submitted that they can all be connected on the basis of an interplay of the principles of substantive efficiency, margins of discretion and procedural good governance.

In reconstructing this case law the argument has submitted that the key to social legitimacy, and concomitantly to Somek's question, lies in finding the balance between applying these principles; the substantive reach of the internal market and the 'switch' towards an evaluative framework that allows for a diversity (a margin of discretion) and plurality of legitimate substantive outcomes, provided that they are pursued in a transparent, coherent and systematic fashion. In effect that means that, to the extent that 
social interests can be accommodated within the substantive scope of the market, the evaluative principle applied by the Court to assess restrictive national or local interests can be substantively oriented and require the more efficient or less restrictive measure. Where the interest pursued is legitimate and based on normative principles that fall outside of 'the scope of the market' the evaluative principle should, however, switch to a procedural assessment that is concerned with principles of good governance. The exercise of the Court to find this 'switch' between evaluative principles that are congruent with the underlying social context, without losing sight of internal market objectives, has been coined as responsive adjudication and the studies in the previous chapter have traced fragments of such responsiveness, albeit incoherently, in the case law of the Court in free movement, competition and state aid rules. Subsequently the intention of this study has been to consistently reconstruct that case law into a coherent model of social legitimacy in which the three evaluative principles of the internal market interact constructively and in congruence with the social context that is being adjudicated. This allows the Court to implement an 'operational rationale' whenever it has to adjudicate a conflict between the objectives of market integration and restrictive domestic (social) interests. All chapters have shown how the terms of substantive efficiency, margins of discretion and good governance provide a common language within a dialogue of mutual responsiveness.

\section{Social legitimacy in the internal market: free movement, competition and state aid}
A. Social legitimacy in EU free movement law

With respect to the free movement rules, I discussed in Chapter II that the adjudicative model adopted by the Court shows the skeleton of the idea of mutual responsiveness. The starting point of the dialogue in free movement takes place on the basis of an unqualified market access test, which allows the opening of a discussion on a, in theory, unlimited range of Member State rules and regulatory schemes. This was noted by, for example, Spaventa, who in very similar terms describes that "[t]he broadening of the scope of the Treaty could be seen as a contribution not so much to deregulation but 
rather to better regulation, through a process of continuous self-reflection and of continuous dialogue between regulators, traders and the Court" ${ }^{3}$. The rationale behind this adjudicative model based on the unlimited scope of the free movement provisions is that the existence of a hierarchical relationship between competing objectives is primarily functional. The conflict is structured only in a prima facie way so that legitimate rights and policies can, from that moment onwards, be established. Within the theory of transnational effects, the prima facie structuring of EU free movement conflicts is in this way a crucial part of the adjudicative model of the Court, allowing it to engage with a range of regulatory contexts and, as explained before within the constitutional construct of the internal market, to initiate a dialogue with Member States that advances internal market integration. However, to perceive the argument from transnational effects in this way requires an answer to Somek's pressing question, which was cited above. The adjudicative model of the Court can, from a plethora of perspectives, only be perceived as an adequate and acceptable technique if, eventually, conflicts between rights and general public interest are resolved on the basis of responsiveness to context, allowing solutions to be found that respond to all the relevant contextual considerations. Perceived from this angle, responsiveness should be an absolute core aspect and function of proportionality analysis. As was introduced before, the answer to Somek's question, presented in this thesis is based on the idea of mutual responsiveness.

However, before expanding on that idea, Chapter II highlighted a number of cases that could be used to argue that the Court, indeed, has slipped into a form of analysis that imposes a limited market primacy ruled balancing framework on restrictive regulatory schemes within Member States. Based on certain lines of case law one may credibly argue that the adjudicative model of the Court in free movement law is functional and under-socialised, threatening the social cohesions, solidarity and identity that a state pursues. The assessment of EU free movement case law in Chapter II confirmed this finding by discussing a case law lineage where the valuation of social context was indeed mainly 'purpose' driven and regulatory choices were assessed within a model that can be termed consequentialist, based on utilitarian principles. As such, it was discussed that the

\footnotetext{
${ }^{3}$ E. Spaventa, "Leaving 'Keck' behind? : The Free Movement of Goods after the Rulings in 'Commission v Italy' and 'Mickelsson and Roos,"' European Law Review 34, no. 6 (2009) at 925.
} 
substantive efficiency model of proportionality, implements a utilitarian approach. In addition to denying an inflexible governing principle (such as the utility principle), incommensurability in the context of the thesis holds that there cannot be a priority rule in genuine conflicts between organizational principles (that is, no value always has priority over another). The normative claims of social legitimacy require the recognition of a plurality of legitimate social purposes and, indeed, a liberal society, such as the EU itself claims to be, contains a diversity of social spheres. European adjudicators should therefore make space for different kinds of valuation and although the adjudicative model of the Court in free movement cases carries the inherent risk of "slipping into a freewheeling rampage of economic due process", Chapter II also found that the Court has created different means to evaluate restrictive social context. Based on an ideal types approach Chapter II deduced from the case law, in addition to the substantive efficiency standard, evaluative standards based on principles of margins of discretion and good governance.

One of the key points of the 'good governance' based case law of the Court is that a system of protection that a Member States installs has to be embedded by ex ante conditions justifying the Member State choices. If systems of protection are coherently and systematically part of an existing normative infrastructure that is tailored towards the level or protection that it seeks to protect, these systems of protection are provided with a definite margin of discretion and unlikely to be struck down by EU law. In other words, Member States systems of protection need to be transparent, systematic and internally coherent but if these conditions are taken into account then the level of protection and the means through which this level of protection is sought remains largely at the discretion of the Member States. Here the dialogue becomes mutual because Member States bear a responsibility to structure their regulatory affairs in a way that the internal market rules can actually be applied in a responsive manner.

Looking through the lens of social legitimacy at EU free movement adjudication tells a mixed story. On the one hand there is clearly responsiveness, which shows a concern for diversity and respect for local social context. On the other hand there are plenty of cases where the Court foregoes social context and pushes a normative perception of the way in which social objectives and market integration relate to each 
other. What is identified in the chapter as lacking is, primarily a consistent use of the ideal type proportionality models by the Court. In the application of each of these 'ideal type' models, the Court seems to be without a clear rationale as to when a definite margin of discretion is explicitly granted to Member States, when interests are to be considered sensitive and when a focus on procedural context is more appropriate than an evaluation of the necessity of the substantive measures themselves. This incoherence is problematic from the perspective of social legitimacy. On the one hand because a normative unitary standard of valuation may be pushed that is unresponsive to legitimate social context within a Member State. On the other, through allowing margins of discretion to Member States where regulatory measures could have potentially been implemented in a more Union friendly way.

I then argued that the key to social legitimacy and, concomitantly, Someks' question, is hidden within the different evaluative principles developed by the Court and what is lacking is a rationale to determine exactly when to apply one of the unveiled standards to a specific social context. This choice should find its basis in the identification of the nature of a conflict in terms of normative principles, which responds to the potential mixes of different types of normative infrastructures of economies on a Member State level and on this basis the internal market can be positioned within such legitimate social purposes. This connects to the first Chapter, which developed the idea that the diversity of preferences and social orientations in the EU is the product of specific historical experiences, political contestation, societal learning and continuous political decision-making. The consequentialist evaluations that demand a 'one-size-fitsall philosophy' are for this reason "normatively flawed because of its disregard of the normative infrastructure of the economy"4. In this way the normative fabric of the economic orders within Member States can be seen as their "social acquis", which should be recognised within EU law. ${ }^{5}$ It was argued previously that the compromise of embedded liberalism depends on a constructive interplay between the objectives of market integration with domestic social objectives. The internal market infrastructure is

\footnotetext{
${ }^{4}$ C. Joerges, 'Market Integration and Europeanisation of Private Law', Jean Monnet Project Conference Paper (May 2015), on file with author.

${ }^{5}$ Ibid.
} 
in this view infused with a strong social purpose and the objective of market integration becomes a tool for the beginning of a societal dialogue. In its ideal form the dialogue in a first stage 'uses' the narrow normative framework of market access to tease out and understand regulatory choices that restrict free trade objectives and in a second stage adopts an evaluative principle that is then congruent with the regulatory context that gave rise to the restriction.

On this point the argument has put forward a test of inherent irreconcilability. The choice for an evaluative standard can be instructed by the identification of the nature of conflicting objectives as being inherently irreconcilable. On the basis of a prima facie structuring of a conflict based on the 'narrow' aims of market access, the Court would first assess whether the restrictive aims, which are pursued by Member Sates are inherently irreconcilable with substantive efficiency objectives of the internal market (i.e. the less restrictive measure). Within the model proposed, if found to be irreconcilable, the Court would then switch to an assessment of the procedural context of the measures on the basis of good governance principles. As such, within the dialogue of mutual responsiveness, inherently irreconcilable local domestic values will be separated within a rationale of supranational market integration and vice versa market integration objectives are pursued on the basis of procedural unity, transparency, consistency and coherence within those local structures. As such, in the EU free movement rules the dialogue of mutual responsiveness takes place on the basis of the three core concepts of substantive efficiency, margins of discretion and good governance. We shall see below that these three concepts indeed connect all areas of internal market law.

\section{B. Social legitimacy in EU competition law}

The issue of valuation in law and the related problems of indeterminacy and incommensurability surface in a clearly distinct yet comparable way in the EU competition rules. The issue of valuation of social context is slightly more distinctly present within the application of the competition rules. That is to say, social objectives may, within EU competition law, be more explicitly discussed exclusively in terms of their merits within an efficiency-based evaluation. Similar to the EU free movement 
rules, evaluative standards within competition law may value social realities within a metric that risks doing violence to potentially genuine and worthwhile aspects of objectives that are pursued on a Member State level. The competition rules have a direct influence on social relations and on the way that societal objectives are pursued collectively by undertakings. For example, undertakings may want themselves to collectively set a fair trade minimum standards or a state wants a particular sector to develop a sector wide solution that induces mutual trust and develop a shared commitment to a societal objective. If such undertakings are (potential) competitors then the agreements amongst the undertakings pursuing such wider societal objectives are likely to restrict competition. Fair trade standards or sustainable energy production are increasingly being used by undertakings to distinguish themselves from each other in the market. A collective or minimum standard may therefore significantly restrict competition. Moreover, most economic theory tells us that commercial entities operate on the basis of incentives and as a rule, undertakings may therefore be presumed to act only in their self-interest. The collective pursuit of proclaimed wider societal objectives should therefore always be met with a healthy level of suspicion. 'We' also do not necessarily want what these undertakings have to offer us in the terms of what they perceive as wider social objectives. In other words, 'We Don't Want Mark Zuckerberg's Charity!', right?' This latter issue points towards a democratic legitimacy issue.

However, in the presence of a trend of a retracting and increasingly deferential state, potential genuine intentions should not be all too readily dismissed on this basis alone. Moreover, some countries, such as the Netherlands, are based on a highly consensus based culture that includes economic sectors and supply chains in their socioeconomic policy-making. Hence, particularly the latter, provides an argument that the EU competition rules, in light of their broader constitutional role and commitment to respect regulatory diversity, should be able to accommodate private initiatives that restrict competition. The EU competition rules went through two important developments that influence the ability of EU competition law to accommodate regulatory diversity.

6 https://www.jacobinmag.com/2015/12/facebook-zuckerbergs-charity-gates-philantrophy/ (accessed 10-121015) 
First, the so-called more 'economic approach' on the basis of which the Commission is now of the opinion that only 'economic efficiencies' or 'pro-competitive effects' of restrictive agreements are accepted in order to fulfil the first condition of the exemption criteria and decisive value is attached to the objective qualification and concretization, in purely economic terms, of the claimed benefits that may be effectuated by restrictive agreements in order to qualify for an exemption. ${ }^{7}$ Within this context, for example the Dutch competition authority, eager to impress the European Commission, has pursued cases on the basis of the idea that, where undertakings pursue standards collectively, they should only do so if they can demonstrate that efficiencies arise and consumers will directly benefit. Hence, their actions should be completely in accordance with an understanding of what matters for society in terms of the market, more particularly, the consumer ruled market.

Next, the 'modernisation' of EU competition law has involved a decentralisation of the application of the competition rules. This implies, firstly, that national competition authorities are now, theoretically, the main enforcers of EU competition law and, secondly, that undertakings themselves are to 'self-assess' their status under the competition rules, whereas formerly they were able to request for official 'exemption decisions' from competition authorities. As such, the enforcement of the competition rules should be internalised all the way down into the minds and calculus of the undertakings themselves. In view of the potentially enormous fines that can be imposed on undertakings for competition law infringements, this is not an idle threat. The following picture arises. A retracting state that increasingly defers socio-economic policy making to undertakings; a European Commission that pushes for a one-dimensional idea of what matters in terms of socio-economic policy - at least whenever it infringes the competition rules - and undertakings that feel increasingly compelled to structure their potentially green and social objectives in accordance with what is efficient and for the sole benefit of a consumer.

The normative concern, based on social legitimacy, is that evaluative standards may translate societal realities within a metric that risks doing violence to potentially genuine and worthwhile aspects of those objectives. Moreover, an additional point of

7 See further Chapter III sections I and II. 
normative concern of particular relevance for the competition rules is that where an evaluative standard adopts a unitary metric, the balancing of competing values becomes simply a matter of calculation. This is not to say that the calculations will be simple, but that the nature of the problem is transformed into one of quantification. Consequently, in situations where there is a manifest irreconcilability between normative orders, quantification risks loosing the expressive value that is inherent in such a normative conflict and the consequent potential for social learning that arises from it. It foregoes the question when competition objectives and non-competition objectives are actually and genuinely irreconcilable. I submitted that the answer to this question matters because it provides instruction as to how evaluative rationales should deal with the interaction between competition and non-competition concerns.

The chapter engaged with some of the important literature on the extent that "noncompetition' interests should and can be integrated within competition law assessments. I discussed that the concept of the non-competition objective has never really been dissected very well within the literature in terms of the potential conflict that exists with the competition interest and that this is where the chapter contributes to the literature specifically. The normative demands of social legitimacy require a mechanism within the competition law assessment to single out the non-competition interest. I submitted an operational rationale to identify potential non-competition interests as objectives that fall outside of concerns that are related with the efficient functioning of markets - it is in this sense residual and defined through a process of opposition within the competition law analysis. There is an acceptance of the primacy of competition but merely in terms of a dialogue, which requires a 'responsive' space for the non-competition interest to be identified as a residual and conflicting objective.

The case studies in the competition chapter have demonstrated that these are not mere theoretical quibbles but manifest in a concrete and tangible way. The case of the Friesian horse, the Energy agreement and the Chicken of Tomorrow all demonstrate, first, the difficulties for competition law to accommodate private led competition restrictive agreements that pursue wider societal objectives. Both the health of the Friesian horse and the Chicken of Tomorrow can be seen as potentially genuine objectives and as pursuing interests that are irreconcilable with an approach that quantifies value within a 
calculative framework. Animal welfare is not a number! However, was the pedigree not actually concerned with financial gain since an unhealthy horse is simply worth less money? And is sustainable meat not a key factor for both producers and retailers to disassociate themselves from others in the market? In that case we are talking about quantifiable quality issues and something that could perhaps be quantified within the exemption criteria of 101(3) TFEU. The Energy agreement brought together civil society actors from all levels of society in the formulation of a 'climate agreement' that was intent on moving towards more sustainable energy sources. Such a society wide agreement should surely not be derailed by concerns related to the 'efficiency merits' of the closing down of a few coal plants? Isolating that aspect from the rest of the agreement would not do justice to the broader societal aims of the agreement, for which the closing down of the coal plants constituted an inherent part. However, was this 'grand societal narrative' perhaps not hijacked by a few energy companies to collectively restrict the output of an out-dated energy source, which they would lose in the long term in any case and thereby solve a difficult coordination problem they would have otherwise faced in a situation of full competition?

The case studies demonstrate two important facets of the purported dialogue of mutual responsiveness. On the one hand, there should be a form of responsiveness, a potential accommodation of a genuine non-competition interest that is residual. That is to say an interest that is not captured or becomes damaged somehow in the strict evaluation on the basis of alone its efficiency merits. Indeed, this approach accepts the primacy of competition but merely to open a conversation and a 'responsive' space for the noncompetition interest to be identified as a residual and conflicting objective. There is therefore an implicit understanding that non-competition interests are dynamic because the underlying fabric can develop and evolve. This is reflective of the idea that competition law does not exist in a vacuum but should be able to respond to the current values and aims of society and is as susceptible to change as political thinking and social objectives are generally. Because views and insights shift over a period of time, competition law is infused with the need to move and adapt towards developing notions of what is to be perceived as a noncompetition interest. If we accept that effective competition constitutes an important public interest, but only one of the worthwhile 
interests in society, forming part of a range of other interests that are potentially worth pursuing and in flux, we should ask the question if effective competition and 'broader' societal interests can be aligned harmoniously within an evaluative framework that requires the 'net efficiency result' to be positive. On the other hand the case studies demonstrate a need for good governance, on the basis of institutional design that embeds the concerned objectives within a framework that ensures a form of political oversight. This is in a nutshell the dialogue of mutual responsiveness as perceived within the competition rules.

Fragments of this dialogue of mutual responsiveness can be found in the case law of the Court of Justice, which is more refined than it is often accredited with. From the perspective of social legitimacy the Court of Justice has with the Albany and Poucet Pistre lines of case law established the requirement for context specific and responsive valuations of different social spheres and set out the beginnings of a more comprehensive rationale to determine, in a dynamic way, the constructive interplay between competition and non-competition spheres. As was demonstrated in the AOK Bunderverband case there is recognition of a potential irreconcilability between normative orders for which the Court of Justice has developed a type of valuation that is specific to the organisation of a sector on the basis of a solidarity principle. Wouters has been discussed as an extension of this idea, widening the scope of potential irreconcilable non-competition interests to be transposed to a type of valuation outside of the strict application of the exemption criteria of 101(3) TFEU. The emphasis on mutual responsiveness is present in all cases, although slightly confused in Wouters. It is clear that solidarity or the integrity of the profession of attorneys are interests that originate from the normative choices and institutional design in economies of the Member States. However, the Court is not specific in outlining what is crucial in this design, leaving it rather unclear what the facets of a public law institutional framework would have to look like, to accommodate the pursuit of private initiatives that pursue a non-competitive interest. To complete the dialogue of mutual responsiveness a connection was made to a line of cases where the Court has been quite explicit about these requirements. The Arduino, Cipolla and Mauri cases all concern the design of the public-private framework, which needs to ensure that the aspired goals are, at important points, fed with public legitimacy and provided with 
affirmative political oversight in order to be excused from the scope of the competition rules.

The case law of the Court of Justice provides a basis for the dialogue of mutual responsiveness and ensures social legitimacy in the application of the competition rules. The Court has developed a responsive model that is capable of identifying objectives that are genuine and inherent to the pursuit of interests, which are irreconcilable with the aims of the competition law framework. This context-specific in concreto approach puts emphasis on the expressive value of the interplay of competition and non-competition interests, which requires a specific and concrete articulation of the limits of both competition and genuinely irreconcilable non-competition interests. In this way competition law becomes essentially a tool for societal dialogue, testing old conventions and requiring the renewed articulation of the pursuit of potentially out-dated and vested public interests. On the other hand, it avoids the valuation of regulatory systems merely on the basis of their 'efficiency' merits, whilst accommodating a diversity of social spheres that is subject to different means of valuation. This is all part of the responsiveness part of the dialogue. That this is a dialogue requiring mutual responsiveness is reflected in the requirements to fulfil a standard of good governance in the organisation of regulatory affairs. As such, the approach suggested in this Chapter purports a holistic approach that again conceives the market and the social sphere as 'communicating vessels'. Competition derived evaluative standards serve as a tool to tease out discriminatory, disingenuous regulatory choices within Member States but allow for genuine social objectives to exist in accordance with good governance principles that focus on the quality and systemacy of a governance process, instead of on the rationality and efficiency of its outcome. As such it can be seen, again, that the dialogue of mutual responsiveness takes place on the basis of the three core concepts of substantive efficiency, margins of discretion and good governance.

C. Social legitimacy of EU state aid law

Social legitimacy concerns in EU state aid law arise on the basis of the normative rationales that Member States are conditioned to implement in their regulatory affairs on 
the basis of this area of internal market law. The central normative assumption behind the state aid rules is that the role of the state in the market should not lead to competition distortions between undertakings. As such it is reflective of a joint commitment of the Member States to ensure competitive markets. The Commission has turned the state aid regime into a largely pre-determined and proceduralised area of law. As such, the qualification of a regulatory measure as state aid implies a shift towards an arena of control where policy has to fulfil certain predetermined proxies. It matters whether policy objectives developed by Member States are to be defined within the technocratic domain of the proceduralised world of the state aid rules or whether they are allowed to take shape within 'normal politics' and the democratic arenas of the Member States. The chapter posits that sometimes the political process of the pursuit of some regulatory objectives is what matters most. This is reminiscent of the normative concerns that were developed in the first chapter: some non-economic objectives tend to share or require a social and political pact that underlies the objectives that are pursued. That is to say, regulatory objectives may pursue objectives or are by nature to be attributed to a particular sphere of accountability. On this basis it can be normatively inappropriate to have them evaluated within the procedural, technocratic State aid framework of the Commission or to enforce a market rationale on the way regulatory objectives are to be pursued. As such, even if, theoretically speaking, a market or technocratic approach towards something like regulating access to public infrastructure would accommodate the functional features of an objective, there may be something lost in the process of pursuing the objective as part of a genuine political or regulatory process

Hence, the moment of defining a state measure as a state aid counts. It is at this juncture, where a decision is made whether a policy or regulatory framework can be developed outside of the state aid rationale or within the standards and justifications that are already prescribed in state aid control. The chapter therefore argued that the moment of defining a state aid measure should be responsive to the circumstances and rationales of the specific regulatory context that gave rise to a selective advantage and a distortion of competition. However, the Dassonville like reasoning of the Court in Steenkolenmijn captures a wide range of regulatory contexts, on the basis of their effects. Potential social objectives that underlie regulatory choices do, in principle, not matter for the assessment 
of a measure in terms of state aid. Instead, the chapter demonstrated how market derived rationales have a tendency to be applied expediently in order to determine whether the effects of a regulatory choice leads to a selective advantage for undertakings.

The Court has established that the application of a market-based evaluation of a governmental intervention should in principle be preceded by an assessment of the 'nature of the measure'. That means that, in principle, it is only if the state is acting to participate on the market that market based standards should be used to evaluate whether any advantages have been granted. If, instead, the state is acting as a regulator, the 'market rationality' principle is replaced with evaluative standards based on questions whether regulation, asymmetrically, benefits a specific (group of) undertaking(s) or whether a measure involves a state resource. Social legitimacy then depends on whether the chosen evaluative standard is congruent with the underlying social context. It is on this point that some concerns were identified because the Court and the GC sometimes struggle in finding a coherent rationale for this distinction. Specifically, market rationales can become expedient and pervasive because regulatory action is often approached separately, without an explicit analysis of a potentially wider societal context. As such, the setting of charges for the use of public infrastructure (RyanAir) becomes a commercial decision and allowing the use of state assets free of charge, whereas they could have been sold or put up for auction, becomes a potential waste of economic resources (Dutch Nox/Eventech). In this way regulatory choices may be evaluated within a metric that risks doing violence to potentially genuine and worthwhile, wider, aspects of those objectives. The point here, from the view of the normative expectations that were developed in the first chapter, is the recognition of embedded social context within an economic rationale. Some communal contexts lend themselves easily to economic regulation. The 'instrumental community' context fits within a form of regulation based on an evaluative principle of efficiency. Problems may arise, however, when economic substantive efficiency oriented governance mechanisms would be installed to regulate social context based on trust, informal values, public spiritedness and so forth. The balance from the perspective of state aid is difficult because such amorphous elements of state-society-market relations are, from a state aid perspective, perceived as important factors contributing to in-transparency and constitutive to relationships, which are likely 
to end up in granting covert advantages to some undertakings and not to others. The rigidity of the prudent private investor standard leaving aside all social, regional-policy and sectoral considerations is, at least partly, based on an idea of administrability and transparency in state aid matters. On the other hand, there is the potential for an inherent reductionist view of the legitimate relationship between the state and the market at play. It is reductionist because the valuation of state action may exclude normative orientations within the infrastructure of economies on a Member State level.

As such, the market based regulatory standards that state aid law introduces may condition public bodies towards actions that are justified exclusively on the grounds of their commercial self-interest and thereby crowd out potential alternative visions towards the appropriate role of public authorities and the direction that policy objectives take. At the same time, the wave of new public management, which installed efficiency principles within Member States' regulatory affairs has made it more difficult to conceptualise alternative forms of governance outside of the spectrum of cost-benefit analysis. Essentially those processes have obscured the difference between market and non-market approaches in regulatory intervention. Nevertheless, EU internal market law is not committed to these principles and should allow, explicitly, for the possibility of social diversity.

Nevertheless, the Court has demonstrated responsiveness in the application of the State aid rules in some lines of case law where it sought to disentangle commercial transactions entered into by Member States from the non-commercial and regulatory objectives that accompany them. The case law allows for what may be seen as the inherent justifications of measures that grant selective economic advantages but are part of general regulatory or legislative schemes, which are themselves incorporating legitimate regulatory objectives. Such legitimate and genuinely pursued 'reference frameworks' are able to pull individual measures that form an inherent part of such frameworks out of the realm of the state aid regime.

The chapter reconstructed the case law of the Court within the dialogue of mutual responsiveness in the following way. The substantive reach of the internal market is reflected in the market derived standards such as the MEOP, which requires a 'switch' towards an evaluative framework that allows for a diversity (a margin of discretion) and 
plurality of legitimate possibly inefficient substantive outcomes, provided that they are pursued in a transparent, coherent and systematic fashion; in accordance with requirements of good governance. Underlying this switch in the state aid rules is the idea of a 'genuine regulatory activity', which is not based on a formalistic idea of traditional state powers but can be shaped in a dynamic fashion by the Member States in their fulfilment of tasks towards its population in the social, cultural and educational areas. Thus, the social legitimacy of the state aid rules depends on the extent and level of sophistication adopted in legal reasoning that identifies instances of 'genuine regulatory activity' before adopting evaluative principles that are congruent to the conflict that is being adjudicated.

\section{Some final remarks}

Clearly, a problem for internal market adjudication that is committed to social diversity within the Union is that plurality may be bought at the price of allowing too much. Internal market adjudication requires coherent approaches to avoid that social diversity turns into a carte blanche for communities who prefer their own values at the expense of other Member States. Nevertheless, if we indeed accept the argument that social diversity is a value to which the EU internal market is committed then market derived utilitarian standards, despite the overarching value of 'administrability', are not appropriate means to adjudicate all types of internal market conflicts, because they simply fail to capture and weigh the true social significance of some restrictive rules. However, it was found with regard to the three areas of the internal market that many restrictive Member State regulations perish within the evaluative frameworks of the Court because Member States themselves do not really understand the functions of their own laws. Such regulatory indeterminacy tends not to fulfil consequentialist, purposive driven evaluative standards. As such, indeterminacy has been identified as a central cause for potential social legitimacy issues in all areas of internal market law and the dialogue of mutual responsiveness serves as a means to improve the articulation of regulatory choices of Member States. In a very real sense the Court calls for better regulation by the Member States. However, better regulation is not necessarily regulation that speaks market talk 
and the Court has indeed demonstrated that it will respond to genuine regulatory choices and rationales in the pursuit of objectives that are legitimate and serve an important social commitment or normative orientation of a local economy. The point is that responsive adjudication will need something to respond to.

This issue of indeterminacy has some broader structural relevance, not touched upon directly in the thesis, and this was observed occasionally in the fringes of the discussion of the negative effects of utilitarian purpose driven standards. The internal market floats as a legal reality above the Member States and, thereby, installs dominant principles of organisation. As soon as there is a restriction, Member State's will have to conform to a discourse that recognises and allows legitimate objectives to restrict market integration and submerge to a rationality that will determine the suitable means to achieve these objectives. However, in the regulatory vacuum left by Member States, principles of public management and the better, smarter regulation initiatives of the European Commission are likely to become a dominant form of governmentality within the European Union (if they not already are). The fact that there is no immediate autonomous or self-sustainable rationale to support non-market based regulation means that it is much easier and seemingly more transparent to connect regulatory objectives to market-based types of regulation. In this process, the objective becomes either re-defined as a corrective to market processes (as an externality) or is completely translated within a market metric: e.g. pursuing a sustainable environment through installing self-regulatory trading mechanisms in rights to pollute. This type of smart regulation is nurtured and promoted by the European Commission. Clearly these 'smart' forms of regulatory design will also quickly fulfil the evaluative standards of the Court. The point of indeterminacy is that social diversity and plurality are not a given and will have to be institutionally 'protected' in order to survive within the purpose driven rationales of the European Union. Therefore, although there are ways in which the institutional set up of the EU seems to share Polanyi's concerns for embedding markets in social foundations, the dominant trend of governance in the European Union is clearly to move towards utilitarian types of 'impact assessments' and 'evidence centred' policy making. The underlying rationale of these efforts are in close proximity to Polany's observations regarding the choice of design for institutional infrastructures in the process of the 
industrial revolution: "the economic system is organized in separate institutions, based on specific motives and conferring a special status, society must be shaped in such a manner as to allow that system to function according to its own laws". Although we have seen in the studies of the previous chapters that this is not necessarily in all cases dismissive of social objectives, not all societal realities will be equally valued or accommodated within such consequentialist thinking.

As such, the conclusions offered by this thesis only unveil part of the story. The proposed responsive model of adjudication provides the Court with an adjudicative model through which it can communicate with domestic social objectives/actors in a more constructive manner, explaining what is required from domestic governance in the context of a supranational market integration rationale. As such, the adjudicative rationales of the Court have been reconstructed towards a consistently more responsive model that is able to accommodate Member State diversity and promote the objectives of the internal market; an integrated market that is responsive to a Member State's differing sets of social contexts. However, these findings will have to be completed with a more complete account of the effects of internal market legislation, governance and fiscal oversight in order to establish to what extent the respect for social diversity is a part of the values that are actually purported in the internal market.

Despite these shortcomings, the study has demonstrated how the internal market can become the platform of a societal dialogue, which the argument of transnational effects had conceived for it, in accordance with the normative claims of social legitimacy. The internal market chapters demonstrate the shared problems and pitfalls that prevent the realisation of this preconceived social purpose for the internal market. I have attempted in this study to allow for the structural inclusion of this social purpose within European legal space by developing a common shared language of substantive efficiency, margins of discretion and good governance, within a dialogue of mutual responsiveness. 
Chapter V - Conclusion 


\section{BIBLIOGRAPHY}

Acemogluy D. and Jackson, M. O., 'Social Norms and the Enforcement of Laws', NBER

Working Paper No. 20369 (Agust 2004), http://nber.org/papers/w20369

Akman, P. ,'Consumer Welfare and Article 102 EC: Practice and Rhetoric', World Competition 32(2009), 71

- - 'Searching for the Long-Lost Soul of Article 82EC' Oxford Journal of Legal Studies 29(2009), 267

Allan T.R.S., 'Democracy, Legality, and Proportionality' in Huscroft, Miller, and Webber (eds.), Proportionality and the Rule of Law: Rights, Justification, Reasoning (CUP 2014) 205

Amato G., Antitrust and the Bounds of Power (Hart Publishing, 1997)

Andriychuk O., 'Dialectical Antitrust: An Alternative Insight into the Methodology of the EC Competition Law Analysis in a period of Economic Downturn', European Competition Law Review, 31(2010), 155

- - ' Rediscovering the Spirit of Competition: On the Normative Value of the Competitive Process' European Competition Journal 6((2010)), p. 575-610

Ankersmit L., 'Het einde van de kiloknallers? De grenzen aan zelfregulering van duurzaam vlees onder het kartelverbod' Actualiteiten Mededingingsrecht (2011), 149

- - Globalization and the Internal Market: Process-based Measures Within the EU Legal Order' (2015, PhD thesis, Vrije Universiteit Amsterdam).

Apeldoorn B. van, 'The Contradictions of 'Embedded Neoliberalism' and Europe's Multilevel Legitimacy Crisis: The European Project and its Limits', in B. Van Apeldoorn, J. Drahokoupil, and L. Horn (eds), Contradictions and limits of neoliberal European governance: from Lisbon to Lisbon (Palgrave Macmillan 2008)

Ashiagbor D., 'Unravelling the Embedded Liberal Bargain: Labour and Social Welfare Law in the Context of EU Market Integration', 19 European Law Journal 3(2013), 324

Azoulai L., "The Court of Justice and the Social Market Economy: The Emergence of an Ideal and the Conditions for Its Realization" (2008) 45 Common Market Law Review 1335; - - $\quad$ "The European Court of Justice and the Duty to Respect Sensitive National Interests" [2013] in Judicial activism at the European Court of Justice, at 167 
Bacon K., 'Differential Taxes, State Aids and the Lunn Poly Case' (1999) European Competition Law Review, 384

Baquero Cruz J., Between competition and free movement : the economic constitutional law of the European Community (Hart Publishing 2002), 123

- - 'Services of General Interest and EC Law' in G. de Búrca (ed.), EU Law and the Welfare State - In Search of Solidarity, (Oxford University Press 2005), 16.

Barnard C. and S. Deakin, 'Market Access and Regulatory Competition', in C. Barnard and J. Scott (eds.), The Law of the Single European Market, unpacking the premises (Hart, 2002)

Barnard C., 'Viking and Laval: An Introduction' (2007-2008) 10 CYELS 464;

_ _ _Social dumping or dumping socialism' (2008) 67 CLJ 262 at 264.

- - " "Derogations, Justifications, ad the Four Freedoms: is State Interest Really Protected?" in Barnard and Odudu (eds), The Outer Limits of European Union Law (Oxford, hart Publishing, 2009) 273

Bartosch A., 'Clarification or Confusion - How to reconcile the ECJ's rulings in Altmark and Chronopost', European State Aid Law Quarterly 3(2003), 12

- - 'The ruling in BUPA - clarification or modification of Altmark?, EStAL 2(2008), 211

- _ 'Is there a need for a rule of reason in European state aid law? Or how to arrive at a coherent concept of material selectivity', Common Market Law Review 47(2010), 729

Beck T. Jorgensen and L. Bogh Andersen: An Afternath of NPM: Regained Relevance of Public Values and Public Service Motivation in T. Christensen and P. Laegreid (eds.) The Ashgate Research Compnion to New Public Management, (Ashgate Surrey 2011), 335

Beckert J., 'The Great Transformation of Embeddedness: Karl Polanyi and the New Economic Sociology' in C. Hann K. Hart (eds.) Market and Society: The Great Transformation Today, (New York: Cambridge University Press 2009), 38

Behrens P., 'Public service and the internal market', in T. Einhorn (ed.), Spontaneous order, organization and the law. Roads to a European Civil Society (The Hague Asser Press 2003), 43

Bellamy R., 'The liberty of the moderns: Market freedom and democracy within the EU' (2012) 1 Global Constitutionalism, 141

Beramendi P., 'Inequality and the Territorial Fragmentation of Solidarity', International Organization 4(2007), 783 
Besselink L.F.M, 'National and Constitutional Identity before and after Lisbon' 6(2010) Utrecht Law Review, 36

Biondi A., "Some reflections on the notion of "State Resources" in European Community State Aid Law' (2007) 30 Fordham International Law Journal, 1426

- - 'BUPA v Commission' EStAL (2008) at 408

Biondi, A. and M. Farley, 'The relationship between state aid and the single market', in Szyszcak, E. (ed), Research Handbook on State Aid (Cheltenham, Edward Elgar, 2011), 277

Biondi A., and L. Rubini, 'Aims, Effects and Justifications: EC State Aid Law and Its Impact on National Social Policies', in Dougan, M. and Spaventa, E. (eds), Social Welfare and EU Law (Hart Publishing, 2005), 79

Blauberger M., 'With Luxembourg in mind...the remaking of policies in the face of ECJ jurisprudence’ 19(2012) Journal of European Public Policy, 109

Block F., "Karl Polanyi and the Writing of The Great Transformation," Theory and Society : Renewal and Critique in Social Theory 32(2003), 275

Block F. and Somers M., The Power of Market Fundamentalism: Karl Polanyi's Critique, (Harvard University Press, 2014)

Bogaert van den and Cuyvers A., "Money for nothing: The case law of the EU Court of Justice on the regulation of gambling", Common market law review 48(2011), 1175

Bogdandy A von and Schill S, 'Overcoming Absolute Primacy : Respect for National Identity under the Lisbon Treaty' (2011) Common Market Law Review, 48

Boeger N., 'Solidarity and EC competition law' (2007) European Law Review, 319

Bork R.H., The Antitrust Paradox: A Policy at war with itself (New York, Basic Books 1978)

Boston J., "Basic NPM Ideas and their Development" in T. Christensen and P. Laegreid (eds.), The Ashgate Research Companion to New Public Management, (Surrey Ashgate 2011)

Boutin X. and R. Peduzzi, "Searching for 'Good Aid': The Role of Evaluation,” European State Aid Law Quarterly 14(2015), 250 
Bovens M., "New Forms of Accountability and EU-Governance," Comparative European Politics 5(2007), 104-20.

B. Bouwens and J. Dankers, Competition and Varieties of Coordination in K. Sluyterman (ed.), 'Varieties of Capitalism and Business History - The Dutch Case', (Routledge 2015) 105

Buckel S. and L. Oberndorfer, 'Die lange Inkubationszeit des Wettbewerbs der Rechtsordnungen - Eine Genealogie der Rechtsfälle Viking/Laval/Rüffert/Luxemburg aus der Perspektive einer materialistischen Europarechtstheorie' in A.F. Lescano, F. Rödl and C. Schmid (eds), Europäische Gesellschaftsverfassung. Zur Konstitutionalisierung sozialer Demokratie in Europa (Nomos 2009)

Buendía Sierra J.L. and P. Rivas, J. Manuel, “The Almunia Package: State Aid and Services of General Economic Interest" in E. Szyszcak and J.W. van de Gronden (eds.) Financing Services of General Economic Interest, (The Hague T.M.C. Asser Press 2013), 125

Búrca G. de, "The Quest for Legitimacy in the European Union”, Modern Law Review 59 (1994), 349

- - EU law and the welfare state: in search of solidarity (Oxford University Press 2005)

Buttigie E., 'Competition Law: Safeguarding the Consumer Interest. A Comparative Analysis of US Antitrust Law and EC Competition Law'in J. Drexl, W. Kerber, R. Podszun, (eds.), Competition Policy and the Economic Approach - Foundations and Limitations, (Cheltenham: Edward Elgar 2010)

Caporaso J. and Tarrow S., 'Polanyi in Brussels: Supranational Institutions and the Transnational Embedding of Markets', (2009) 63 International Organization, p. 593-620;

Casey D., 'Disintegration: Environmental Protection and Article 81 EC' (2009) 15 European Law Journal, 362

Cecco F. de, State Aid and the European Economic Constitution (Hart Publishing 2013)

Chalmers D., G. Davies, and G. Monti, European Union Law; Cases and Materials (second edition, Cambridge University Press 2010),

Christensen T. and P. Laegreid (eds.), The Ashgate Research Compnion to New Public Management (Ashgate Surrey 2011) 
Cloots E., National Identity in EU Law, (Oxford: OUP 2015)

Cooter R. D., “Three Effects of Social Norms on Law: Expression, Deterrence, and Internalization," Oregon Law Review 79(2000) p. 1-22

Copeland P., "International Political Economy and European Integration- Applying Karl Polanyi's The Great Transformation.” IPEG Papers on Global Political Economy 40 (2009)$1-26$

Cormick J. Mc, Environmental Policy in the European Union (Palgrave 2001)

Coser L., The Functions of Social Conflict (New York: The Free Press, 1956)

Cotterrell R., 'Rethinking 'Embeddedness': Law, Economy, Community' (2013) 40 Journal of Law and Society 49-67

Cover, R., 'Foreword: Nomos and Narrative', Harvard Law Review 97[1983], p. 4-68

Craig P. and G. de Burca, EU Law text, cases and materials (Oxford University Press, 2011)

Craig P., 'Competence and Member State Autonomy: Causality, Consequence and Legitimacy' in Hans W. Micklitz and Bruno de Witte, (eds.) The European Court of Justice and the autonomy of the Member States, (Oxford Legal Studies Research Paper No. 57/2009) - _ _The Lisbon Treaty : Law, Politics, and Treaty Reform’ (Oxford 2013)

Crane D.A., 'The tempting of Antitrust: Robert Bork and the goals of Antitrust Policy', Antitrust Law Journal 79(2014), 835

Craven R., "State Aid and Sports Stadiums: EU Sports Policy or Deference to Professional Football”, European Competition Law Review, (9)2014, 453

Crocioni P., 'Can State Aid Policy Become more Economic-Friendly?' (2006) World Competition, 89

Crouch C., Making Capitalism Fit for Society (Cambridge-Malden MA, Polity Press, 2013) 37.

Dahrendorf R., The Modern Social Conflict: An Essay on the Politics of Liberty (London: Weidenfeld and Nicolson 1988) 
Damjanovic D., "The EU Market Rules as Social Market Rules : Why the EU Can Be a Social Market Economy," Common Market Law Review 50, no. 6 (2013): 1685-1717

Dale G., Karl Polanyi : The Limits of the Market (Cambridge Polity Press, 2010)

Dani M., "Rehabilitating social conflicts in European Public Law”, (2012)18 European Law Journal at p. 621.

Davies A., 'One Step Forward, Two Steps Back? Laval and Viking at the ECJ' (2008) 37 ILJ 126;

Davies G., "What does Article 86 actually do?" in M. Krajewski, U. Neergaard \& J. van de Gronden (eds.), The Changing Legal Framework for Services of General Interest in Europe (The Hague Asser Press 2009), 51

- - "Understanding Market Access: Exploring the Economic Rationality of Different Conceptions of Free Movement Law," German Law Journal 11, no. 7-8 (2010), 671

- - 'The Court's jurisprudence on free movement of goods: Pragmatic presumptions, not philosophical principles' (2012) 2 European Journal of Consumer Law, 25

- - "Internal market adjudication and the quality of life in Europe", (2014) EUI Working Paper 2014/07.

- - 'Democracy and Legitimacy in the Shadow of Purposive Competence' 21(2015) European Law Journal, 2

Dashwood A, 'Viking and Laval: Issues of horizontal Direct Effect' (2007-2008) 10 CYELS 525 ;

Dawson M. and Witte B. de, 'The EU Legal Framework of Social Inclusion and Social Protection: Between the Lisbon Strategy and the Lisbon Treaty', in B. Cantillon et al. (eds.), Social Inclusion and Social Protection in the EU: Interactions between Law and Policy (Intersentia, Cambridge 2012

Dawson M. and Witte F de, (2013) Constitutional balance in the EU after the Euro-crisis. Modern Law Review, 76 (5). pp. 817-844.

Deakin S., 'Regulatory competition after Laval' (2007-2008) 10 CYELS 581;

- - $\quad$ 'The Lisbon Treaty, the Viking and Laval Judgments and the Financial Crisis: In Search of New Foundations for Europe's Social Market Economy', in N. Bruun et al., The Lisbon Treaty and Social Europe (Hart, Oxford 2012), p. 19.

- - $\quad$ "The Lisbon Treaty, the Viking and Laval judgments, and the financial crisis: in search of new foundations for Europe's 'social market economy'" in N. Bruun, K. 
Lörcher and I. Schömann (eds), The Lisbon Treaty and Social Europe (Hart Publishing 2012), pp. 19-43

Dhondt N., Integration of environmental protection into other EC policies: legal theory and practice (Europa Law Publishing 2003)

Dibben P. and P. Higgins, 'New Public Management: Marketization, Managerialism and Consumerism' in P. Dibben, G. Wood and I. Roper (eds.) Contesting Public Sector Reforms, (London, Palgrave Macmillan 2004)

Dobbins T., 'The Case for "beneficial Constraints": Why Permissive Voluntarism Impedes Workplace Cooperation in Ireland', Economic and Industrial Democracy 35(2010) p. 497

Dougan M. and E. Spaventa (eds.), Social welfare and EU law (Oxford Hart 2005)

Dukes R., The Labour Constitution. The Enduring Idea of labour Law, (Oxford: Oxford University Press, 2014)

Dunn W. and D. Miller, 'A Critique of New Public Management and the Neo-Weberian State Advancing a Critical theory of Administrative Reform', Public Organization Review, 7(2007), 345

Durkheim E., The Division of Labor in Society (New York Free Press of Glencoe 1964)

Dyzenhaus D., 'Proportionality and Deference in a Culture of Justification' in Huscroft, Miller, and Webber (eds.), Proportionality and the Rule of Law: Rights, Justification, Reasoning (CUP 2014) 234

Ebner A., 'Transnational Markets and the Polanyi Problem' in Christian Joerges and Josef Falke (eds), Globalisation and the Potential of Law in Transnational Markets (Hart Publishing 2011) at p. 28.

Ehlermann D. , 'The Contribution of EC Competition Policy to the Single Market' (1992) 29 Common Market Law Review, 257

Enteman W., Managerialism : The Emergence of a New Ideology (WIsconsin: University of Wisconsin Press, 1993) 
Ferrera M., 'Modest Beginnings, Timid Progresses: What Next for Social Europe?', in B. Cantillon et al., Social Inclusion and Social Protection in the EU: Interactions between Law and Policy (Intersentia, Cambridge 2012), p. 17-39.

Fraser N., 'Can Society Be Commodities All the Way down? Post-Polanyian Reflections on Capitalist Crisis' (2014) 43 Economy and Society 541.

Fuller L. and Winston K., "The Forms and Limits of Adjudication" (1978) 92 Harvard Law Review at p. 353.

Gardbaum S.,'Proportionality and Democratic Constitutionalism' in Huscroft, Miller, and Webber (eds.), Proportionality and the Rule of Law: Rights, Justification, Reasoning (CUP 2014).

Gerbrandy A., "Competition Law and Private-Sector Sustainability Initiatives" in A. Colombi Ciacchi, M. Heldeweg, B. van der Meulen and A. Neerhof (eds), Law \& Governance: Beyond the Public-Private Law Divide? (The Hague: Eleven International Publishing, 2013), 83

- - 'Duurzaamheidsbelangen in het mededingingsrecht', Nederlands Tijdschrift voor Europees Recht, 9(2013), 326

- - Addressing the Legitimacy Problem for Competition Authorities Taking into Account Non-Economic Values: The Position of the Dutch Competition Authority', European Law Review 40(2015), 770

Gerner-Beuerle C., "Shareholders between the Market and the State : The VW Law and Other Interventions in the Market Economy," Common Market Law Review 49(2012) 97-144.

Giubboni S., Social Rights and Market Freedoms in the European Constitution. A Labour Law Perspective, (Cambridge: Cambridge University Press, 2006)

Glyn A., Capitalism Unleashed: Finance, Globalization and Welfare (Oxford: OUP, 2007

Goetschy J., 'Taking stock of social Europe: is there such a thing as a Community Social Model?', in M. Jespen, and A. S. Pascual, (eds.), Unwrapping the European Social Model (Bristol 2006), p. 66.

- - ' The Lisbon Strategy and Social Europe: Two Closely Linked Destinies' in M.D. Rodrigues (ed.) Europe, Globalization and the Lisbon Agenda, (Cheltenham: Edward Elgar 2009) 74-90

Granovetter M., 'Economic Action and Social Structure: the Problem of Embeddedness', American Journal of Sociology, 91(1985), 481 
Gromnicka E., 'Services of General Economic Interest in the State Aid Regime:

Proceduralisation of Political Choices?', European Public Law, 11 (2005), 429

Gryse C. de, 'Historical and Institutional Background to the Cross-industry Social Dialogue', in A.D. Dufresne, and P. Pochet (eds.), The European Sectoral Social Dialogue (Brussels: P.I.E. 2006), p. 31

Hall P.A., 'Varieties of Capitalism and the Euro Crisis', West European Politics 37(2014) p. $1223-1243$.

Hall P. A. and Soskice D. W., Varieties of Capitalism : The Institutional Foundations of Comparative Advantage (Oxford University Press 2001)

Hancher L., "Towards a new definition of a State aid under European Law- Is there a new concept of State aid emerging", (2003) EStAL, 365

Hart H. L. A., The Concept of Law (Oxford: Clarendon Press 1961)

Hassel A., 'Adjustments in the Eurozone: Varieties of Capitalism and the Crisis in Southern Europe', LEQS Paper No. 76/2014;

- - 'The German Model in Transition', in B. Unger (ed.), The German Model, (Düsseldorf: Hans-Böckler-Stiftung 2015), p. 105-134

Hay J.R., and A. Shleifer, Private Enforcement of Public Laws: A Theory of Legal Reform," American Economic Review, 88(1998) p. 398-403

Hay J. R., A. Shleifer, and R. W. Vishny, 'Toward a Theory of Legal Reform', European Economic Review, 40(1996) p. 559-567

Hees, S. van, 'A sustainable competition policy for Europe. - A research on how the European cartel rules can make a stronger contribution to Europe's sustainable development goals’, (Utrecht University, Utrecht 2013)

Hemerijck A., 'The Self-Transformation of the European Social Model(s)', in G. Esping Andersen (ed.), Why we need a Welfare State (Oxford: OUP, 2002) 178

Hervey T.K., 'Social solidarity: a buttress against internal market law' in J. Shaw (ed.), Social Law and Policy in an Evolving European Union (Hart Publishing 2000) p. 31-47 
- - $\quad$ 'If only it were so simple: Public Health Services and EU Law', in M. Cremona (ed.), Market Integration and Public Services in the European Union (Oxford University Press 2011), p. 179-250

Hirschmann A.O., 'Social Conflicts as Pillars of Democratic Market Society', (1994) 22 Political Theory, 206

Hix S. and Follesdal A., "Why There Is a Democratic Deficit in the EU: A Response to Majone and Moravscik", Common Market Studies, 44(2006) 533

Hohfeld W.N., 'Some Fundamental Legal Conceptions as Applied in Judicial Reasoning' (1913) 23 The Yale Law Journal 16.

Holmes C., 'Problems and Opportunities in Polanyian Analysis Today', Economy and Society Economy 41 (2012), p. 468.

Hooghe L. and Marks G., 'The Making of a Polity: The Struggle over European Integration', in H. Kitschelt, et al (eds), Continuity and Change in Contemporary Capitalism, (Cambridge University Press 1999), p. 70-97.

Höpner. M. and A. Schäfer (2010), A New Phase of European Integration: Organized Capitalisms, West European Politics 33

- - 'Embeddedness and Regional Integration: Waiting for Polanyi in a Hayekian Setting' (2012) 66 International Organization 429.

Hoque Z. and J. Moll, 'Public Sector Reform: Implications for Accounting, Accountability and Performance of State- Owned Entities - An Australian Perspective', International Journal of Public Sector Management, 14(2001), 305

Horne R.E., 'Limits to labels: The role of eco-labels in the assessment of product sustainability and routes to sustainable consumption', International Journal of Consumer Studies 33(2009), 175

Horváth E., Mandating Identity : Citizenship, Kinship Laws and Plural Nationality in the European Union (Kluwer Law International 2007) at p. 126.

Horwitz M.J., The Transformation of American Law, 1870-1960: The Crisis of Legal Orthodoxy (Oxford University Press 1992). p. 193. 
Jansson M.S. and H. Kalimo, 'De Minimis meets "Market access": transformations in the substance - and the syntax - of EU free movement law?', (2014) 51, Common Market Law Review, at 523

Joerges C., 'A Critique of the Disregard for History in European Constitutional Theory: Are Those that Forget the Past Doomed to Repeat its Mistakes?', Florence, EUI Working Paper LAW No. 2005/14;

- _ "Deliberative Political Processes" Revisited: What Have we Learnt About the Legitimacy of Supranational Decision-Making ?', (2006) 44 Journal of Common Market Studies 779, at 790

- - "What is Left of the European Economic Constitution?" (European University Institute, Working Paper Law No. 2004/13, 2004).

- - "Unity in Diversity as Europe's Vocation and Conflicts Law as Europe's Constitutional Form", in R. Nickel and A. Greppi (eds.), The Changing Role of Law in the Age of Supra- and Transnational Governance, (Baden-Baden: Nomos, 2014), 125176

- - 'Market Integration and Europeanisation of Private Law', Jean Monnet Project Conference Paper (May 2015), on file with author.

Joerges C. and F. Rödl, 'Informal Politics, Formalised Law and the "Social Deficit" of European Integration: Reflections after the Judgments of the ECJ in Viking and Laval' (2009) 15 European Law Journal, pp. 1-19;

Joerges C. and J. Neyer, "From Intergovernmental Bargaining to Deliberative Political Processes”, 3(1997) European Law Journal, p. 273

Judt T., Postwar: A History of Europe since 1945 (Penguin Group (USA) Incorporated 2006)

Kaupa C., 'Maybe not activist enough? On the Court's alleged neoliberal bias in its recent labor cases', B. in de Witte, E. Muir and M. Dawson, Judicial Activism at the European Court of Justice: Causes, Responses and Solutions (Edward Elgar Publishing 2013), p. 56-75.

Kieran F., 'A Separation of Powers Approach to Non-efficiency Goals in EU Competition Law' European Public Law 19(2013), 189

Kilpatrick C., 'Laval's Regulatory Conundrum: Collective Standard-Setting and the Court's New Approach to Postal Workers' (2009) 34 ELRev 844;

Kjølbye L., 'The New Commission Guidelines on the Application of Article 81 (3): an Economic Approach to Article 81'(2004) 25 European Competition Law Review, 566 
Klasse M., "The Impact of Altmark: The European Commission Case Law Responses” in E. Szyszcak and J.W. (eds.) in Financing Services of General Economic Interest, (The Hague T.M.C. Asser Press 2013), 35

Komninos A.P., 'Non-competition Concerns: Resolution of Conflicts in the Integrated Article 81 EC' (2008) The University of Oxford Centre for Competition Law and Policy Working Paper (L) 08/05

Konstadinides T., 'Constitutional Identity as a Shield and as a Sword : The European Legal Order within the Framework of National Constitutional Settlement' (2011) 13 Cambridge yearbook of European legal studies p. 195

Krajewski M., 'Providing Legal Clarity and Securing Policy Space for Public services through a legal framework for services of general economic interest: squaring the circle?', (2008) 14 European Public Law at 377

- _ Commodifying and Embedding Services of General Interest in Transnational Contexts: The example of healthcare liberalisation in the EU and the WTO', in Christian Joerges and Josef Falke (eds), Karl Polanyi, Globalisation and the Potential of Law in Transnational Markets (Hart 2011)

Kumm M., "The idea of Socratic contestation and the right to justification: The point of rights-based proportionality review", 4 Law \& Ethics of Human Rights (2010), 157

Kurcz B., D. Vallindas, 'Can general measures be...selective? Some thoughts on the interpretation of a state aid definition' 45(2008) Common Market Law Review, 159

Ladeur KH, “'Conflicts Law as Europe's Constitutional Form” ... and the Conflict of Social Norms as Its Infrastructure' [2014] in (C. Joerges and C. Glinski eds.), European crisis and the transformation of transnational governance : authoritarian managerialism versus democratic governance,

Lane J.E., New Public Management (Routledge 2002)

Lang, A.T.F. 'Reconstructing Embedded Liberalism: John Gerard Ruggie and Constructivist Approaches to the Study of the International Trade Regime' (2006) 9 Journal of International Economic Law 81, at 86-89

Lange B., F. Haines, and D. Thomas (eds), Regulatory Transformations : Rethinking Economy-Society Interactions, (Oxford Hart Publishing, 2015) 
Laren L. Mc, 'Explaining Mass-Level Euroskepticism: Identity, Interests, and Institutional Distrust' Acta Politica 42(2007) p. 233-51; H. Kriesi, West European Politics in the Age of Globalization (Cambridge 2009).

Lavrijssen S., 'The Protection of Non-Competition Interests; What Role for Competition Authorities after Lisbon?', European Law Review 5(2010), 635

Lianos, I., 'Some reflections on the question of the goals of EU Competition Law', (2013) CLES Working Paper Series 3/2013

- - In Memoriam Keck: The Reformation of the EU Law on the Free Movement of Goods', (2015) 2 European Law Review

Lindsay M.J., 'In Search of Laissez-Faire Constitutionalism', Harvard Law Review 3(2010) 55

Lenaerts K., "The Court's Outer and Inner Selves: Exploring the External and Internal Legitimacy of the European Court of Justice" in H. Clemens et al. (eds), Judging Europe's Judges : The Legitimacy of the Case Law of the European Court of Justice (Hart, 2013), p....

Lenaerts K. and T. Heremans, 'Contours of a European Social Union in the Case-Law of the European Court of Justice’ (2006) 2 European Constitutional Law Review, p. 101-115.

Lindstrom N., 'Service Liberalization in the Enlarged EU: A Race to the Bottom or the Emergence of Transnational Political Conflict?' Journal of Common Market Studies 49(2010) p. 1307-27

Lopez J.J.P., The Concept of State Aid under EU Law - From internal market to competition and beyond (Oxford University Press 2015)

Lovdahl-Gormsen L., 'The Conflict Between Economic Freedom and Consumer Welfare in the Modernization of Article 82 EC' European Competition Journal 3(2007), 329

Lugard P. and L. Hancher, 'Honey, I Shrunk the Article! A Critical Assessment of the Commission's Notice on Article 81(3) of the EC Treaty' (2004) 25 European competition law review, 410

Macaulay S., 'Non-Contractual Relations in Business: A Preliminary Study', 28(1963) American Sociological Review, 55 
Majone G., 'Dilemmas of European Integration. The Ambiguities and Pitfalls of Integration by Stealth', (Oxford: Oxford University Press 2005) 191.

- - 'The Deeper Euro-Crisis or: The Collapse of the EU Political Culture of Total Optimism, EUI Working Paper LAW 2015/10.

Malmberg J and T Sigeman, 'Industrial Action and EU Economic Freedoms: The Autonomous Collective Bargaining Model Curtailed by the European Court of Justice' (2008) 45 CMLRev 1115;

Marglin S.and J. Schor, The Golden Age of Capitalism : Reinterpreting the Postwar Experience (Oxford University Press 1990).

Marks G., L. Hooghe and K. Blank, "European Integration since the 1980s: State-Centric versus Multi-Level Governance”, (1996) 34 Journal of Common Market Studies, pp. 343-78

Mathisen G., "Consistency and Coherence as Conditions for Justification of Member State Measures Restricting Free Movement," Common Market Law Review 47, no. 4 (2010): $1021-48$.

Maduro M.P., We the Court, (Oxford: Hart Publishing 1998)

- _ $\quad$ 'Reforming the Market or the State? Article 30 and the European Constitution: Economic F reedom and Political Rights', (1997) 3 European Law Journal p. 55-82.

Menendez A., 'European Citizenship after Martinez Sala and Baumbast: Has European Law Become More Human but Less Social? RECON Online Working Paper 2009/05 (Oslo: University of Oslo, ARENA - Centre for European Studies 2009)

- - "Which citizenship? Whose Europe? - The many paradoxes of European citizenship", (2014) German Law Journal, 907-933

Moller K., 'Proportionality and Rights Inflation', in Huscroft, Miller, and Webber (eds.), Proportionality and the Rule of Law: Rights, Justification, Reasoning (CUP 2014) 155-172

Monti M., Commissioner for Competition, European Commission, Competition in Professional Services: New Light and New Challenges, For Bundesanwaltskammer Berlin (2003) available at http://europa.eu/rapid/press-release_SPEECH-03-149_en.htm (accessed 10-12-2015).

Monti G., EC Competition Law (Cambridge UP 2006)

- _ _Article 81 EC and Public Policy' (2002) 39 Common Market Law Review 1057-1099 
- - $\quad$ 'EU Competition Law from Rome to Lisbon' in C Heide-Jorgensen et al (eds), Aims and Values in Competition Law (Copenhagen, DJOF Publishing, 2013)

Morijn J., 'Balancing fundamental rights and common market freedoms in union law: Schmidberger and Omega in the light of the European constitution', (2006) 12 European law Journal 15-40

Mortelmans K., 'Towards Convergence in the Application of the Rules on Free Movement and Competition?' 38(2001) Common Market Law Review, 613

Mulder J., 'A New Chapter in the European Court of Justice Gambling Saga: A Stacked Deck?' (2011) 38 Legal Issues of Economic Integration, Issue 3, pp. 243-262.

_ - 'Finding the public interest and the case of the Friesien horse', 2013 ACLE Conference Paper http://acle.uva.nl/events/competition--regulationmeetings/conference-papers-9th-cr-meeting-2013.html (accessed 10-12-2015)

- - 'Re-embedding EU Governance Fields: A Research Agenda', in C. Joerges and C. Glinski (eds.), The European Crisis and the Transformation of Transnational Governance. Authoritarian Managerialism versus Democratic Governance, (Oxford: Hart Publishing 2014), at 181

- - ' Op het snijvlak van onafhankelijkheid en openheid :wat is de rol van de ACM in een duurzamemaatschappij?', SEW 2014, p. 565-578;

- - 'Een duurzame maatschappij, wat mag dat kosten?', NJB 2015/1400 1912-1920.

Muiller T., "Efficiency control in State aid and the Power of Member States to define SGEIs", European State Aid Law Quarterly, 1(2009), 8

Mulder M., Zomer S., Benning T., and J. Leenheer, 'Economic assessment ACM, Effects of the Chicken of Tomorrow - Costs and benefits for consumers' October 2014 (accessible on acm.nl)

Munck R., 'Globalization and Contestation : A Polanyian Problematic' Globalizations 3(2006), p. 175-186.

Nazzini R., 'Article 81 EC Between Time Present and Time Past - A Normative Critique of “Restriction of Competition” in EU law' (2006) 43 Common Market Law Review, 497

Neven D. and V, Verouden, 'Towards a more refined Economic approach in State Aid Control' in W. Mederer, N. Pesaresi and M. van Hoof (eds) EU Competition Law (Claeys\&Casteels 2008), 99 
Nicolaides P., 'Fiscal State Aid in the EU: the limits of Tax autonomy' (2004) World Competition, 319

Nihoul P., 'Freedom of Choice': The Emergence of a Powerful Concept in European Competition Law' Concurrences 3(2012), 55

Nourse V., and G. Shaffer, "Varieties of New Legal Realism: Can a New World Order Prompt a New Legal Theory?" Cornell Law Review 95 (2009) , p. 65.

Novitz T, 'A Human Rights Analysis of the Viking and Laval Judgments' (2007-2008) 10 CYELS 541;

Odudu O., 'Interpreting Article 81(1): object as subjective intention' 26(2001) European Law Review, 60

- - The Boundaries of EC Competition Law: The Scope of Article 81 (Oxford University Press, 2006)

- - $\quad$ 'The Wider Concerns of Competition Law' Oxford Journal of Legal Studies 30(2010), 599

OECD (2010), Public Administration after "New Public Management": Value for Money in Government, Vol. 1, OECD Publishing, Paris.

Oliver P., Free Movement of Goods in the European Community: under Articles 28 to 30 of the EC Treaty, (London: Sweet \& Maxwell 2003)

- - ' Of Trailers and Jet Skis: Is the Case Law on Article 34 TFEU Hurtling in a New Direction?', Fordham International Law Journal 33(2011), at 1469

Osborne D. and T. Gaebler, "Reinventing government: how the entrepreneurial spirit is transforming the public sector", (New York Addison Wesley Publishing Company 1992)

Pallemaerts M., The New Climate Policies of the European Union : Internal Legislation and Climate Diplomacy (Vubpress 2010)

Paulus A.L. ,Commentary to Andreas Fischer-Lescano and Gunther Teubner: The Legitimacy of International Law and the Role of the State' Michigan Journal of International Law 25(2003) p. 1047-58

Picciotto S., "Liberalization and Democratization: The Forum and the Hearth in the Era of Cosmopolitan Post-Industrial Capitalism," Law and Contemporary Problems 63(2000), 157 
Piris J.C., 'The Lisbon Treaty: A Legal and Political Analysis', (Cambridge University Press 2010)

Pijnacker- Hordijk H., 'Beoordeling van duurzaamheidsinitiatieven onder het mededingingsrecht', Markt \& Mededinging 2013

Polanyi K., The Great Transformation: The Political and Economic Origins of our Time, 2nd edn (Boston MA, The Beacon Press, [1944] 2001)

Posner R., Economic Analysis of Law (Boston: Little, Brown, 1972).

- - (1997), 'Social Norms and the Law: An Economic Approach', The American Economic Review 87(1997), p. 365-369.

Prechal S., 'Free Movement and Procedural Requirements: Proportionality Reconsidered', (2008) 3 Legal Issues of Economic Integration 201

Prosser T., The limits of competition law (Oxford UP 2005

- - 'Competition Law and Public Services: From single market to citizenship rights', 11(2005) European Public Law 543, 562

Putnam H., 'Meaning and Reference' 70(1973) The Journal of Philosophy, 699

Quigley C., 'General Taxation and State Aid', in A. Biondi, P. Eeckhout and J. Flynn (eds), The Law of State Aid in the European Union (Oxford University Press, 2004), 207

- - European State Aid Law and Policy (Oxford Hart Pub., 2015)

Rawi A., and J. G. Ruggie. "The Principles of Embedded Liberalism: Social Legitimacy and Global Capitalism." in New Perspectives on Regulation D. Moss and J. Cisternino (eds.), (Cambridge 2009), 151

Rusche T.M., "The Almunia Package" in E. Szyszcak and J.W. van de Gronden (eds.) Financing Services of General Economic Interest, (The Hague T.M.C. Asser Press 2013), 108

Regan M., "Public infrastructure procurement: A comparative analysis of adversarial and nonadversarial contracting arrangements", (2012) Public infrastructure bulletin, 3

Reynolds S., 'Housing policy as a restriction of free movement and MSs discretion to design programmes of social protection: libert' Common Market Law Review 52(2015), 259 
Rodrigues S., 'The European Commission's Reform Strategy' in E. Szyszcak and J.W. van de Gronden (eds.) in Financing Services of General Economic Interest, (The Hague 2013, T.M.C. Asser Press);

Rodrik D., The Globalization Paradox, (London-New York: W.W. Norton, 2011)

Rompuy B. van, Economic Efficiency: The Sole Concern of Modern Antitrust Policy? NonEfficiency Considerations under Article 101 TFEU, (Kluwer 2012)

Rose N. S, Governing the Present: Administering Economic, Social and Personal Life (Polity 2008)

Ross M., 'State Aids: Maturing into a Constitutional Problem' (1995) Yearbook of European law, 79;

- - 'State Aid and National Courts: Definitions and Other Problems - a Case of Premature Emancipation?' (2000) Common Market Law Review. 401;

- - 'Article 16 EC and Services of General Economic Interest: from Derogation to Obligation' (2000) 25 European Law Review, 22

- - 'Decentralization, Effectiveness, and Modernization: Contradiction in terms?' (2004) in A. Biondi, P. Eeckhout and J. Flynn (eds), The Law of State Aid in the European Union (Oxford University Press, 2004).

- - 'Promoting solidarity: From public services to a European model of competition?' 44(2007) Common Market Law Review, 1057

- - "A healthy approach to Services of General Economic Interest? The BUPA Judgment in the CJEU of First instance", European Law Review, 34 (2009), 127.

Ruggie J.G., "International Regimes, Transactions and Change: Embedded Liberalism in the Postwar Economic Order, International Organization”, 36(2) International Regimes (1982), 379-415.

_ _ _ , 'Taking Embedded Liberalism Global: The Corporate Connection', Institute for International Law and Justice Working Paper 2003/2, New York University School of Law

- - "Multilateralism: The Anatomy of an Institution," International Organization 46, no. 3 (1992): 561-98.

Sabel C.F. and J. Zeitlin, 'Experimentalist Governance in the European Union towards a New Architecture' (Oxford University Press 2010)

Sandel M., 'What Money Can’t Buy’ (Farrar, Straus and Giroux 2012) 
Sangiovanni A., 'Solidarity in the European Union', 196(2013) Oxford Journal of Legal Studies, 1

Sassen S., "On concentration and centrality in the global city" in P. Knox, L.Taylor, J. Peter (eds.), World Cities in a World-System. (Cambridge UP 1995), p. 63-75.

Sauter W. and H. Schepel, State and market in European Union law: the public and private spheres of the internal market before the EU Courts (Cambridge University Press 2009)

Savevska M., "Polanyian Reading of the Socio-Economic Transformations of the European Union”, Journal of Contemporary European Studies, 22(2014) p. 395-410.

Scharffs B. G., 'Adjudication and the Problems of Incommensurability', (2001) 42 Wm. \& Mary L. Rev., 1367

Scharpf F.W, 'Negative and Positive Integration in the Political Economy of European Welfare States' in G. Marks, F.W Schaprf, P. Schmitter and W. Streeck (eds) Governance in the European Union (London Sage publication 1996) at p. 15.

- _ 'The European Social Model: Coping with Challenges of Diversity', 40 JCMS 4 (2002),p. 645-670;

- - 'Legitimacy in the Multilevel European Polity' (2009) 1 European Political Science Review at p. 173.

- - 'The asymmetry of European integration, or why the EU cannot be a "social market economy"” (2009) 8, Socio-Economic Review, pp. 211-250 ;

- - 'After the Crash: A Perspective on Multilevel European Democracy', European Law Journal 21(2015), p. 384-405.

Scott J. and Marshall G., 'A Dictionary of Sociology', (OUP 2009

Schepel H., "Delegation of regulatory powers to private parties under EC competition law: towards a procedural public interest test”, Common Market Law Review 39 (2002) p. 31-51. - - The Constitution of Private Governance: Product Standards in the Regulation of Integrating Markets (Hart Pub 2005)

- - Constitutionalising the Market, Marketising the Constitution, and to Tell the Difference : On the Horizontal Application of the Free Movement Provisions in EU Law' , European Law Journal 18(2012), p. 177-200

- _ _Rules of recognition: A constructivist approach to transnational private regulation' in P. F. Kjaer, P. Jurčys, R. Yatsunami (eds), Regulatory Hybridization in the Transnational Sphere (Martinus Nijhoff Publishers 2013), p. 193. 
Sciarra S, 'Viking and Laval: Collective Labour Rights and Market Freedoms in the Enlarged EU’ (2007-2008) 10 CYELS 563;

Scott J., 'Mandatory or imperative requirements in the EU and the WTO', in C. Barnard and J. Scott, The Law of the Single European Market : Unpacking the Premises (Oxford: Hart, 2002) at p. 269.

Schiek D., 'The EU Constitution of Social Governance in an Economic Crisis in Defence of a Transnational Dimension to Social Europe', Maastricht Journal of Comparative and European Law 2 (2013) p. 185-208

- - Economic and Social Integration: the Challenge for EU Constitutional Law (Edward Elgar, Cheltenham 2012), p. 102-106

- - 'The EU's Socio-economic Model(s) and the Crisi(e)s - any perspectives?', in D. Schiek (ed.), The EU Economic and Social Model in the Global Crisis, (Ashgate, Farnham 2013).

Schmidt V., 'Democracy and Legitimacy in the European Union Revisited: Input, Output and "Throughput”" (2013) 61 Political Studies at p. 2

Shaw J., Social law and policy in an evolving European Union, (Oxford Hart 2000)

Shuibhne N.N., "Margins of Appreciation: National Values, Fundamental Rights and EC Free Movement Law", European Law Review, 32(2009), p. 230-256.

- - The Coherence of EU Free Movement Law (Oxford: Oxford University Press, 2013)

Shuibhne N.N., N Maci, 2013, 'Proving Public Interest: The Growing Impact of Evidence in Free Movement Case Law', Common Market Law Review, vol 50, no. 4, pp. 965-1005.

Simmel G., 'The Sociology of Conflict. I', 9(1904) American Journal of Sociology, 491

Smith A., An Inquiry into the Nature and Causes of the Wealth of Nations (London, UK: George Routledge \& Sons, 1776; reprint, 1893)

Snell J., "The Notion of Market Access : A Concept or a Slogan?," Common Market Law Review 47, no. 2 (2010).

- - "Varieties of Capitalism and the Limits of European Economic Integration," Cambridge Yearbook of European Legal Studies 13 (2011): 415-34

Somek A., 'Individualism: An Essay on the Authority of the European Union', (Oxford: Oxford University Press 2008) 
- _ "The argument from transnational effects I: Representing outsiders through freedom of movement", 16 ELJ (2010), 320

- - "Engineering Equality : An Essay on European Anti-Discrimination Law" (Oxford University Press 2011)

- - "The social Question in a Transnational Context" LSE "Europe in Question" Discussion Paper series, June 2011.

Spaventa E., 'From Gebhard to Carpenter: Towards a (non-)economic European constitution' (2004) 41 Common Market Law Review, p. 743-773

- - 'Leaving 'Keck' behind? : The Free Movement of Goods after the Rulings in 'Commission v Italy' and 'Mickelsson and Roos,"' European Law Review 34, no. 6 (2009) p. 914-32

Sternberg E., 'Justifying Public Intervention without Market Externalities: Karl Polanyi's Theory of Planning in Capitalism', Public Administration Review, 53(1993), p. 100-109.

Streeck W., 'Beneficial Constraints: On the Economic Limits of Rational Voluntarism', in Hollingsworth, J. Rogers and Boyer, Robert (eds), Contemporary Capitalism: The Embeddedness of Institutions , (Cambridge: Cambridge University Press 1997), p. 197-218.

- - $\quad$ 'Educating Capitalists: A Rejoinder to Wright and Tsakalotos', Socio-Economic Review 2(2010) p. 425

- _ 'E Pluribus Unum? Varieties and Commonalities of Capitalism”, (2010) Cologne: MPIfG Discussion Paper $10 / 12$

- - $\quad$ The Crises of Democratic Capitalism', New Left Review 71(2011), p .26

Sunstein C.R., 'Incommensurability and Valuation in Law' Michigan Law Review 92(1994), 779

Syrpis P., 'Reconciling Economic Freedoms and Social Rights - The Potential of Commission v Germany (Case C-271/08, Judgment of 15 July 2010), Industrial Law Journal 40(2011), 222

Syrpis P and T Novitz, 'Economic and Social Rights in Conflict: Political and Judicial Approaches to their Reconciliation' (2008) 33 ELRev 411.

Szyszczak E., 'Public Services in Competition Markets' (2001) 21 Yearbook of European Law, 35

- - The Regulation of the State in Competitive Markets in the EU (Oxford Hart Publishing, 2007) 
Teubner G and A Fischer-Lescano, 'Regime-collisions: The Vain Search for Legal Unity in the Fragmentation of Global Law' Michigan Journal of International Law 25(2004) p 9991046

- - $\quad$, 'Reply to Andreas L. Paulus Consensus as Fiction of Global Law' (2003) 25 Michigan Journal of International Law, 1059.

Teubner G., Transnational Economic Constitutionalism in the Varieties of Capitalism (Ms. Frankfurt 2015)

Terry L.S., 'The European Commission Project Regarding Competition in Professional Services', 29(2009) Northwestern Journal of International Law \& Business, 1

Tholoniat L., 'The Career of the Open Method of Coordination : Lessons from a "Soft" EU Instrument' (2010) 33 West European Politics, 93

Toth F., 'Healthcare Policies over the Last 20 Years: Reforms and Counter-Reforms' (2010) 95 Health policy p. 82

Townley C., Article 81 EC and Public Policy, (Oxford: Hart 2009)

Tsakalotos E., 'Market Constraints, Economic Performance and Political Power: Modernizers versus Leftists', Socio-Economic Review 2(2004), 415

Tulio M. , F. Zanin and C. P. Migueles, 'Trust as an element of informal coordination and its relationship with organizational performance', EconomiA 14(2013), 77

Vedder H., Competition law and environmental protection in Europe: towards sustainability? (Europa Law Publishing 2003)

Verouden V., 'EU State Aid Control: The Quest for Effectiveness' European State Aid Law Quarterly 14(2015), 459

Vossestein J., annotation of Wouters in Common Market Law Review 39(2002), 841

Watson P., EU Social and Employment Law (Oxford: Oxford University Press 2009).

Whish R. and D. Bailey, 'Competition Law', (OUP, Oxford 2012)

Weatherhill S., "The Court's Case Law on the Internal Market: 'A Circumloquacious Statement of the Result, Rather than a Reason for Arriving at It'?", in H. Clemens et al., 
Judging Europe's Judges : The Legitimacy of the Case Law of the European Court of Justice (Hart, 2013), p. 104.

- _ 'Viking and Laval: the EU internal market perspective' in M Freedland and J. Prassl (eds.), Viking, Laval and Beyond, (Hart 2014), 32.

Weiler J.H.H., “The Transformation of Europe", Yale Law Journal 100(1991) at p.2403

- _ "Fin-De-Siècle: Do the New Clothes Have an Emperor?", in The constitution of Europe: 'Do the new clothes have an emperor? And other essays on European integration, (Cambridge University Press, 1999) 238

"Fundamental rights and fundamental boundaries", in The Constitution of Europe: 'Do the new clothes have an emperor' and other essays on European integration, (CUP 1999), p. 102-129.

- - "The Constitution of the Common Market Place: Text and Context in the Evolution of the Free movement of Goods", in P Craig and G De Burca (eds), The evolution of EU law (Oxford, OUP 1999) at 372

- - In the Face of Crisis: Input Legitimacy, Output Legitimacy and the Political Messianism of European Integration, Journal of European Integration, (2012), 826.

- _ 'Van Gend en Loos: The Individual as Subject and Object and the Dilemma of European Legitimacy', International Journal of Constitutional Law 12(2014) p. 94103

Weiler J.H.H., and N.J.S. Lockhart, "'Taking Rights Seriously' seriously: The European Court of Justice and its fundamental rights jurisprudence', (1995) 32 Common Market Law Review, 593

Wendt I., EU Competition Law and Liberal Professions: an Uneasy Relationship? (Leiden: Brill Academic Publishers, 2012)

Wesseling R., The Modernisation of EC Antitrust Law (Oxford, Hart Publishing 2000)

Whitman J., 'Consumerism versus Producerism: A study in Comparative Law' (2007) Yale Law Journal, 340

Wilson T., "Infrastructure Financing and State Aid Post Leipzig-Halle", European State Aid Law Quarterly, 1/2014, 24

Winterstein A., 'Nailing the Jellyfish: Social Security and Competition Law' (1999) 20 European Competition Law Review, 324 
Witt A.C., 'Public Policy Goals under EU Competition Law: now is the Time to set the House in order'(2012) 8 European Competition Journal, 443

Witte B. de, "Non-market values in internal market legislation" in N. Shuibhne (ed.), Regulating the internal market (Elgar 2006), 63

Witte F. de, "Sex, Drugs \& EU Law: The Recognition of Moral and Ethical Diversity in EU Law," Common Market Law Review 50, no. 6 (2013): 1545-78

- - Justice in the EU: The Emergence of Transnational Solidarity (Oxford: OUP, 2015),

Woldendorp J., The Polder Model: From Disease to Miracle? Dutch Neo-corporatism 19652000 (2005 PhD thesis, Vrije Universiteit Amsterdam)

Woodruff D., 'Governing by Panic: The Politics of the Eurozone Crisis', LEQS Paper No. 81/2014. October 2014

Zimmer D., (ed.), The Goals of Competition Law, (Cheltenham: Edward Elgar 2012) 


\section{CONSULTED CASES/LEGISLATION /DECISIONS}

\section{Court of Justice of the European Union Judgments}

\section{Numerical order}

Case 30/59 Steenkolenmijnen v High Authority [1961] ECR 119

Case 26/62, N.V. Algemene Transport- en Expeditie Onderneming van Gend \& Loos v. Netherlands Inland Revenue Administration, [1963] ECR 1

Case 6/64, Costa v. ENEL, [1964] ECR 586

Case 173/73 Italy v Commission [1974] ECR 709

Case 8/74 Dassonville [1974] ECR 00837

Case 8/74 Procureur du Roi v Benoît and Gustave Dassonville [1974] ECR 837

Case 43/75 Defrenne [1976] ECR 00455

Case 120/78 Rewe-Zentral AGv Bundesmonopolverwaltung für Branntwein (Cassis de Dijon) [1979] ECR 650

Case 261/81 Walter Rau Lebensmittelwerke v. De Smedt PVBA, [1982] ECR 3961

Case 178/84 Commission v. Germany [1987] ECR 01227

Case C-234/84 Kingdom of Belgium v Commission of the European Communities (Meura) [1986] ECR 02263

Case C-118/85 Commission v Italy [1987] ECR 2619

Case C-303/88 Italian Republic v Commission [1991] ECR I-01433

Case C-41/90 Höfner and Elser [1991] ECR I-1979

Case C-76/90 Säger v Dennemeyer [1991] ECR I-04221

Cases C-179/90 Merci convenzionali porto di Genova [1991] ECR I-5889 
Cases C-72/91 and C-73/91 Sloman Neptun [1993] ECR I-887

Case C-159/91 and C-160/91 Poucet Pistre 1993 ECR I-00637

Case C-185/91 Reiff Bundesanstalt für den Güterfernverkehr [1993] ECR I-5801

Case C-189/91 Petra Kirsammer Hack [1993] ECR I-6185

Case C-230/91 Corbeau [1993] ECR I - 2534

Case C-267/91 and C-268/91, Keck and Mithouard [1993] ECR I-06097.

Case C-320/91 Corbeau [1993] ECR I-2533

Case C-275/92 Schindler ECR [1994] I-01039.

Cases C-278/92, C-279/92 and C-280/92 Spain v Commission [1994] ECR I-4103

Case C-292/92 Ruth Hünermund and Others v. Landesapothekerkammer BadenWürttemberg [1993] ECR I-06787

Case C-364/92 SAT Fluggesellschaft('Eurocontrol [1994] ECR I-43

Case C-387/92 Banco Exterior de España [1994] ECR I-877

Case C-42/93 Spain v Commission [1994] ECR I-4175

Case C-56/93 Belgium v Commission [1996] ECR I-723

Case C-153/93 Delta [1994] ECR I-2517

Case C-384/93 Alpine Investments [1995] ECR I-01141

Case C-412/93 Leclerc-Siplec [1995] ECR I-179

Case C-415/93 Union royale belge des sociétés de football association and Others $v$ Bosman and Others [1995] ECR I-04921

Case C-55/94 Gebhard v Consiglio dell'Ordine degli Avvocati e Procuratori di Milano 
[1995] I-04165

Case C-140/94-C-142/94 DIP e.a. [1995] ECR I-3257

Case C-241/94 France v Commission (Kimberly Clark) [1996] ECR I-4551

Case C-70/95 - Sodemare and Others v Regione Lombardia [1997] ECR I-03395

Case C-242/95 GT-Link A/S [1997] ECR I-4449,

Case C-343/95 Diego Calì \& Figli [1997] ECR I-1547

Case C-35/96 Commission v Italy [1998] ECR I-3851

Case C-67/96 Albany [1999] ECR I-05751

Case C-266/96, Corsica Ferries France SA [1998] ECR I-3949

Case C-342/96 Spain v Commission [1999] ECR I-2459

Case C-52-54/97 Viscido, Scandella and Terragnolo v Ente Poste Italiane [1998] ECR I02629

Case C-75/97 Belgium v Commission [1999] ECR I-03671

Cases C-115-117/97 Brentjens [1999] ECR I-6025

Case C-124/97, Läärä ECR [1999], I-6067

Case C-200/97 Ecotrade, [1998] ECR I-07907

Case C-212/97, Centros Ltd v Erhvervs- og Selskabsstyrelsen [1999] ECR I-01459

Case C-219/97 Drijvende Blokken [1999] ECR I-6121

Case C-251/97 France v Commission [1999] ECR I-6639

Case C-256/97 DM Transport [1999] I-03913

Case C-295/97 Piaggio [1999] ECR I-03735 
Case C-67/98 Zenatti [1999] ECR I-7289

Cases C-180/98 to C-184/98 Pavlov and Others [2000] ECR I-6451

Case C-222/98 van der Woude [2000] ECR I-7111, paragraph 22

Case C-324/98 Telaustria and Telefonadress [2000] ECR I-10745

Case C-367/98 Commission v Portugal [2002] ECR I-04731.

Case C-379/98 - PreussenElektra [2001] ECR I-02099

Case C-405/98, Konsumentombudsmannen (KO) v. Gourmet International Products AB (GIP), [2001] ECR I-1795

Case C-480/98 Spain v Commission (Magefesa) [2000] ECR I-8717

Case C-35/99 Arduino [2002] ECR I-01529

Case C-54/99 Eglise de schientologie [2000] ECR I-01335,

Case C-143/99, Aria-Wien Pipeline, [2001] ECR I-8365

Case C-309/99 Wouters [2002] ECR I-1577

Case C-483/99 Commission v France [2002[ ECR I-04781

Case C-475/99 Ambulanz Glöckner [2001] ECR I-08089

Case C-503/99 Commission v Belgium [2002] ECR I-044809,

Case C-60/00 Carpenter [2002] ECR I-06279

Case C-112/00 Schmidberger, [2003] ECR I-5659

Case C-208/00, Überseering BV v Nordic Construction Company Baumanagement GmbH [2002] ECR I-09919

Case C-218/00 Cisal [2002] ECR I-691 
Case C-280/00 Altmark Trans and Regierungspräsidium Magdeburg [2003] ECR I-7747

Case C-323/00 P DSG Dradenauer Stahlgesellschaft v Commission [2002] ECR I-03919

Case C-409/00 Spain v Commission [2003] ECR I-01487

Case C-463/00 Commission v Spain [2003] ECR I-04581.

Case C-5/01 Belgium v Commission (Cockerill) [2002] ECR I-11991

Case C-82/01 Aéroports de Paris [2002] ECR 2002 I-09297

Cases C-83/01P C - 93/01P and C - 94/01P Chronopost and Others $v$ Ufex and Others [2003] I-04777

Case C-167/01, Kamer van Koophandel en Fabrieken voor Amsterdam v Inspire Art Ltd. [2003] ECR I-10155

Case C-243/01, Gambelli [2003] ECR I-13031

Cases C-264/01, C-306/01, C-354/01 and C-355/01 AOK-Bundesverband and Others [2004] ECR I-2493

Case C-463/01 Commission v Germany [2004] ECR I-11705

Case C-36/02 Omega Spielhallen v. Oberbürgermeisterin derBundesstadt Bonn [2004] ECR I-9609

Case C-309/02 Radlberger v Land Baden-Wurttemberg [2004] ECR I-11763

Case C-442/02 CaixaBank France [2004] ECR I-08961.

Case C-205/03 P - FENIN v Commission [2006] ECR I-06295

Case C-250/03 Mauri [2005] ECR I-01267

Case C-320/03 Commission v. Austria [2005] ECR I-09871

Case C-442/03 P - P\&O European Ferries (Vizcaya) v Commission [2006] ECR I-04845 
Case C-446/03, Marks \& Spencer [2005] ECR I-10837

Case C-94/04 - Cipolla and Others [2006] ECR I-11421

Case C-158/04 and C-159/04 Alfa Vita Vassilopoulos [2006] ECR I-08135

Case C-170/04 Klas Rosengren and Others v Riksåklagaren, [2007] ECR I-04071 para. 56.

Case C-196/04, Cadbury Schweppes [2006] ECR I-07995

Case C-222/04 Cassa di Risparmio di Firenze [2006] ECR I-00289

Case C-338/04 Placania [2007] ECR I-01891

Case C-434/04 Criminal proceedings against Ahokainen and Leppik, [2006] ECR I-9171,

Case C-519/04 Meca-Medina [2006] ECR I-06991

Case C-444/05 Stamatelaki [2007] ECR I-03185

Case C-110/05 Commission v. Italy (Trailers), [2009] ECR I-519

Case C-112/05 Commission v. Germany, [2007] ECR I-8995

Case C-142/05 Mickelsson en Roos [2009] ECR I-04273

Case C-295/05 Asociación Nacional de Empresas Forestales (Asemfo) v Transformación Agraria SA (Tragsa) and Administración del Estado [2007] ECR I-2999

Case C-318/05 Commission v Germany [2007] ECR I-6957

Case C-341/05, Laval [2007] ECR I-11767

Case C-438/05, International Transport Workers' Federation and Finnish Seamen's Union v Viking Line ABP and Ö̈ Viking Line Eesti, [2007] ECR I-10779

Case C-244/06 Medien Vertriebs [2008] ECR I-00505

Case C-341-342/06p La Poste v UFEX and Others [2008] ECR I-04777 
Case C-346/06 Ruffert [2008] ECR I-01989

Case C-487/06 P British Aggregates v Commission [2008] ECR I-10515

Case C-141/07 Commission v Germany [2008] ECR I-6935

Case C-169/07 Hartlauer [2009] ECR I-01721

Case C-209/07 Competition Authority v Beef Industry Development Society Ltd and Barry Brothers (Carrigmore) Meats Ltd. [2008] ECR I-8637

Cases C-316/07, C-358/07 to C-360/07, C-409/07 and C-410/07, [2010] Stoss and Others ECR I-08069

Case C-431/07 P - Bouygues and Bouygues Télécom v Commission [2009] ECR I-02665

Case C-46/08 Carmen Media [2010] ECR I-08149

Case C-91/08 Wall [2010] ECR I-0,

Case C-58/08 Vodafone and Others [2010] ECR I-4999,

Case C-203/08 Betfair [2010] ECR I-04695

Case C-206/08 Eurawasser [2009] ECR I-0

Case C-271/08 Occupational pensions [2010] ECR I-07091

Case C-279/08 P - Commission v Netherlands [2011] ECR I-07671

Case C-333/08 Commission v France [2010] ECR I-00757

Case C-400/08 Commission v Spain [2011] ECR I-01915.

Cases C-403/08 and C-429/08 Football Association Premier League Ltdv QC Leisure, [2011] ECR I-000

Case C-515/08 Santos Palhota [2010] ECR I-000 
Case C-108/09 Ker Optika [2010]

Case C-137/09 Josemans [2010] ECR I-13019

Case C-437/09 AG2R Prevoyance

Case C-439/09 Pierre Fabre Dermo-Cosmétique SAS v Président de l'Autorité de la Concurrence, [2011] ECR I-000

Case C-475/99 - Ambulanz Glöckner [2001] ECR I-08089

Case C-124/10 P European Commission v EDF and others [2012] ECR nyp

Case C-275/10 Residex Capital IV [2011] ECR I-13043

Case C-417/10 3M Italia [2012] np

Case C-288/11 P - Mitteldeutsche Flughafen and Flughafen Leipzig-Halle v Commission, [2012] np

Case C-577/11 DKV Belgium [2013] np

Case C-1/12 Ordem dos Técnicos Oficiais de Conta [2013] np

Case C-6/12 P [2013] np

Case C-136/12 CNG [2013] np

Case C-214/12 P, Land Burgenland v Commission [2013] np

Case C-367/12 Sokoll-Seebacher [2014] np

Case C-390/12 Pfleger [2014] np

Case C-559/12 France v Commission (La Poste) [2014] np

Case C-91/13 - Essent Energie Productie [2014] np

Case C-113/13 Azienda sanitaria locale [2014] np 
Case C-271/13 P - Rousse Industry v Commission [2015] np

Case C-413/13 FNV Kunsten t. Staat der Nederlanden [2014] np

Case C-423/13 - Vilniaus energija [2014] np

Case C-518/13 - Eventech [2015] np

Case C-39/14, BVVG Bodenverwertungs- und-verwaltungs GmbH [BVVG] v Landkreis Jerichower Land [2015] np

Case C-357/14 P - Electrabel and Dunamenti Erômü v Commission [2015] np

Case C-333/14 The Scotch Whisky Association and Others $v$ The Lord Advocate, [2015] nyp

Case C-357/14 P - Electrabel and Dunamenti Erômü v Commission [2015] np

\section{General Court Judgments}

\section{Numerical order}

Case T-358/94 Air France v Commission [1996] ECR II-02109

Case T-106/95 FFSA and Others [1997] ECR II-00229

Cases T-129/95, T-2/96 and T-97/96 Neue Maxhütte Stahlwerke and Lech-Stahlwerke v Commission [1999] ECR II-17

Case T-46/97 SIC v Commission [2000] ECR II-2125

Case T-152/99, Hamsa v Commission [2002] ECR II-3049, para. 166.

Case T-228/99 WestLB v Commission [2003] ECR II-435.

Case T-319/99 - Fenin v Commission [2003] ECR II-00357 
Case T-98/00 Linde v Commission [2002] ECR II-03961

Case T-318/00 Freistaat Thüringen v Commission [2005] ECR II-4179, para. 180.

Case T-109/01 Fleuren Compost v Commission (Judgment of 14 January 2004);

Case T-210/02, British Aggregates v. Commission, [2006] ECR II-2789

Case T-313/02 Meca-Medina and Majcen v Commission [2004] ECR II-0000

Case T-289/03 - BUPA and Others v Commission [2008] ECR II-00081

Case T-155/04- Selex [2006] ECR II-04797

Case T-156/04 - EDF v Commission [2009] ECR II-04503; Case C-124/10 P European Commission v Électricité de France (EDF), nyr

Case T-196/04 - Ryanair v Commission [2008] ECR II-03643

Case T-233/04 Netherlands v Commission [2008] ECR II-00591

Case T-163/05 DEP - Bundesverband deutscher Banken v Commission [2010] ECR II00387

Case T-443/08 - Freistaat Sachsen and Others v Commission [2011] II-01311

Case T-137/10 Belgium hospitals case (CBI)

Case T-489/11 Rousse Industry v Commission [2013] ECR np.

Case T-309/12 - Zweckverband Tierkörperbeseitigung v Commission nyp

\section{Legislation / Policy documents}

Guidelines on the application of Article 81(3) of the Treaty [2004] OJ C101/ 97

Guidelines on the applicability of Article 101 of the Treaty on the Functioning of the European Union to horizontal co-operation agreements [2011] OJ C11/1 
Guidelines on regional State aid for 2014-2020 (OJ C 209 of 23.7.2013)

Guidelines on State aid to promote risk finance investments (OJ C 19, 22.1.2014)

Guidelines on State aid for environmental protection and energy 2014-2020 (OJ C 200, 28.6.2014,)

Guidelines on State aid for rescuing and restructuring non-financial undertakings in difficulty (OJ C 249, 31.07.2014, p. 1)

Guidelines for the application of State aid rules in relation to the rapid deployment of broadband networks (OJ C 25 of 26.1.2013,p. 1)

Guidelines on State aid to airports and airlines (OJ C 99, 4.4.2014, p. 3)

Guidelines for State aid in the agriculture and forestry sector and in rural areas 2014 to 2020 (OJ C 204, 1.7.2014, p. 1)

Framework for State aid for research and development and innovation (OJ C 198, 27.6.2014)

Commission Regulation (EU) No 651/2014 of 17 June 2014 declaring certain categories of aid compatible with the internal market in application of Articles 107 and 108 of the Treaty Text with EEA relevance

Communication from the Commission to the European Parliament, the Council, the European economic and social Committee and the Committee of the regions - EU State aid modernisation (SAM) (COM/2012/0209 final)

Communication from the Commission on State aid for films and other audiovisual works (C 332, 15.11.2013, p. 1)

Communication - Criteria for the analysis of the compatibility with the internal market of State aid to promote the execution of important projects of common European interest (OJ C 88 of 20.6.2014,p. 4)

Communication from the Commission: Professional Services-Scope for More Reform: Follow-Up to the Report on Competition in Professional Services, at 10, COM (2005) 405 final (Sept. 5, 2005) 
EUROPE 2020: A Strategy for Smart, Sustainable and Inclusive Growth, COM(2010) 2020.

M. Monti, 'A new strategy for the single market: at the service of Europe's Economy and Society, (2010)

http://ec.europa.eu/internal_market/strategy/docs/monti_report_final_10_05_2010_en.pdf

\section{Decisions}

CECED (Case IV.F.1/36.718) Commission Decision 2000/475/EC [2000] OJ L187/47

Commission, 16 December 2003, State aid N 475/2003 Security of Supply Ireland (CADA)

Commission, 16 November 2004, State aid N 381/2004 Broadband Infrastructure Project Pyrénées-Atlantiques

Commission, 3 May 2005, State aid N 382/2004 Broadband infrastructure project Limousin (Dorsal)

Commission, 30 September 2009, State aid N 331/2008 Broadband Hauts de Seine

Commission, 24 May 2007 Energy supply Slovenia OJ 2007 L 219/9

Commission, 15 September 2009, State aid N 206/2009 Financing of the public transport services in district of Anhalt-Bitterfeld

Commission, 15 September 2009, State aid N 207/2009, Financing of the transport services in district of Wittenberg

ACM Visiedocument Mededinging \& Duurzaamheid, mei 2014, www.acm.nl/nl/publicaties/publicatie/12930/Visie-mededinging-en-duurzaamheid

ACM position paper 5 December 2007:

https://www.acm.nl/nl/publicaties/publicatie/6544/NMa-Mededingingswet-staat-geentariefafspraken-voor-zelfstandigen-toe-in-caos/

Besluit van de Minister van Economische Zaken van 6 mei 2014, nr. WJZ / 14052830, houdende beleidsregel inzake de toepassing door de Autoriteit Consument en Markt van 
art. 6 lid 3 Mededingingswet bij mededingingsbeperkende afspraken die zijn gemaakt ten behoeve van duurzaamheid

Dutch Appellate Court of Arnhem 10-03-2010, Case nr. 200.002.794

Dutch competition authorities ACM: ACM, 'Notitie ACM over sluiting 5 kolencentrales in SER Energieakkoord' www.acm.nl/nl/publicaties/publicatie/12033/Notitie-ACM-oversluiting-5-kolencentrales-in-SER-Energieakkoord

ACM, 'Notitie ACM over sluiting 5 kolencentrales in SER Energieakkoord' www.acm.nl/nl/publicaties/publicatie/12033/Notitie-ACM-over-sluiting-5-kolencentralesin-SER-Energieakkoord/

Case 2432 - 17 April 2001 ACM assessment of the sustainability agreements 'Chicken of Tomorrow' (ACM/DM/2014/206028), January 2015 